\title{
ORSphere: Critical, Bare, HEU(93.2)-Metal Sphere
}

\author{
Margaret A. Marshall
}

September 2013

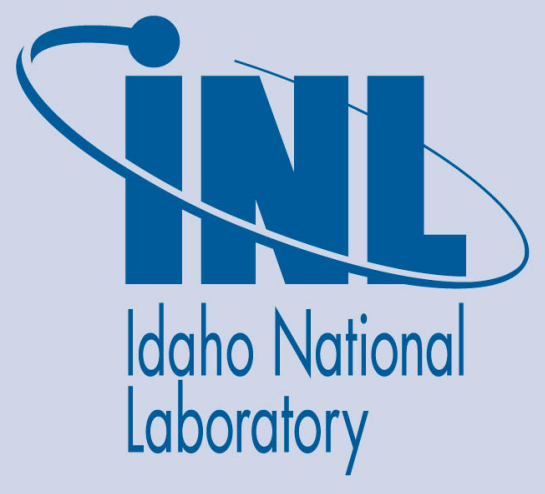

The INL is a U.S. Department of Energy National Laboratory operated by Battelle Energy Alliance 
INL/EXT-13-28721

\title{
ORSphere: Critical, Bare, HEU(93.2)-Metal Sphere
}

\author{
Margaret A. Marshall
}

September 2013

\section{Idaho National Laboratory \\ Idaho Falls, Idaho 83415}

http://www.inl.gov

Prepared for the

U.S. Department of Energy

Office of Nuclear Energy

Under DOE Idaho Operations Office

Contract DE-AC07-05ID14517 


\title{
ORSPHERE: CRITICAL, BARE, HEU(93.2)-METAL SPHERE
}

\author{
Evaluator \\ Margaret A. Marshall \\ Idaho National Laboratory \\ Internal Reviewers \\ John D. Bess \\ J. Blair Briggs \\ Christine E. White
}

Independent Reviewers

James P. Dyrda

Nigel P. Tancock

Atomic Weapons Establishment (AWE)

John T. Mihalczo

Oak Ridge National Laboratory 
NEA/NSC/DOC(95)03/II

Volume II

HEU-MET-FAST-100

\section{ORSPHERE: CRITICAL, BARE, HEU(93.2)-METAL SPHERE}

IDENTIFICATION NUMBER: HEU-MET-FAST-100

SPECTRA

KEY WORDS: acceptable, bare, critical experiment, highly enriched, metal, ORALLOY, ORCEF, sphere, unmoderated, unreflected, uranium

\subsection{DETAILED DESCRIPTION}

In the early 1970s Dr. John T. Mihalczo (team leader), J.J. Lynn, and J.R. Taylor performed experiments at the Oak Ridge Critical Experiments Facility (ORCEF) with highly enriched uranium (HEU) metal (called Oak Ridge Alloy or ORALLOY) in an attempt to recreate GODIVA I results with greater accuracy than those performed at Los Alamos National Laboratory in the 1950s (HEU-MET-FAST-001). The purpose of the Oak Ridge ORALLOY Sphere (ORSphere) experiments was to estimate the unreflected and unmoderated critical mass of an idealized sphere of uranium metal corrected to a density, purity, and enrichment such that it could be compared with the GODIVA I experiments. "The very accurate description of this sphere, as assembled, establishes it as an ideal benchmark for calculational methods and cross-section data files." (Reference 1) While performing the ORSphere experiments care was taken to accurately document component dimensions ( $\pm 0.0001 \mathrm{in}$.), masses ( $\pm 0.01 \mathrm{~g}$ ), and material data. The experiment was also set up to minimize the amount of structural material in the sphere proximity. A three part sphere was initially assembled with an average radius of $3.4665 \mathrm{in}$. and was then machined to an average radius of $3.4420 \mathrm{in}$. (3.4425 in. nominal ${ }^{\mathrm{a}}$ ). These two spherical configurations were evaluated and judged to be acceptable benchmark experiments; however, the two experiments are highly correlated.

Information for the evaluation was compiled from Reference 1 and 2, the experimental logbook; ${ }^{\mathrm{b}}$ additional drawings and notes provided by the experimenter; and communication with the lead experimenter, John T. Mihalczo.

\section{$1.1 \quad$ Overview of Experiment}

The uranium metal sphere used in the ORSphere experiments was originally used to "measure the neutron leakage spectrum in slightly subcritical systems [in order] to validate calculation models" at the General Atomic Company linear accelerator in San Diego in 1965 (Reference 1). The vertical assembly machine in the East cell of ORCEF was used to assemble the sphere (see Figure1-1). Support structures were constructed to support the three parts of the sphere. Various modifications were made to the ORSphere from 1971 until 1975 when it was ultimately sent to the Oak Ridge Y-12 plant for destruction by recasting. The changes and modifications pertinent to this evaluation include the use of HEU pins to convert the original five part sphere into three primary parts (see Figure1-2 and Figure1-3), filling of a 1.000-in-diameter target

\footnotetext{
${ }^{\text {a }}$ The nominal radius was the dimension on the work request to the Y-12 machine shops for fabrication. Personal communication with J.T. Mihalczo, July 8, 2013.

${ }^{\mathrm{b}}$ Radiation Safety Information Computation Center (RSICC), The ORNL Critical Experiments Logbooks, Book 108r, http://rsicc.ornl.gov/RelatedLinks.aspx?t=criticallist. 


\section{NEA/NSC/DOC(95)03/II \\ Volume II}

\section{HEU-MET-FAST-100}

hole, filling of a thermocouple groove at the top of the center plate, drilling of a 0.136 -in-dia diametral hole, and re-machining of the sphere from a 3.4665-in. average radius to a 3.4420-in. average radius.

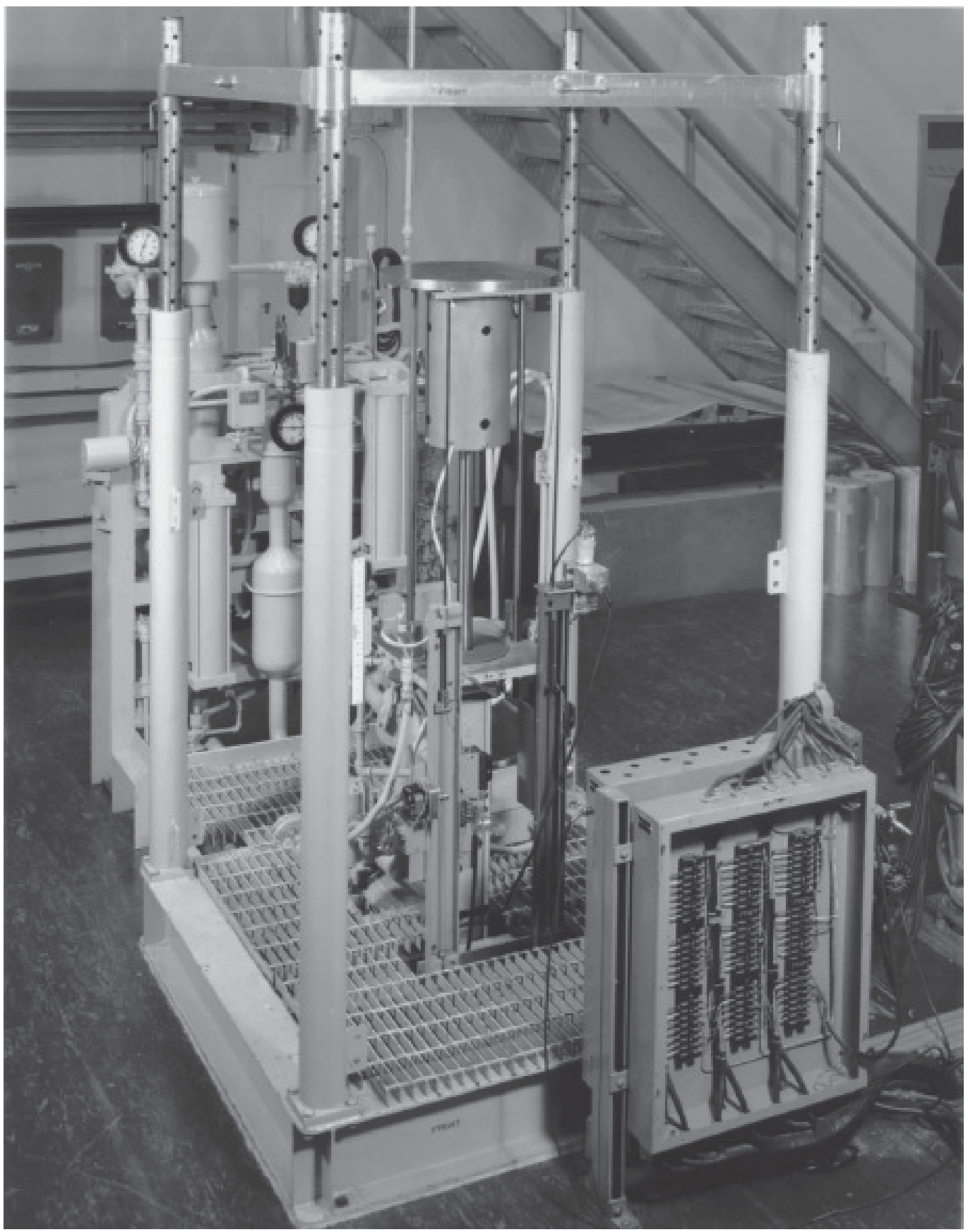

Figure1-1. Photograph of the Vertical Assembly Machine. ${ }^{a}$

${ }^{a}$ E. R. Rohrer, et al., "Neutron Physics Division Annual Progress Report, September 1, 1961,” ORNL-3193, Oak Ridge National Laboratory (1961). 
NEA/NSC/DOC(95)03/II

Volume II

HEU-MET-FAST-100

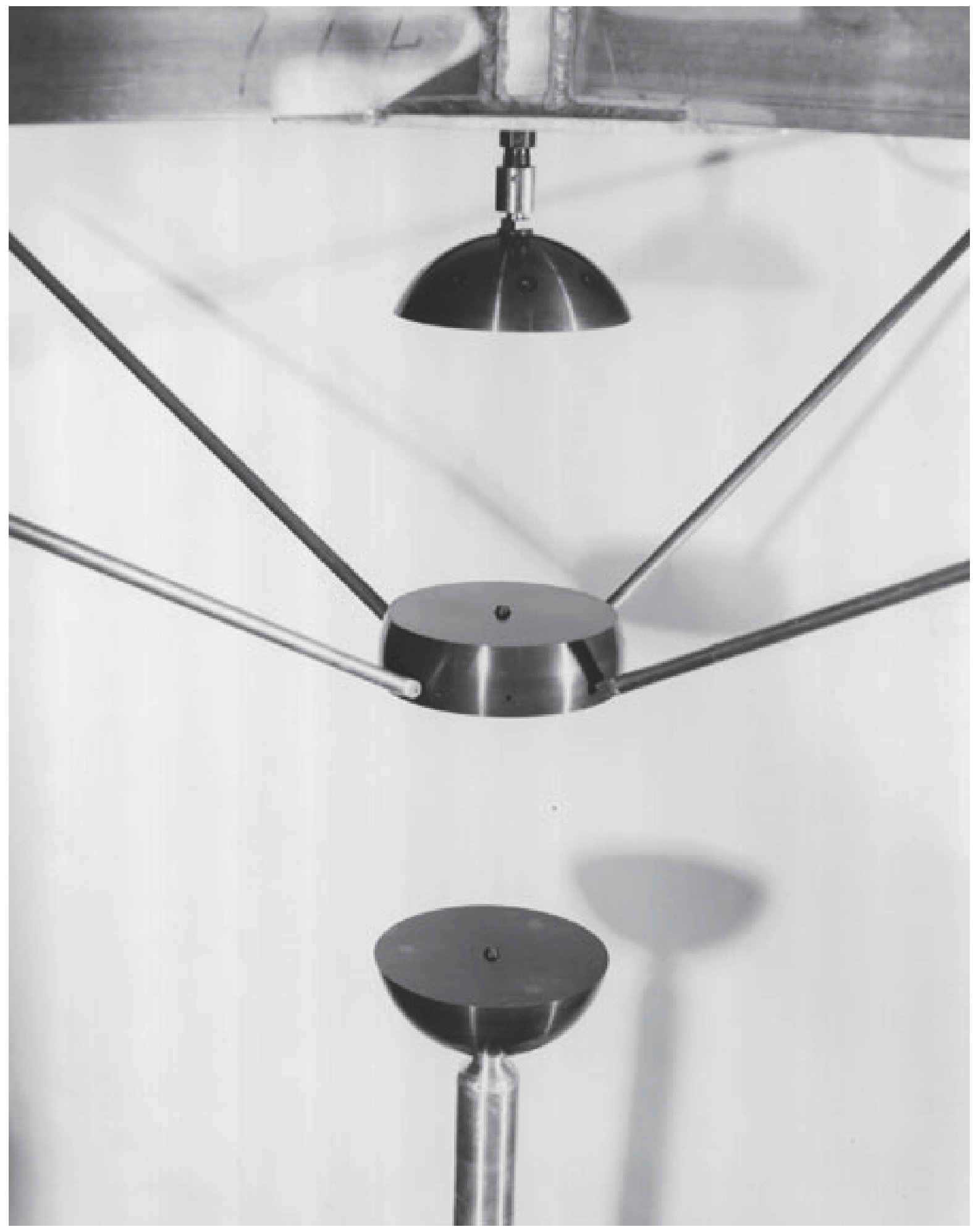

Figure1-2. Photograph of the Disassembled Three Part Sphere. 
NEA/NSC/DOC(95)03/II

Volume II

HEU-MET-FAST-100

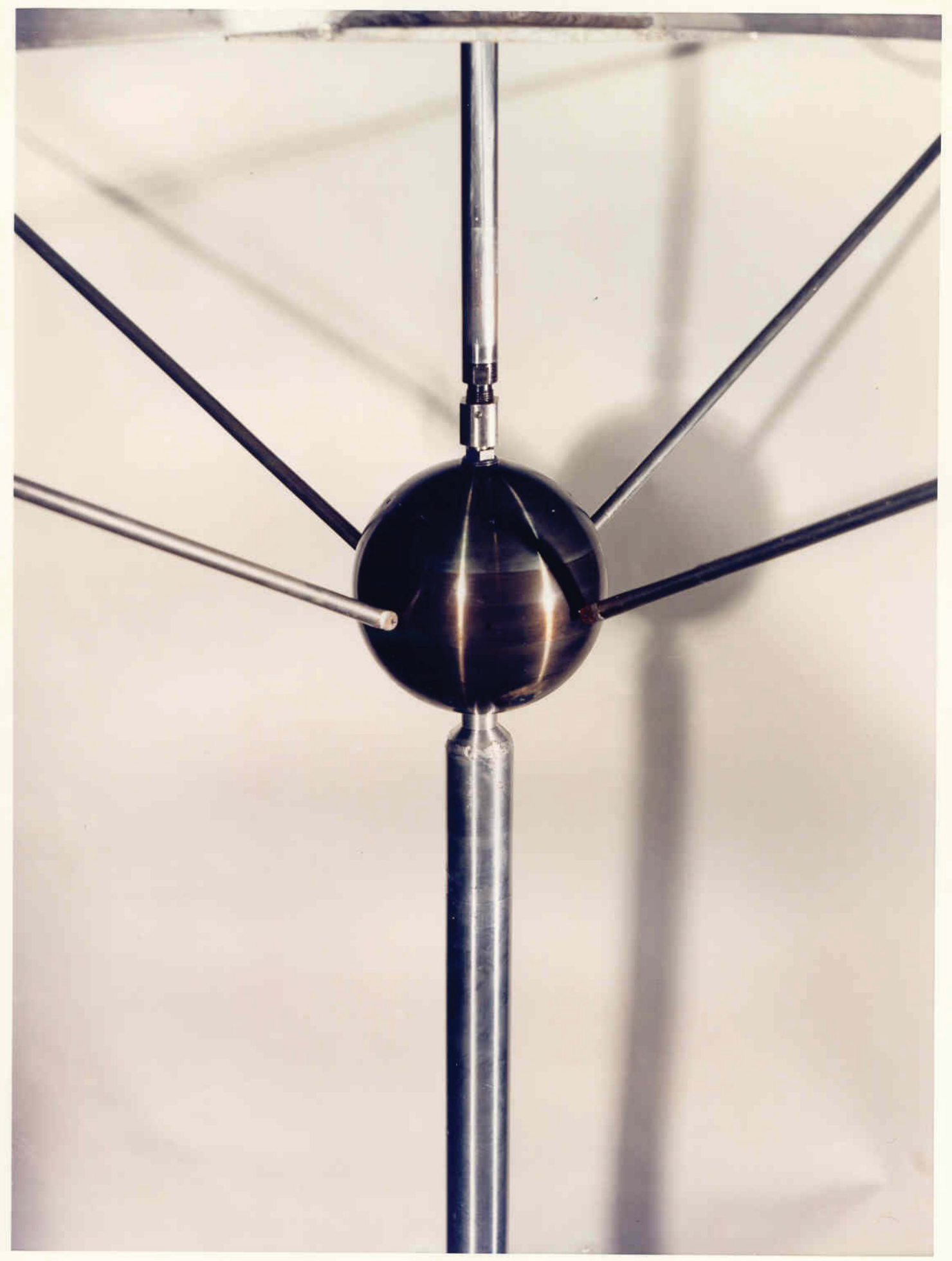

Figure1-3. Photograph of the Assembled Three Part Sphere (3.4665-in.-radius). 
NEA/NSC/DOC(95)03/II

Volume II

HEU-MET-FAST-100

\subsection{Description of Experimental Configuration}

The ORSphere had five major parts, a lower polar cap, a lower plate, a central plate, an upper plate, and an upper polar cap. The sphere, when assembled, was as shown in Figure 1-4. Dimensions and masses of the sphere were measured to high accuracies at $\mathrm{Y}-12$ plant at $70^{\circ} \mathrm{F}$. Non-spherical dimensions were measured to $\pm 0.0001 \mathrm{in}$. and certified masses were measured to $\pm 0.01 \mathrm{~g}$, as was typical for measurements performed at Y-12 to support ORCEF ORALLOY experiments. ${ }^{a}$ The spherical dimensions were also measured to $\pm 0.0001 \mathrm{in}$. When the sphere was assembled the gaps between the plates were generally $0.0000_{-0.0000}^{+0.0001} \mathrm{in}$. However, there was one exception for the 3.4665 -in.-average-radius sphere which had a gap between the lower plate and the central plate of $0.0045 \mathrm{in}$. on one side of the sphere and no gap on the opposite side caused by a projection of a pin. The tilt of the center plate did not cause the center plate to overhang past the edge of the lower plate; this was prevented by the center support structure. ${ }^{\mathrm{b}}$. The worth of this gap was $5.0 \pm$ $0.2 \varnothing$ (based on $2.25 \times 10^{-3}$ in. average gap and $2.2 \pm 0.1 \notin$ per thousandth of an inch gap worth) (Reference 1). Spherical surfaces were machined to a finish of $32 \times 10^{-6}$ in. Machining specifications stated that flat surfaces were to be finished "to less than 0.002 in. total indicator reading (TIR). However, the flatness was actually very much better than this, typically less than \pm 0.0001 in." (Reference 1 ). Cutoff alignment cones were used to ensure accurate lateral alignment when the sphere was assembled. Figure 1-5 through Figure 1-14 are drawings of the five sphere parts and are taken from Reference 1. Underlined dimensions are measured values. All other dimensions are manufacturing drawing dimensions. Figure 1-15 is reproduced from a drawing provided by the experimenter that had handwritten dimensions. Various details of the sphere are described below.

"A polonium/beryllium source was used. It was on a thin $\operatorname{rod}(\sim 1 / 4$ inch) and was withdrawn about 4 feet into a small shield. When performing measurements the fission rate in the assembly was sufficiently high that the source contribution was negligible. When $\mathrm{Cf}$ sources in ionization chambers were used for special measurements the $\mathrm{Po} / \mathrm{Be}$ source was removed from the room."

When assembled the reactivity of the 3.4665-in.-average-radius ORSphere was $68.1 \pm 2.0 \varnothing$. The uncertainty of $\pm 2.0 \varnothing$ "include assembly reproducibility, reactor period measurements uncertainty, and uncertainties in the delayed neutron parameters" (Reference 1). The 3.4420-in.-average-radius ORSphere had a reactivity of $-23.4 \not{ }^{\mathrm{d}}$ The diametral rod was filled with a 0.1293 -in.-diameter ORALLOY filler rod for both spheres. Reference 1 gives the effective delayed neutron fraction of the sphere was $0.0066 \pm 0.00005$ based on GODIVA measurements. The effective delayed neutron fraction was derived from a central void reactivity measurement using the ORSphere. A value of $0.00657 \pm 0.00002$ was obtained. ${ }^{\mathrm{e}}$ A description of this measurement and the derivation of the delayed neutron fraction are given in Section 1.5.

The effect of moving the sphere from its location $11.7 \mathrm{ft}$ from the 5-ft-thick concrete west wall, $12.7 \mathrm{ft}$ from the 2-ft-thick concrete north wall and $9.2 \mathrm{ft}$ above the concrete floor of the $35 \times 35 \times 30$-ft-high east cell of the

\footnotetext{
${ }^{a}$ J. T. Mihalczo, T. Gregory Schaaff, "Uncertainties in Masses, Dimensions, Impurities, and Isotopics of HEU Metal Used in Critical Experiments at ORCEF," ORNL/TM-2012/32, Oak Ridge National Laboratory (2012).

${ }^{\mathrm{b}}$ Personal email communication with J.T. Mihalczo, July 17, 2013.

${ }^{\mathrm{c}}$ Personal email communication with J.T. Mihalczo, June 19, 2013.

${ }^{\mathrm{d}}$ Reference 1 gives a reactivity of $-23 \phi$. The logbook, gives an average reactivity of $-23.4 \phi$.

e J. T. Mihalczo, J. J. Lynn, and J. R. Taylor, "The Central Void Reactivity in the Oak Ridge National Laboratory Enriched Uranium (93.2) Metal Sphere,” Nucl. Sci. Eng., 130, 153-163 (1998).

Revision: 0

Date: September 30, 2013

Page 5 of 160
} 
critical experiments facility to the center of the cell was less than the reproducibility of sphere reconfiguration, which is given as approximately $0.3 \notin$ in Reference 1 . The sphere reproducibility was measured for the 3.4420-in.-average-radius sphere as $0.17 \phi$ on the same day and approximately $0.27 \varnothing$ from day to day.

It should be noted that the distance from the center of the sphere to the bottom of the upper polar cap in Figure 1-14 does not equal one half the height of the center plate plus the height of the upper plate $(0.5626+0.7662$ in. $=1.3288$ in. $)$ minus the shift of the center of the center plate below the center of the sphere (-0.02 in.). The value in Figure 1-14 is 1.3488 and is believed to be incorrect simply due to the addition rather than subtraction of the shift of the center of the plate below the center of the sphere.

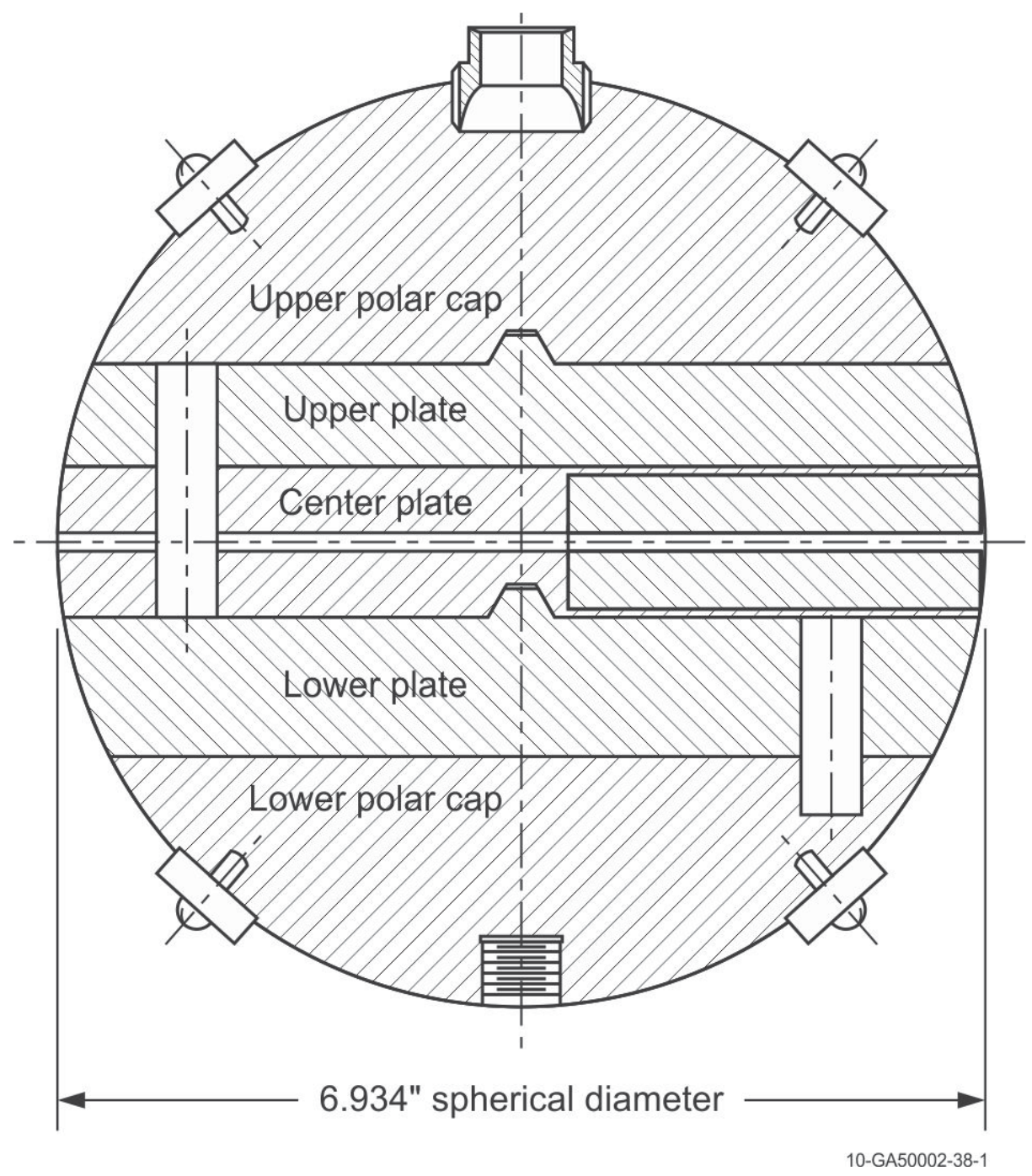

Figure 1-4. Sketch of the Assembly of Five Sphere Parts. ${ }^{a}$

\footnotetext{
${ }^{a}$ Redrawn from Reference 1. Although not shaded the pins in the lower polar cap and lower plate and the upper plate and center plate and the mass adjustment buttons were all HEU. The diameter should be given as 6.933 in. to correspond to the 3.4665 in. radius sphere. Personal communication with J.T. Mihalczo, July 8, 2013. 


\section{NEA/NSC/DOC(95)03/II \\ Volume II}

HEU-MET-FAST-100

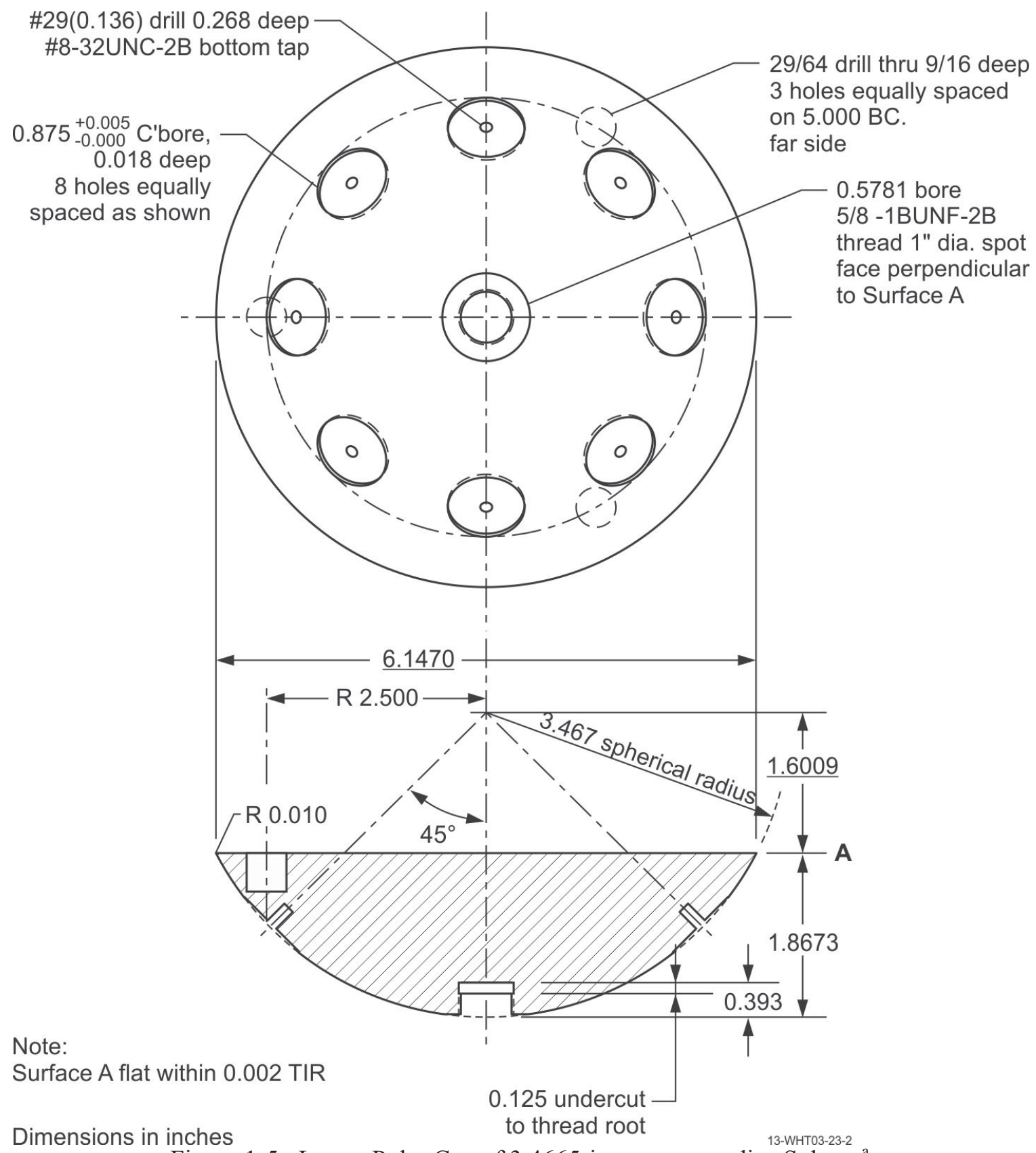

Figure 1-5. Lower Polar Cap of 3.4665-in.-average-radius Sphere. ${ }^{\mathrm{a}}$

${ }^{a}$ Redrawn from Reference 1. BC stands for bolt circle which is the theoretical circle upon which the center of the HEU pins are equally spaced. Nominal radius is given. 


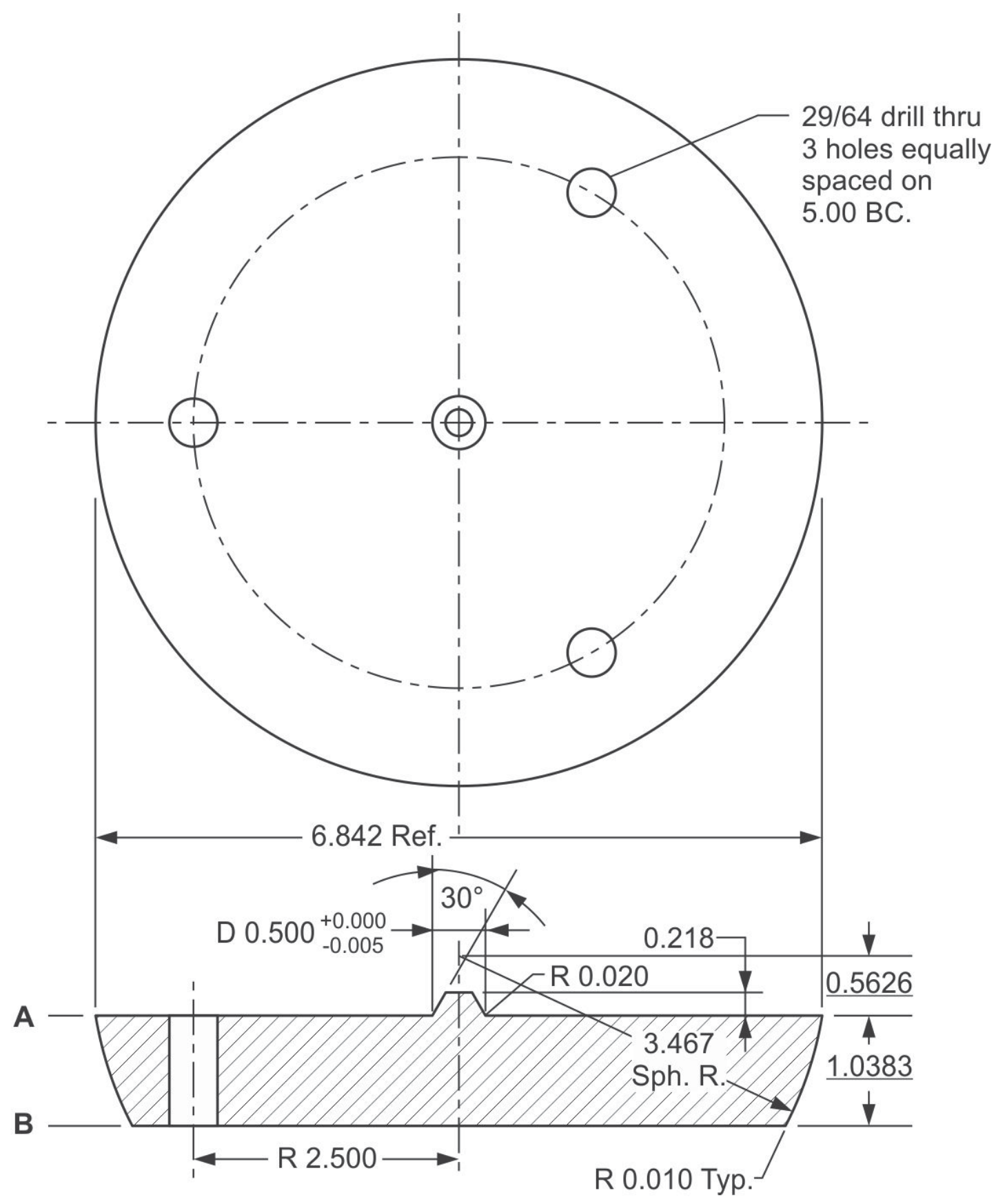

Note:

Surface A and B flat and parallel within 0.002 TIR

Dimensions in inches

10-GA50002-38-3

Figure 1-6. Lower Plate of 3.4665-in.-average-radius Sphere. ${ }^{\mathrm{a}}$

\footnotetext{
${ }^{a}$ Redrawn from Reference 1. BC stands for bolt circle which is the theoretical circle upon which the center of the HEU pins are equally spaced. Nominal radius given. 


\section{NEA/NSC/DOC(95)03/II \\ Volume II}

\section{HEU-MET-FAST-100}

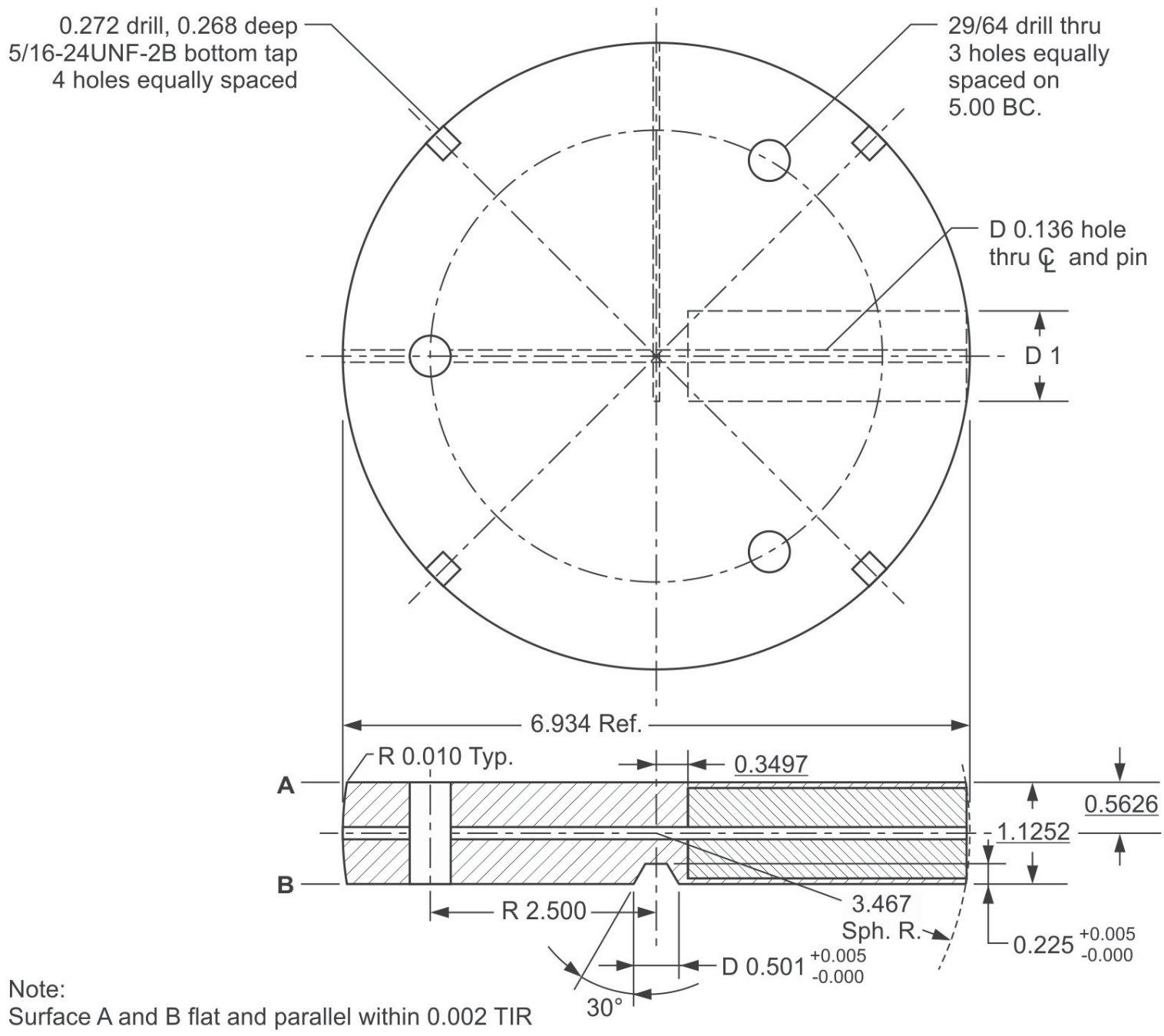

Dimensions in inches

10-GA50002-38-4

Figure 1-7. Center Plate of 3.4665-in.-average-radius Sphere. ${ }^{a}$

${ }^{a}$ Redrawn from Reference 1. BC stands for bolt circle which is the theoretical circle upon which the center of the HEU pins are equally spaced. Nominal radius given. 


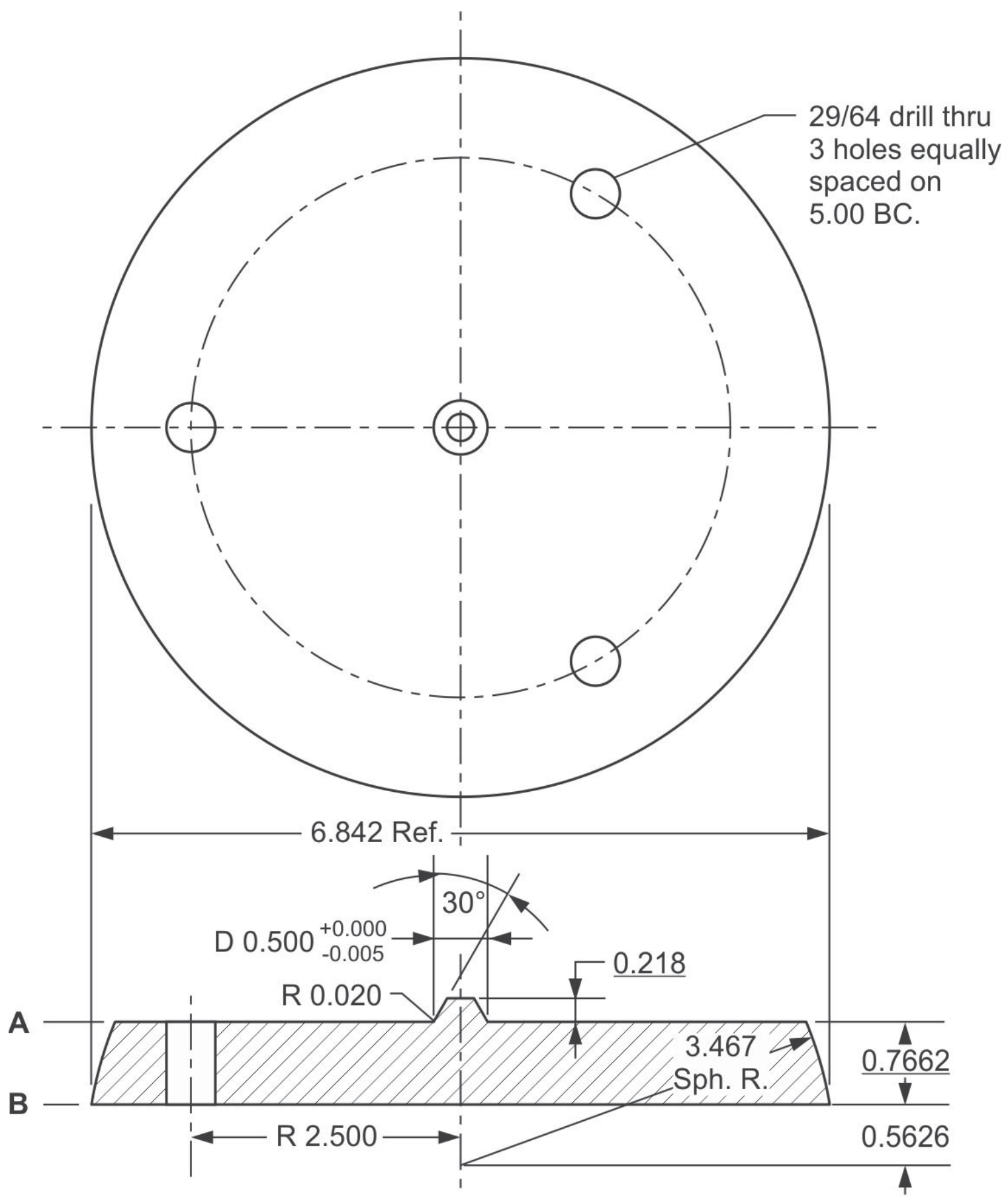

Note:

Surface A and B flat and parallel within 0.002 TIR

Dimensions in inches

Figure 1-8. Upper Plate of 3.4665-in.-average-radius Sphere. ${ }^{\mathrm{a}}$

\footnotetext{
${ }^{a}$ Redrawn from Reference 1. BC stands for bolt circle which is the theoretical circle upon which the center of the HEU pins are equally spaced. Nominal radius given. 
NEA/NSC/DOC(95)03/II

Volume II

HEU-MET-FAST-100

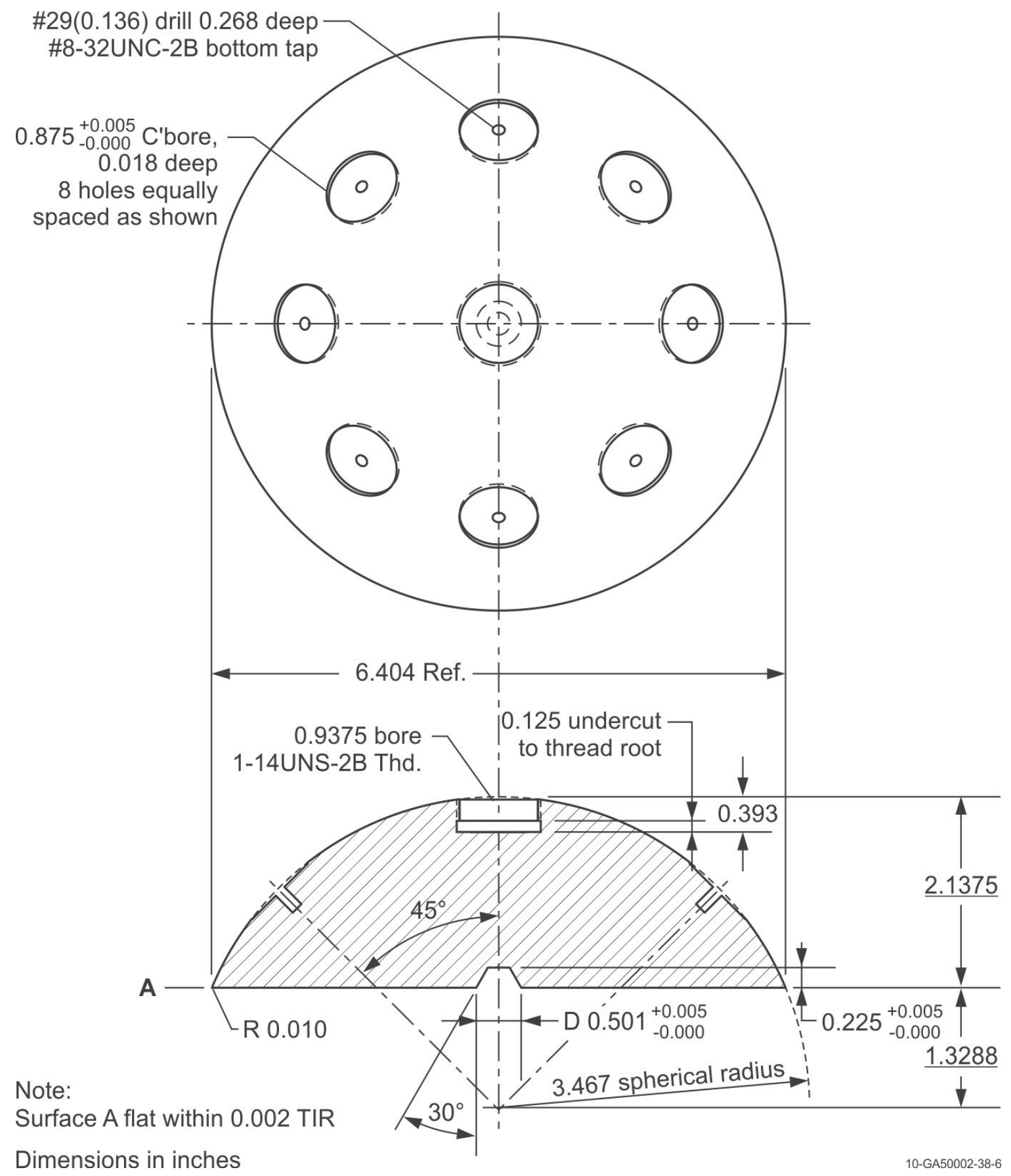

Figure 1-9. Upper Polar Cap of 3.4665-in.-average-radius Sphere. ${ }^{a}$

${ }^{a}$ Redrawn from Reference 1. Nominal radius given. 


\section{NEA/NSC/DOC(95)03/II \\ Volume II}

\section{HEU-MET-FAST-100}

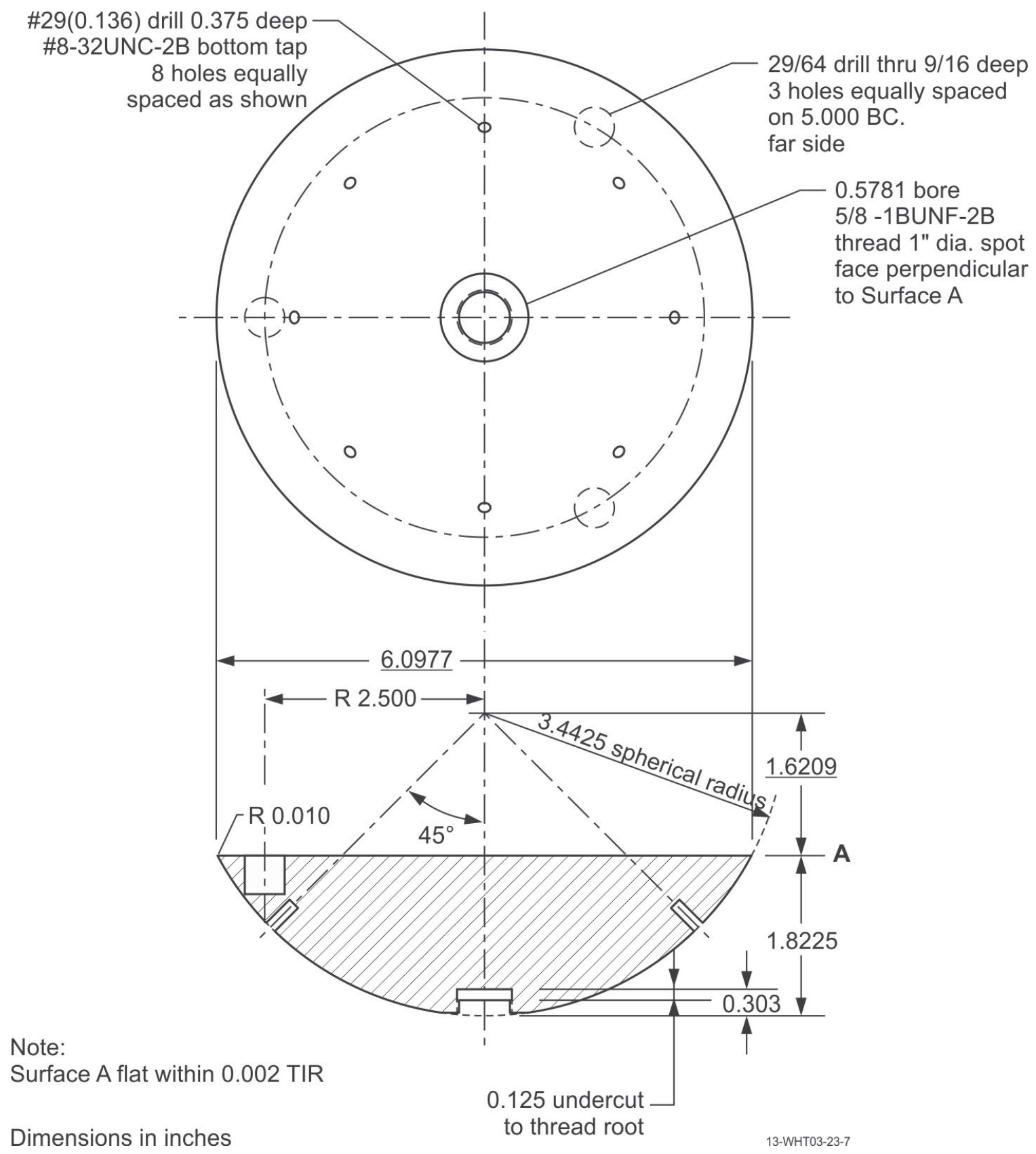

Figure 1-10. Lower Polar Cap of 3.4425-in.-nominal-radius (3.4420-in.-average-radius) Sphere. ${ }^{\text {a }}$

${ }^{a}$ Redrawn from Reference 1. BC stands for bolt circle which is the theoretical circle upon which the center of the HEU pins are equally spaced. 


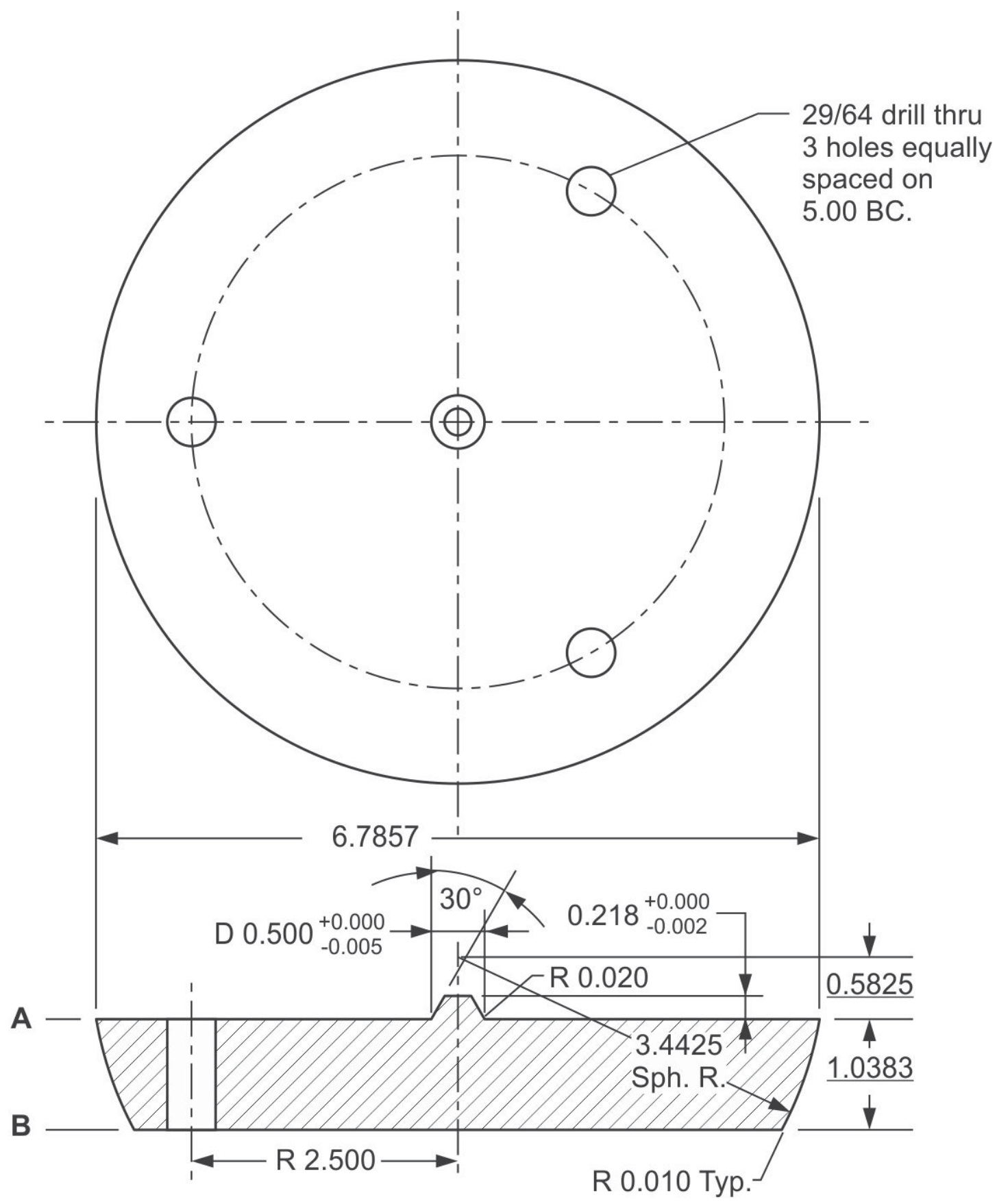

Note:

Surface A and B flat and parallel within 0.002 TIR

Dimensions in inches

10-GA50002-38-8

Figure 1-11. Lower Plate of 3.4425-in.-nominal-radius (3.4420-in.-average-radius) Sphere. ${ }^{\text {a }}$

\footnotetext{
${ }^{a}$ Redrawn from Reference 1. BC stands for bolt circle which is the theoretical circle upon which the center of the HEU pins are equally spaced. 


\section{NEA/NSC/DOC(95)03/II}

Volume II

\section{HEU-MET-FAST-100}

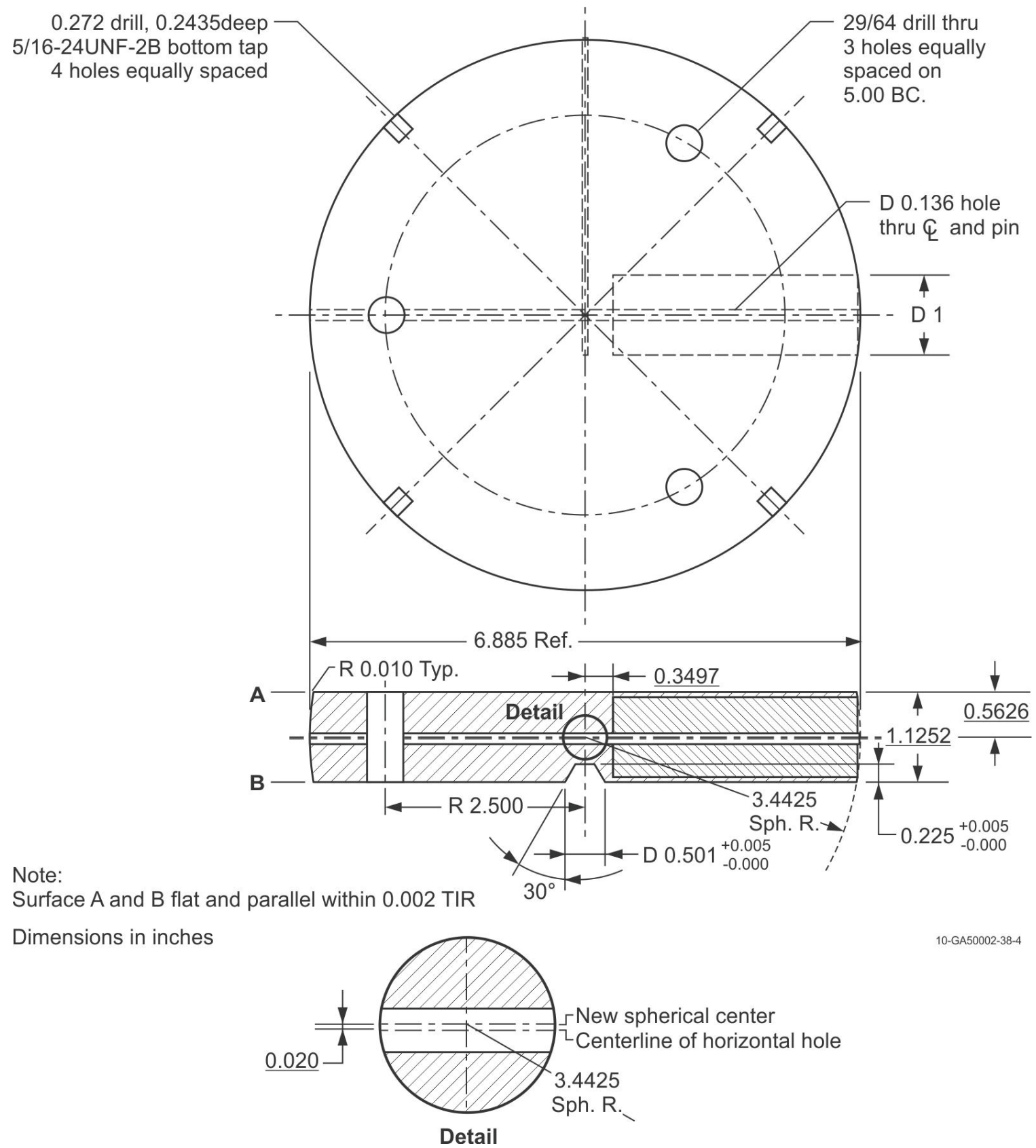

Figure 1-12. Center Plate of 3.4425-in.-nominal-radius (3.4420-in.-average-radius) Sphere. ${ }^{\mathrm{a}}$

\footnotetext{
${ }^{a}$ Redrawn from Reference 1. BC stands for bolt circle which is the theoretical circle upon which the center of the HEU pins are equally spaced. 


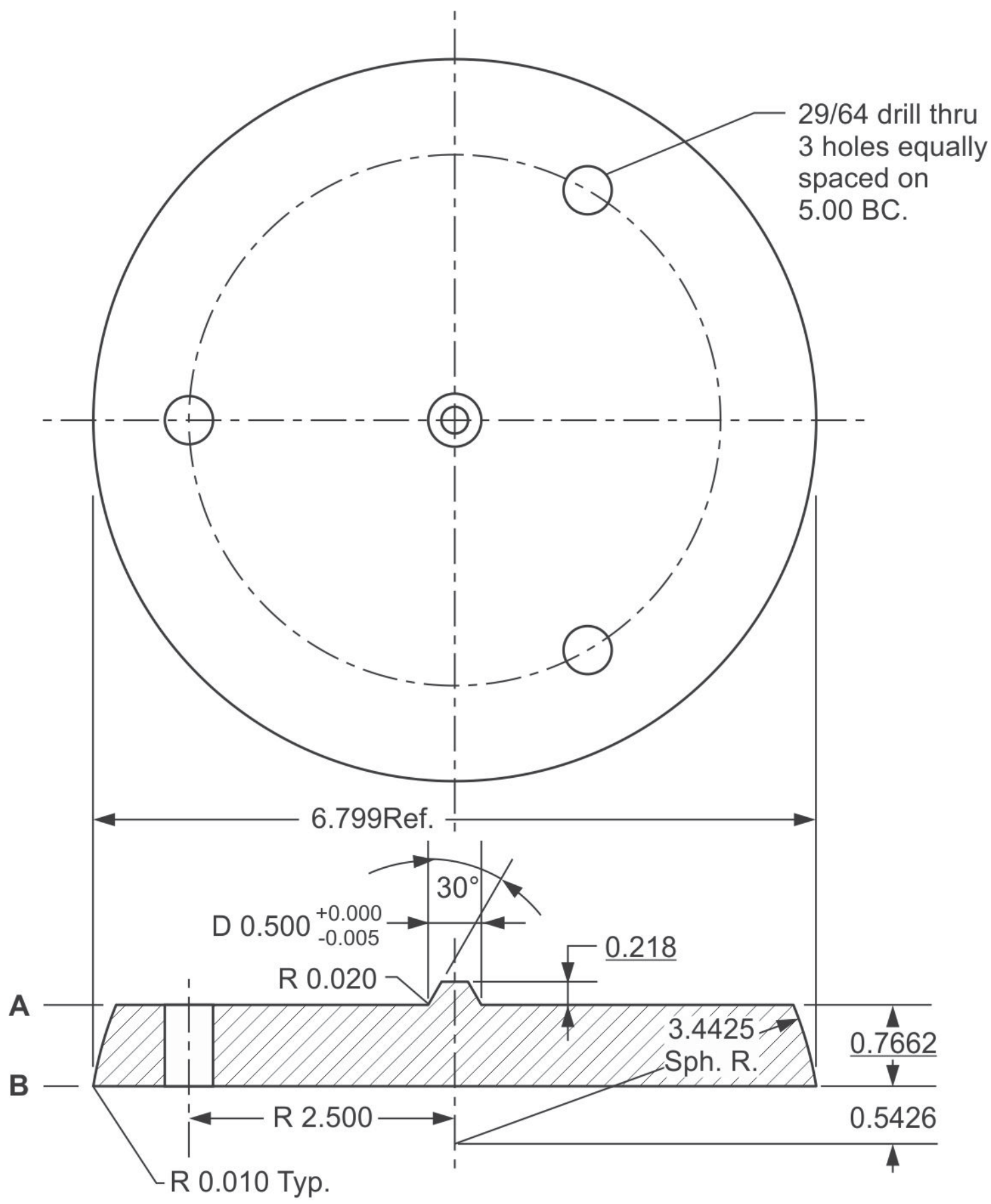

Note:

Surface A and B flat and parallel within 0.002 TIR

Dimensions in inches

10-GA50002-38-10

Figure 1-13. Upper Plate of 3.4425-in.-nominal-radius (3.4420-in.-average-radius) Sphere. ${ }^{a}$

\footnotetext{
${ }^{a}$ Redrawn from Reference 1. BC stands for bolt circle which is the theoretical circle upon which the center of the HEU pins are equally spaced. 
NEA/NSC/DOC(95)03/II

Volume II

HEU-MET-FAST-100

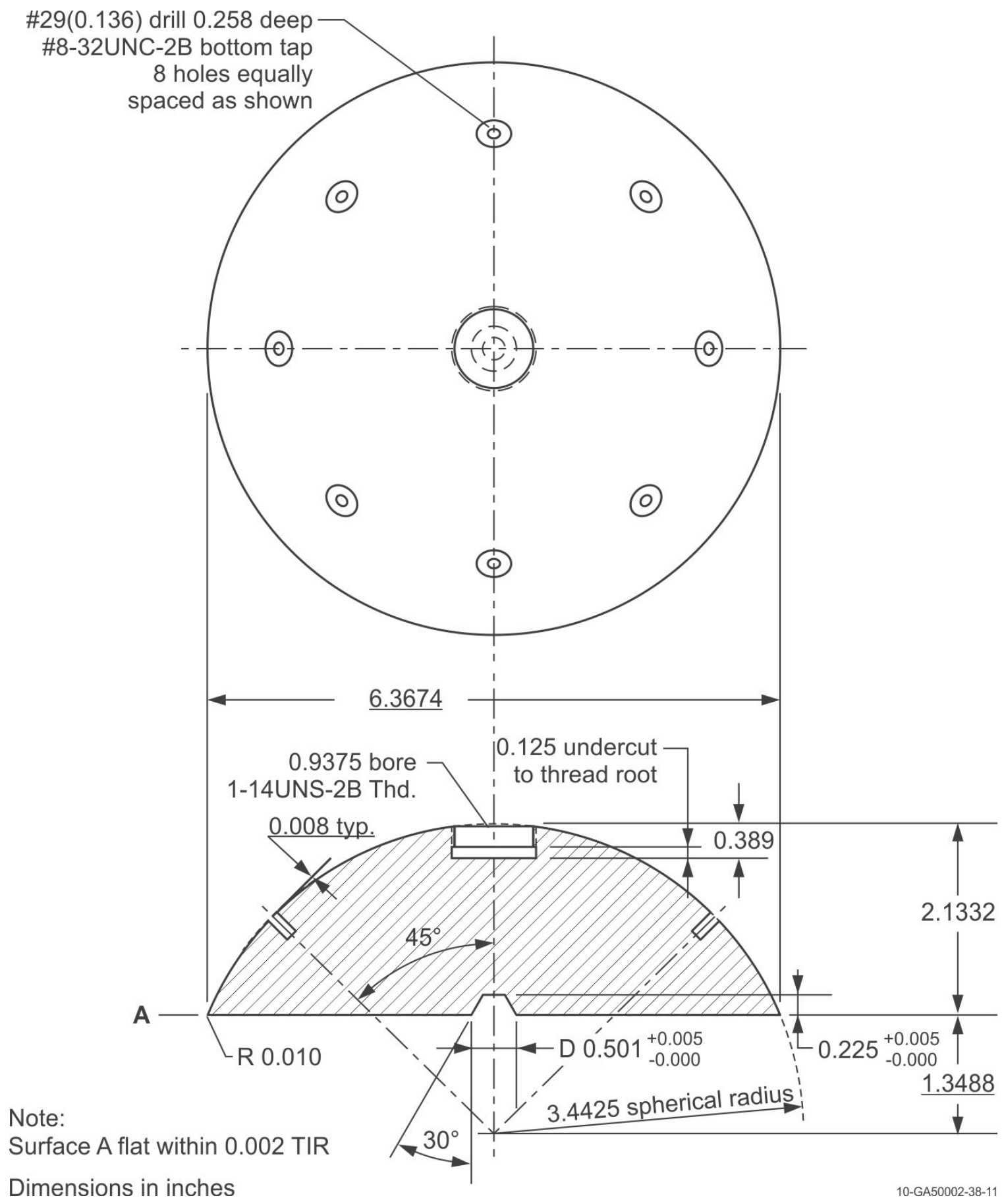

Figure 1-14. Upper Polar Cap of 3.442- in.-nominal-radius (3.4420-in.-average-radius) Sphere. ${ }^{\text {a }}$

${ }^{a}$ Redrawn from Reference 1 . The distance from the center of the sphere to the bottom of the upper polar cap should actually have been $1.3088 \mathrm{in}$. It is believed this is simply a calculation error caused by adding rather than subtracting the 0.02 in. shift in the center of the sphere from the larger sphere to the smaller sphere. 


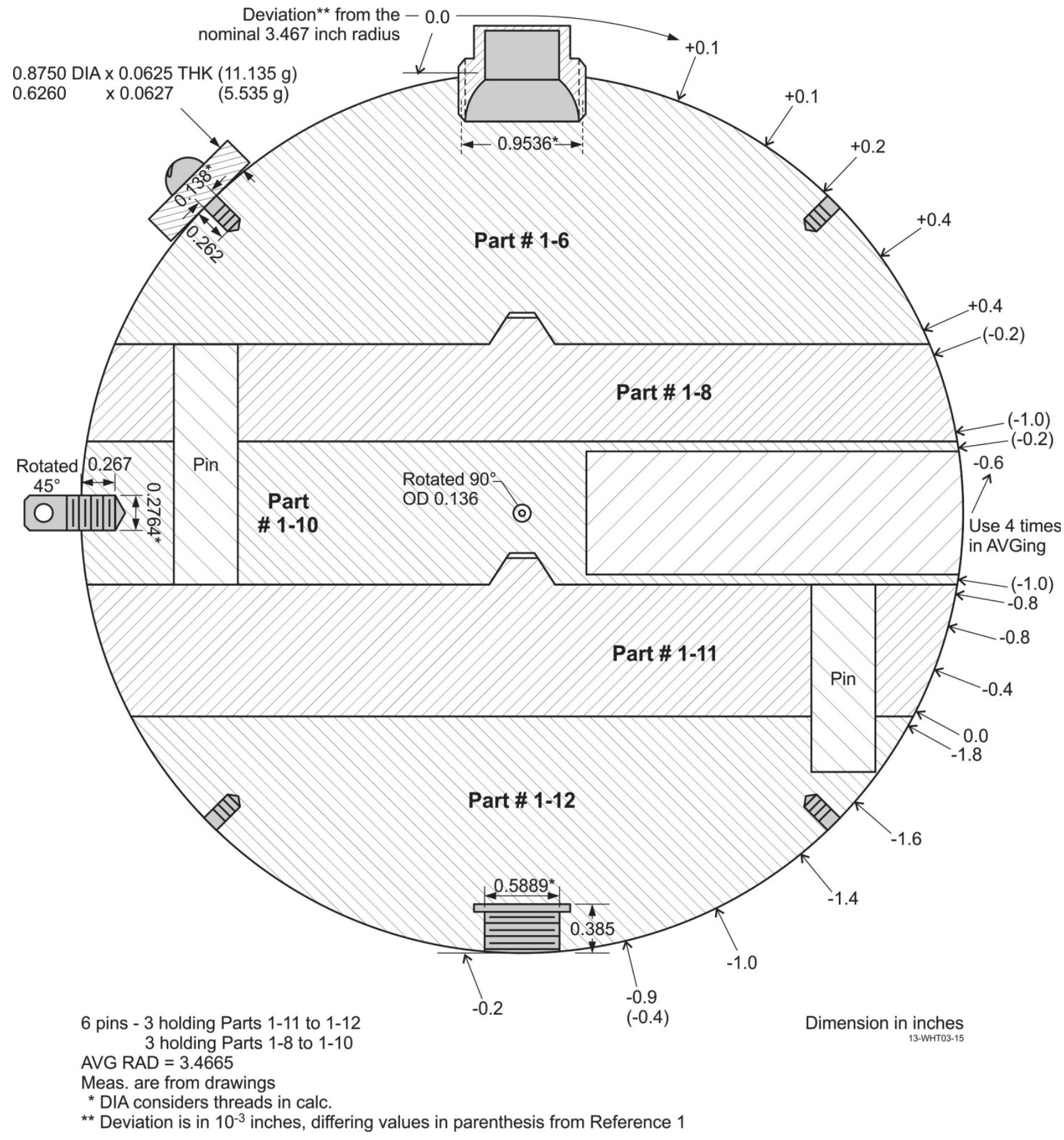

Figure 1-15. Measured Dimensions. ${ }^{\text {a }}$

\footnotetext{
${ }^{a}$ Redrawn from handwritten dimensions on a drawing provided by the experimenter and personal communication with the experimenter, J.T. Mihaclzo, July 2013. The pin does not break the surface of the sphere. Multiple deviation from spherical measurements were equally spaced (see Table 1-1). 
NEA/NSC/DOC(95)03/II

Volume II

HEU-MET-FAST-100

\subsubsection{Pins}

After the ORSphere parts were returned to Oak Ridge National Laboratory from the General Atomic Company linear accelerator (LINAC) facility various changes were made. The tapped screws holes that were originally used with stainless steel screws to hold the lower polar cap to the lower plate and the center plate to the upper plate were drilled to a diameter of 0.4530 in. (the drawings gave a drill diameter of 29/64 in., which is slightly larger). Six (three in each section) slightly oversized diameter pins of HEU metal replaced the screws to attach the lower polar cap to the lower plate and the center plate to the upper plate. The HEU pins were cooled, inserted, and then warmed to ambient temperature (shrink fit) to ensure no voids were present around the pins. The three pins in each section were at a diameter of $5.000 \mathrm{in}$. and were equally spaced. The pins in the central section extended from the bottom of the center plate to the top of the upper plate. The pins in the lower section extended only partially into the lower polar cap. According to Figure 15 and Figure 1-10 they extended 9/16 in. (0.5625 in. or $1.42875 \mathrm{~cm}$ ) deep. According to the experimenter the pins were not deep enough to extend into the mass button recesses and did not break the curve of the surface of the 3.4665-in.-average-radius sphere. ${ }^{\mathrm{a}}$ This discrepancy is discussed in Section 2.2.7. For the 3.4665-in. sphere the top of one of the pins in the bottom section was flush with the surface of the lower plate. One of the pins extended beyond the lower plate upper surface by $2.3 \times 10^{-3} \mathrm{in}$. and the top of the third pin sat below the upper surface of the lower plate by 0.0005 in. This pin projection caused a 0.0045 -in. gap on the side of the sphere closest to the pin and no gap on the opposite side of the sphere. When the sphere was machined to an average radius of 3.4420 in. the pin that extended beyond the upper surface of the lower plate was machined until it was 0.0005 in. below the upper surface of the plate. Thus, for the second sphere the top of two of the pins were 0.0005 in. below the upper surface of the lower plate and one pin was flush with the surface.

\subsubsection{Target Hole Plug and Diametral Hole and Rod}

The original 1.000-in.-diameter target hole, which extended radially to within 0.350 in. (nominal, $0.3497 \mathrm{in.}$ measured) of the center of the sphere, allowed "the electron beam from the linear accelerator to impinge on the uranium close to the center of the sphere" (Reference 1). This target hole was plugged by shrink fit with an HEU plug a few thousandths of an inch diametrically larger than the hole, thus there was no void introduced between the plug and the center plate. After the target hole was filled a 0.136-in.-diameter diametral hole was drilled through the center of the sphere. This hole went through the target hole plug and one of the HEU pins. Two 0.1293-in.-diameter filler rods of 4.265- and 2.745-in. lengths (17.117 and 11.046 $\mathrm{g}$, respectively) were inserted into the diametral hole during the critical assembly of the parts. Dimensional certification reports give the rod lengths as $4.2650 \mathrm{in}$. and $2.7545 \mathrm{in}$. and the diameter as $0.1290 / 0.1295$ in., which averaged to 0.1293 in. The length of the shorter filler rod did not agree between Reference 1 and the certification report, this discrepancy is discussed in Section 2.2.4. The masses on the dimensional certification report are the same as those given in Reference 1. The total length of two filler rods was greater than the length of the diametral hole. ${ }^{\mathrm{b}}$

\footnotetext{
${ }^{a}$ Personal email communication with J.T. Mihalczo, February 3, 2013.

${ }^{\mathrm{b}}$ Personal communication with J.T. Mihalczo, April 15, 2013. The diametral filler rod was not machined to match the curve of the sphere.

Revision: 0

Date: September 30, 2013

Page 18 of 160
} 
NEA/NSC/DOC(95)03/II

Volume II

HEU-MET-FAST-100

\subsubsection{Thermocouple}

"The thermocouple groove in the center plate... [of the original sphere used at General Atomic had] a width of $0.070 \mathrm{in} . \pm 0.004 \mathrm{in}$. and accommodated a thermocouple that was 0.062 inches in diameter. This groove for the center thermocouple extended 3/8 in. past the center [of the sphere]. However, at a radius of $1.625 \mathrm{in}$. to the outer radius of the sphere the groove was cut deeper to accommodate another thermocouple at a radius of about $1.65 \mathrm{~cm}$. Thus, the depth of the groove was $0.140 \mathrm{in}$. into a radius of $1.625 \mathrm{in}$. and $0.70 \mathrm{in}$. from a radius of 1.625 in. to $3 / 8$ in. past the center." "a A figure provided by the experimenter has the depths as being $0.058 \pm 0.002 \mathrm{in}$. and $0.116 \pm 0.002 \mathrm{in}$. According to the experimenter the depths in the drawing should be used. ${ }^{\mathrm{b}}$ The thermocouple groove was also filled by shrink fit with HEU metal and machined flat.

\subsubsection{Sphere Radius}

After the pin holes, target hole, and thermocouple groove were filled, the sphere was re-machined to a nominal radius of $3.467 \mathrm{in}$. (average radius of 3.4665in.). After the 3.4665-in.-radius sphere was assembled and all measurements were performed the bottom section of the sphere, made up of the lower polar cap and the lower plate, was re-machined to a radius of $3.439 \mathrm{in}$. The sphere was then reassembled. Finally the three sections of sphere were all machined to a nominal radius of 3.4425 in. (actual average radius of $3.4420 \mathrm{in}$.). When the entire sphere was re-machined to the 3.4420-in.-average radius the center of the sphere was $0.020 \mathrm{in}$. above the previous center of the sphere thus the center of the diametral hole was $0.020 \mathrm{in}$. below the center of the 3.4420-in.-average-radius sphere. This resulted in a change of angle for the mass adjustment button recesses with respect to the center of the 3.4420-in-average-radius sphere. This change in angle is not reflected in Figures 1-10 and 1-14. ${ }^{\mathrm{c}}$

The machined sphere parts were not perfectly spherical. The deviation from spherical of each part was measured using a sweep gauge and is shown in Figure 1-15 for the 3.4665-in. sphere and given in Tables 1-1 and 1-2 for both spheres. Sweep gauge measurements are point measurements and are not averaged around the entire equator however due to machining techniques the radius should not have varied around the entire sphere equator at a given axial height. ${ }^{\mathrm{d}}$ Discrepancies between Table 1-1 and Table 1-2 and the drawing are shown in Figure 1-15. Tables 1-1 and 1-2 also give the vertical height and certified masses of each section.

\footnotetext{
a Personal email communication between J.T. Mihalczo and T. Murray, December 10, 2011. The thermocouple groove was for experiments at General Atomic.

${ }^{\mathrm{b}}$ Personal email communication with J.T. Mihalczo, February 4, 2013.

${ }^{c}$ Personal email communication with J.T. Mihalczo, July 8, 2013.

${ }^{\mathrm{d}}$ Personal phone communication with J.T. Mihalczo, April 24, 2013.

Revision: 0

Date: September 30, 2013

Page 19 of 160
} 
NEA/NSC/DOC(95)03/II

Volume II

HEU-MET-FAST-100

Table 1-1. Measured Dimensions and Certified Masses of the Nominal 3.467-in-radius Sphere Parts (Reference 1, additions by the evaluator are italic).

\begin{tabular}{|c|c|c|c|c|}
\hline & $\begin{array}{l}\text { Number } \\
\text { of points } \\
\text { measured }\end{array}$ & $\begin{array}{l}\text { Deviation from } 3.467-\text { in radius } \\
\text { (a) } \\
\left(10^{-3} \text { in. }\right)\end{array}$ & $\begin{array}{c}\text { Vertical } \\
\text { Height }^{(b)} \text { (in.) }\end{array}$ & $\begin{array}{l}\text { Certified Mass }^{(\mathrm{c})} \\
\text { (g) }\end{array}$ \\
\hline Upper Polar Cap & 6 & $\begin{array}{l}0.0 \text { at pole },+0.1,+0.1,+0.2,+0.4, \\
+0.4 \text { at bottom }\end{array}$ & $2.1375^{(\mathrm{d})}$ & $12,042.76^{(\mathrm{e})}$ \\
\hline Upper Plate & 2 & -0.2 at top to -1.0 at bottom & 1.8914 & $21,095.06^{(\mathrm{f})}$ \\
\hline Central Plate & 2 & -0.2 at top to -1.0 at bottom & & \\
\hline Lower Plate & 4 & -0.8 at top, $-0.8,-0.4$ to 0.0 at bottom & 1.0383 & $20,310^{(\mathrm{g})}$ \\
\hline Lower Polar Cap & 6 & $\begin{array}{l}-1.8 \text { at top, }-1.6,-1.4,-1.0,-0.4, \text { to }- \\
0.2 \text { at pole }\end{array}$ & $1.8673^{(\mathrm{d})}$ & $\begin{array}{l}\text { Included in } \\
20,310 \mathrm{~g} \text { of } \\
\text { previous entry }\end{array}$ \\
\hline
\end{tabular}

(a) Measured with a sweep gage at $70^{\circ} \mathrm{F}$ at the $\mathrm{Y}-12$ Plant. Multiple readings are equally spaced. Average radius is 3.4665 in. or $8.0849 \mathrm{~cm}$.

(b) The radius obtained from the sum of vertical heights, divided by 2, is $3.4673 \mathrm{in}$. or $8.8068 \mathrm{~cm}$. The masses given are with all penetration of the sphere parts empty: screw holes for mass adjustment buttons, upper, lower, and central supports, voids and void around alignment cones and in the diametral hole. The masses were obtained on a large temperature and humidity controlled glass-enclosed balance traceable to the National Bureau of Standards and usually reported out to $0.01 \mathrm{~g}$.

(c) Sum of these certified masses is 53,448.82 g. (Masses actually add to 53,447.82; this is believed to be a typographical error.)

(d) Polar height as if the parts were fabricated with no holes drilled at the poles.

(e) This mass does not include the $64 \mathrm{~g}$ of uranium in the socket for the attachment of the upper polar cap to its piston rod. Although the support rod for the upper polar cap socket is referred to in Reference 1 as a piston it is technically not since the drive used in these experiments for the upper polar cap was a mechanical screw drive. (Personal communication with the experimenter, J.T. Mihalczo, July 8. 2013.)

(f) Mass of upper and central plate after they were pinned together as one part with uranium metal pins. This mass does not include the 0.1293-in-dia., 4.265- and 2.745-in-long filler rod for the 0.136-in-dia. diametral hole which had masses of 17.117 and $11.046 \mathrm{~g}$, respectively, and the uranium of the upper socket, which had a mass of $64 \mathrm{~g}$. Thus the total uranium mass of the sphere was $53,240.27 \mathrm{~g}$, which includes the $64 \mathrm{~g}$ in the socket for the attachment of the upper polar cap to its piston rod. (The 53,240.27 mass is an incorrect mass that was carried over from the older Reference 2. It is believed that the $2.745 \mathrm{in}$. length for the filler rod should actually be $2.7545 \mathrm{in}$., see Seection 1.2.2.)

(g) Mass of the lower section consisting of the lower plate and lower polar cap was reported out only to 1-g accuracy. This mass is larger than that reported for this part in a previous publication (Reference 2), which omitted the mass of the pins that hold the lower polar cap and lower plate together. 
Table 1-2. Measured Dimensions and Certified Masses of the 3.4420-in-radius Uranium Metal Sphere Parts. (Reference 1).

\begin{tabular}{clcc}
\hline \multirow{2}{*}{ Sections $^{(\text {a) }}$} & \multicolumn{1}{c}{$\begin{array}{c}\text { Deviation from 3.4425-in radius } \\
\left(10^{-3} \text { in. }\right)\end{array}$} & $\begin{array}{c}\text { Vertical Height }^{(\mathrm{c})} \\
\text { (in })\end{array}$ & $\begin{array}{c}\text { Certified Mass }^{(\mathrm{d})} \\
(\mathrm{g})\end{array}$ \\
\hline Top & +1.2 at pole to -0.5 at bottom & $2.1332^{(\mathrm{e})}$ & $11,883.24$ \\
Middle & -1.7 at top to -2.9 at bottom & 1.8914 & $20,814.95$ \\
Bottom & +0.2 at top to +0.8 at pole & $2.8608^{(\mathrm{e})}$ & $19,624.59$ \\
\hline
\end{tabular}

(a) The central section now consists of the central and upper plate pinned together, and the bottom section of the lower polar cap and lower plate pinned together.

(b) Measured with a sweep gage at $70^{\circ} \mathrm{F}$ at the Y-12 Plant. There is near continuous variation between end points. Average radius is 3.4420 in. or $8.7427 \mathrm{~cm}$.

(c) The radius obtained from the sum of vertical heights divided by 2 is 3.4427 in. or $8.7445 \mathrm{~cm}$.

(d) The masses of the sphere sections with all penetration holes empty. The sum of these certified masses is $52,322.78 \mathrm{~g}$.

(e) Polar height (to actual pole which is above the uranium metal due to the holes for the support).

The masses given in Table 1-1 and Table 1-2 can be verified with dimensional certification reports provided by the experimenter. The masses for the top and center section of Case 1; the top, middle, and bottom section of Case 2; and the diametral filler rods all match the masses given in the dimensional certification reports. For the bottom section of Case 1 the lower polar cap mass was given as 9,400.02 $\mathrm{g}$ and the lower plate mass was given as $10,610.27 \mathrm{~g}$. These masses were measured before the parts were pinned together. The 20,310 g mass in Table 1-1 was obtained from nuclear material control and accountability records. ${ }^{\text {a }}$ Dimension certification reports were given for three pins with the following diameters, lengths and masses.

$\begin{array}{llll} & \text { Pin1 } & \text { Pin2 } & \text { Pin3 } \\ \text { Diameter (in.) } & 0.4997 / 0.4998 & 0.4995 / 0.4997 & 0.4992 / 0.4995 \\ \text { Length (in.) } & 1.6650 & 1.6652 & 1.6655 \\ \text { Mass (g) } & 100.190 & 100.206 & 100.226\end{array}$

The pins did not break the surface of the lower polar cap. The parts were pinned and then the pins were machined to approximately match the surface of the plates. These dimensions and masses are further discussed in Section 2.2.7.

\subsubsection{Mass Adjustment Button Recesses}

Each of the two polar caps had eight equally spaced mass adjustment button recesses to partially accommodate mass adjustment buttons. In the center of the recesses there were tapped screw holes that were used with screws to hold the mass adjustment buttons in place. Mass adjustment buttons were used to add uranium mass and adjust reactivity but none were used in the two configurations evaluated here. For Case 1, the button recesses had a measured screw hole radius, which was then adjusted to account for threads to obtain a screw hole diameter of 0.138 in. as given in Figure 1-15. In the original sphere, the recesses into which the mass adjustment buttons fit had a radius of $0.875_{-0.000}^{+0.005} \mathrm{in}$. The depth of the recess was 0.018-in.

\footnotetext{
${ }^{a}$ Personal phone communication with J.T. Mihalczo, April 24, 2013.

Revision: 0

Date: September 30, 2013

Page 21 of 160
} 
deep measured at the edge of the recess. ${ }^{a}$ When the ORSphere was re-machined the mass adjustment button recesses and screw holes were not re-drilled so the depth and diameter of the mass adjustment button recesses were reduced. ${ }^{\mathrm{b}}$ "The mass adjustment buttons recesses were located $45^{\circ}$ from the equator of the original GA sphere. So, when the machining moved the sphere center slightly, this angle was changed slightly in the final assembly."

\subsubsection{Upper Support Structure}

The upper polar cap was attached to the upper support structure using a stainless steel socket that was surrounded by $64 \mathrm{~g}$ of HEU metal that was screwed into a tapped hole in the upper polar cap. The hole into which the socket threaded had a measured and adjusted, to account for the threads, diameter of $0.9536 \mathrm{in}^{\mathrm{d}}$ The depth of the hole was 0.393 in. for the larger sphere and 0.389 in. for the smaller sphere (see Figure 1-9 and Figure 1-14). A manufacturing drawing was provided of the socket and is given in Figure 1-16.

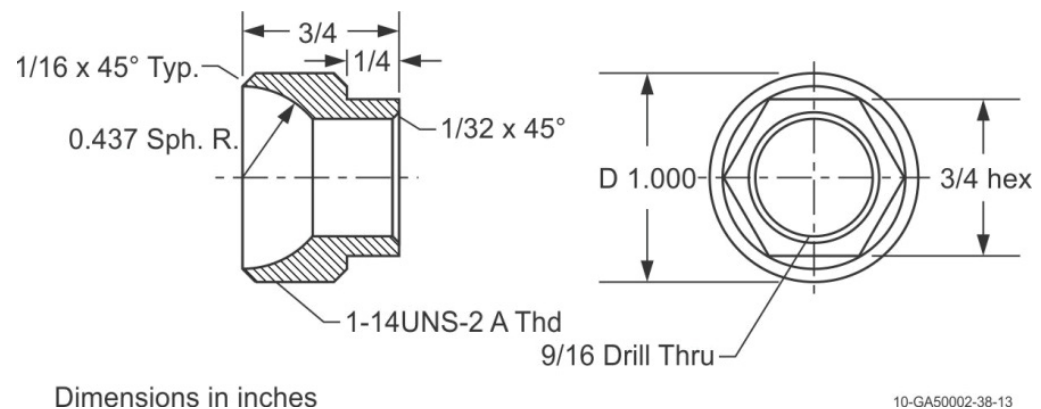

Figure 1-16. Upper Socket Dimensions. ${ }^{\mathrm{e}}$

According to the experimenter, the density of the $64 \mathrm{~g}$ of uranium was $18.75 \mathrm{~g} / \mathrm{cm}^{3}$. The measured worth of the upper socket, including the $64 \mathrm{~g}$ of uranium, was $10.2 \pm 0.1 \not$. The following method was used to measure the reactivity of the upper polar cap:

The sphere was assembled to exactly delayed criticality by adjusting the number and location of surface uranium mass adjustment buttons and the position of a small aluminum reflector used for fine reactivity adjustment. The lower section of the sphere was lowered with the upper polar cap resting on the central section. The upper piston rod $^{\mathrm{g}}$ was detached and withdrawn upward and the material in the upper support structure hole removed. A small hydrogenous reflector was added to the upper section of the sphere and the sphere reassembled. The presence of the hydrogenous reflector resulted in the system rising at an exponential rate with positive reactor period. At sufficiently high fission rate for measurement the hydrogenous reflector was completely removed. The reactivity was

\footnotetext{
${ }^{\text {a }}$ Personal email communication with J.T. Mihaclzo, January 30, 2013.

${ }^{\mathrm{b}}$ Personal email communication with J.T. Mihaclzo, March 13, 2013.

${ }^{\mathrm{c}}$ Personal email communication with J.T. Mihalczo, June 19, 2013.

${ }^{\mathrm{d}}$ This diameter is to the middle of the threads. Personal email communication with J.T. Mihaclzo, February 6, 2013

${ }^{\mathrm{e}}$ Redrawn from Reference 1.

${ }^{\mathrm{f}}$ Personal phone communication between J.B. Briggs and J.T. Mihalczo, March 27, 2012.

${ }^{g}$ Although the support rod for the upper polar cap socket is referred to in Reference 1 as a piston it is technically not since the drive used in these experiments for the upper polar cap was a mechanical screw drive. (Personal communication with the experimenter, J.T. Mihalczo, July 8. 2013.)

Revision: 0

Date: September 30, 2013

Page 22 of 160
} 
determined from the negative stable reactor period measurement using the inhour equation with the six group delayed neutron parameters of Keepin. ${ }^{a}$ The negative reactivity associated with removing the upper support structure was $10.2 \pm 0.1 \varnothing$ (piston rod and material in support hole. (Reference 1)

The upper socket acted as a flexible joint attaching the upper polar cap to a rod moved by a mechanical screw driver and attached to cross beam supports for the upper section of the sphere. The worth of the aluminum cross beam supports was $0.70 \pm 0.09 \notin{ }^{\mathrm{b}}$ The upper polar cap was lowered 24 in. until it completely rested on the central sphere section when the sphere was assembled. Figure1-17 shows the upper polar cap, the socket, and the support rod attachment.

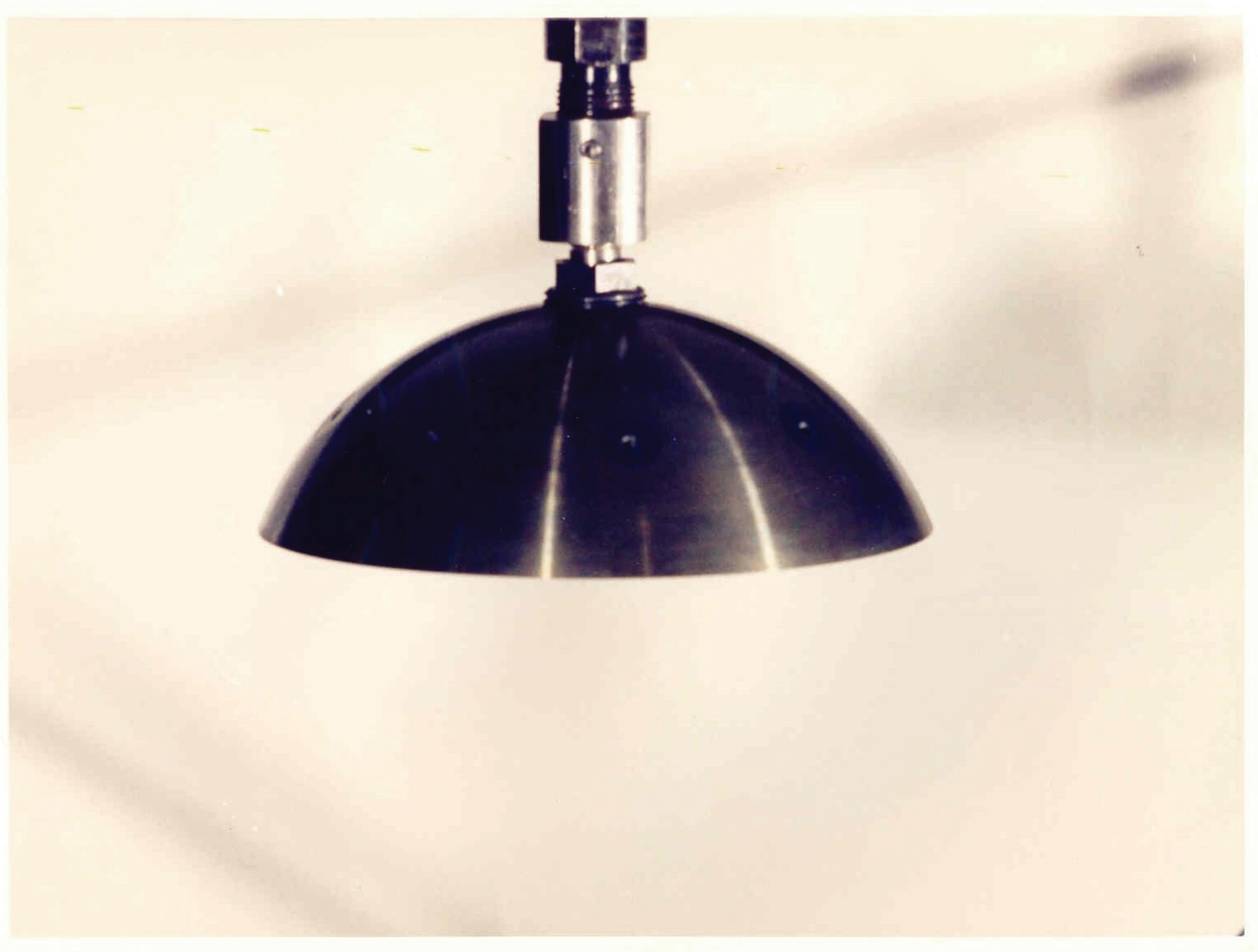

Figure1-17. Upper Polar Cap and Socket with Support Rod Attachment.

\footnotetext{
${ }^{a}$ The change to the quoted text (in italics) was made by the experimenter, J.T. Mihalczo on April 15, 2013.

${ }^{b}$ Material of the cross beam provided via personal communication with the experimenter, J.T. Mihalczo, July 8, 2013. 
HEU-MET-FAST-100

\subsubsection{Central Support Structure}

The center section was supported by four stainless steel tubes, which attached to the center plate by pins to threaded steel parts in the uranium. The steel parts threaded into holes with a measured and adjusted for threading diameter of 0.2764 in. (Figure 1-15). The joint between the tubes and the center plate was allowed to flex to ensure ideal positioning of the plate during assembly. Figure1-18 shows the center section of the sphere and the four thin walled stainless steel support tubes. ${ }^{\text {a }}$ The stainless steel tubing attached to the 4-ft.square post of the vertical assembly machine. The worth of the central support structure was determined by doubling the support structure material and then measuring the change in reactivity in a manner similar to that used to determine the worth of the upper polar cap socket. The worth of the central support structure and the lower support structure (see Section 1.2.8), including the post of the vertical assembly machine was 14.29 $\pm 0.05 \not$. It was measured in a manner similar to that described in Section 1.2.6, but by doubling the material present and measuring the reactivity change.

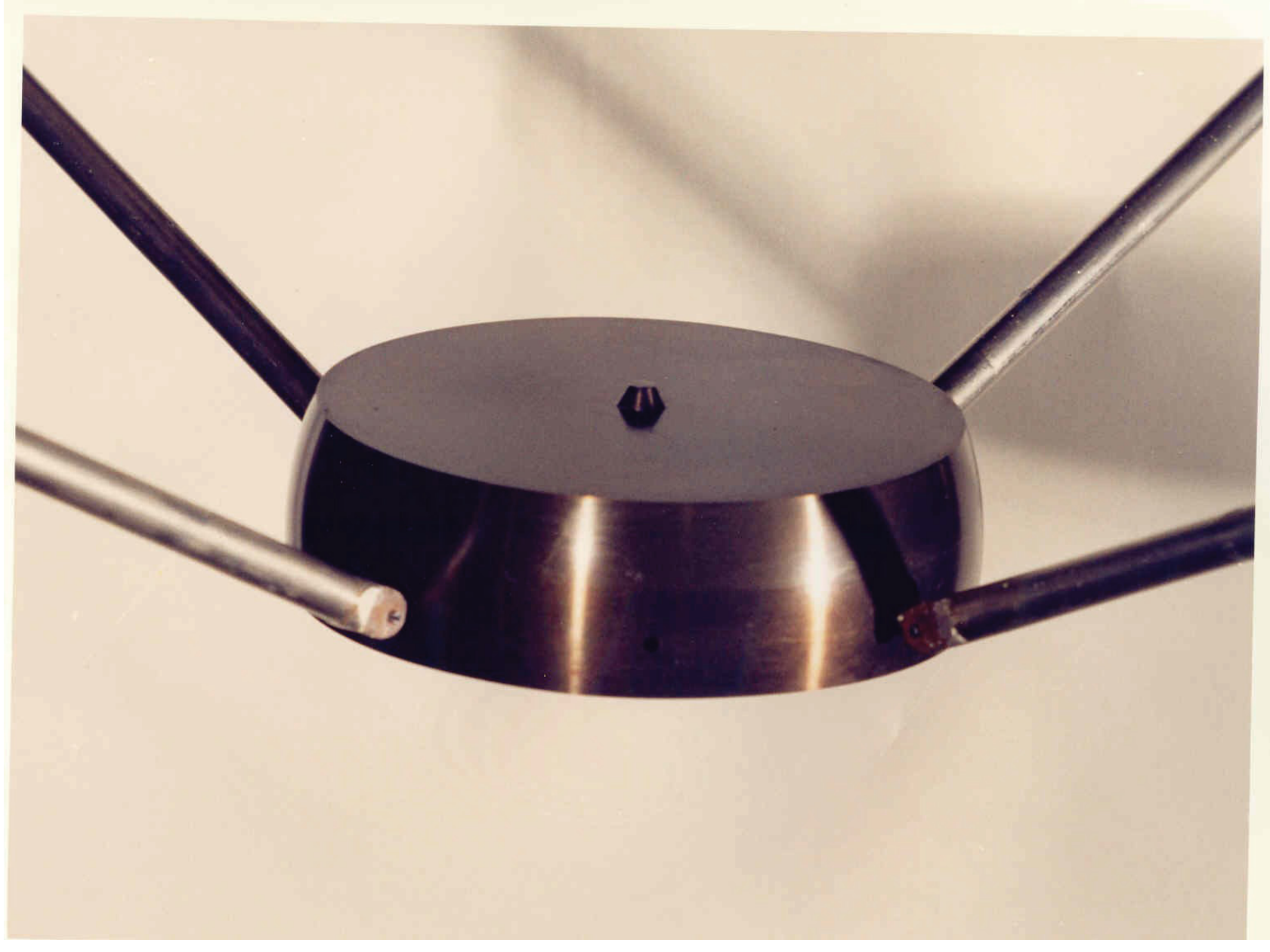

Figure1-18. Center Section and Support Structure.

\footnotetext{
${ }^{a}$ Material of the support tubes provided by the experimenter, J.T. Mihalczo, July 8, 2013. 


\subsubsection{Lower Support Structure}

A brass bolt threaded into a hole at the pole of the lower polar cap. The brass bolt did not have a 1-in.diameter as was stated in Reference 1 but a diameter of 0.5889 in., measured and adjusted for threading, as given in Figure 1-15. ${ }^{\mathrm{a}}$ The brass bolt was originally 0.5-in. long but was cut to 3/8 in. on February 25, 1971, to 0.320 in. on April 21, 1971, and finally to 0.303 in. on June 24, 1971. " "The shortest [brass bolt] was for the 3.4420-in. sphere. The middle length was for the 3.4665-in. sphere and the longest was for the first assembly of the [General Atomics] sphere." The brass bolt was attached to a lightweight aluminum (Type 6061-T6) support stand that was on the moveable stainless steel table of the vertical assembly machine.

Figure 1-19 shows the lower section of sphere and the top of the attached support stand. Two stands were made to position the sphere 36 or 102 in. above the moveable table. "The taller stand raised the sphere from the vertical lift to minimize the reflection of neutrons from the lower structure of the vertical lift and increase the distance from the floor." During assembly the lower polar cap and lower plate were lifted approximately $22 \mathrm{in}$. until they came into contact with the bottom of the center plate and lifted center plate, upper plate, and upper polar cap, which had already been lowered, approximately 0.020 in. Figure 1-20 is a schematic of the lower support stand. The worth of the central support structure (see Section 1.2.7) and the lower support structure, including the post of the vertical assembly machine was $14.29 \pm 0.05 \not$. It was determined by doubling the support structure material and then measuring the change in reactivity in a manner similar to that used to determine the worth of the upper polar cap socket.

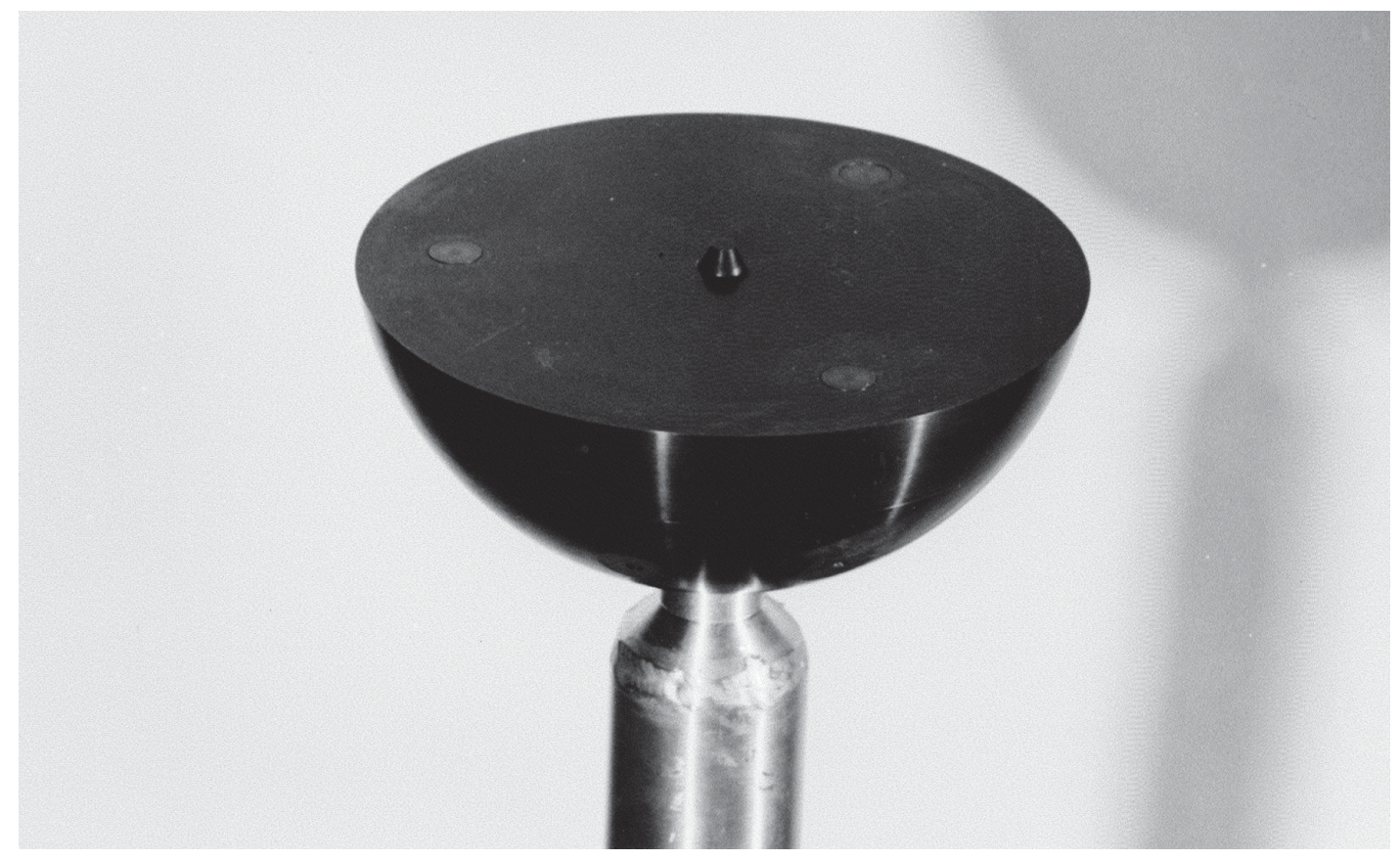

Figure 1-19. Bottom Section of Sphere with Lower Support.

\footnotetext{
${ }^{a}$ Personal email communication with J.T. Mihalczo, February 14, 2013.

${ }^{\mathrm{b}}$ Taken from hand written notes on a drawing provided by J.T. Mihalczo.

${ }^{c}$ Personal email communication with J.T. Mihalczo, March 8, 2013.

${ }^{\mathrm{d}}$ Personal communication with J.T. Mihalczo, April 15, 2013. 

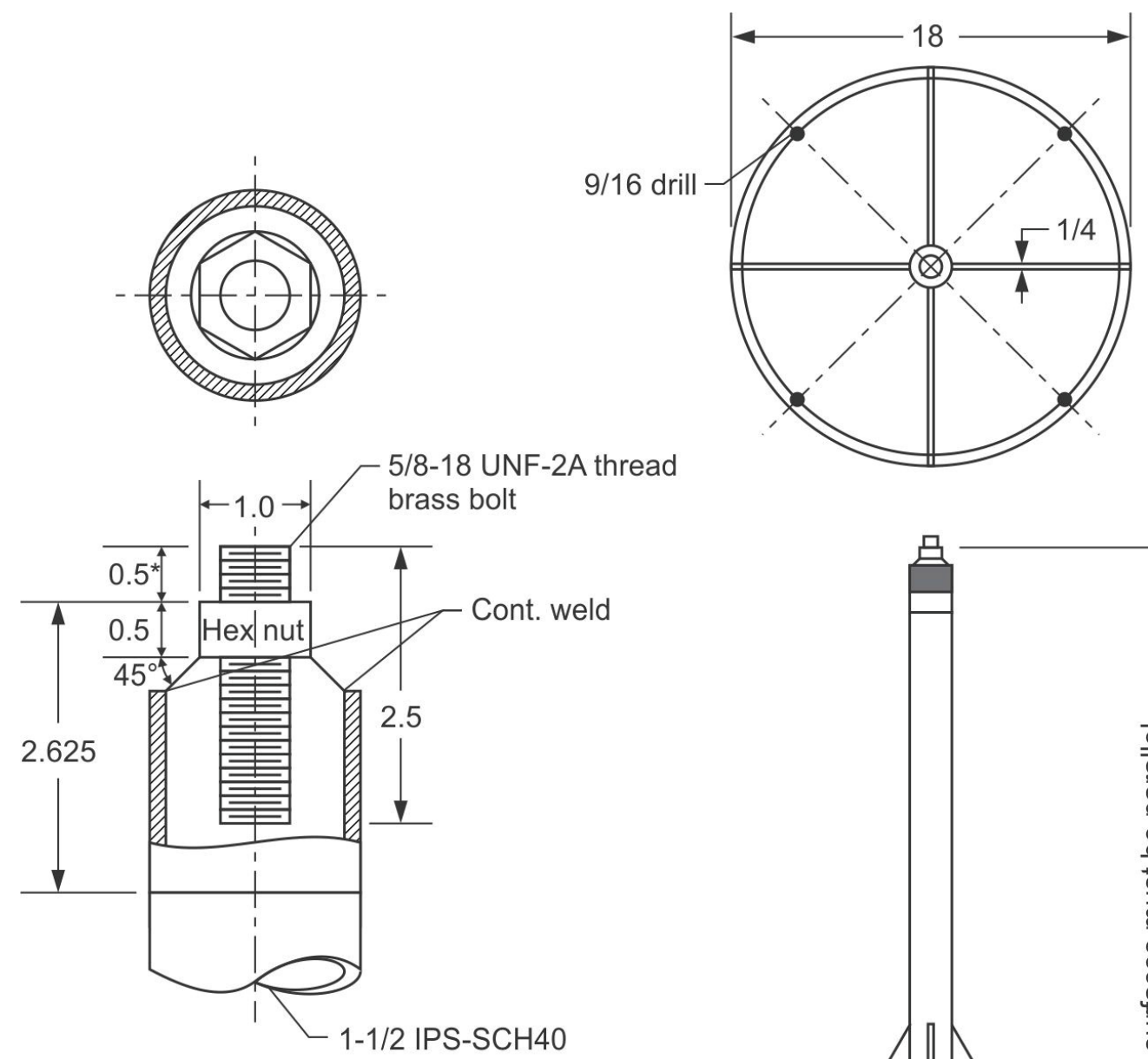

${ }^{*}$ Reduce as needed for reduction in sphere radius

Dimensions in inches

13-WHT03-23-12

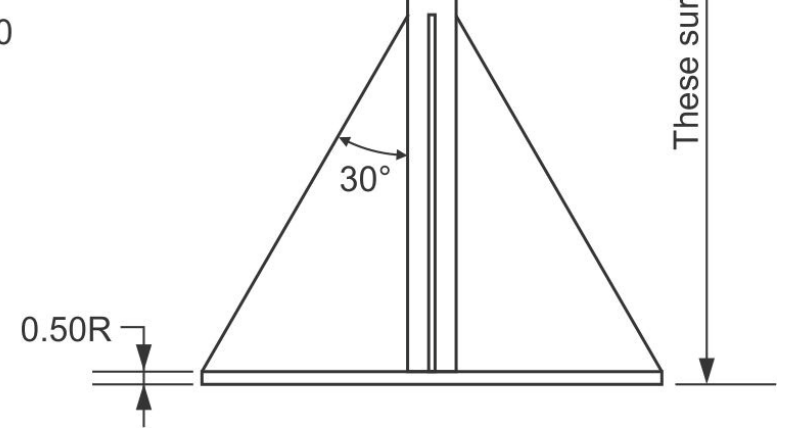

Figure 1-20. Shorter Lower Support Stand Dimensions. ${ }^{a}$

(The taller support stand was 102 in.)

${ }^{\text {a }}$ Redrawn from Reference 1.

Revision: 0

Date: September 30, 2013 


\subsection{Description of Material Data}

\subsubsection{Uranium}

The ORSphere was made of ORALLOY, an Oak Ridge HEU alloy. Different parts of the sphere had different isotopic content as shown in Table 1-3. An impurity analysis was performed on most of the parts and is given in Table 1-4. The enrichments at Y-12 slowly decreased over time. The first six entries in Table 1-3 were measured when the sphere was originally fabricated in the 1960s and the latter entries in the table were for parts fabricated in the 1970s.

Table 1-3. Isotopic Content of Uranium Metal Parts (Reference 1, additions by the evaluator are italic).

\begin{tabular}{lcccc}
\hline \multirow{2}{*}{ Part Description } & \multicolumn{4}{c}{ Isotopic Content (wt.\%) ${ }^{(\mathrm{a})}$} \\
\cline { 2 - 5 } & ${ }^{234} \mathrm{U}$ & ${ }^{235} \mathrm{U}$ & ${ }^{236} \mathrm{U}$ & ${ }^{238} \mathrm{U}$ \\
\hline Upper Polar Cap & 0.9844 & $93.21^{(\mathrm{b})}$ & 0.03593 & 5.76967 \\
Upper Plate & 0.9844 & $93.21^{(\mathrm{b})}$ & 0.03593 & 5.76967 \\
Central Plate & 0.9843 & $93.2^{(\mathrm{b})}$ & 0.03592 & 5.77978 \\
Lower Plate & 0.9845 & $93.22^{(\mathrm{b})}$ & 0.03593 & 5.75957 \\
Lower Polar Cap & 0.9841 & $93.18^{(\mathrm{b})}$ & 0.03592 & 5.79998 \\
Mass adjustment buttons and upper socket & 0.9846 & $93.23^{(\mathrm{b})}$ & 0.03594 & 5.74946 \\
Plug for target hole & 0.9954 & 93.156 & 0.451 & 5.3976 \\
Pins for central part & 0.986 & 93.171 & 0.424 & 5.419 \\
Pins for lower part & 0.9954 & 93.156 & 0.451 & 5.3976 \\
Filler rods for 0.136-in-dia diametral hole & 0.9954 & 93.156 & 0.451 & 5.3976 \\
Mass adjustment buttons (0.063 in. thick) & 0.9954 & 93.156 & 0.451 & 5.3976 \\
\hline
\end{tabular}

(a) These enrichments were from the average monthly enrichments of $\sim 93.2 \mathrm{wt.} \%{ }^{235} \mathrm{U}$ ORALLOY parts at the Y-12 for the month in which the parts were fabricated except where noted. The ${ }^{234} U$ and ${ }^{236} U$ are known to $\pm 1 \%$ of the values stated, and the ${ }^{235} U$ to four significant figures (i.e. \pm 0.005 ). The ${ }^{238} U$ percentage is by difference and is not accurate beyond the third digit. The weighted average enrichments for these parts comprising the major parts, target hole filler and pins are $0.9844 \mathrm{wt} . \%$ ${ }^{234} \mathrm{U}, 93.20 \mathrm{wt} . \%{ }^{235} \mathrm{U}, 0.04626 \mathrm{wt} . \%{ }^{236} \mathrm{U}$, and $5.7693 \mathrm{wt} . \%{ }^{238} \mathrm{U}$. (The weighted averaged enrichment calculation could not be reproduced because the weight of the target hole filler and pins was not given.)

(b) Measured and documented values. 
NEA/NSC/DOC(95)03/II

Volume II

HEU-MET-FAST-100

Table 1-4. Impurity Content of Enriched Uranium Sphere Parts (Reference 1).

\begin{tabular}{|c|c|c|c|c|c|c|c|c|c|c|c|c|c|c|}
\hline \multirow[b]{2}{*}{$\begin{array}{l}\text { ORNL } \\
\text { Part \# }\end{array}$} & \multirow[b]{2}{*}{$\begin{array}{c}\text { Part } \\
\text { Description }\end{array}$} & \multirow[b]{2}{*}{$\begin{array}{l}\text { Gram U } \\
\text { per } \\
\text { gram of } \\
\text { uranium }^{\text {metal }}{ }^{(a)} \\
\text { x100 }\end{array}$} & \multicolumn{12}{|c|}{ Impurity Content $(\mathrm{ppm})^{(\mathrm{c})}$} \\
\hline & & & $\begin{array}{l}\text { Boron } \\
\text { Equiv- } \\
\text { alent }^{(b)}\end{array}$ & $\mathrm{Be}$ & $\mathrm{Li}$ & $\mathrm{Al}$ & $\mathrm{Si}$ & $\begin{array}{l}\text { Total } \\
\mathrm{Fe}, \\
\mathrm{Mn}, \\
\mathrm{Ni}, \mathrm{Cr}, \\
\mathrm{V} \mathrm{Cu}\end{array}$ & B & Co & $\mathrm{Ca}$ & $\mathrm{C}$ & $\mathrm{O}$ & $\mathrm{N}$ \\
\hline $1-6$ & $\begin{array}{l}\text { Upper Polar } \\
\text { Cap }\end{array}$ & 99.961 & 0.647 & $<0.01$ & $<0.2$ & 6 & 80 & 85 & 0.5 & $<1$ & $<10$ & 202 & 20 & 30 \\
\hline $1-8$ & Upper Plate & 99.966 & 0.408 & $<0.01$ & $<0.2$ & 4 & 100 & 34 & 0.3 & $<1$ & $<10$ & 159 & 20 & 30 \\
\hline $1-10$ & Central Plate & 99.966 & 0.328 & $<0.01$ & $<0.2$ & 4 & 200 & 50 & 0.2 & $<1$ & $<10$ & 159 & 20 & 30 \\
\hline $1-11$ & Lower Plate & 99.949 & 0.629 & $<0.01$ & $<0.2$ & 8 & 125 & 57 & 0.5 & $<1$ & $<10$ & 142 & 20 & 30 \\
\hline $1-12$ & $\begin{array}{l}\text { Lower Polar } \\
\text { Cap }\end{array}$ & 99.912 & 0.242 & $<0.01$ & $<0.2$ & 5 & 100 & 83 & 0.1 & $<1$ & $<10$ & 179 & 20 & 30 \\
\hline $1-4$ & $\begin{array}{l}16 \text { Mass } \\
\text { Adjustment } \\
\text { Buttons, } \\
0.250 \text {-in. } \\
\text { Thick }\end{array}$ & 99.955 & 0.348 & $<0.01$ & $<0.2$ & 2 & 200 & 68 & 0.2 & $<1$ & $<10$ & 306 & 20 & 30 \\
\hline $1-5$ & $\begin{array}{l}16 \text { Mass } \\
\text { Adjustment } \\
\text { Buttons, } \\
0.125 \text {-in. } \\
\text { Thick }\end{array}$ & 99.955 & 0.348 & $<0.01$ & $<0.2$ & 2 & 200 & 68 & 0.2 & $<1$ & $<10$ & 306 & 20 & 30 \\
\hline $1-1$ & $\begin{array}{l}\text { Socket for } \\
\text { upper polar } \\
\text { cap }\end{array}$ & 99.955 & 0.348 & $<0.01$ & $<0.2$ & 2 & 200 & 68 & 0.2 & $<1$ & $<10$ & 306 & 20 & 30 \\
\hline
\end{tabular}

(a) Reported to 5 digits; accurate to 4 digits.

(b) Boron equivalent is the parts per million boron that has the same thermal neutron absorption cross section as all impurities. Boron equivalent is only for elements in the table excluding oxygen and nitrogen. Boron equivalent is an approximation for the effect of impurities for assemblies with thermal neutron spectra where the predominant effect is boron absorption but is irrelevant for fission spectrum assemblies.

(c) In addition to these impurities, there were $20 \mathrm{ppm}$ oxygen and $30 \mathrm{ppm}$ nitrogen.

In Reference 1 the experimenter points out that the $\mathrm{g} \mathrm{U} / \mathrm{g}$ material and the impurity content are independently measured and the sum of the uranium weight fraction and the impurity content does not sum to the theoretical total of 1 . He suggests a composition of $99.95 \mathrm{~g}$ of uranium per $100 \mathrm{~g}$ of material, $5 \mathrm{ppm}, \mathrm{Al}, 120$ ppm Si, 62 ppm metals, 0.3 ppm B, 168 ppm C, 20 ppm O, and 30 ppm N be assumed for all uranium parts.

Table 1-3 does not provide an isotopic analysis for the filler of the thermocouple groove. The experimenter suggests the use of the same isotopics as the target hole plug since it was filled at the same time. ${ }^{\text {a }}$ Table 1-4 does not provide an impurity analysis for the HEU pins, the filler rods, or for the target hole and thermocouple groove filler material.

\footnotetext{
${ }^{a}$ Personal email communication between T. Murray and J.T. Mihaclzo, December 9, 2011.

Revision: 0

Date: September 30, 2013

Page 28 of 160
} 
Reference 2 gives hydrostatically measured densities of $18.74,18.77$, and $18.72 \mathrm{~g} / \mathrm{cm}^{3}$ for the top, middle, and bottom sections of sphere. The experimenter provided a log page with the measured densities as 18.74, 18.74 , and $18.72 \mathrm{~g} / \mathrm{cm}^{3}$. . Reference 1 gives a calculated density of $18.754 \pm 0.007 \mathrm{~g} / \mathrm{cm}^{3}$. The experimenter has indicated that these measured and this calculated densities should not be used but rather densities calculated using mass and dimension measurements should be used. ${ }^{\mathrm{b}}$

\subsubsection{Non-Uranium Components}

The support structure was made of various materials. The exact composition of these materials was not given. The lower support structure was on the stainless steel moveable table of the vertical lift. The lower support structure was made of aluminum (Type 6061-T6) 1.5-in.-OD, Schedule 40 pipe and was welded to a brass bolt which screwed into the lower polar cap. The type of stainless steel or brass was not specified. ${ }^{\mathrm{c}}$

The center section of the sphere was attached to the four vertical posts of the vertical assembly machine by stainless steel tubing which was attached by pins to threaded steel parts in the center plate. The type of stainless steel was not specified in the reports but stainless steel Type 304 was used. ${ }^{\mathrm{d}}$

The material within the upper socket for the upper polar cap was stainless steel, but the material of the support rod above the socket and the cross beam material supporting the upper polar cap were not specified in the reports but stainless steel Type 304 was used. $^{\mathrm{c}}$

\section{$1.4 \quad$ Temperature Data}

Dimensional measurements of all parts were performed at the Y-12 plant at $70{ }^{\circ} \mathrm{F}\left(21.1{ }^{\circ} \mathrm{C}\right)$. All ORSphere experiments were performed at $24.5^{\circ} \mathrm{C}\left(76^{\circ} \mathrm{F}\right)$. The temperature coefficient for the ORSphere should be the same as the measured coefficient of $1 / 3 \phi$ per degree centigrade for GODIVA I, ${ }^{\mathrm{e}}$ as is typically used for other ORCEF bare HEU experiments.

\footnotetext{
${ }^{a}$ Personal email communication with J.T. Mihalczo, August 6, 2013.

${ }^{\mathrm{b}}$ When asked about the measured densities the experimenter said, "It is not that they were wrong. They are not as accurate as the densities obtained from the very accurately measured dimensions and masses. They do not agree with those from dimensions and masses. For previous uranium metal parts we always used the densities from the masses and dimensions." Personal phone communication with J.T. Mihalczo, April 24, and July 19, 2013.

${ }^{\mathrm{c}}$ In an Appendix of Reference 1 a sample input deck created by Denise B. Pelowitz was provided. The input deck used pure copper for the brass but commented that the zinc was not included because cross section data were not available at that time.

${ }^{\mathrm{d}}$ Personal communication with J.T. Mihalczo, April 15, 2013.

${ }^{\mathrm{e}}$ Personal email communication with J.T. Mihalczo, March 11, 2013.

Revision: 0

Date: September 30, 2013

Page 29 of 160
} 
NEA/NSC/DOC(95)03/II

Volume II

HEU-MET-FAST-100

\subsection{Supplemental Experimental Measurements}

Various measurements were performed with the ORSphere components. As indicated previously, the five primary parts of the sphere were used to measure the neutron leakage spectrum in a subcritical HEU sphere using the LINAC at the General Atomics Company in San Diego, California. ${ }^{a}$

Experimental measurements were performed to assess the worth of structural components and estimate the effects of imperfections in the sphere. The reactivity worth of uranium of the surface of the sphere was obtained using measurements with the mass adjustment buttons. (References 1 and 2)

The spatial distribution of the neutron importance and fission density were performed to properly account for spatial effects in the point kinetics description of Rossi- $\alpha$ measurements. ${ }^{b}$

Prompt neutron decay constants, $\alpha$, were measured at delayed criticality., ${ }^{\text {c,de }}$

The reactivity worth of a central void region of the sphere was measured to evaluate the effective delayed neutron fraction. ${ }^{f, g}$ The worth of the central void region was measured by performing stable reactor period measurements for the sphere with and without a 0.460-in.-diameter uranium sphere inserted at the center of the ORSphere. These measurements were performed after the completion of the critical assembly measurements described in this evaluation and the diametral hole of the central plate had been reconfigured. Diametral filler rods were designed such that only a 0.460 -in.-diameter sphere was void when the uranium sphere was removed. The stable reactor period with and without the small sphere of uranium present were measured 43 times with seven different detectors. The Inhour equation and delayed neutron parameters from Keepin et al. ${ }^{\mathrm{h}}$ was used to convert stable reactor period to reactivity in cents. The worth of the central void can then be found by comparing the system reactivity for the two states, with and without the sphere present. The worth of the region was then calculated in units of $\Delta \mathrm{k}$ using $\mathrm{S}_{n}$ transport theory methods. The ratio of the central void worth in units of cents/dollars and $\Delta \mathrm{k}$ then gives the effective delayed neutron fraction for the system. A value of $0.00657 \pm 0.00002 \beta_{\text {eff }}$ was obtained.

\footnotetext{
${ }^{a}$ J. L. Russell, Jr. and A. E. Profio, "Adequacy of Fast and Intermediate Cross Section Data from Measurement of Neutron Spectra in Bulk Media," GA-7059, General Atomics, San Diego, CA (April 27, 1966).

b J. T. Mihalczo, "Neutron Importance and Fission Density in Uranium-235-Enriched Uranium and Plutonium Metal Spheres,” Nucl. Sci. Eng., 56, 271-290 (1975).

c J. T. Mihalczo, "The Effective Delayed Neutron Fraction from Fission in an Unreflected Uranium Sphere from Time Correlation Measurements with Californium-252," Nucl. Sci. Eng., 60, 262-275 (1976).

d J. T. Mihalczo, "Prompt Neutron Decay for an Unreflected and Unmoderated Uranium (HEU) Metal Sphere," PHYSOR 1996, Mito, Japan, September 16-20 (1996).

' J. T. Mihalczo, "Prompt Neutron Decay for Delayed Critical Bare and Natural-Uranium-Reflected Metal Spheres of Plutonium and Highly Enriched Uranium," Nucl. Tech., 175, 498-508 (2011).

f J. T. Mihalczo, J. J. Lynn, and J. R. Taylor, "The Central Void Reactivity in the Oak Ridge Enriched Uranium (93.2) Metal Sphere," ORNL/TM-13349, Oak Ridge National Laboratory (1997).

g J. T. Mihalczo, J. J. Lynn, and J. R. Taylor, "The Central Void Reactivity in the Oak Ridge National Laboratory Enriched Uranium (93.2) Metal Sphere,” Nucl. Sci. Eng., 130, 153-163 (1998).

${ }^{\text {h }}$ G. R. Keepin, T. F. Wimett, and R. K. Zeigler, "Delayed Neutrons from Fissionable Isotopes of Uranium, Plutonium and Thorium," J. Nucl. Energy, 6, (1957).
}

Revision: 0

Date: September 30, 2013

Page 30 of 160 
NEA/NSC/DOC(95)03/II

Volume II

HEU-MET-FAST-100

\subsection{EVALUATION OF EXPERIMENTAL DATA}

The two spherical assemblies (one slightly supercritical, one slightly subcritical) were evaluated using Monte Carlo N-Particle (MCNP) Version 5-1.60 and ENDF/B-VII.0 ${ }^{\mathrm{b}}$ neutron cross section libraries. The effect of the uncertainty in measured parameters was found individually by increasing and decreasing the specified parameter value by a given amount; the $\Delta \mathrm{k}_{\text {eff }}$ for that uncertainty was found by taking one-half of the difference between the $\mathrm{k}_{\text {eff }}$ values for the perturbed models. All models were calculated such that the statistical uncertainty in $\mathrm{k}_{\text {eff }}, \sigma_{\mathrm{MC}}$, is \pm 0.00002 . When the calculated $\Delta \mathrm{k}_{\text {eff }}$ was less than \pm 0.00006 $\left(3 \sqrt{1 / 2\left(0.00002^{2}+0.00002^{2}\right)}\right)$ the uncertainty effect cannot be determined with any certainty due to statistical uncertainty of the MCNP calculation and the effect is set as being \pm 0.00006 (prior to any scaling of the results, if necessary). The magnitude of most perturbations was increased beyond the specified $1 \sigma$ uncertainties in order to obtain statistically significant results. The ratio of the perturbation to the $1 \sigma$ uncertainty for the parameter was used as a "scaling factor" to convert the calculated $\Delta \mathrm{k}_{\text {eff }}$ to a $1 \sigma$ uncertainty in $\mathrm{k}_{\text {eff. }}$ Statistically significant $1 \sigma$ uncertainties that were less than \pm 0.00001 were considered negligible.

Henceforth, the 3.4665-in. $(8.80491 \mathrm{~cm})$-average-radius sphere will be referred to as Case 1 and the 3.4420 in. $(8.74268 \mathrm{~cm})$-average-radius sphere will be referred to as Case 2.

\subsection{Evaluation of Critical Measurement}

The reactivity of Case 1 was $+68.1 \pm 2.0 \phi$. The reactivity of Case 2 was $-23.4 \phi$. The same $\pm 2.0 \phi$ uncertainty given for Case 1 was also applied to Case 2 . The uncertainty of the reactivity includes assembly reproducibility $( \pm 0.3 \varnothing)$, reactor period measurements uncertainties, and uncertainties in the delayed neutron parameter. The experimenter provided a $\beta_{\text {eff }}$ for the system of $0.0066 \pm 0.00005$, based on GODIVA I measurements. It was later obtained using ORSphere void measurements data; the resultant $\beta_{\text {eff }}$ value was determined to be $0.00657 \pm 0.00002$. $^{\text {cd }}$ The $\beta_{\text {eff }}$ was also calculated as part of this evaluation using two methods. The first method used $\mathrm{k}_{\text {prompt }}$, calculated by MCNP5, and compared it to $\mathrm{k}_{\text {eff }}$ to calculate $\beta_{\text {eff }}$ $\left(\beta_{\text {eff }}=1-\mathrm{k}_{\text {prompt }} / \mathrm{k}_{\mathrm{eff}}\right.$ ). ${ }^{\mathrm{e}}$ The second method used MCNP5 to calculate $\beta_{\text {eff }}$ directly using adjoint-weighted methods capabilities in MCNP5-1.60. ${ }^{\mathrm{f}}$ Both methods used ENDF/B-VII.0 neutron cross section libraries. The results were slightly lower than the measured worth at approximately 0.00649 . The measured $\beta_{\text {eff }}$ of $0.00657 \pm 0.00002$ was used in this evaluation. Any systematic uncertainty in the delay neutron parameter $\mathrm{s}$ and nuclear data would be negligible since the reactivity is found by differences of the

${ }^{a}$ F. B. Brown, R. F. Barrett, T. E. Booth, J. S. Bull, L. J. Cox, R. A. Forster, T. J. Goorley, R. D. Mosteller, S. E. Post, R. E. Prael, E. C. Selcow, A. Sood, and J. Sweezy, "MCNP Version 5," LA-UR-02-3935, Los Alamos National Laboratory (2002).

${ }^{\mathrm{b}}$ M. B. Chadwick, et al., "ENDF/B-VII.0: Next Generation Evaluated Nuclear Data Library for Nuclear Science and Technology," Nucl. Data Sheets, 107, 2931-3060 (2006).

' J. T. Mihalczo, J. J. Lynn, and J. R. Taylor, "The Central Void Reactivity in the Oak Ridge Enriched Uranium (93.2) Metal Sphere," ORNL/TM-13349, Oak Ridge National Laboratory (1997).

d J. T. Mihalczo, J. J. Lynn, and J. R. Taylor, "The Central Void Reactivity in the Oak Ridge National Laboratory Enriched Uranium (93.2) Metal Sphere," Nucl. Sci. Eng., 130, 153-163 (1998).

${ }^{\text {e }}$ R. K. Meulekamp and S. C. van der Marck, "Calculating the Effective Delayed Neutron Fraction with Monte Carlo," Nucl. Sci. Eng., 152, 142-148 (2006).

f B.C. Kiedrowski, et al., "MCNP5-1.60 Feature Enhancements and Manual Clarifications," LA-UR-10-06217, Los Alamos National Laboratory (2010).

Revision: 0

Date: September 30, 2013

Page 31 of 160 
system reactivity. The measured reactivity in cents, $\beta_{\text {eff, }}$ and the calculated measured reactivity in terms of $\Delta \mathrm{k}_{\text {eff }}$ are given in Table 2-1.

Table 2-1. Uncertainty in Reactivity Measurement of Critical Configurations.

\begin{tabular}{|c|ccc|c|ccc||}
\hline Case & $\begin{array}{c}\text { Measured } \\
\text { Reactivity }(\varnothing)\end{array}$ & $\pm \sigma$ & $\beta_{\text {eff }}(1 \sigma)$ & Reactivity $\left(\Delta \mathrm{k}_{\text {eff }}\right)$ & \pm & $\sigma$ \\
\hline 1 & +68.1 & \pm & 2.0 & $0.00657 \pm 0.00002$ & 0.00447 & \pm & 0.00013 \\
2 & -23.4 & \pm & 2.0 & $0.00657 \pm 0.00002$ & -0.00154 & \pm 0.00013 \\
\hline
\end{tabular}

\subsection{Evaluation of Dimension and Mass Uncertainties}

Dimensions and masses were measured to high accuracies using precise equipment at the Oak Ridge Y-12 plant. Non-spherical dimensions had an uncertainty of $\pm 0.0001 \mathrm{in}$. Masses had an uncertainty of $\pm 0.01 \mathrm{~g}$. Masses were measured on a "large glass balance with temperature and humidity control that measured the mass of 20 kilogram parts to a precision of 0.001 gram and that they normally reported out the results to 0.01 gram. ... [T] his accuracy was produced by applying a correction for the difference in buoyancy of the ORALLOY and reference standard weights in air." Surfaces were finished such that the gaps between plates were $0.0000_{-0.0000}^{+0.00254} \mathrm{~cm}$, except for Case 1; the gap between the lower plate and the center plate was $0.01143 \mathrm{~cm}$ on one side of the sphere and $0 \mathrm{~cm}$ on the other due to the projection of a pin $0.005842 \mathrm{~cm}$ above the surface of the lower plate. The deviation from spherical for the two spheres was given in Table 1-1 and Table 1-2. Appendix B and C give example calculations for the volume of various sphere parts as well as AutoCAD ${ }^{\circledR}$ volumes calculated by Christine E. White of Idaho National Laboratory.

It should be noted that an uncertainty of 0.0004 in. rather than $0.0001 \mathrm{in}$. has been given for ORALLOY parts used in ORCEF critical experiments. This uncertainty is specifically stated as being for ORALLOY cylinders and annuli. ${ }^{\text {a }}$ The experimenter has asserted that the uncertainty in the dimension measurements is 0.0001 in. for the ORSphere experiment. ${ }^{b}$

\subsubsection{Sphere Radius}

The uncertainty effect of the sphere radius was evaluated using the simple benchmark model. The radius of the simple benchmark model sphere was determined by creating a perfect sphere with a volume equal to the total uranium metal volume of the as-built sphere. This led to a conservation of mass and mass density in the simple benchmark model. The systematic measurement uncertainty in the radius and deviation from spherical was given as $0.254 \times 10^{-3} \mathrm{~cm}$; however, there is additional uncertainty in our ability to perfectly describe the curvature of the ellipsoidal parts with only a finite number of measurements. This additional

\footnotetext{
a J. T. Mihalczo, T. Gregory Schaaff, "Uncertainties in Masses, Dimensions, Impurities, and Isotopics of HEU Metal Used in Critical Experiments at ORCEF," ORNL/TM-2012/32, Oak Ridge National Laboratory (2012).

${ }^{\mathrm{b}}$ Measuring to the nearest 1/10,000 inch would have been easily possible in the 1970's. Personal communication between J. Blair Briggs and Neal G. Boyce, Machinist Design Engineer, Idaho National Laboratory, 30 April, 2013. Revision: 0 
HEU-MET-FAST-100

uncertainty is discussed further is Section 2.2.2. A scaling factor was used when perturbing the sphere radius. Uranium metal mass was conserved during all perturbations. Results can be found in Table 2-2.

Table 2-2. Effect of the Uncertainty in Sphere Radius.

\begin{tabular}{|c|c|ccc|c|c|ccc||}
\hline \hline Case & $\begin{array}{c}\text { Deviation } \\
(\mathrm{cm})\end{array}$ & $\Delta \mathrm{k}_{\text {eff }}$ & \pm & $\sigma_{\mathrm{MC}}$ & $\begin{array}{c}\text { Scaling } \\
\text { Factor }\end{array}$ & $\begin{array}{c}1 \sigma \\
(\mathrm{cm})\end{array}$ & $\begin{array}{c}\Delta \mathrm{k}_{\text {eff }} \\
(1 \sigma)\end{array}$ & \pm & $\sigma_{\text {statistical }}$ \\
\hline \hline 1 & 0.01 & 0.00187 & \pm & 0.00002 & 39.4 & $2.54 \times 10^{-4}$ & 0.00005 & \pm & $<0.00001$ \\
\hline 2 & 0.01 & 0.00189 & \pm & 0.00002 & 39.4 & $2.54 \times 10^{-4}$ & 0.00005 & \pm & $<0.00001$ \\
\hline
\end{tabular}

\subsubsection{Curve of Ellipsoidal Parts}

The deviation from spherical of the sphere parts was measured at a finite number of points using a sweep gage. Although the sweep gage measurements were point measurements due to the fabrication methods the deviation from spherical would be the same around the entire curve of the sphere at a given plane. ${ }^{\text {a }}$

However, because the curvature of the parts was described with only a finite number of measurements there is additional uncertainty in both the description and the modeling approximation of the curvature of those parts. This uncertainty is reflected in inconsistency in the uranium densities between Case 1 and Case 2 . Total mass values for each configuration were accurately measured so the inconsistencies must be due to additional uncertainty in total volumes. An estimate of that uncertainty can be obtained by using the reported mass values and forcing the densities of Case 1 and 2 to be equal for each section of sphere. The deviation of the volume is then converted to a percent volume deviation for each sphere section. The mass weighted average of the absolution percent volume deviation for each sphere is $0.12 \%$. This corresponds to a metal volume change of approximately 3.41 and $3.34 \mathrm{~cm}^{3}$ for Case 1 and 2, respectively, for the simple benchmark model. The volume decrement translated into an uncertainty in the radius of approximately $0.0035 \mathrm{~cm}$ and an uncertainty in $\mathrm{k}_{\mathrm{eff}}$ of about 0.00066 . This method is most likely an overestimate of the uncertainty but is treated as a $1 \sigma$ uncertainty and is included in the total experimental uncertainty summarized in Section 2.5.

\subsubsection{Gaps Between Plates}

The gap between the plates was given as $0.0000_{-0.0000}^{+0.000254} \mathrm{~cm}$. In the detailed benchmark model the plates were modeled as touching except for between the lower plate and center plate of Case 1, which had a pin projecting above the surface of the lower plate causing a tilt to the center and upper section of the sphere. A model similar to the detailed benchmark model, except with only $\mathrm{Si}, \mathrm{B}$, and $\mathrm{C}$ uranium metal impurities present for ease of modeling, was used to perturb the gap between plates. Each gap was perturbed individually. When the gap between the lower plate and center plate of Case 1 was perturbed the tilt of the center plate, and all plates above it, was kept constant. Pins held the lower polar cap to the lower plate and the center plate to the upper plate. The length of the pins depended on the height of the plates so when a gap was modeled between the plates the pins were modeled as still going through those gaps thereby increasing the length of the pins. This increased the volume of the pins and thus reduced the calculated density of the material as the total mass of the section of sphere was conserved. Although the gap uncertainty was given as

\footnotetext{
${ }^{a}$ Personal phone communication with J.T. Mihalczo, April 24, 2013.

Revision: 0

Date: September 30, 2013

Page 33 of 160
} 
NEA/NSC/DOC(95)03/II

Volume II

HEU-MET-FAST-100

$+0.000254 \mathrm{~cm}$ (0.0001 in.), because a gap of $0.0005 \mathrm{in}$. was discussed in Appendix A of Reference 1 the $1 \sigma$ uncertainty in the gap was arbitrarily increased by a factor of 5 to $0.00127 \mathrm{~cm}$. The results of the perturbation of the gap between plates for Case 1 and Case 2 are given in Table 2-3.

The tilt between the lower and center plate of Case 1 was also evaluated. The gap between the top of the lower plate and the bottom of the center plate was $0.01143 \mathrm{~cm}$ on one side of the sphere and $0 \mathrm{~cm}$ on the opposite. The resulting upward shift and tilt of the center plate, and all plates above it, was $0.003510385 \mathrm{~cm}$ and 0.0231340494 degrees (see Appendix E). The gap angle was evaluated by first creating a version of the detailed model without the pin protruding above the top surface of the lower plate; this resulted in a slight change in the density but had a negligible effect. Next, a model with the center plate sitting flat on the lower plate was created. The change in $\mathrm{k}_{\text {eff }}$ between these two models is a one sided bounding uncertainty for the tilt angle. The results are given in Table 2-3.

Table 2-3. Effect of the Uncertainty in the Gap Thickness Between Plates.

\begin{tabular}{|c|c|c|c|c|c|c|c|c|}
\hline Case & $\begin{array}{l}\text { Deviation } \\
\quad(\mathrm{cm})\end{array}$ & $\Delta \mathrm{k}_{\mathrm{eff}}$ & $\sigma_{\mathrm{MC}}$ & $\begin{array}{l}\text { Scaling } \\
\text { Factor }\end{array}$ & $\begin{array}{c}1 \sigma \\
(\mathrm{cm})\end{array}$ & $\Delta \mathrm{k}_{\mathrm{eff}}(1 \sigma)$ & \pm & $\sigma_{\text {statistical }}$ \\
\hline \multicolumn{9}{|c|}{ Lower Polar Cap/Lower Plate Interface ${ }^{(\mathrm{a})}$} \\
\hline 1 & 0.0127 & $0.00041 \pm$ & 0.00003 & 10 & $1.27 \times 10^{-3}$ & 0.00004 & \pm & $<0.00001$ \\
\hline 2 & 0.0127 & $0.00044 \pm$ & 0.00003 & 10 & $1.27 \times 10^{-3}$ & 0.00004 & \pm & $<0.00001$ \\
\hline \multicolumn{9}{|c|}{ Lower Plate/Center Plate Interface ${ }^{(b)}$} \\
\hline 1 & 0.0127 & $0.00073 \pm$ & 0.00003 & 10 & $1.27 \times 10^{-3}$ & 0.00007 & \pm & $<0.00001$ \\
\hline 2 & 0.0127 & $0.00111 \pm$ & 0.00003 & 10 & $1.27 \times 10^{-3}$ & 0.00011 & \pm & $<0.00001$ \\
\hline \multicolumn{9}{|c|}{ Center Plate/Upper Plate Interface ${ }^{(a)}$} \\
\hline 1 & 0.0127 & $0.00089 \pm$ & 0.00003 & 10 & $1.27 \times 10^{-3}$ & 0.00009 & \pm & $<0.00001$ \\
\hline 2 & 0.0127 & $0.00076 \pm$ & 0.00003 & 10 & $1.27 \times 10^{-3}$ & 0.00008 & \pm & $<0.00001$ \\
\hline \multicolumn{9}{|c|}{ Upper Plate/Upper Polar Cap Interface } \\
\hline 1 & 0.0127 & $0.00058 \pm$ & 0.00003 & 10 & $1.27 \times 10^{-3}$ & 0.00006 & \pm & $<0.00001$ \\
\hline 2 & 0.0127 & $0.00052 \pm$ & 0.00003 & 10 & $1.27 \times 10^{-3}$ & 0.00005 & \pm & $<0.00001$ \\
\hline \multicolumn{9}{|c|}{ Tilt Angle } \\
\hline 1 & - & $-0.00038 \pm$ & 0.00003 & $2 \sqrt{3}$ & - & -0.00011 & \pm & 0.00001 \\
\hline
\end{tabular}

(a) Due to the HEU pins holding these two plates together this perturbation resulted in a material density change; the total mass was conserved.

(b) When perturbing the gap the tilt of the center plate, and thus all plates above it, was held constant.

\subsubsection{Diametral Hole and Filler Rod Dimensions}

A hole was drilled through the center of the Case 1 sphere with a diameter of $0.34544 \mathrm{~cm}$. For Case 2, the center line of the diametral hole was $0.0508 \mathrm{~cm}$ below the center of the sphere. Two filler rods were placed

Revision: 0

Date: September 30, 2013

Page 34 of 160 
in this hole when the sphere was taken to critical for both Case 1 and Case 2. The lengths of the shorter filler rod disagreed between Reference 1 and the dimensional certificate. Because all other masses and dimensions for the filler rods agreed between Reference 1 and the dimensional certificate it is believed that the length in Reference 1 is incorrect and the correct length is $2.7545 \mathrm{in}$. The two diametral filler rods were 10.8331- and 6.99643-cm long, had a 0.328422-cm diameter, and weighed 17.117 and $11.046 \mathrm{~g}$, respectively. This corresponded to an average density of $18.64596 \mathrm{~g} / \mathrm{cm}^{3}$. The $1 \sigma$ uncertainty in the diametral hole and filler rod diameters and filler rod length was the measurement uncertainty in non-spherical parts, $2.54 \times 10^{-4} \mathrm{~cm}$. The total length of the two filler rods was slightly larger than the length of the diametral hole and would have extended past the curve of the sphere. The results of the uncertainty analysis for the diametral hole and filler rod diameters and filler rod length are given in Table 2-4.

Table 2-4. Effect of the Uncertainty in the Diametral Hole and Filler Rod Dimensions.

\begin{tabular}{||c|c|ccc|c|c|c|c||}
\hline \hline Case & $\begin{array}{c}\text { Deviation } \\
(\mathrm{cm})\end{array}$ & $\Delta \mathrm{k}_{\text {eff }}$ & \pm & $\sigma_{\mathrm{MC}}$ & $\begin{array}{c}\text { Scaling } \\
\text { Factor }\end{array}$ & $\begin{array}{c}1 \sigma \\
(\mathrm{cm})\end{array}$ & $\Delta \mathrm{k}_{\text {eff }}(1 \sigma) \pm \sigma_{\text {statistical }}$ \\
\hline \multicolumn{8}{|c||}{ Diametral Hole Diameter } \\
\hline 1 & 0.00508 & 0.00002 & \pm & 0.00002 & 20 & $2.54 \times 10^{-4}$ & $\mathrm{NEG}^{(\mathrm{a})}$ \\
\hline 2 & 0.00508 & 0.00002 & \pm & 0.00002 & 20 & $2.54 \times 10^{-4}$ & $\mathrm{NEG}^{(\mathrm{a})}$ \\
\hline \multicolumn{8}{|c||}{ Filler Rod Diameter } \\
\hline 1 & 0.00508 & -0.00001 & \pm & 0.00002 & 20 & $2.54 \times 10^{-4}$ & $\mathrm{NEG}^{(\mathrm{a})}$ \\
\hline 2 & 0.00508 & 0.00002 & \pm & 0.00002 & 20 & $2.54 \times 10^{-4}$ & $\mathrm{NEG}^{(\mathrm{a})}$ \\
\hline \multicolumn{8}{|c|}{ Filler Rod Length } \\
\hline 1 & 0.2 & 0.00004 & \pm & 0.00002 & 787 & $2.54 \times 10^{-4}$ & $\mathrm{NEG}^{(\mathrm{a})}$ \\
\hline 2 & 0.2 & -0.00001 & \pm & 0.00002 & 787 & $2.54 \times 10^{-4}$ & $\mathrm{NEG}^{(\mathrm{a})}$ \\
\hline
\end{tabular}

(a) The effect of this perturbation is less than three times the statistical uncertainty of the Monte Carlo calculation despite using a scaling factor thus the perturbation effect was set at \pm 0.00006 . When this value was scaled the $\Delta \mathrm{k}_{\text {eff }}(1 \sigma)$ was negligible.

\subsubsection{Brass Bolt Dimensions}

The brass bolt had a 5/8-18 UNF-2A (inches) thread and fit into the bore hole at the bottom of the lower polar cap which was a 0.5781 -in.-diameter-bore-hole with a 5/8-18 UNF-2B threading. Figure 1-15 gives the diameter of the bore hole and brass bolt as $1.495806 \mathrm{~cm}$ (0.5889 in.). This diameter takes into account the threading and is thus used in the detailed benchmark model. For Case 1 the brass bolt was $0.8128-\mathrm{cm}$ long. For Case 2 the brass bolt was $0.76962-\mathrm{cm}$ long. Because the length of the brass bolt was measured to three decimal places the uncertainty in the brass bolt length was \pm 0.005 in. $(0.0127 \mathrm{~cm})$. The difference between the maximum and minimum diameter of a 5/8-18UNF-2A thread is $0.0131 \mathrm{in} .(0.033274 \mathrm{~cm})$. This value was taken to be a bounding, one-sided uncertainty in the bolt diameter. ${ }^{\text {a }}$ The dimensions of the brass

\footnotetext{
${ }^{a}$ Unified Screw Threads, Standard Series, http://www.efunda.com/designstandards/screws/unified.cfm?start=148\&finish=227

Revision: 0 
NEA/NSC/DOC(95)03/II

Volume II

HEU-MET-FAST-100

bolt were each perturbed individually and are given in Table 2-5. The uncertainty in the bore-hole diameter is evaluated in Section 2.2.7.

Table 2-5. Effect of the Uncertainty in the Brass Bolt Dimensions.

\begin{tabular}{||c|c|ccc|c|c|c||}
\hline \hline Case & $\begin{array}{c}\text { Deviation } \\
(\mathrm{cm})\end{array}$ & $\Delta \mathrm{k}_{\text {eff }}$ & \pm & $\sigma_{\mathrm{MC}}$ & Scaling Factor & $\begin{array}{c}1 \sigma \\
(\mathrm{cm})\end{array}$ & $\Delta \mathrm{k}_{\text {eff }}(1 \sigma) \pm \quad \sigma_{\text {statistical }}$ \\
\hline \multicolumn{7}{|c||}{ Bolt Diameter } \\
\hline 1 & 0.33274 & -0.00007 & \pm & 0.00002 & $10 \cdot 2 \sqrt{3}$ & $0.033274 / 2 \sqrt{3}$ & NEG \\
\hline 2 & 0.33274 & -0.00007 & \pm & 0.00002 & $10 \cdot 2 \sqrt{3}$ & $0.033274 / 2 \sqrt{3}$ & NEG \\
\hline \multicolumn{8}{||c||}{ Bolt Length } \\
\hline 1 & 0.127 & -0.00002 & \pm & 0.00002 & 10 & $2.54 \times 10^{-3}$ & $0.00001^{(\mathrm{a})}$ \\
\hline 2 & 0.127 & -0.00001 & \pm & 0.00002 & 10 & $2.54 \times 10^{-3}$ & $0.00001^{(\mathrm{a})}$ \\
\hline
\end{tabular}

(a) The effect of this perturbation is less than three times the statistical uncertainty of the Monte Carlo calculation despite using a scaling factor thus the perturbation effect was set at \pm 0.00006 (before scaling).

\subsubsection{Uncertainty in Part Masses}

The masses of the bottom, center, and top sections of the sphere are given in Table 1-1 and Table 1-2. The uncertainty in the masses was $\pm 0.01 \mathrm{~g}$ except for the bottom section of Case 1 , which was measured to only $\pm 1 \mathrm{~g}$ accuracy. The total mass of the two diametral filler rods was $28.163 \mathrm{~g}$. The uncertainty in each of these masses was taken to be $\pm 0.01 \mathrm{~g}$ thus the uncertainty in the total mass was $\pm 0.014 \mathrm{~g}$. The density of each part was perturbed individually to reflect the uncertainty of the part mass; the effect of these uncertainties is summarized in Table 2-6. Despite using scaling factors for some of the perturbations, the $\Delta \mathrm{k}_{\mathrm{eff}}$ was still within the statistical noise of the MCNP calculation thus the uncertainty effect was set at \pm 0.00006 (before scaling).

If the mass of the lower polar cap and the lower plate given in the dimensional certification reports are added together a mass of 20,010.29 $\mathrm{g}$ is obtained. This is smaller than the given 20,310 $\mathrm{g}$ bottom section mass by approximately $300 \mathrm{~g}$. This would lead one to believe that the three pins had a total mass of $300 \mathrm{~g}$. However, the volume of the pins is such that the pin density would be extremely high $\left(>20 \mathrm{~g} / \mathrm{cm}^{3}\right)$. The total mass of the three pins described in the dimensional certification reports is approximately 300 grams but these pins were machined after they were fit into bottom section thus reducing the pin mass. However, the experimenter has asserted that the total section mass was measured as being 20,310 $\mathrm{g}$ after the bottom section was pinned together. ${ }^{\text {a }}$ Based on this assertion the 20,310 g is used in the benchmark model for the bottom section mass and was homogenized over the entire bottom section volume as was done for the masses of other sphere sections.

\footnotetext{
a Personal phone communication with J.T. Mihaclzo, April 24, 2013.

Revision: 0

Date: September 30, 2013

Page 36 of 160
} 
NEA/NSC/DOC(95)03/II

Volume II

HEU-MET-FAST-100

Table 2-6. Effect of the Uncertainty in the Sphere Masses.

\begin{tabular}{|c|c|ccc|c|c|c||}
\hline \hline Case & $\begin{array}{c}\text { Deviation } \\
(\mathrm{g})\end{array}$ & $\Delta \mathrm{k}_{\text {eff }}$ & \pm & $\sigma_{\mathrm{MC}}$ & $\begin{array}{c}\text { Scaling } \\
\text { Factor }\end{array}$ & $\begin{array}{c}1 \sigma \\
(\mathrm{g})\end{array}$ & $\Delta \mathrm{k}_{\text {eff }}(1 \sigma) \pm \sigma_{\text {statistical }}$ \\
\hline \multicolumn{7}{|c||}{ Bottom Section Mass } \\
\hline 1 & 1 & -0.00004 & \pm & 0.00002 & 1 & 1 & $0.00006^{(\mathrm{a})}$ \\
\hline 2 & 1 & -0.00002 & \pm & 0.00002 & 100 & 0.01 & $\mathrm{NEG}^{(\mathrm{b})}$ \\
\hline \multicolumn{7}{|c||}{ Center Section Mass } \\
\hline 1 & 1 & 0.00000 & \pm & 0.00002 & 100 & 0.01 & $\mathrm{NEG}^{(\mathrm{b})}$ \\
\hline 2 & 1 & 0.00000 & \pm & 0.00002 & 100 & 0.01 & $\mathrm{NEG}^{(\mathrm{b})}$ \\
\hline 1 & 1 & -0.00004 & \pm & 0.00002 & 100 & 0.01 & $\mathrm{NEG}^{(\mathrm{b})}$ \\
\hline 2 & 1 & -0.00004 & \pm & 0.00002 & 100 & 0.01 & $\mathrm{NEG}^{(\mathrm{b})}$ \\
\hline \multicolumn{7}{|c|}{ Diametral Filler Rod Mass } \\
\hline 1 & 2 & -0.00003 & \pm & 0.00002 & 142.9 & 0.014 & $\mathrm{NEG}^{(\mathrm{b})}$ \\
\hline 2 & 2 & -0.00005 & \pm & 0.00002 & 142.9 & 0.014 & $\mathrm{NEG}^{(\mathrm{b})}$ \\
\hline
\end{tabular}

(a) The effect of this perturbation is less than three times the statistical uncertainty thus the effect of the uncertainty was set at \pm 0.00006 .

(b) The effect of this perturbation is less than three times the statistical uncertainty of the Monte Carlo calculation despite using a scaling factor thus the perturbation effect was set at \pm 0.00006 . When this value was scaled the $\Delta \mathrm{k}_{\mathrm{eff}}(1 \sigma)$ was negligible.

\subsubsection{Dimensions of Uranium Parts and Voids within Sphere}

The masses of individual uranium parts within the sphere, including the HEU pins, target hole plug, thermocouple plug, and alignment cones, were not given, but were included in the total masses reported for the major sections of the sphere. Thus, the original densities for each individual part cannot be calculated and the densities of the smaller parts have very little or no effect on the overall density of the sphere. Each part had a slightly different enrichment thus the dimensions of each part had an effect of the averaged enrichment of the simple benchmark model sphere, which is discussed in Section 2.3. The effect of the dimensions of the HEU pins, target-hole plug, thermocouple plug, alignment cones and alignment cone holes, and the mass adjustment button recesses were evaluated using Case 1 by determining the effect each variation in dimension had on the radius and enrichment of the simple benchmark model. These variations are described below. The uncertainty in the height of the center plate had the maximum effect on the radius and enrichment of the simple benchmark model. A $0.000254 \mathrm{~cm}$ variation in the plate height had a change in the simple benchmark model sphere radius of $6.2 \times 10^{-5} \mathrm{~cm}$. When the effect of perturbing the sphere radius given in Table 2-2 is scaled to this value the resulting $\Delta \mathrm{k}_{\text {eff }}$ is 0.00001 . This is the cutoff value for negligible thus it was judged that all the dimensions described below had a negligible effect on $\mathrm{k}_{\text {eff. }}$ The effects on the average enrichment were all well below the $1 \sigma$ uncertainty in enrichment and were thus also negligible. 
NEA/NSC/DOC(95)03/II

Volume II

HEU-MET-FAST-100

It was found that the effect of uncertainties in the dimensions of the individual uranium parts and void within the sphere had a negligible effect on $\mathrm{k}_{\text {eff }}$ for Case 1. The effect is judged to be negligible for Case 2 as well.

Dimensions given with respect to the center of the sphere or the center of the diametral hole, which was the same for Case 1 but 0.02 in. $(0.0508 \mathrm{~cm})$ apart for Case 2, are given as if the plates sit flush to one another and do not take into account of the tilt between the upper and center plate in Case 1.

Pin Depth in Lower Polar Cap The pin depth in the lower polar cap was given as 9/16 in. (1.42875 cm) in Figure 1-5 and Figure 1-10. However, based on the statement from the experimenter that the pins did not interfere with the mass adjustment buttons both of this depth is too deep. The depth of the pin was arbitrarily decreased to $7 / 16$ in. $(1.11125 \mathrm{~cm})$. The pin depth did not affect the calculation of the density of the sphere but did affect the average enrichment in the simple benchmark model. When the pin depth was varied it was changed from $1.11125 \mathrm{~cm}$ to $1.42875 \mathrm{~cm}$ and had a negligible effect on enrichment.

Pin Diameter in Bottom and Center Sections The pin diameter in the bottom and center portions of the sphere was 0.453 in. $(1.15062 \mathrm{~cm})$. This diameter is a truncation diameter of the 29/64 in. given in the Section 1 figures. The text of Reference 1 gives the pin diameter as $0.4530 \mathrm{in}$. The pin diameter had an effect on the radius and the average enrichment of the simple benchmark model. Because of the discrepancy between the pin diameter in the drawings and the text the uncertainty in the diameter was arbitrarily increased from $\pm 0.000254 \mathrm{~cm}$ to $\pm 0.000508 \mathrm{~cm}$.

Location of Top of Pins in Lower Polar Cap In Case 1 one pin extended above the top of the lower plate by $5.842 \times 10^{-3} \mathrm{~cm}$, one pin sat $1.27 \times 10^{-3} \mathrm{~cm}$ below the flat surface, and the third was flush with the surface. In Case 2 one pin was flush with the top of the lower plate and the top of two pins sat $1.27 \times 10^{-3} \mathrm{~cm}$ below the flat surface. The height of the top of the pins had an effect on the radius and the average enrichment of the simple benchmark model. The uncertainty in the location of the top of the pins was evaluated by making all pins flush with the top surface of the lower plate.

Cutoff Alignment Cone Cutoff alignment cones on the top of the lower plate and upper plate fit into corresponding holes in the center plate and upper polar cap. These alignment cones assured proper lateral alignment of the plates when the sphere was assembled. The diameter, height, and angle of these cones and holes were given in Figure 1-6, Figure 1-7, Figure 1-8, Figure 1-9, Figure 1-11, Figure 1-12, Figure 1-13, and Figure 1-14. The angle of both the cones and the holes was $30^{\circ}$. The diameter of the cones was $1.270_{-0.0127}^{+0.000}$ $\mathrm{cm}$ and the diameter of the holes was $1.27254_{-0.000}^{+0.0127} \mathrm{~cm}$. The height of the cones was $0.55372_{-0.00508}^{+0.000} \mathrm{~cm}$ (uncertainty given in Figure 1-11) and the height of the hole was $0.5715_{-0.000}^{+0.0127} \mathrm{~cm}$. When the diameter and heights of the cones and holes were adjusted the radius and average enrichment of the simple benchmark model were affected.

Mass Adjustment Button Recesses Eight equally spaced mass adjustment button recesses were located on the lower and upper polar caps at a $45^{\circ}$ angle to the center of the original GA Sphere. When the sphere was re-machined as the ORSphere and from Case 1 to Case 2 this angle would have changed slightly. Because the true angle is unknown the button recesses are assumed to be at a $45^{\circ}$ angle to the center of the diametral hole for both cases. The effect of the uncertainty in this angle would be negligible. For Case 1, the button recesses consisted of a $1.11125_{-0.000}^{+0.0127}$-cm radius bore hole which had a depth of $0.4572 \mathrm{~cm}$ at the edge of the recess hole. The mass adjustment buttons were attached by screw and the screw hole had a depth of 0.268 in.

Revision: 0

Date: September 30, 2013

Page 38 of 160 
NEA/NSC/DOC(95)03/II

Volume II

HEU-MET-FAST-100

$(0.68072 \mathrm{~cm})$ in Figure 1-5 and Figure 1-9 (Case 1). In Figure 1-15 the screw-hole depth was given as 0.262 in. $(0.66548 \mathrm{~cm})$ with a measured and adjusted diameter of $0.138 \mathrm{in} .(0.35052 \mathrm{~cm})$. The uncertainty in the recess diameter was $+0.0127 \mathrm{~cm}$, the uncertainty in the bore-hole depth was $\pm 0.000254 \mathrm{~cm}$, and the uncertainty in the screw-hole diameter was $\pm 0.000254 \mathrm{~cm}$. The uncertainty in the screw-hole depth was evaluated by changing the depth from $0.68072 \mathrm{~cm}$ to $0.66548 \mathrm{~cm}$. When the sphere parts were re-machined to a smaller radius the mass adjustment buttons recesses were not re-machined. Thus for the Case 2 detailed benchmark model the distance to the bottom of the screw hole and the bottom of recess from the center of the diametral hole, which was the center of the Case 1 sphere, was kept constant. The curve of the smaller sphere truncated the mass adjustment button recesses such that the depth was reduced for the upper polar cap and only a very small flat spot remained on the lower polar cap. When the dimensions of the mass adjustment button recesses were modified the radius and average enrichment of the simple benchmark model were affected.

Bottom Support Hole The diameter of the support hole for the brass bolt that provided the bottom support had a diameter of $1.495806 \mathrm{~cm}$, as discussed in Section 2.2.5. The uncertainty in the bolt-hole diameter was $2.54 \times 10^{-4} \mathrm{~cm}$. For Case 1, the depth of the support hole was 0.393 in. $(0.99822 \mathrm{~cm})$ in Figure 1-5 and 0.385 in. $(0.9779 \mathrm{~cm})$ in Figure 1-15. The $0.99822 \mathrm{~cm}$ depth was used for the Case 1 detailed benchmark model. The support-hole depth was adjusted to $0.9779 \mathrm{~cm}$ in order to evaluate the effect of the uncertainty in the support-hole depth. The uncertainty in the diameter was evaluated when the diameter of the brass bolt was evaluated. The diameter of the lower support was the same for Case 2. For Case 2, the distance from the center of the diametral hole to the bottom of the support hole was the same as in Case 1. The curve of the smaller sphere made the depth of the support hole shallower. The resulting depth of the bore hole is $0.987298 \mathrm{~cm}$ which does not agree with the support-hole depth in Figure 1-10. It is believed that the bolt height was inadvertently put on Figure 1-10 rather than the true support-hole depth. A 1-in.-diameter (2.54 $\mathrm{cm}$ ) spot face surrounded the bore hole in both Case 1 and 2. The uncertainty in the spot face diameter was $\pm 0.000254 \mathrm{~cm}$. The bottom support-hole dimensions affected the radius and average enrichment of the simple benchmark model.

Thermocouple A rectangular thermocouple groove at the top of the center plate was filled with HEU. The thermocouple groove had a width of $0.070 \pm 0.004 \mathrm{in} .(0.1778 \pm 0.01016 \mathrm{~cm})$. The depth of the thermocouple was $0.058 \pm 0.002$ in. $(0.14732 \pm 0.00508 \mathrm{~cm})$ from $3 / 8 \mathrm{in} .(0.9525 \mathrm{~cm})$ away from the center of the sphere, through the center of the sphere, until a radius of $1.625 \mathrm{in} .(4.1275 \mathrm{~cm})$, at which point the depth increased to $0.116 \pm 0.002$ in. $(0.29464 \pm 0.00508 \mathrm{~cm})$. The uncertainty in the penetration distance and depth transition location was taken to be $\pm 0.01016 \mathrm{~cm}$. Because the groove was filled by shrink fit there was no void around the HEU filler. The dimensions of the thermocouple groove did not affect the radius of the simple benchmark model but did affect the average enrichment of the simple benchmark model.

Target Hole The 1-in.-diameter $(2.54 \mathrm{~cm})$ target hole was filled by shrink fit with a plug so there was no void introduced. The target hole came within $0.3497 \mathrm{in} .(0.888238 \mathrm{~cm})$ of the center of the sphere. The uncertainty in these dimensions was $\pm 0.000254 \mathrm{~cm}$. The dimensions of the target hole did not affect the radius of the simple benchmark model but did affect the average enrichment of the simple benchmark model.

Screw Holes for Central Plate Support Four equally spaced screw holes were present at the center line of center plate for the four support rods. The screw holes had a depth of 0.268 in $(0.68072 \mathrm{~cm})$ in Figure 1-7 for Case 1. As was done with the mass adjustment button recesses the distance from the center of the plate to the bottom of the support rod screw holes was kept constant from the Case 1 detailed benchmark model to

Revision: 0

Date: September 30, 2013

Page 39 of 160 
the Case 2 detailed benchmark model. The curvature of the smaller sphere made the depth of the screw holes shallower. The diameter of the screw holes was given in Figure 1-15 as 0.2764 in. $(0.702056 \mathrm{~cm})$, measured and adjusted for threading. The uncertainty in the diameter was $\pm 0.000254 \mathrm{~cm}$. The depth of the hole was given as $0.267 \mathrm{in} .(0.67818 \mathrm{~cm})$ in Figure $1-15$. To evaluate the uncertainty in the screw-hole depth the depth was adjusted to $0.67818 \mathrm{~cm}$ from $0.68072 \mathrm{~cm}$. The screw holes were empty in the detailed benchmark model. The dimensions of the screw holes had an effect on the radius and average enrichment of the simple benchmark model.

Upper Socket Hole The hole for the upper socket had a diameter of $2.422144 \mathrm{~cm}$. The depth of the hole was 0.393 in. $(0.99822 \mathrm{~cm})$ for Case 1 . As was done with the mass adjustment button recesses the distance from the center of the diametral hole to the bottom of the upper socket hole was kept constant from the Case 1 detailed benchmark model to the Case 2 detailed benchmark model. The curvature of the smaller sphere made the depth of the bore hole shallower. The uncertainty in the diameter and depth was $\pm 0.000254 \mathrm{~cm}$. The dimensions of the upper socket hole affected the radius and average enrichment of the simple benchmark model.

Lower Polar Cap Height The height of the lower polar cap was 1.8673 in. (4.742942 cm) for Case 1 and 1.8225 in. $(4.62915 \mathrm{~cm})$ for Case 2. The top surface of the lower polar cap was $1.6009 \mathrm{in} .(4.066286 \mathrm{~cm})$ from the center of the diametral hole for both cases, which was the center of the sphere for Case 1 . The uncertainty in the height of the lower polar cap was $\pm 0.000254 \mathrm{~cm}$. The lower polar cap height affected the radius and average enrichment of the simple benchmark model.

Lower Plate Height The height of the lower plate was 1.0383 in. $(2.637282 \mathrm{~cm})$ for both Case 1 and 2 . The top of the plate was 0.5626 in. $(1.429004 \mathrm{~cm})$ below the center of the diametral hole. The uncertainty in the height of the lower plate was $\pm 0.000254 \mathrm{~cm}$. The lower plate height affected the radius and average enrichment of the simple benchmark model.

Center Plate Height The height of the center plate was 1.1252 in. $(2.858008 \mathrm{~cm})$ for both Case 1 and 2. The center of the sphere was the same as the center of the center plate for Case 1, but for Case 2 the center of the sphere was $0.0508 \mathrm{~cm}$ above the center of the plate. The diametral hole went through the center of the plate. The uncertainty in the plate height was $\pm 0.000254 \mathrm{~cm}$. The center plate height affected the radius and average enrichment of the simple benchmark model and had the largest effect as is discussed below.

Upper Plate Height The height of the upper plate was 0.7662 in. $(1.946148 \mathrm{~cm})$ for both Case 1 and 2. The bottom of the upper plate was $0.1429004 \mathrm{~cm}$ above the center of the diametral hole in the center plate. The uncertainty in the height of the upper plate was $\pm 0.000254 \mathrm{~cm}$. The upper plate height affected the radius and average enrichment of the simple benchmark model.

Upper Polar Cap Height The height of the upper polar cap was $2.1375 \mathrm{in}$. $(5.42925 \mathrm{~cm})$ for Case 1 and $2.1332 \mathrm{in} .(5.418328 \mathrm{~cm})$ for Case 2 . The bottom of the upper polar cap was $1.3288 \mathrm{in} .(3.375152 \mathrm{~cm})$ above the center of the diametral hole. The uncertainty in the height of the upper polar cap was $\pm 0.000254 \mathrm{~cm}$. The upper plate height affected the radius and average enrichment of the simple benchmark model.

The dimensions of all of the parts and void within the sphere were perturbed individually and the effect of the radius and average enrichment of the simple benchmark model was calculated. The effects of the variation of the parameters were all smaller then the $1 \sigma$ uncertainty in the sphere radius and average enrichment. The largest effect was due to the uncertainty in the center plate height. A $0.000254 \mathrm{~cm}$ 
HEU-MET-FAST-100

variation in the plate height had a change in the simple benchmark model sphere radius of $6.2 \times 10^{-5} \mathrm{~cm}$. When the effect of perturbing the sphere radius given in Table 2-2 is scaled to this value the results $\Delta \mathrm{k}_{\text {eff }}$ is 0.00001 . This is the cutoff value for negligible thus it was judged that all the dimensions described in Section 2.2.7 had a negligible effect on $\mathrm{k}_{\text {eff. }}$. The effects on the average enrichment were all well below the $1 \sigma$ uncertainty in enrichment and were thus also negligible.

\subsection{Evaluation of Material Properties}

\subsubsection{Uranium Fraction and Impurities}

The uranium metal impurity content was as given in Table 1-4. Impurity content was modeled in the detailed benchmark model as being one half the stated value if a detection limit is given or at the stated value if a measured content was given. Oxygen and nitrogen were also included in the detailed benchmark model. All impurities except silicon, boron, and carbon were removed in the simple benchmark model. For the HEU pins, the filler rods, and for the target hole and thermocouple groove filler material the suggested composition of $99.95 \mathrm{~g}$ of uranium per $100 \mathrm{~g}$ of material, $5 \mathrm{ppm}, \mathrm{Al}, 120 \mathrm{ppm} \mathrm{Si}, 62 \mathrm{ppm}$ metals, $0.3 \mathrm{ppm} \mathrm{B}$, $168 \mathrm{ppm} \mathrm{C}, 20 \mathrm{ppm} \mathrm{O}$, and $30 \mathrm{ppm} \mathrm{N}$ was used. When the total weight fraction of uranium plus impurities did not add up to one the weight fractions were normalized to unity.

The impurity content for iron, manganese, nickel, chromium, vanadium, and copper was given as a total content. For the distribution of these six metal impurities the ratio of each metal element to the total content of the six impurities was calculated from impurity measurements for ORALLOY cylinders and annuli (see also HEU-MET-FAST-069). ${ }^{\text {a }}$ Table 2-7 has the given impurity content for the six metals and ratio of the six metal impurities.

Table 2-7. Ratio of Metal Impurities in Oak Ridge Uranium Metal. ${ }^{\text {(a) }}$

\begin{tabular}{|ccc|}
\hline Element & $\begin{array}{l}\text { Impurity Content } \\
\text { (ppm, by weight) }\end{array}$ & Ratio of Metal Impurity \\
\hline \hline $\mathrm{Fe}$ & 0 & 0 \\
\hline $\mathrm{Mn}$ & 56 & 0.297872 \\
\hline $\mathrm{Ni}$ & 100 & 0.531915 \\
\hline $\mathrm{Cr}$ & 7 & 0.037234 \\
\hline $\mathrm{V}$ & 0 & 0 \\
$\mathrm{Cu}$ & 25 & 0.132979 \\
\hline
\end{tabular}

(a) The metal impurity ratio was calculated from the metal impurities reported in HEU-MET-FAST-069.

The uncertainty in the uranium fraction was $\pm 0.0001 \mathrm{~g} \mathrm{U} / \mathrm{g}$ total since it is accurate to four digits. However, a "realistic estimate of the uncertainty for [uranium weight fraction] measurements for a highly purified

\footnotetext{
a J. T. Mihalczo, “Graphite and Polyethylene Reflected Uranium-Metal Cylinders and Annuli," Union Carbide Corporation Nuclear Division, Oak Ridge Y-12 Plant, Y-DR-81 (April 28, 1972).

Revision: 0

Date: September 30, 2013

Page 41 of 160
} 
uranium metal (ORALLOY) with a skilled Y-12 workforce at the time [1960's and 1970's] would be $0.05 \%$ or lower." Based on this the uncertainty in the uranium fraction was increased to $\pm 0.0005 \mathrm{~g} \mathrm{U} / \mathrm{g}$ total.

The impurity content was perturbed $\pm 100 \%$. The uncertainty in impurity measurements at the $\mathrm{Y}-12$ plant at the time of the experiment was $\pm 20 \%$ for impurities measured above 10 micrograms $/ \mathrm{g}-\mathrm{U}$ and $\pm 70 \%$ for impurities below 10 micrograms/g-U. ${ }^{\mathrm{b}}$ These were assumed to be bounding uncertainties. The $1 \sigma$ uncertainty in the silicon and carbon impurities was $20 \% / \sqrt{3}$. The uncertainty in the boron was $70 \% / \sqrt{3}$. The boron, carbon, and silicon impurities were each varied individually. All other impurities were varied simultaneously and the $1 \sigma$ uncertainty was taken to be $70 \% / \sqrt{ } 3$. Impurities beside silicon, boron, and carbon individually had a small effect on $\mathrm{k}_{\text {eff }}$ and if they were perturbed individually the perturbation effect would not be above the statistical noise of the Monte Carlo calculation. The method of perturbing all the minor impurities simultaneously over estimates the true uncertainty. Case 1 was used for the impurity evaluation and it was judged that the results also applied to Case 2. Weight fractions were perturbed before normalization so; after an impurity content was perturbed the total weight fraction was normalized to one. The effects of these perturbations are summarized in Table 2-8.

${ }^{a}$ J. T. Mihalczo, T. Gregory Schaaff, "Uncertainties in Masses, Dimensions, Impurities, and Isotopics of HEU Metal Used in Critical Experiments at ORCEF," ORNL/TM-2012/32, Oak Ridge National Laboratory (2012).

b J. T. Mihalczo, T. Gregory Schaaff, "Uncertainties in Masses, Dimensions, Impurities, and Isotopics of HEU Metal Used in Critical Experiments at ORCEF," ORNL/TM-2012/32, Oak Ridge National Laboratory (2012). 
NEA/NSC/DOC(95)03/II

Volume II

HEU-MET-FAST-100

Table 2-8. Effect of the Uncertainty in the Uranium Impurities.

\begin{tabular}{|c|c|c|c|c|c|c|c|c|}
\hline Case & Deviation & $\Delta \mathrm{k}_{\mathrm{eff}}$ & \pm & $\sigma_{\mathrm{MC}}$ & Scaling Factor & $\Delta \mathrm{k}_{\mathrm{eff}}(1 \sigma)$ & \pm & $\sigma_{\text {statistical }}$ \\
\hline \multicolumn{9}{|c|}{ Uranium Fraction } \\
\hline 1 & 0.001 & -0.00002 & \pm & 0.00002 & 2 & \multirow{2}{*}{\multicolumn{3}{|c|}{$0.00003^{(\mathrm{a})(\mathrm{b})}$}} \\
\hline 2 & & & - & & & & & \\
\hline \multicolumn{9}{|c|}{ Silicon Content } \\
\hline 1 & $100 \%$ & -0.00003 & \pm & 0.00002 & $(100 \% / 20 \%) \sqrt{3}$ & \multirow{2}{*}{\multicolumn{3}{|c|}{$0.00001^{(\mathrm{a})(\mathrm{b})}$}} \\
\hline 2 & - & & - & & - & & & \\
\hline \multicolumn{9}{|c|}{ Boron Content } \\
\hline 1 & $100 \%$ & 0.00000 & \pm & 0.00002 & $(100 \% / 70 \%) \sqrt{3}$ & \multirow{2}{*}{\multicolumn{3}{|c|}{$0.00002^{(\mathrm{a})(\mathrm{b})}$}} \\
\hline 2 & - & & - & & - & & & \\
\hline \multicolumn{9}{|c|}{ Carbon Content } \\
\hline 1 & $100 \%$ & -0.00026 & \pm & 0.00002 & $(100 \% / 20 \%) \sqrt{3}$ & \multirow{2}{*}{-0.00003} & \multirow{2}{*}{\multicolumn{2}{|c|}{$\pm \quad<0.00001^{(\mathrm{b})}$}} \\
\hline 2 & - & & - & & - & & & \\
\hline \multicolumn{9}{|c|}{ All Other Impurities } \\
\hline 1 & $100 \%$ & -0.00011 & \pm & 0.00003 & $(100 \% / 70 \%) \sqrt{3}$ & -0.00004 & \pm & 0.00001 \\
\hline 2 & $100 \%$ & -0.00009 & \pm & 0.00003 & $(100 \% / 70 \%) \sqrt{3}$ & -0.00004 & \pm & 0.00001 \\
\hline
\end{tabular}

(a) The effect of this perturbation is less than three times the statistical uncertainty of the Monte Carlo calculation despite using a scaling factor thus the perturbation effect was set at \pm 0.00006 (before scaling).

(b) Case 1 was used to evaluate this uncertainty and it was judged that the results also apply to Case 2.

\subsubsection{Uranium Isotopics}

At the time of the experiment HEU metal isotopic content could be measured at Y-12 with an uncertainty of 0.0017 wt. $\%{ }^{234} \mathrm{U}, 0.0177$ wt. $\%{ }^{235} \mathrm{U}$, and 0.0130 wt. $\%{ }^{236} \mathrm{U} .{ }^{\mathrm{a}}$ In Table $1-3$ the uncertainty in the ${ }^{234} \mathrm{U}$ and ${ }^{236} \mathrm{U}$ content was given as $\pm 1 \%$ of the isotopic content and the uncertainty in the ${ }^{235} \mathrm{U}$ was $\pm 0.005 \mathrm{wt} . \%$. Because the typical uncertainties for the Y-12 plant were larger than the uncertainties given in Reference 1 for ${ }^{235} U$ and ${ }^{236} U$ the typical uncertainties are used as the $1 \sigma$ uncertainties but the $\pm 1 \%$ is used for the ${ }^{234} U$. The effect of the uncertainty in enrichment was determined using the simple benchmark model. The ${ }^{238} \mathrm{U}$ content was the difference between the unity and the sum of the other isotopic contents. When perturbing isotopic contents, in order to maintain a balance, ${ }^{238} \mathrm{U}$ content was adjusted accordingly. The results of this analysis are given in Table 2-9.

a J. T. Mihalczo, T. Gregory Schaaff, "Uncertainties in Masses, Dimensions, Impurities, and Isotopics of HEU Metal Used in Critical Experiments at ORCEF,” ORNL/TM-2012/32, Oak Ridge National Laboratory (2012).

Revision: 0

Date: September 30, 2013

Page 43 of 160 
NEA/NSC/DOC(95)03/II

Volume II

HEU-MET-FAST-100

Table 2-9. Effect of the Uncertainty in the Uranium Enrichment.

\begin{tabular}{|c|c|c|c|c|c|c|c|c|c|}
\hline Case & Deviation & $\Delta \mathrm{k}_{\text {eff }}$ & \pm & $\sigma_{\mathrm{MC}}$ & $\begin{array}{l}\text { Scaling } \\
\text { Factor }\end{array}$ & $1 \sigma$ & $\Delta \mathrm{k}_{\mathrm{eff}}(1 \sigma)$ & \pm & $\sigma_{\text {statistical }}$ \\
\hline \multicolumn{10}{|c|}{${ }^{234} \mathrm{U}$ Content } \\
\hline 1 & $10 \%^{(\mathrm{a})}$ & -0.00036 & \pm & 0.00002 & 10 & $1 \%^{(\mathrm{a})}$ & -0.00004 & \pm & $<0.00001$ \\
\hline 2 & $10 \%^{(\mathrm{a})}$ & -0.00037 & \pm & 0.00002 & 10 & $1 \%{ }^{(a)}$ & -0.00004 & \pm & $<0.00001$ \\
\hline \multicolumn{10}{|c|}{${ }^{235} \mathrm{U}$ Content } \\
\hline 1 & 0.177 wt. $\%$ & -0.00089 & \pm & 0.00002 & 10 & 0.0177 wt. $\%$ & -0.00009 & \pm & $<0.00001$ \\
\hline 2 & 0.177 wt. $\%$ & -0.00093 & \pm & 0.00002 & 10 & 0.0177 wt. $\%$ & -0.00009 & \pm & $<0.00001$ \\
\hline \multicolumn{10}{|c|}{${ }^{236} \mathrm{U}$ Content } \\
\hline 1 & 0.039 wt. $\%$ & -0.00003 & \pm & 0.00002 & 3 & 0.0130 wt. $\%$ & \multicolumn{3}{|c|}{$0.00002^{(b)}$} \\
\hline 2 & 0.039 wt. $\%$ & -0.00003 & \pm & 0.00002 & 3 & 0.0130 wt. $\%$ & \multicolumn{3}{|c|}{$0.00002^{(b)}$} \\
\hline
\end{tabular}

(a) It should be noted that the uncertainty in ${ }^{234} \mathrm{U}$ is $10 \%$ of the given weight percent.

(b) The effect of this perturbation is less than three times the statistical uncertainty of the Monte Carlo calculation despite using a scaling factor thus the perturbation effect was set at \pm 0.00006 (before scaling).

\subsubsection{Non-Uranium Material}

The type of brass for the brass bolt in the lower polar cap was not given. In the sample MCNP model in Appendix A of Reference 1, only copper was used but a comment indicated that zinc was left out because cross section data were not available. Based on this information C83400 Red Brass was used in the detailed benchmark model at a nominal density of $8.8 \mathrm{~g} / \mathrm{cm}^{3}$. . The brass was $90 \mathrm{wt} . \%$ copper and $10 \mathrm{wt} . \%$ zinc.

To determine the effective uncertainty in the brass the material was switched out for C85800 Yellow Brass, which has the lowest copper content of the red and yellow brass. ${ }^{\text {a }}$ C85800 Yellow Brass had a composition of:

$\begin{array}{ll}58 \text { wt. } \% & \mathrm{Cu} \\ 1 \text { wt. } \% & \mathrm{Sn} \\ 1 \text { wt. } \% & \mathrm{~Pb} \\ 40 \text { wt. } \% & \mathrm{Zn}\end{array}$

The $1 \sigma$ uncertainty in the density of the brass was $\pm 0.2 \mathrm{~g} / \mathrm{cm}^{3}$. The effect of switching out the material and of varying the density is given in Table 2-10.

\footnotetext{
a E. Oberg, et.al., "Machinery's Handbook," Industrial Press, Inc., New York, New York, $24^{\text {th }}$ ed., 1992.

Revision: 0

Date: September 30, 2013

Page 44 of 160
} 
NEA/NSC/DOC(95)03/II

Volume II

HEU-MET-FAST-100

Table 2-10. Effect of the Uncertainty in the Non-Uranium Material Compositions.

\begin{tabular}{|c|c|c|c|c|c|c|c|}
\hline Case & Deviation & $\Delta \mathrm{k}_{\mathrm{eff}}$ & \pm & $\sigma_{\mathrm{MC}}$ & $\begin{array}{l}\text { Scaling } \\
\text { Factor }\end{array}$ & $1 \sigma$ & $\Delta \mathrm{k}_{\mathrm{eff}}(1 \sigma) \quad \pm \quad \sigma_{\text {statistical }}$ \\
\hline \multicolumn{8}{|c|}{ Brass Composition } \\
\hline 1 & \multirow{2}{*}{$\begin{array}{c}\text { C85800 } \\
\text { Yellow } \\
\text { Brass }\end{array}$} & $<0.00000$ & \pm & 0.00002 & 1 & - & $0.00006^{\text {(a) }}$ \\
\hline 2 & & 0.00001 & \pm & 0.00002 & 1 & - & $0.00006^{(\mathrm{a})}$ \\
\hline \multicolumn{8}{|c|}{ Brass Density } \\
\hline 1 & $1 \mathrm{~g} / \mathrm{cm}^{3}$ & -0.00002 & \pm & 0.00002 & 5 & $0.2 \mathrm{~g} / \mathrm{cm}^{3}$ & $0.00001^{(b)}$ \\
\hline 2 & $1 \mathrm{~g} / \mathrm{cm}^{3}$ & -0.00002 & \pm & 0.00002 & 5 & $0.2 \mathrm{~g} / \mathrm{cm}^{3}$ & $0.00001^{(\mathrm{b})}$ \\
\hline
\end{tabular}

(a) The effect of this perturbation is less than three times the statistical uncertainty thus the effect of the uncertainty was set at \pm 0.00006 .

(b) The effect of this perturbation is less than three times the statistical uncertainty of the Monte Carlo calculation despite using a scaling factor thus the perturbation effect was set at \pm 0.00006 (before scaling).

\section{$2.4 \quad$ Temperature Uncertainty}

The experiments were carried out at $24.5^{\circ} \mathrm{C}$. A $1 \sigma$ uncertainty in temperature is taken to be $\pm 2{ }^{\circ} \mathrm{C}$. The temperature coefficient was $-1 / 3 \notin /{ }^{\circ} \mathrm{C}$. The effect of the uncertainty in the temperature would have been $\pm 0.000044 \Delta \mathrm{k}_{\text {eff. }}$

\subsection{Total Uncertainty in Critical Configuration}

All $1 \sigma$ uncertainties are compiled in Table 2-11. An uncertainty is considered to have a negligible effect (NEG) when the magnitude of the $1 \sigma \Delta \mathrm{k}_{\text {eff }}$ is $\leq 0.00001$. The total uncertainties are $\pm 0.00075 \Delta \mathrm{k}_{\text {eff }}$ for Case 1 and $0.00071 \Delta \mathrm{k}_{\text {eff }}$ for Case 2. The experimenter indicated the total uncertainty for both cases should be approximately $\pm 0.0004 \Delta \mathrm{k}_{\text {eff. }}$. The evaluated uncertainties are larger than this suggested value. The uncertainty for Case 1 is larger due to the larger measurement uncertainty effect and the uncertainty in the tilt angle. The two spheres are judged to be acceptable as criticality safety benchmark experiments.

\footnotetext{
${ }^{a}$ Personal email communication with J.T. Mihalczo, April 17, 2013. 
Table 2-11. Total Uncertainty in Experimental Configuration.

\begin{tabular}{|c|c|c|c|c|}
\hline & & & Case 1 & Case 2 \\
\hline & \pm & $1 \sigma$ & $\pm \Delta \mathrm{k}_{\mathrm{eff}}(1 \sigma)$ & $\pm \Delta \mathrm{k}_{\mathrm{eff}}(1 \sigma)$ \\
\hline Reactivity Measurement & \pm & $2.0 \phi^{(\mathrm{a})}$ & 0.00013 & 0.00013 \\
\hline Radius & \pm & $2.54 \times 10^{-4} \mathrm{~cm}$ & 0.00005 & 0.00005 \\
\hline Curve of Ellipsoidal Parts & & ee Section 2.2 .2 & 0.00066 & 0.00066 \\
\hline Lower Polar Cap/Lower Plate Gap & \pm & $2.54 \times 10^{-4} \mathrm{~cm}$ & 0.00004 & 0.00004 \\
\hline Lower Plate/Center Plate Gap & \pm & $2.54 \times 10^{-4} \mathrm{~cm}$ & 0.00007 & 0.00011 \\
\hline Center Plate/Upper Plate Gap & \pm & $2.54 \times 10^{-4} \mathrm{~cm}$ & 0.00009 & 0.00008 \\
\hline Upper Plate/Upper Polar Cap Gap & \pm & $2.54 \times 10^{-4} \mathrm{~cm}$ & 0.00006 & 0.00005 \\
\hline Tilt Angle & & ee Section 2.2 .3 & -0.00011 & - \\
\hline Diametral Hole Diameter & \pm & $2.54 \times 10^{-4} \mathrm{~cm}$ & NEG & NEG \\
\hline Diametral Rod Diameter & \pm & $2.54 \times 10^{-4} \mathrm{~cm}$ & NEG & NEG \\
\hline Diametral Rod Length & \pm & $2.54 \times 10^{-4} \mathrm{~cm}$ & NEG & NEG \\
\hline Brass Bolt Diameter & \pm & $0.033274 / 2 \sqrt{ } 3 \mathrm{~cm}$ & NEG & NEG \\
\hline Brass Bolt Height & \pm & $2.54 \times 10^{-3} \mathrm{~cm}$ & 0.00001 & 0.00001 \\
\hline Bottom Section Mass & \pm & $\begin{array}{c}\text { Case } 1-1 \mathrm{~g} \\
\text { Case } 2-0.01 \mathrm{~g}\end{array}$ & 0.00006 & NEG \\
\hline Center Section Mass & \pm & $0.01 \mathrm{~g}$ & NEG & NEG \\
\hline Top Section Mass & \pm & $0.01 \mathrm{~g}$ & NEG & NEG \\
\hline Diametral Filler Rod Mass & \pm & $0.014 \mathrm{~g}$ & NEG & NEG \\
\hline Parts and Voids Within Sphere & & ee Section 2.2 .7 & NEG & NEG \\
\hline Uranium fraction & \pm & $0.0005 \mathrm{gU} / \mathrm{gTotal}$ & 0.00003 & 0.00003 \\
\hline Silicon & \pm & $20 \% / \sqrt{3}$ & 0.00001 & 0.00001 \\
\hline Boron & \pm & $70 \% / \sqrt{3}$ & 0.00002 & 0.00002 \\
\hline Carbon & \pm & $20 \% / \sqrt{3}$ & -0.00003 & -0.00003 \\
\hline Other Impurities & \pm & $70 \% / \sqrt{3}$ & -0.00004 & -0.00004 \\
\hline${ }^{234} \mathrm{U}$ Content & \pm & $1 \%$ & -0.00004 & -0.00004 \\
\hline${ }^{235} \mathrm{U}$ Content & \pm & 0.0177 wt. $\%$ & -0.00009 & -0.00009 \\
\hline${ }^{236} \mathrm{U}$ Content & \pm & 0.0130 wt. $\%$ & 0.00002 & 0.00002 \\
\hline Brass Density & \pm & $0.2 \mathrm{~g} / \mathrm{cm}^{3}$ & 0.00006 & 0.00006 \\
\hline Brass Composition & & ee Section 2.3 .3 & 0.00001 & 0.00001 \\
\hline Temperature & \pm & $2{ }^{\circ} \mathrm{C}$ & 0.00004 & 0.00004 \\
\hline \multicolumn{3}{|c|}{ Total Experimental Uncertainty } & 0.00071 & 0.00070 \\
\hline
\end{tabular}

(a) Reactivity Uncertainty includes reproducibility, reactor period measurement, and delayed neutron parameter uncertainties. 
NEA/NSC/DOC(95)03/II

Volume II

HEU-MET-FAST-100

\subsection{BENCHMARK SPECIFICATIONS}

Detailed and simple benchmark models were created with MCNP5 using ENDF/B-VII.0, JEFF3.1, and JENDL-3.3 neutron cross section libraries. The biases of any simplifications or assumptions were calculated for both the detailed and simple models. All models were run in MCNP5 such that the statistical uncertainty $(1 \sigma)$ of $k_{\text {eff }}$ was not more than 0.00002 . Benchmark specifications for both the detailed and simple model are described in Sections 3.2 and 3.3.

The effects of individual simplifications were calculated in a step-wise fashion. The overall calculated simplification biases were found by comparing the detailed and simple benchmark model to the as-built model. The as-built model already includes measured simplification corrections. A $\beta_{\text {eff }}$ of $0.00657 \pm 0.00002$ was used for this evaluation (see Section 2.1).

\subsection{Description of Model}

A simplification bias of $-35 \varnothing$ was given in Reference 1. Some explanation of this value is given in Appendix A of Reference 1 but it is impossible to determine what simplifications are included in this bias and how the bias was calculated. Because this bias cannot be accurately quantified it is not used in the derivation of the benchmark $k_{\text {eff }}$ value. ${ }^{a}$ Measured corrections of $-14.29 \pm 0.05 \not$ for the center, lower support structure, and four posts of the vertical assembly machine; $-0.70 \pm 0.09 \phi$ for the cross beam for the upper support structure; and $-10.2 \pm 0.10 \notin$ for the upper polar cap socket and attached support rod were given in Reference 1. These corrections yield a measured correction of approximately $-25.19 \pm 0.14 \varnothing$ for the structural support. This is the value used in the derivation of the benchmark $\mathrm{k}_{\text {eff }}$ value because these support structures cannot be accurately modeled due to lack of dimensions and material data. The measured correction of the support structure was determined by doubling the support structure and measuring the change in reactivity. It is uncertain if doubling the support structure gives change in reactivity equal to the reactivity change for removing the structure thus the uncertainty in the measured corrections was increased to at least $\pm 10 \%$. This uncertainty is typical of HEU ORCEF experiments at the time (HEU-MET-FAST-051). The measured corrections for the support structure used in the benchmark models were $-14.29 \pm 1.429 \phi$ for the center, lower support structure, and four posts of the vertical assembly machine; $-0.70 \pm 0.09 \notin$ for the cross beam for the upper support structure (the given uncertainty of $\pm 0.09 \notin$ was retained because it was larger than a $\pm 10 \%$ uncertainty); and $-10.2 \pm 1.02 \not$ for the upper polar cap socket and attached support rod. This yields a total measured correction for support structure of $-25.19 \pm 1.76 \phi$.

A model to approximate the support structure worth was created using assumed dimensions and materials and is described in Appendix F. The support structure worth for the assumed dimensions and materials was approximately $-20.3 \pm 1.1 \not$. Although slightly lower than the measure structure worth, this approximation agrees with the measure value within $3 \sigma$.

\footnotetext{
${ }^{a}$ This value was derived by Gordon Hansen using reactivity coefficients measured in GODIVA to make corrections. (Personal email communication with J.T. Mihaclzo, July 29, 2013.)

Revision: 0

Date: September 30, 2013

Page 47 of 160
} 
NEA/NSC/DOC(95)03/II

Volume II

HEU-MET-FAST-100

\subsubsection{Description of Detailed Benchmark Model Simplifications}

Five simplifications were made to obtain the detailed benchmark model: first, the room and air were removed, this was a calculated bias; second, the stainless steel plate of the vertical lift machine was removed, this was also a calculated bias; third, the upper support structure was removed, this was a measured correction worth $0.70 \pm 0.09 \notin$; fourth, the upper polar cap socket and support rod above it was removed, this was a measured correction worth $10.2 \pm 0.10 \phi$; and fifth, the center and lower support structure was removed, this was also a measured correction worth $14.29 \pm 0.05 \varnothing$. There was also a temperature correction since all part measurements were performed at $21{ }^{\circ} \mathrm{C}$ and the experiment was completed at $24.5^{\circ} \mathrm{C}$. The temperature correction was $-1 / 3 \notin$ per ${ }^{\circ} \mathrm{C}$ with an assumed uncertainty of $\pm 10 \%$.

Measured corrections were used for the upper support structure, the upper polar cap socket and support rod, and the center and lower support structures because these features could not be accurately modeled due to lack of dimensions and material data. Calculating a simplification bias for the support structure would produce a large bias uncertainty due to the lack of information for the support structure. The measured corrections were used instead to reduce the bias uncertainty. The $-0.70 \pm 0.09 \varnothing$ was used for the cross beam for the upper support structure. For the upper socket, including the $64 \mathrm{~g}$ of uranium, and the support rod above it a correction of $-10.2 \pm 0.10 \notin$ was used. For the center and lower support structure a correction of $14.29 \pm 0.05 \varnothing$ was used. It is believed that the brass bolt is not a part of the correction worth for the center and lower support structure. It is believed that the screws in the center plate were accounted for in the correction for the center and lower support structure thus the screw holes are empty in the detailed benchmark model.

It is believed that the effect of the stainless steel table of the vertical lift machine, upon which the lower support structure sat, was not included in the measured bias for the center and lower support structure. The effect of the 45.72-cm diameter, 2.38-cm thick, and $31.2 \mathrm{~kg}$ stainless steel Type 304 table (HEU-COMP-FAST-004) was evaluated and treated as an additional bias in the detailed benchmark model.

The bias of the room return was calculated by modeling the center of the sphere as being $387.096 \mathrm{~cm}$ $(12.7 \mathrm{ft})$ away from the $60.96-\mathrm{cm}-(2-\mathrm{ft})$-thick north wall, $713.232 \mathrm{~cm}(23.4 \mathrm{ft})$ from the $60.96-\mathrm{cm}--(2-\mathrm{ft})-$ thick east wall, $682.752 \mathrm{~cm}$ (22.4) from the 60.96-cm--(2-ft)-thick south wall, $356.616 \mathrm{~cm}(11.7 \mathrm{ft})$ from the $152.4-\mathrm{cm}--(5-\mathrm{ft})-$ thick west wall, $280.416 \mathrm{~cm}(9.2 \mathrm{ft})$ above the $60.96-\mathrm{cm}--(2-\mathrm{ft})$-thick floor and $629.7168 \mathrm{~cm}$ $(22.66 \mathrm{ft})$ below the $60.96-\mathrm{cm}--(2-\mathrm{ft})$-thick ceiling. All walls, the floor and ceiling were modeled as being Oak Ridge Concrete (as was used in HEU-MET-FAST-081). ${ }^{a}$

The effect of moving the sphere to the center of the room had a negligible effect since the reactivity change was within the uncertainty of reproducibility. Based on this it is judged that the effect of any other equipment or structure within the experiment room would have had a negligible effect on the critical measurements.

Detailed comparison between the measured curvature of the ellipsoidal parts and the modeling approximation of that curvature shows no discernible differences. Therefore, additional modeling bias due to approximation of the measured curvature with ellipsoidal equations is insignificant. However, there is additional uncertainty in both the description and the modeling approximation of the curvature of those parts

\footnotetext{
${ }^{a}$ SCALE: A Modular Code System for Performing Standardized Computer Analyses for Licensing Evaluation, ORNL/TM-2005/39 Version 5, Volume III, Section M.8, Oak Ridge National Laboratory, April 2005.

Revision: 0

Date: September 30, 2013

Page 48 of 160
} 
using a finite number of measurements. This uncertainty is accounted for as part of the experimental uncertainty and discussed in Section 2.2.2.

The simplification bias of the detailed benchmark model is given in Table 3-1. Biases were calculated using ENDF/B-VII.0, JEFF3.1, and JENDL-3.3 cross section libraries. ${ }^{a}$

Table 3-1. Summary of Simplification Biases for the Detailed Benchmark Model.

\begin{tabular}{|c|c|c|c|c|c|c|}
\hline & \multicolumn{3}{|c|}{ Case 1} & \multicolumn{3}{|c|}{ Case 2} \\
\hline Room Return and Air & -0.00032 & \pm & 0.00003 & -0.00033 & \pm & 0.00003 \\
\hline Stainless Steel Table & -0.00004 & \pm & 0.00003 & -0.00001 & \pm & 0.00003 \\
\hline \multicolumn{7}{|l|}{ Calculated Simplification Bias } \\
\hline ENDF/B-VII.0 & -0.00037 & \pm & 0.00003 & -0.00037 & \pm & 0.00003 \\
\hline JEFF3.1 & -0.00030 & \pm & 0.00003 & -0.00034 & \pm & 0.00003 \\
\hline JENDL-3.3 & -0.00036 & \pm & 0.00003 & -0.00028 & \pm & 0.00003 \\
\hline Overall Calculated Simplification Bias ${ }^{(a, b)}$ & -0.00034 & \pm & 0.00005 & -0.00033 & \pm & 0.00005 \\
\hline $\begin{array}{l}\text { Upper Support Structure Correction } \\
(0.70 \pm 0.09 \phi)^{(\mathrm{c})}\end{array}$ & -0.00005 & \pm & 0.00001 & -0.00005 & \pm & 0.00001 \\
\hline $\begin{array}{l}\text { Support rod and Upper Socket Correction } \\
(10.2 \pm 10 \%)\end{array}$ & -0.00067 & 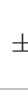 & 0.00007 & -0.00067 & $\perp$ & 0.00007 \\
\hline $\begin{array}{l}\text { Center and Lower Support Structure } \\
\text { Correction }(14.29 \pm 10 \%)\end{array}$ & -0.00094 & & 0.00009 & -0.00094 & \pm & 0.00009 \\
\hline $\begin{array}{l}\text { Temperature Correction } \\
\left(1 / 3 \text { фper }{ }^{\circ} \mathrm{C} \pm 10 \%\right)\end{array}$ & 0.00008 & + & 0.00001 & 0.00008 & $\perp$ & 0.00001 \\
\hline Additional Equipment in Room & \multicolumn{3}{|c|}{$\mathrm{NEG}^{(\mathrm{d})}$} & \multicolumn{3}{|c|}{$\mathrm{NEG}^{(\mathrm{d})}$} \\
\hline Overall Simplification Bias & -0.00192 & + & 0.00013 & -0.00191 & I & 0.00013 \\
\hline
\end{tabular}

(a) The overall calculated simplification bias is found by comparing the detailed benchmark model to the as-built model. The as-built model already includes measured simplification biases.

(b) The calculated simplification bias is the average of the three cross section libraries. The uncertainty is the standard deviation of the three libraries' biases.

(c) The given uncertainty was retained for the upper support structure correction because it was larger than a $10 \%$ uncertainty.

(d) Because the effect of moving the sphere to the center of the room was within the reproducibility of the sphere the effect of additional equipment in the room was judged to be negligible.

\subsubsection{Description of Simple Benchmark Model Simplifications}

The simple benchmark model had the same five simplifications of the detailed benchmark model plus the bias of removing the brass bolt, removing all impurities except silicon, boron, and carbon, and homogenizing the uranium as one solid sphere. The effect of each of these simplifications is given in Table 3-2. The overall simplification biases were calculated using ENDF/B-VII.0, JEFF3.1, and JENDL-3.3 cross section libraries. $^{b}$

\footnotetext{
a JEFF3.1 and JENDL-3.3 Results were provided by John D. Bess of Idaho National Laboratory.

b JEFF3.1 and JENDL-3.3 Results were provided by John D. Bess of Idaho National Laboratory. 
There was also a temperature correction since all measurements were performed at $21{ }^{\circ} \mathrm{C}$ and the experiment was completed at $24.5^{\circ} \mathrm{C}$. The temperature bias was $-1 / 3 \notin$ per ${ }^{\circ} \mathrm{C}$ with an assumed uncertainty of $\pm 10 \%$ and was used to adjust $\mathrm{k}_{\text {eff }}$ to the benchmark model temperature of $21{ }^{\circ} \mathrm{C}$.

The geometry of each of these components is described in Section 3.2.1. When impurities were removed they were replaced with void thus reducing the total material weight fraction.

When homogenizing the uranium as one solid sphere the mass and mass density of the uranium was conserved. This essentially distributed the voids around the outside of sphere and reduced the radius. This approach is valid because the majority of the voids were at the edge of the sphere. The calculated bias of Case 1 for the homogenization of the sphere as one solid sphere was larger than the calculated bias for Case 2 because there were more mass adjustment button-recesses voids present.

Table 3-2. Summary of Simplification Biases for the Simple Benchmark Model.

\begin{tabular}{|c|c|c|c|c|c|c|}
\hline & \multicolumn{3}{|c|}{ Case 1} & \multicolumn{3}{|c|}{ Case 2} \\
\hline Room Return and Air & -0.00032 & \pm & 0.00003 & -0.00033 & \pm & 0.00003 \\
\hline Stainless Steel Table & -0.00004 & \pm & 0.00003 & -0.00001 & \pm & 0.00003 \\
\hline Remove Brass Bolt & -0.00011 & \pm & 0.00003 & -0.00012 & \pm & 0.00003 \\
\hline Remove Impurities Except Si, B, and C & -0.00011 & \pm & 0.00003 & -0.00011 & \pm & 0.00003 \\
\hline Homogenize as One Sphere & 0.00091 & \pm & $0.00003^{(\mathrm{a})}$ & 0.00030 & \pm & $0.00003^{(a)}$ \\
\hline \multicolumn{7}{|l|}{ Overall Calculated Simplification Bias ${ }^{(\mathrm{b})}$} \\
\hline ENDF/B-VII.0 & 0.00019 & \pm & 0.00003 & -0.00032 & $\perp$ & 0.00003 \\
\hline JEFF3.1 & 0.00019 & \pm & 0.00003 & -0.00029 & \pm & 0.00003 \\
\hline JENDL-3.3 & 0.00016 & \pm & 0.00003 & -0.00022 & \pm & 0.00003 \\
\hline Overall Calculated Simplification Bias ${ }^{(\mathrm{c})}$ & 0.00018 & \pm & 0.00005 & -0.00028 & \pm & 0.00005 \\
\hline Upper Support Structure Bias $(0.70 \pm 0.09 \phi)^{(d)}$ & -0.00005 & $I$ & 0.00001 & -0.00005 & \pm & 0.00001 \\
\hline $\begin{array}{l}\text { Remove Support rod and Upper Socket (10.2 } \pm \\
10 \%)\end{array}$ & -0.00067 & \pm & 0.00007 & -0.00067 & + & 0.00007 \\
\hline $\begin{array}{l}\text { Center and Lower Support Structure Bias } \\
(14.29 \pm 10 \%)\end{array}$ & -0.00094 & \pm & 0.00009 & -0.00094 & I & 0.00009 \\
\hline Temperature Bias $\left(1 / 3\right.$ \& per $\left.{ }^{\circ} \mathrm{C} \pm 10 \%\right)$ & 0.00008 & \pm & 0.00001 & 0.00008 & \pm & 0.00001 \\
\hline Additional Equipment in Room & \multicolumn{3}{|c|}{$\mathrm{NEG}^{(\mathrm{e})}$} & \multicolumn{3}{|c|}{$\mathrm{NEG}^{(\mathrm{e})}$} \\
\hline Overall Simplification Bias & -0.00140 & \pm & 0.00013 & -0.00185 & \pm & 0.00013 \\
\hline
\end{tabular}

(a) The calculated bias of Case 1 for the homogenization of the sphere as one solid sphere was larger than the calculated bias for Case 2 because there were more mass adjustment button-recesses voids present.

(b) The overall calculated simplification bias is found by comparing the simple benchmark model to the as-built model. The as-built model already includes measured simplification biases.

(c) The calculated simplification bias is the average of the three cross section libraries. The uncertainty is the standard deviation of the three libraries' biases.

(e) The given uncertainty was retained for the upper support structure correction because it was larger than a $10 \%$ uncertainty.

(d) Because the effect of moving the sphere to the center of the room was within the reproducibility of the sphere the effect of additional equipment in the room was judged to be negligible. 
NEA/NSC/DOC(95)03/II

Volume II

HEU-MET-FAST-100

\subsection{Benchmark Model Dimensions}

\subsubsection{Description of Detailed Benchmark Model}

A summary of the methods used to derive ellipsoid equations, part volumes, and densities along with a summary of all part volumes, masses, and density is given in Appendices B and C.

A high number of digits on dimensions have been retained not to imply high accuracy but rather to reduce rounding error in the derivation of other dimensions and calculation of volumes.

Bottom Section The lower polar cap and the lower plate were pinned together with HEU pins to make the bottom section of the sphere. For Case 1 the two sections of sphere were machined separately before they were pinned together. For Case 2 the two sections were machined at the same time. The mass of the section was 20,310 $\mathrm{g}$ for Case 1 and 19,624.59 $\mathrm{g}$ for Case 2. The dimensions of the pins are given in Figures 3-1, -2, $-3,-5,-6$, and -7 .

The top of one of the HEU pins extended above the top of the lower plate by $0.005842 \mathrm{~cm}$, one sat 0.00127 $\mathrm{cm}$ below the top of the lower plate, and the third was flush with the top of the lower plate for Case 1. For Case 2 two of the pins were $0.00127 \mathrm{~cm}$ below the top of the lower plate and the third pin was flush with the top of the lower plate. This yields three different pin volumes for Case 1 and two for Case 2. The pin whose center is at $(-6.35,0, \mathrm{z})$ was modeled as protruding $0.005842 \mathrm{~cm}$ above the top of the lower plate for Case 1 and $-0.00127 \mathrm{~cm}$ below the top of the lower plate for Case 2. The top of the pin whose center is at $(3.17500$, $5.49926, \mathrm{z})$ was modeled $-0.00127 \mathrm{~cm}$ below the top of the lower plate for both cases. The top of the pin whose center is at $(3.17500,-5.49926, \mathrm{z})$ was modeled flush with the top of the lower plate for both cases. It should be noted that the diametral hole was drilled through the pin in the center section whose center is at $(-6.35,0, \mathrm{z})$.

The location of the mass adjustment buttons recesses were calculated for Case 1 with respect to the center of the diametral hole and then kept constant for Case 2 (see Section 2.2.7). The average sphere radius of $8.80491 \mathrm{~cm}$ was used in these calculations.

The dimensions of the lower polar cap and lower plate for Case 1 are given in Figure 3-1 and Figure 3-2 and the bottom section of the sphere for Case 2 is given in Figure 3-3. The surface of the sphere was actually an ellipsoid and took into account the deviation from spherical of each section of the sphere by using the deviation at the pole/bottom and the top of each section to derive an ellipsoid equation. These equations took into account the fact that the sum of the heights of the sections of the sphere did not add to the average diameter of the sphere (Case 1 and 2) and the fact that the center of the sphere was $0.0508 \mathrm{~cm}$ higher than the center of the diametral hole which was the center of the model (Case 2). The equation of the resulting ellipsoid is given in Table 3-3 and Table 3-4. 
NEA/NSC/DOC(95)03/II

Volume II

HEU-MET-FAST-100

Table 3-3. Ellipsoid Coefficients for Bottom Section of Sphere, Case 1. ${ }^{\text {(a) }}$

\begin{tabular}{|cccccccc|}
\hline \multicolumn{7}{|c|}{$A x^{2}+B y^{2}+C(z-\bar{z})^{2}+G=0$} \\
\hline $\begin{array}{c}\text { Deviation From } \\
\text { Spherical }(\mathrm{cm})^{(b)}\end{array}$ & $\begin{array}{c}\mathrm{A} \\
\left(\mathrm{cm}^{-2}\right)\end{array}$ & $\begin{array}{c}\mathrm{B} \\
\left(\mathrm{cm}^{-2}\right)\end{array}$ & $\begin{array}{c}\mathrm{C} \\
\left(\mathrm{cm}^{-2}\right)\end{array}$ & $\begin{array}{c}\mathrm{G} \\
(--)\end{array}$ & $\begin{array}{c}z^{(\mathrm{c})} \\
(\mathrm{cm})\end{array}$ \\
\hline $\begin{array}{c}\text { Lower Polar } \\
\text { Cap }\end{array}$ & $\begin{array}{c}-4.75 \mathrm{E}-03 \\
\text { top }\end{array}$ & $\begin{array}{c}-5.08 \mathrm{E}-04 \\
\text { pole }\end{array}$ & 61.02204 & 61.02204 & 60.95049 & -4724.72940 & -0.004826 \\
Lower Plate & $\begin{array}{c}-2.03 \mathrm{E}-03 \\
\text { top }\end{array}$ & $\begin{array}{c}0 \text { at } \\
\text { bottom }\end{array}$ & 14.49263 & 14.49263 & 14.45685 & -1122.97037 & 0 \\
\hline \hline
\end{tabular}

(a) An example of the derivation of these coefficients is given in Appendix B.

(b) The deviation from spherical is based off a radius $8.80491 \mathrm{~cm}$.

(c) This axial shift was due to the fact that the sum of the heights of the sections did not add up to the average diameter of the sphere.

Table 3-4. Ellipsoid Coefficients for Bottom Section of Sphere, Case 2. ${ }^{\text {(a) }}$

\begin{tabular}{|c|c|c|c|c|c|c|c|}
\hline \multicolumn{8}{|c|}{$A x^{2}+B y^{2}+C(z-\bar{z})^{2}+G=0$} \\
\hline & $\begin{array}{l}\text { Deviati } \\
\text { Spheric }\end{array}$ & $\begin{array}{l}\text { n From } \\
1(\mathrm{~cm})^{(\mathrm{b})}\end{array}$ & $\begin{array}{c}\mathrm{A} \\
\left(\mathrm{cm}^{-2}\right) \\
\end{array}$ & $\begin{array}{c}\mathrm{B} \\
\left(\mathrm{cm}^{-2}\right)\end{array}$ & $\begin{array}{c}\mathrm{C} \\
\left(\mathrm{cm}^{-2}\right)\end{array}$ & $\begin{array}{c}\text { G } \\
(--)\end{array}$ & $\begin{array}{l}\bar{Z}^{(\mathrm{c})} \\
(\mathrm{cm})\end{array}$ \\
\hline Bottom Section & $\begin{array}{c}5.08 \mathrm{E}-04 \text { at } \\
\text { top }\end{array}$ & $\begin{array}{c}2.03 \mathrm{E}-03 \text { at } \\
\text { pole }\end{array}$ & 74.30313 & 74.30313 & 74.27648 & -5681.57126 & 0.050546 \\
\hline
\end{tabular}

(a) An example of the derivation of these coefficients is given in Appendix B.

(b) The deviation from spherical is based off the nominal radius of $8.74395 \mathrm{~cm}$.

(c) This axial shift was due to the fact that the sum of the heights of the sections did not add up to the average diameter of the sphere and the shift of the center of the sphere $0.0508 \mathrm{~cm}$ above the center of the diametral rod which was the center of the model. 


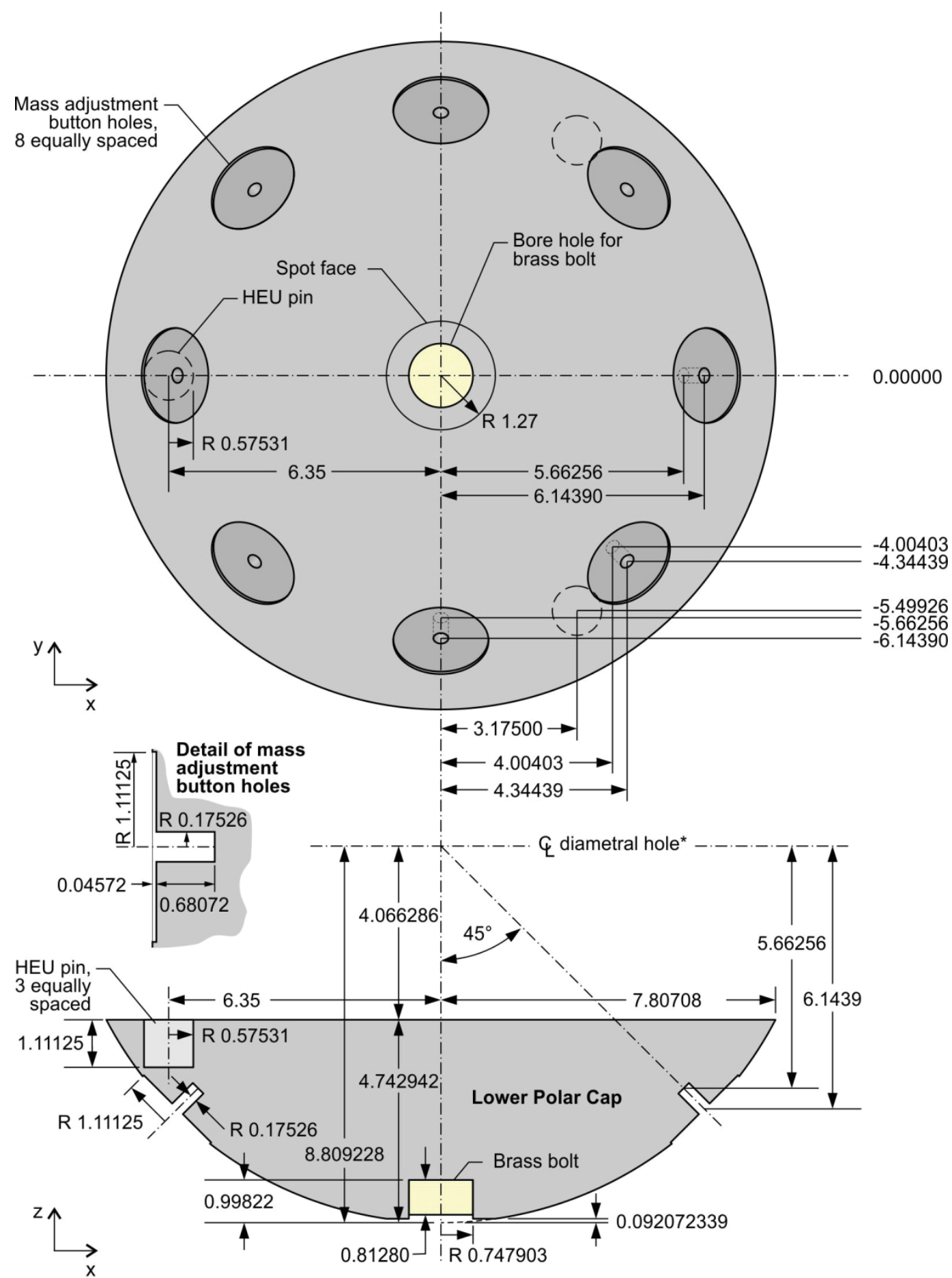

*The centerline of the diametral hole is also the centerline of the sphere Dimensions in $\mathrm{cm}$

Figure 3-1. Lower Polar Cap for Case 1 (Detailed Benchmark Model). ${ }^{\text {a }}$

${ }^{a}$ A high number of digits on dimensions have been retained not to imply high accuracy but rather to reduce rounding error in the derivation of other dimensions and the calculation of volumes. 
NEA/NSC/DOC(95)03/II

Volume II

HEU-MET-FAST-100

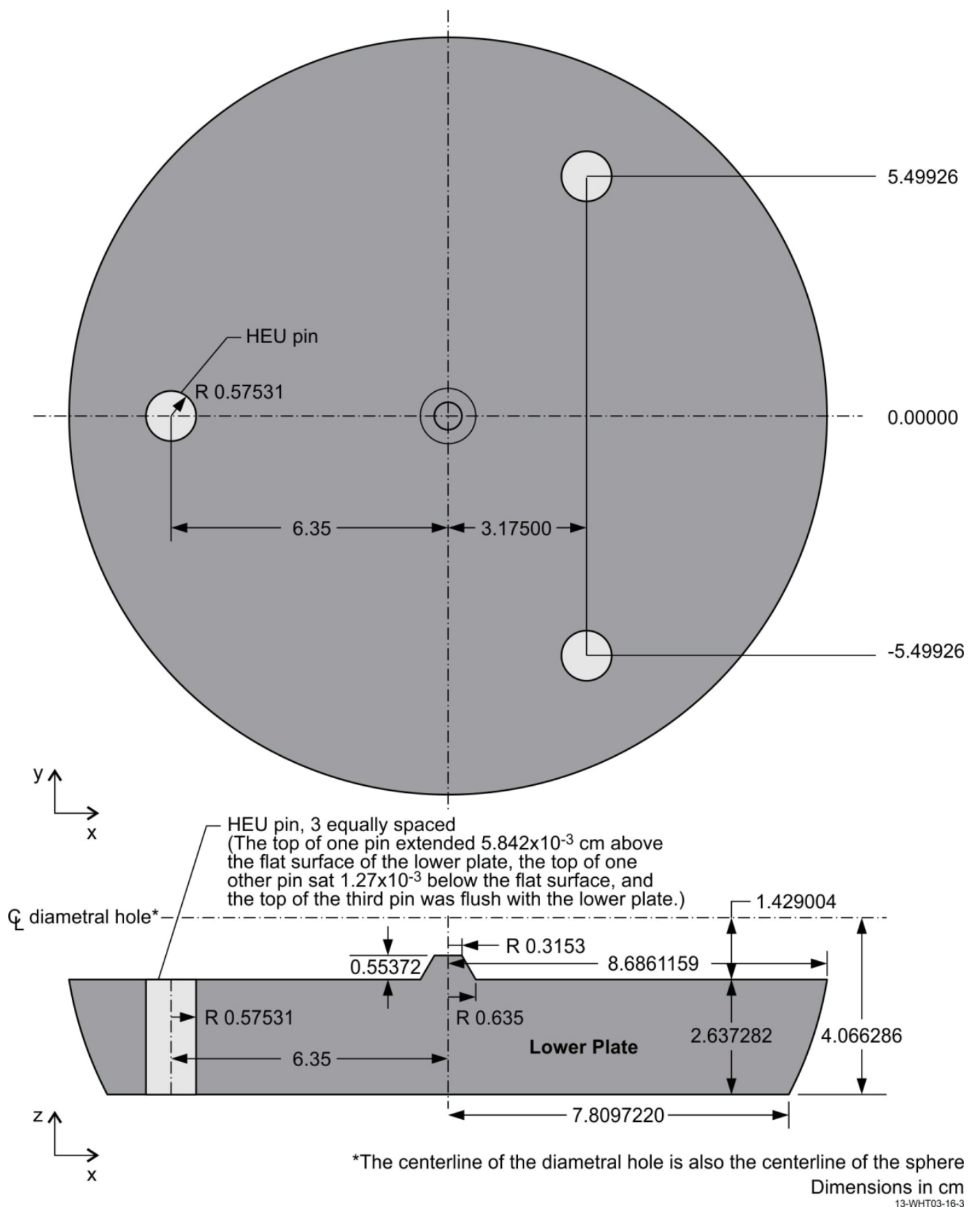

Figure 3-2. Lower Plate for Case 1(Detailed Benchmark Model). ${ }^{a}$

\footnotetext{
${ }^{a}$ A high number of digits on dimensions have been retained not to imply high accuracy but rather to reduce rounding error in the derivation of other dimensions and the calculation of volumes.

Revision: 0 


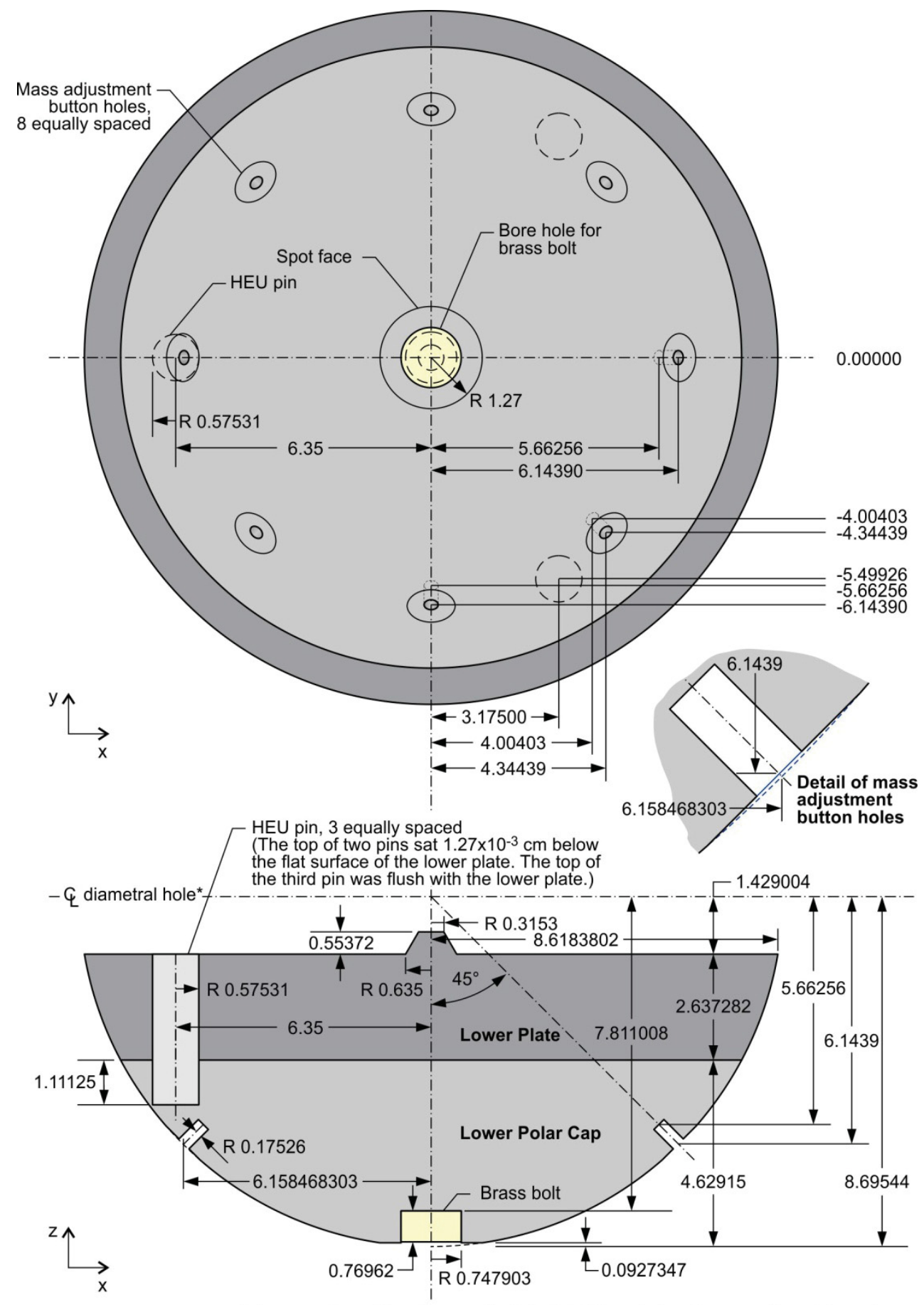

${ }^{\star}$ The centerline of the diametral hole is $0.0508 \mathrm{~cm}$ below the centerline of the sphere

Figure 3-3. Bottom Section of Sphere for Case 2.

\footnotetext{
${ }^{a}$ A high number of digits on dimensions have been retained not to imply high accuracy but rather to reduce rounding error in the derivation of other dimensions and the calculation of volumes. 
Center Section The center plate and upper plate were pinned together with HEU pins to make the center section of the sphere. For Case 1 the two sections were machined separately and then pinned together. For Case 2 the two sections were machined at the same time. The mass of the center section of sphere was 21,095.06 g for Case 1 and 20,814.95 g for Case 2. The diametral rod was $17.82953 \mathrm{~cm}$ long, was centered in the diametral hole and had a mass of $28.163 \mathrm{~g}$ for both cases. The diameter of the diametral hole was constant across the sphere and through the target hole plug. The diametral rod could move freely within the diametral hole.

The location of the center support screw holes was calculated for Case 1 with respect to the center of the diametral hole using the average radius of $8.80491 \mathrm{~cm}$ and then kept constant for Case 2 (see Section 2.2.7).

Due to a protrusion of an HEU pin above the top of the lower plate in Case 1 all plates above the center plate were tilted. The gap between the top of the lower plate and the bottom of the center plate was $0.01143 \mathrm{~cm}$ on one side of the sphere and $0 \mathrm{~cm}$ on the opposite. This corresponds to a vertical shift of $0.00351038 \mathrm{~cm}$ and an angle of 0.0231340494 degrees (see Appendix E). The benchmark model was such that the gap was on the negative $x$ side of the sphere and the plates meet on the positive $x$ side of the sphere. Using the angle of 0.0231340494 degrees the center plate would have overhung the edge of the lower plate by approximately $0.008 \mathrm{~cm}$. Because of the center support structure this would not have happened. It is believed that the calculated overhang is due to the unknown point of rotation of the center plate. If the point of rotation is fixed at the center of the plate, such that the centers of the lower and center plates remain perpendicular and, using the given vertical shift and angle, the edge of the plates are actually $\sim 3.4 \times 10^{-6} \mathrm{~cm}$ apart rather than touching. This gap is within the uncertainty in the gap between plates. At the opposite side of the plates the gap should be $0.01143 \mathrm{~cm}$, but is only $\sim 0.007 \mathrm{~cm}$. The effect of the different gap is within the uncertainty in the tilt angle. The gap is shown in Figure 3-4.

The dimensions of the center plate and upper plate for Case 1 are given in Figure 3-5 and Figure 3-6 and for Case 2 are given in Figure 3-7. Figure 3-8 shows a three-dimensional rendering of the thermocouple groove without the HEU filler. The surface of the sphere was actually an ellipsoid and took into account the deviation from spherical of each section of the sphere by using the deviation at the bottom and top of each section to derive an ellipsoid equation. For Case 1 the deviation at the center of the plate had to be used as well and was taken from Figure $1-15$ as being $-0.6 \times 10^{-3}$ in. $\left(-1.52 \times 10^{-3} \mathrm{~cm}\right)$. The equations for the ellipsoids are given in Table 3-5 and Table 3-6. 
Table 3-5. Ellipsoid Coefficients for Center of Sphere, Case 1. ${ }^{\text {(a) }}$

\begin{tabular}{|c|c|c|c|c|c|c|c|}
\hline \multicolumn{8}{|c|}{$A x^{2}+B y^{2}+C(z-\bar{z})^{2}+G=0$} \\
\hline & $\begin{array}{l}\text { Deviati } \\
\text { Spherica }\end{array}$ & $\begin{array}{l}\text { n From } \\
1(\mathrm{~cm})^{(b)}\end{array}$ & $\begin{array}{c}\mathrm{A} \\
\left(\mathrm{cm}^{-2}\right)\end{array}$ & $\begin{array}{c}\mathrm{B} \\
\left(\mathrm{cm}^{-2}\right)\end{array}$ & $\begin{array}{c}\mathrm{C} \\
\left(\mathrm{cm}^{-2}\right)\end{array}$ & $\begin{array}{l}\mathrm{G} \\
(--)\end{array}$ & $\begin{array}{c}\bar{Z} \\
(\mathrm{~cm})\end{array}$ \\
\hline $\begin{array}{l}\text { Center Plate- } \\
\text { Lower Half }\end{array}$ & $\begin{array}{c}-2.54 \mathrm{E}-03 \text { at } \\
\text { bottom }\end{array}$ & $\begin{array}{c}-1.52 \mathrm{E}-03 \text { at } \\
\text { center }\end{array}$ & 2.042052 & 2.042052 & 2.05994 & -158.25826 & 0 \\
\hline $\begin{array}{l}\text { Center Plate- } \\
\text { Upper Half }\end{array}$ & $\begin{array}{c}-1.52 \mathrm{E}-03 \text { at } \\
\text { center }\end{array}$ & $\begin{array}{c}-5.08 \mathrm{E}-04 \text { at } \\
\text { top }\end{array}$ & 2.042052 & 2.042052 & 2.024163 & -158.25826 & 0 \\
\hline Upper Plate & $\begin{array}{c}-2.54 \mathrm{E}-03 \text { at } \\
\text { bottom }\end{array}$ & $\begin{array}{c}-5.08 \mathrm{E}-04 \text { at } \\
\text { top }\end{array}$ & 9.349599 & 9.349599 & 9.313822 & -724.34990 & 0 \\
\hline
\end{tabular}

(a) An example of the derivation of these coefficients is given in Appendix B.

(b) The deviation from spherical is based off a radius $8.80491 \mathrm{~cm}$.

Table 3-6. Ellipsoid Coefficients for Center Section of Sphere, Case 2. ${ }^{\text {(a) }}$

\begin{tabular}{|c|c|c|c|c|c|c|c|}
\hline \multicolumn{8}{|c|}{$A x^{2}+B y^{2}+C(z-\bar{z})^{2}+G=0$} \\
\hline & $\begin{array}{l}\text { Deviati } \\
\text { Spheric }\end{array}$ & $\begin{array}{l}\text { n From } \\
1(\mathrm{~cm})^{(\mathrm{b})}\end{array}$ & $\begin{array}{c}\mathrm{A} \\
\left(\mathrm{cm}^{-2}\right)\end{array}$ & $\begin{array}{c}\mathrm{B} \\
\left(\mathrm{cm}^{-2}\right)\end{array}$ & $\begin{array}{c}\mathrm{C} \\
\left(\mathrm{cm}^{-2}\right)\end{array}$ & $\begin{array}{c}\mathrm{G} \\
(--)\end{array}$ & $\begin{array}{c}\bar{Z} \\
(\mathrm{~cm})\end{array}$ \\
\hline Center Section & $\begin{array}{c}-7.37 \mathrm{E}-03 \text { at } \\
\text { bottom }\end{array}$ & $\begin{array}{c}-4.32 \mathrm{E}-03 \text { at } \\
\text { Top }\end{array}$ & 9.3496 & 9.3496 & 9.29633 & -713.52645 & 0 \\
\hline
\end{tabular}

(a) An example of the derivation of these coefficients is given in Appendix B.

(b) The deviation from spherical is based off the nominal radius of $8.74395 \mathrm{~cm}$. 
NEA/NSC/DOC(95)03/II

Volume II

HEU-MET-FAST-100

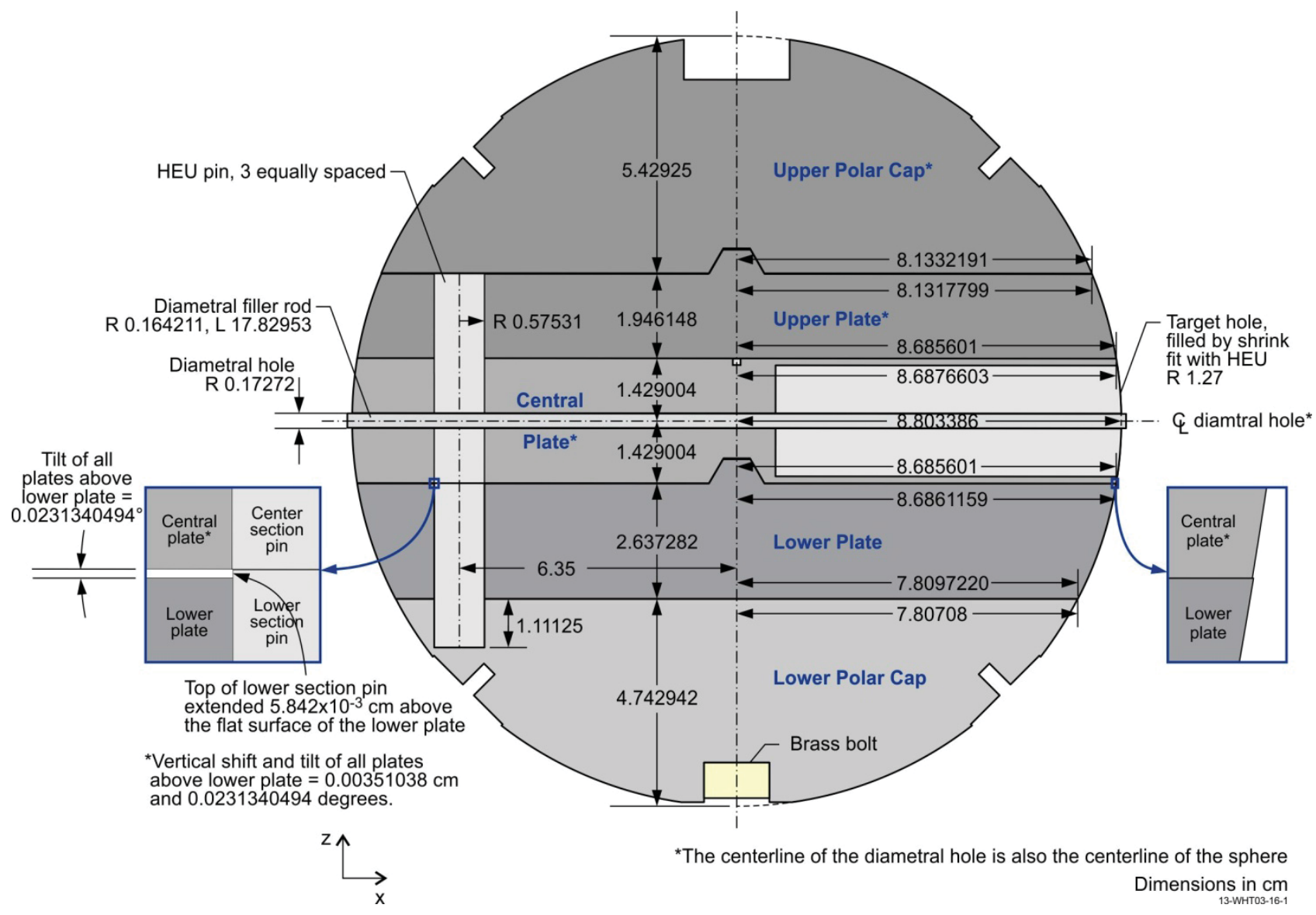

Figure 3-4. Tilt Between Lower Plate and Center Plate, Case 1(Detailed Benchmark Model). ${ }^{\text {a }}$

${ }^{a}$ A high number of digits on dimensions have been retained not to imply high accuracy but rather to reduce rounding error in the derivation of other dimensions and the calculation of volumes.

Revision: 0 


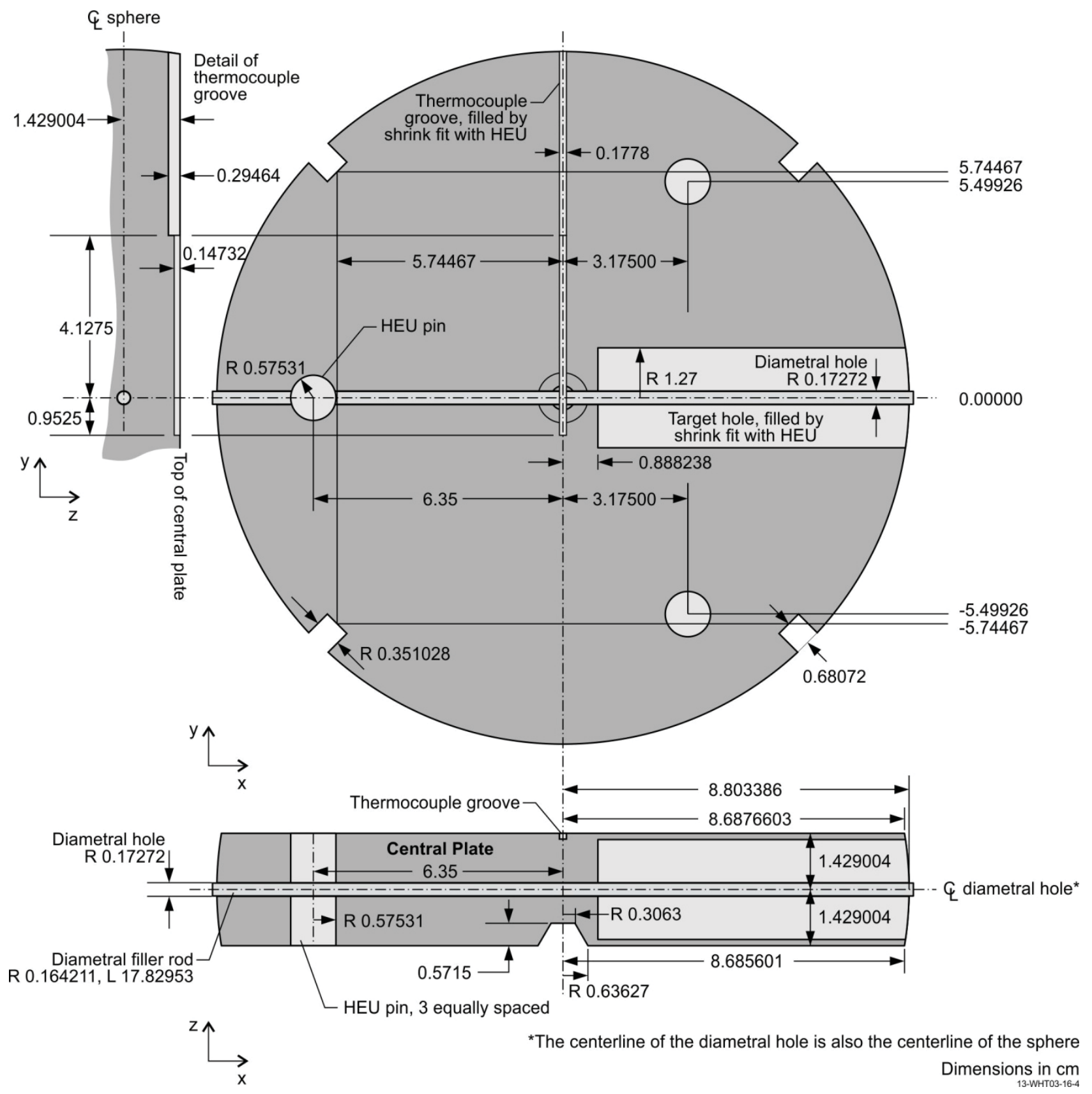

Figure 3-5. Center Plate, Case 1(Detailed Benchmark Model). ${ }^{\mathrm{a}}$

\footnotetext{
${ }^{a}$ A high number of digits on dimensions have been retained not to imply high accuracy but rather to reduce rounding error in the derivation of other dimensions and the calculation of volumes.

Revision: 0 


\section{NEA/NSC/DOC(95)03/II}

Volume II

\section{HEU-MET-FAST-100}

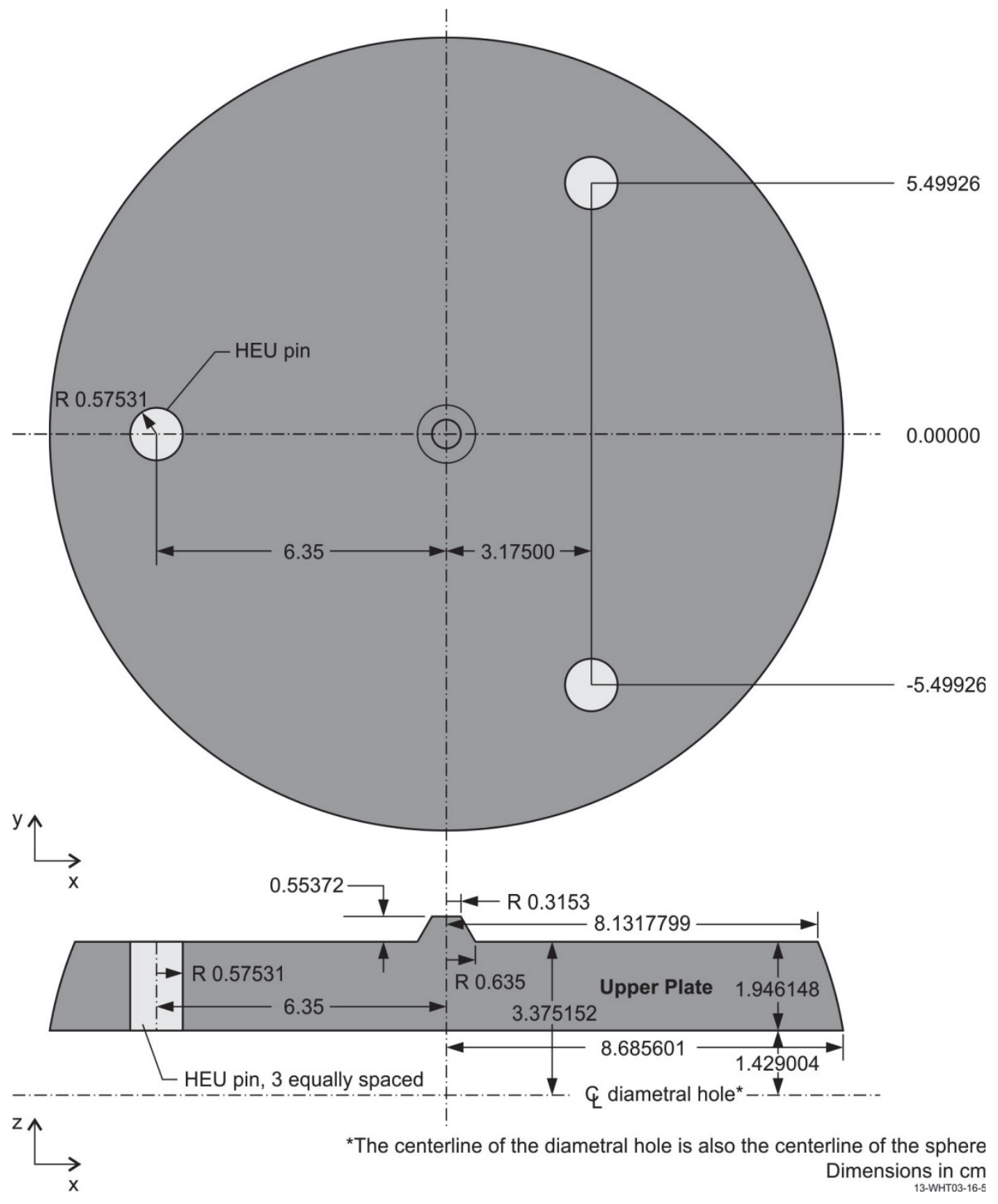

Figure 3-6. Upper Plate, Case 1(Detailed Benchmark Model). ${ }^{\mathrm{a}}$

\footnotetext{
${ }^{a}$ A high number of digits on dimensions have been retained not to imply high accuracy but rather to reduce rounding error in the derivation of other dimensions and the calculation of volumes. 

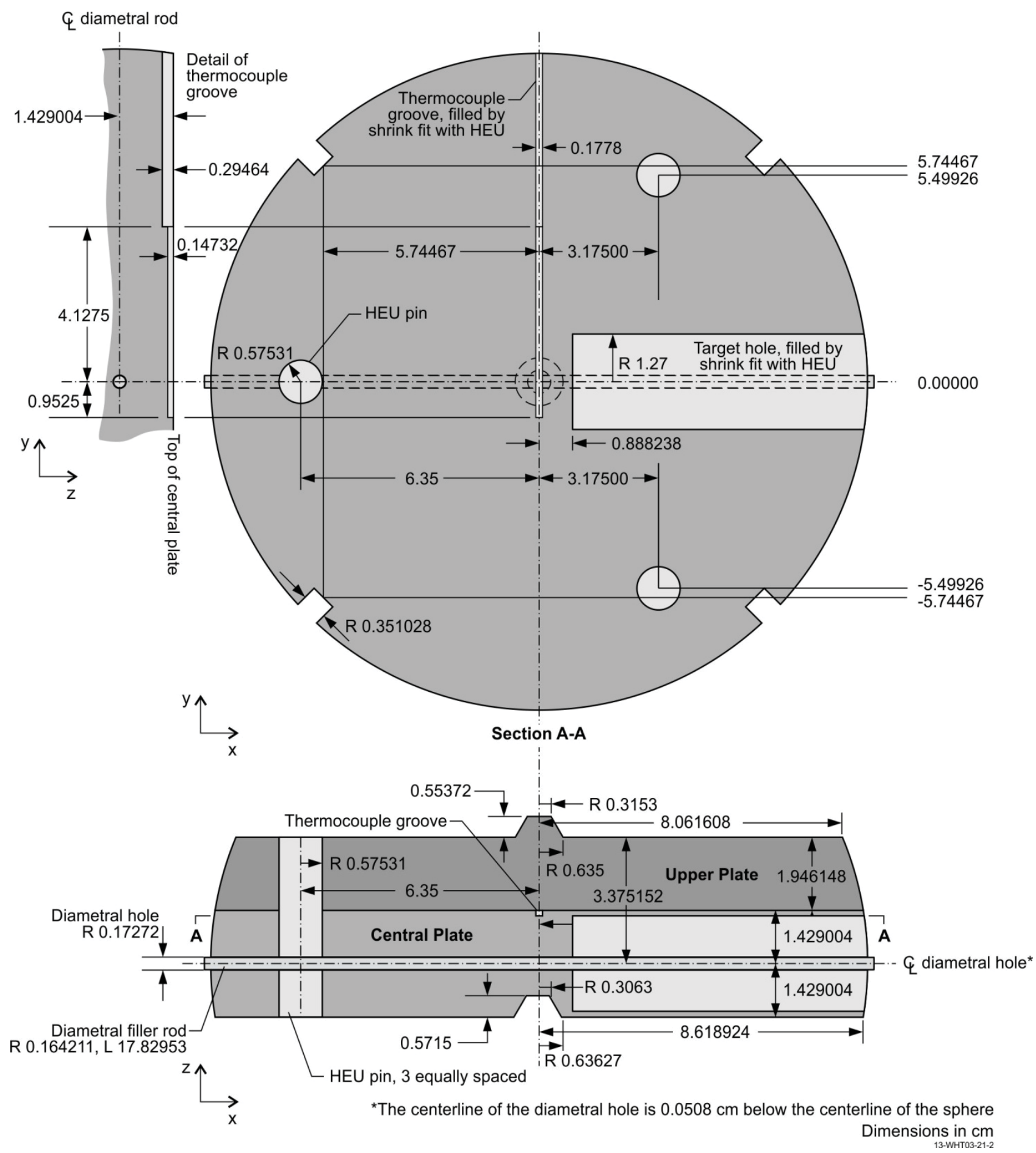

Figure 3-7. Center and Upper Plate, Case 2 (Detailed Benchmark Model). ${ }^{a}$

\footnotetext{
${ }^{a}$ A high number of digits on dimensions have been retained not to imply high accuracy but rather to reduce rounding error in the derivation of other dimensions and the calculation of volumes.

Revision: 0 


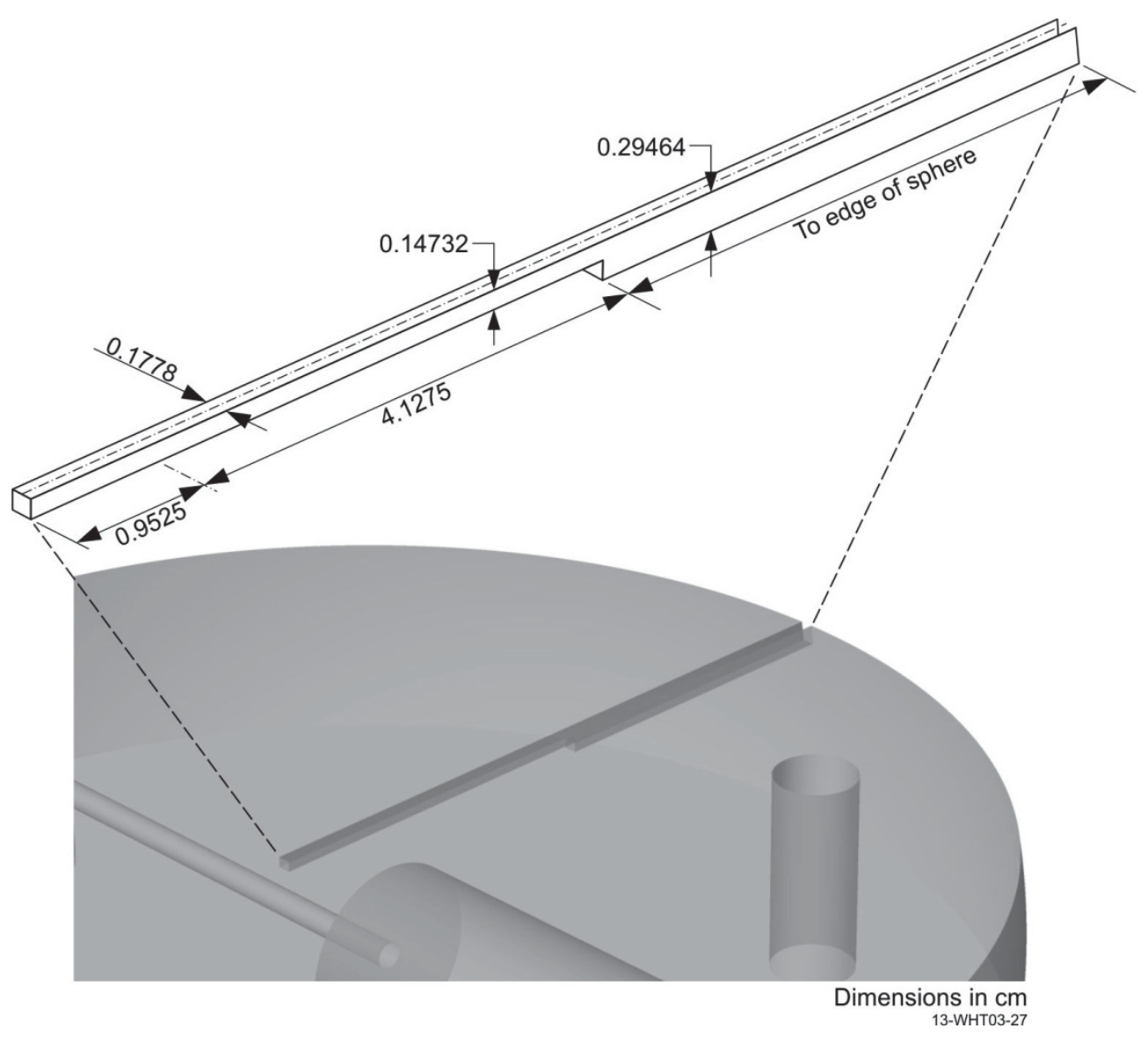

Figure 3-8. Thermocouple Groove in Center Plate, Groove is Filled with HEU, Case 2 (Detailed Benchmark Model).

Top Section The upper polar cap was the top section of the sphere for Case 1 and 2. The mass of the upper polar cap was 12,042.76 g for Case 1 and 11,883.24 g for Case 2.

The location of the mass adjustment buttons-recesses were calculated for Case 1 with respect to the center of the diametral hole and then kept constant for Case 2. The average sphere radius of $8.80491 \mathrm{~cm}$ was used in these calculations.

The dimensions of the upper polar cap are given in Figure 3-9 and Figure 3-10 for Case 1 and 2, respectively. The surface of the sphere was actually an ellipsoid and took into account the deviation from spherical by using the deviation at the bottom and the top pole of the upper polar cap to derive an ellipsoid equation. These equations took into account the fact that the sum of the heights of the sections of the sphere did not add up to the average diameter of the sphere (Case 1 and 2) and the fact that the center of the sphere was $0.0508 \mathrm{~cm}$ higher than the center of the diametral hole which was the center of the model in Case 2 . The equations of the resulting ellipsoids are given in Table 3-7 and Table 3-8. 
Table 3-7. Ellipsoid Coefficients for Top Section of Sphere, Case 1. ${ }^{\text {(a) }}$

\begin{tabular}{|c|c|c|c|c|c|c|c|}
\hline \multicolumn{8}{|c|}{$A x^{2}+B y^{2}+C(z-\bar{z})^{2}+G=0$} \\
\hline & $\begin{array}{l}\text { Deviation } \\
\text { Spherical }\end{array}$ & $\begin{array}{l}\text { From } \\
\mathrm{cm})^{(\mathrm{b})}\end{array}$ & $\begin{array}{c}\mathrm{A} \\
\left(\mathrm{cm}^{-2}\right)\end{array}$ & $\begin{array}{c}\mathrm{B} \\
\left(\mathrm{cm}^{-2}\right)\end{array}$ & $\begin{array}{c}\mathrm{C} \\
\left(\mathrm{cm}^{-2}\right)\end{array}$ & $\begin{array}{c}G \\
(--)\end{array}$ & $\begin{array}{l}\bar{Z}^{(\mathrm{c})} \\
(\mathrm{cm})\end{array}$ \\
\hline $\begin{array}{c}\text { Upper Polar } \\
\text { Cap }\end{array}$ & $\begin{array}{l}\text { 1.02E-03 at } \\
\text { Bottom }\end{array}$ & $\begin{array}{l}0.0 \text { at } \\
\text { Top }\end{array}$ & 66.13136 & 66.13136 & 66.14925 & -5128.31605 & -0.000508 \\
\hline
\end{tabular}

(a) An example of the derivation of these coefficients is given in Appendix B.

(b) The deviation from spherical is based off a radius $8.80491 \mathrm{~cm}$.

(c) This axial shift was due to the fact that the sum of the heights of the sections did not add up to the average diameter of the sphere and the shift of the center of the sphere $0.0508 \mathrm{~cm}$ above the center of the diametral hole which was the center of the model.

Table 3-8. Ellipsoid Coefficients for Top Section of Sphere, Case 2. ${ }^{\text {(a) }}$

\begin{tabular}{|c|c|c|c|c|c|c|c|}
\hline \multicolumn{8}{|c|}{$A x^{2}+B y^{2}+C(z-\bar{z})^{2}+G=0$} \\
\hline & $\begin{array}{l}\text { Deviati } \\
\text { Spherica }\end{array}$ & $\begin{array}{l}\text { From } \\
(\mathrm{cm})^{(\mathrm{b})}\end{array}$ & $\begin{array}{c}\mathrm{A} \\
\left(\mathrm{cm}^{-2}\right)\end{array}$ & $\begin{array}{c}\mathrm{B} \\
\left(\mathrm{cm}^{-2}\right)\end{array}$ & $\begin{array}{c}\mathrm{C} \\
\left(\mathrm{cm}^{-2}\right)\end{array}$ & $\begin{array}{c}\mathrm{G} \\
(--)\end{array}$ & $\begin{array}{l}\bar{Z}^{(\mathrm{c})} \\
(\mathrm{cm})\end{array}$ \\
\hline $\begin{array}{c}\text { Upper Polar } \\
\text { Cap }\end{array}$ & $\begin{array}{c}-1.27 \mathrm{E}-03 \text { at } \\
\text { bottom }\end{array}$ & $\begin{array}{c}3.05 \mathrm{E}-03 \text { at } \\
\text { top }\end{array}$ & 65.4299 & 65.4299 & 65.3544 & -5000.26418 & 0.046482 \\
\hline
\end{tabular}

(a) An example of the derivation of these coefficients is given in Appendix B.

(b) The deviation from spherical is based on the nominal radius of $8.74395 \mathrm{~cm}$.

(c) This axial shift was due to the fact that the sum of the heights of the sections did not add up to the average diameter of the sphere and the shift of the center of the sphere $0.0508 \mathrm{~cm}$ above the center of the diametral hole which was the center of the model. 


\section{NEA/NSC/DOC(95)03/II \\ Volume II}

\section{HEU-MET-FAST-100}

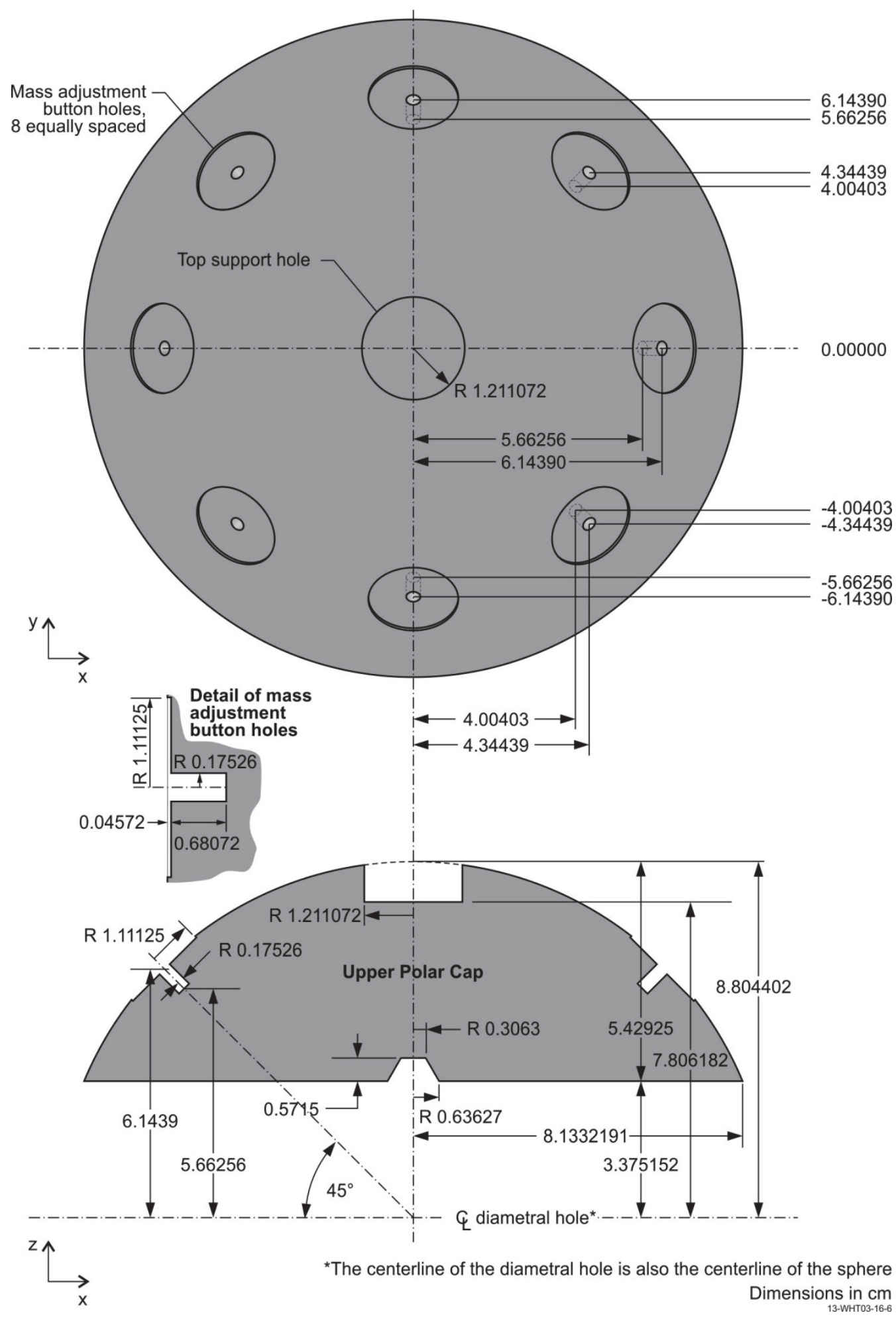

Figure 3-9. Upper Polar Cap for Case 1(Detailed Benchmark Model). ${ }^{a}$

\footnotetext{
${ }^{a}$ A high number of digits on dimensions have been retained not to imply high accuracy but rather to reduce rounding error in the derivation of other dimensions and the calculation of volumes. 


\section{NEA/NSC/DOC(95)03/II \\ Volume II}

\section{HEU-MET-FAST-100}

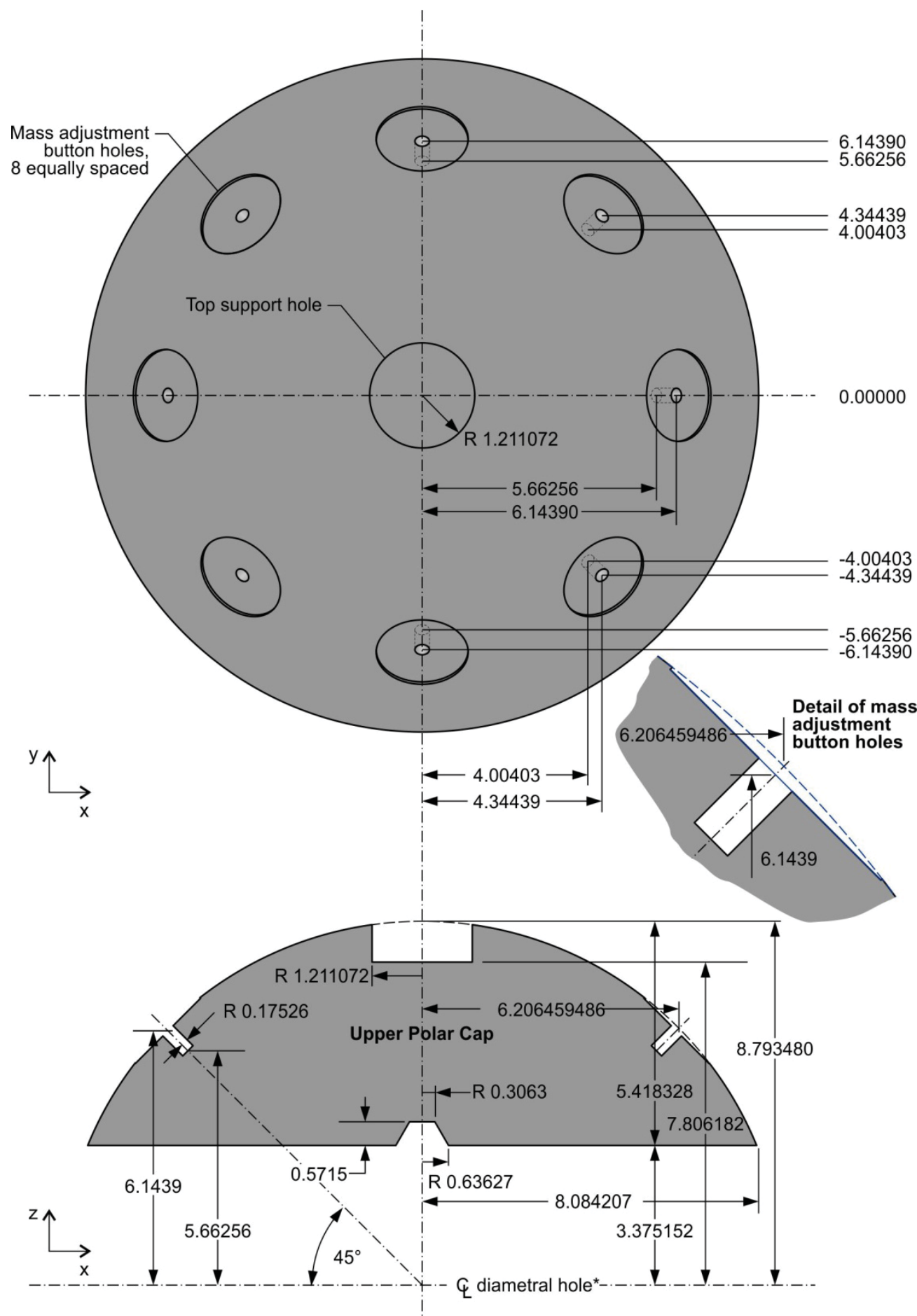

${ }^{*}$ The centerline of the diametral hole is $0.0508 \mathrm{~cm}$ below the centerline of the sphere Dimensions in $\mathrm{cm}$

Figure 3-10. Upper Polar Cap for Case 2 (Detailed Benchmark Model). ${ }^{a}$

\footnotetext{
${ }^{a}$ A high number of digits on dimensions have been retained not to imply high accuracy but rather to reduce rounding error in the derivation of other dimensions and the calculation of volumes. 


\subsubsection{Description of Simple Benchmark Model}

The simple benchmark model was a solid sphere of uranium. Mass and mass density were conserved. The mass of the sphere was the sum of the masses of the bottom, center, and top section of sphere, and the mass of the diametral filler rod. These masses are given in Table 3-9.

Table 3-9. Uranium Masses in Simple Benchmark Model.

\begin{tabular}{|ccc|}
\hline Sphere Section & $\begin{array}{c}\text { Case 1 } \\
\text { Mass }(\mathrm{g})\end{array}$ & $\begin{array}{c}\text { Case 2 } \\
\text { Mass }(\mathrm{g})\end{array}$ \\
\hline Bottom & 20,310 & $19,624.59$ \\
\hline Center & $21,095.06$ & $20,814.95$ \\
\hline Top & $12,042.76$ & $11,883.24$ \\
\hline Diametral Filler Rod & 28.163 & 28.163 \\
\hline Total & $53,475.983$ & $52,350.943$ \\
\hline
\end{tabular}

The total uranium volume of each sphere was calculated, using part dimensions, as being $2,845.486142 \mathrm{~cm}^{3}$ for Case 1 and 2,786.924436 $\mathrm{cm}^{3}$ for Case 2 (see Appendix C). The resulting sphere radii were 8.79068305 $\mathrm{cm}$ and $8.72995881 \mathrm{~cm}$ for Cases 1 and 2, respectively. ${ }^{\mathrm{a}}$

\subsection{Material Data}

\subsubsection{Material Data of Detailed Benchmark Model}

The material data for the uranium in the detailed benchmark model is given in Table 3-10 through Table 315.

\footnotetext{
${ }^{a}$ The density varies between Case 1 and Case $2\left(18.7933\right.$ and $\left.18.7845 \mathrm{~g} / \mathrm{cm}^{3}\right)$. This inconsistency is discussed in Section 2.2.2. 


\section{NEA/NSC/DOC(95)03/II \\ Volume II}

HEU-MET-FAST-100

Table 3-10. Uranium Masses in Bottom Section of Detailed Benchmark Model, Case 1.

\begin{tabular}{|rccc||}
\hline & \multicolumn{3}{c||}{ Atom Density (atom/b-cm) } \\
\cline { 2 - 4 } $\begin{array}{c}\text { Element } \\
\text { Isotope }\end{array}$ & Lower Polar Cap & Lower Plate & Lower Section Pins \\
\hline \hline U Total & $4.8117 \mathrm{E}-02$ & $4.8119 \mathrm{E}-02$ & $4.8120 \mathrm{E}-02$ \\
\hline${ }^{234} U$ & $4.7588 E-04$ & $4.7609 E-04$ & $4.8136 \mathrm{E}-04$ \\
${ }^{235} U$ & $4.4867 \mathrm{E}-02$ & $4.4888 \mathrm{E}-02$ & $4.4856 \mathrm{E}-02$ \\
${ }^{236} U$ & $1.7222 \mathrm{E}-05$ & $1.7228 \mathrm{E}-05$ & $2.1624 \mathrm{E}-04$ \\
\hline${ }^{238} \mathrm{U}$ & $2.7575 \mathrm{E}-03$ & $2.7383 \mathrm{E}-03$ & $2.5662 \mathrm{E}-03$ \\
\hline $\mathrm{Be}$ & $6.2845 \mathrm{E}-09$ & $6.2824 \mathrm{E}-09$ & - \\
\hline $\mathrm{Li}$ & $1.6320 \mathrm{E}-07$ & $1.6314 \mathrm{E}-07$ & - \\
\hline $\mathrm{Al}$ & $2.0991 \mathrm{E}-06$ & $3.3575 \mathrm{E}-06$ & $2.0984 \mathrm{E}-06$ \\
\hline $\mathrm{Si}$ & $4.0332 \mathrm{E}-05$ & $5.0398 \mathrm{E}-05$ & $4.8381 \mathrm{E}-05$ \\
\hline $\mathrm{Mn}$ & $5.0977 \mathrm{E}-06$ & $3.4996 \mathrm{E}-06$ & $3.8065 \mathrm{E}-06$ \\
\hline $\mathrm{Ni}$ & $8.5210 \mathrm{E}-06$ & $5.8498 \mathrm{E}-06$ & $6.3628 \mathrm{E}-06$ \\
\hline $\mathrm{Cr}$ & $6.7326 \mathrm{E}-07$ & $4.6220 \mathrm{E}-07$ & $5.0274 \mathrm{E}-07$ \\
\hline $\mathrm{Cu}$ & $1.9675 \mathrm{E}-06$ & $1.3507 \mathrm{E}-06$ & $1.4691 \mathrm{E}-06$ \\
\hline $\mathrm{B}$ & $1.0478 \mathrm{E}-07$ & $5.2371 \mathrm{E}-07$ & $3.1422 \mathrm{E}-07$ \\
\hline $\mathrm{Co}$ & $9.6105 \mathrm{E}-08$ & $9.6073 \mathrm{E}-08$ & - \\
\hline $\mathrm{Ca}$ & $1.4132 \mathrm{E}-06$ & $1.4127 \mathrm{E}-06$ & - \\
\hline $\mathrm{C}$ & $1.6881 \mathrm{E}-04$ & $1.3387 \mathrm{E}-04$ & $1.5838 \mathrm{E}-04$ \\
\hline $\mathrm{O}$ & $1.4160 \mathrm{E}-05$ & $1.4155 \mathrm{E}-05$ & $1.4155 \mathrm{E}-05$ \\
\hline $\mathrm{N}$ & $2.4262 \mathrm{E}-05$ & $2.4254 \mathrm{E}-05$ & $2.4253 \mathrm{E}-05$ \\
\hline $\mathrm{Total}$ & $4.8385 \mathrm{E}-02$ & $4.8359 \mathrm{E}-02$ & $4.8380 \mathrm{E}-02$ \\
\hline \hline
\end{tabular}




\section{NEA/NSC/DOC(95)03/II \\ Volume II}

HEU-MET-FAST-100

Table 3-11. Uranium Masses in Bottom Section of Detailed Benchmark Model, Case 2.

\begin{tabular}{|c|c|c|c|}
\hline \multirow[b]{2}{*}{$\begin{array}{l}\text { Element/ } \\
\text { Isotope }\end{array}$} & \multicolumn{3}{|c|}{ Atom Density (atom/b-cm) } \\
\hline & Lower Polar Cap & Lower Plate & Lower Section Pins \\
\hline U Total & $4.7980 \mathrm{E}-02$ & 4.7982E-02 & 4.7983E-02 \\
\hline${ }^{234} U$ & $4.7452 E-04$ & $4.7473 E-04$ & $4.7998 E-04$ \\
\hline${ }^{235} \mathrm{U}$ & $4.4739 E-02$ & $4.4760 E-02$ & $4.4728 E-02$ \\
\hline${ }^{236} U$ & $1.7173 E-05$ & $1.7179 E-05$ & $2.1562 E-04$ \\
\hline${ }^{238} U$ & $2.7496 E-03$ & $2.7305 E-03$ & $2.5589 E-03$ \\
\hline $\mathrm{Be}$ & $6.2666 \mathrm{E}-09$ & $6.2645 \mathrm{E}-09$ & - \\
\hline $\mathrm{Li}$ & $1.6273 \mathrm{E}-07$ & $1.6268 \mathrm{E}-07$ & - \\
\hline $\mathrm{Al}$ & 2.0931E-06 & $3.3479 \mathrm{E}-06$ & 2.0924E-06 \\
\hline $\mathrm{Si}$ & 4.0217E-05 & $5.0255 \mathrm{E}-05$ & 4.8243E-05 \\
\hline $\mathrm{Mn}$ & $5.0831 \mathrm{E}-06$ & $3.4896 \mathrm{E}-06$ & $3.7956 \mathrm{E}-06$ \\
\hline $\mathrm{Ni}$ & $8.4967 \mathrm{E}-06$ & $5.8331 \mathrm{E}-06$ & $6.3446 \mathrm{E}-06$ \\
\hline $\mathrm{Cr}$ & $6.7134 \mathrm{E}-07$ & $4.6088 \mathrm{E}-07$ & $5.0130 \mathrm{E}-07$ \\
\hline $\mathrm{Cu}$ & $1.9618 \mathrm{E}-06$ & $1.3468 \mathrm{E}-06$ & $1.4649 \mathrm{E}-06$ \\
\hline $\mathrm{B}$ & $1.0448 \mathrm{E}-07$ & $5.2222 \mathrm{E}-07$ & $3.1332 \mathrm{E}-07$ \\
\hline $\mathrm{Co}$ & $9.5830 \mathrm{E}-08$ & $9.5798 \mathrm{E}-08$ & - \\
\hline $\mathrm{Ca}$ & $1.4091 \mathrm{E}-06$ & $1.4087 \mathrm{E}-06$ & - \\
\hline $\mathrm{C}$ & $1.6833 \mathrm{E}-04$ & $1.3349 \mathrm{E}-04$ & $1.5793 \mathrm{E}-04$ \\
\hline $\mathrm{O}$ & 1.4119E-05 & $1.4115 \mathrm{E}-05$ & $1.4114 \mathrm{E}-05$ \\
\hline $\mathrm{N}$ & 2.4192E-05 & $2.4184 \mathrm{E}-05$ & $2.4184 \mathrm{E}-05$ \\
\hline Total & 4.8247E-02 & $4.8221 \mathrm{E}-02$ & 4.8242E-02 \\
\hline
\end{tabular}


NEA/NSC/DOC(95)03/II
Volume II

HEU-MET-FAST-100

Table 3-12. Uranium Masses in Center Section of

Detailed Benchmark Model, Case 1.

\begin{tabular}{|c|c|c|c|c|}
\hline \multirow[b]{2}{*}{$\begin{array}{l}\text { Element/ } \\
\text { Isotope }\end{array}$} & \multicolumn{4}{|c|}{ Atom Density (atom/b-cm) } \\
\hline & Central Plate & Upper Plate & $\begin{array}{l}\text { Pins for Center } \\
\text { Section }\end{array}$ & $\begin{array}{c}\text { Plug for Target Hole } \\
\text { and Thermocouple } \\
\text { Groove }\end{array}$ \\
\hline U Total & 4.8045E-02 & 4.8051E-02 & $4.8050 \mathrm{E}-02$ & $4.8050 \mathrm{E}-02$ \\
\hline${ }^{234} U$ & $4.7526 E-04$ & $4.7537 E-04$ & $4.7611 E-04$ & $4.8065 E-04$ \\
\hline${ }^{235} U$ & $4.4809 E-02$ & $4.4819 E-02$ & $4.4798 E-02$ & $4.4791 E-02$ \\
\hline${ }^{236} U$ & $1.7196 E-05$ & $1.7203 E-05$ & $2.0300 E-04$ & $2.1593 E-04$ \\
\hline${ }^{238} U$ & $2.7437 E-03$ & $2.7392 E-03$ & $2.5726 E-03$ & $2.5625 E-03$ \\
\hline $\mathrm{Be}$ & $6.2717 \mathrm{E}-09$ & $6.2724 \mathrm{E}-09$ & - & - \\
\hline $\mathrm{Li}$ & $1.6286 \mathrm{E}-07$ & $1.6288 \mathrm{E}-07$ & - & - \\
\hline $\mathrm{Al}$ & $1.6759 \mathrm{E}-06$ & $1.6761 \mathrm{E}-06$ & $2.0953 \mathrm{E}-06$ & 2.0953E-06 \\
\hline $\mathrm{Si}$ & $8.0500 \mathrm{E}-05$ & $4.0255 \mathrm{E}-05$ & $4.8311 \mathrm{E}-05$ & 4.8311E-05 \\
\hline $\mathrm{Mn}$ & $3.0646 \mathrm{E}-06$ & $2.0842 \mathrm{E}-06$ & $3.8010 \mathrm{E}-06$ & $3.8010 \mathrm{E}-06$ \\
\hline $\mathrm{Ni}$ & $5.1226 \mathrm{E}-06$ & $3.4838 \mathrm{E}-06$ & $6.3535 \mathrm{E}-06$ & $6.3535 \mathrm{E}-06$ \\
\hline $\mathrm{Cr}$ & $4.0475 \mathrm{E}-07$ & $2.7526 \mathrm{E}-07$ & $5.0200 \mathrm{E}-07$ & $5.0200 \mathrm{E}-07$ \\
\hline $\mathrm{Cu}$ & $1.1828 \mathrm{E}-06$ & $8.0440 \mathrm{E}-07$ & $1.4670 \mathrm{E}-06$ & $1.4670 \mathrm{E}-06$ \\
\hline $\mathrm{B}$ & 2.0913E-07 & $3.1373 \mathrm{E}-07$ & $3.1376 \mathrm{E}-07$ & $3.1376 \mathrm{E}-07$ \\
\hline $\mathrm{Co}$ & $9.5908 \mathrm{E}-08$ & $9.5919 \mathrm{E}-08$ & - & - \\
\hline $\mathrm{Ca}$ & $1.4103 \mathrm{E}-06$ & $1.4105 \mathrm{E}-06$ & - & - \\
\hline $\mathrm{C}$ & $1.4965 \mathrm{E}-04$ & $1.4966 \mathrm{E}-04$ & $1.5815 \mathrm{E}-04$ & $1.5815 \mathrm{E}-04$ \\
\hline $\mathrm{O}$ & $1.4131 \mathrm{E}-05$ & $1.4133 \mathrm{E}-05$ & $1.4134 \mathrm{E}-05$ & $1.4134 \mathrm{E}-05$ \\
\hline $\mathrm{N}$ & $2.4212 \mathrm{E}-05$ & $2.4215 \mathrm{E}-05$ & $2.4217 \mathrm{E}-05$ & $2.4217 \mathrm{E}-05$ \\
\hline Total & 4.8327E-02 & 4.8289E-02 & 4.8309E-02 & 4.8309E-02 \\
\hline
\end{tabular}


NEA/NSC/DOC(95)03/II

Volume II

HEU-MET-FAST-100

Table 3-13. Uranium Masses in Center Section of

Detailed Benchmark Model, Case 2.

\begin{tabular}{|c|c|c|c|c|}
\hline \multirow[b]{2}{*}{$\begin{array}{l}\text { Element/ } \\
\text { Isotope }\end{array}$} & \multicolumn{4}{|c|}{ Atom Density (atom/b-cm) } \\
\hline & Central Plate & Upper Plate & $\begin{array}{l}\text { Pins for Center } \\
\text { Section }\end{array}$ & $\begin{array}{c}\text { Plug for Target Hole } \\
\text { and Thermocouple } \\
\text { Groove }\end{array}$ \\
\hline U Total & 4.8157E-02 & 4.8162E-02 & $4.8161 \mathrm{E}-02$ & $4.8161 \mathrm{E}-02$ \\
\hline${ }^{234} U$ & $4.7637 E-04$ & $4.7647 E-04$ & $4.7722 E-04$ & $4.8177 E-04$ \\
\hline${ }^{235} U$ & $4.4913 E-02$ & $4.4923 E-02$ & $4.4902 E-02$ & $4.4895 E-02$ \\
\hline${ }^{236} U$ & $1.7236 E-05$ & $1.7243 E-05$ & $2.0347 E-04$ & $2.1643 E-04$ \\
\hline${ }^{238} U$ & $2.7501 E-03$ & $2.7456 E-03$ & $2.5786 E-03$ & $2.5684 E-03$ \\
\hline $\mathrm{Be}$ & $6.2863 \mathrm{E}-09$ & $6.2870 \mathrm{E}-09$ & - & - \\
\hline $\mathrm{Li}$ & $1.6324 \mathrm{E}-07$ & $1.6326 \mathrm{E}-07$ & - & - \\
\hline $\mathrm{Al}$ & $1.6798 \mathrm{E}-06$ & $1.6800 \mathrm{E}-06$ & 2.1002E-06 & 2.1002E-06 \\
\hline $\mathrm{Si}$ & $8.0687 \mathrm{E}-05$ & $4.0348 \mathrm{E}-05$ & 4.8423E-05 & 4.8423E-05 \\
\hline $\mathrm{Mn}$ & $3.0717 \mathrm{E}-06$ & $2.0890 \mathrm{E}-06$ & $3.8098 \mathrm{E}-06$ & $3.8098 \mathrm{E}-06$ \\
\hline $\mathrm{Ni}$ & $5.1345 \mathrm{E}-06$ & $3.4919 \mathrm{E}-06$ & $6.3683 \mathrm{E}-06$ & $6.3683 \mathrm{E}-06$ \\
\hline $\mathrm{Cr}$ & $4.0569 \mathrm{E}-07$ & $2.7590 \mathrm{E}-07$ & $5.0317 \mathrm{E}-07$ & $5.0317 \mathrm{E}-07$ \\
\hline $\mathrm{Cu}$ & $1.1855 \mathrm{E}-06$ & $8.0626 \mathrm{E}-07$ & $1.4704 \mathrm{E}-06$ & $1.4704 \mathrm{E}-06$ \\
\hline $\mathrm{B}$ & $2.0961 \mathrm{E}-07$ & $3.1446 \mathrm{E}-07$ & $3.1449 \mathrm{E}-07$ & $3.1449 \mathrm{E}-07$ \\
\hline $\mathrm{Co}$ & $9.6131 \mathrm{E}-08$ & $9.6142 \mathrm{E}-08$ & - & - \\
\hline $\mathrm{Ca}$ & $1.4136 \mathrm{E}-06$ & $1.4137 \mathrm{E}-06$ & - & - \\
\hline $\mathrm{C}$ & 1.4999E-04 & $1.5001 \mathrm{E}-04$ & $1.5852 \mathrm{E}-04$ & $1.5852 \mathrm{E}-04$ \\
\hline $\mathrm{O}$ & $1.4164 \mathrm{E}-05$ & $1.4165 \mathrm{E}-05$ & $1.4167 \mathrm{E}-05$ & $1.4167 \mathrm{E}-05$ \\
\hline $\mathrm{N}$ & $2.4268 \mathrm{E}-05$ & $2.4271 \mathrm{E}-05$ & $2.4274 \mathrm{E}-05$ & $2.4274 \mathrm{E}-05$ \\
\hline Total & 4.8439E-02 & 4.8402E-02 & $4.8421 \mathrm{E}-02$ & $4.8421 \mathrm{E}-02$ \\
\hline
\end{tabular}




\section{NEA/NSC/DOC(95)03/II \\ Volume II}

HEU-MET-FAST-100

Table 3-14. Uranium Atom Densities in Top Section and Diametral Filler Rod of Detailed Benchmark Model, Case 1.

\begin{tabular}{|c|c|c|}
\hline \multirow[b]{2}{*}{$\begin{array}{l}\text { Element/ } \\
\text { Isotope }\end{array}$} & \multicolumn{2}{|c|}{ Atom Density (atom/b-cm) } \\
\hline & Upper Polar Cap & Diametral Filler Rod \\
\hline U Total & $4.8150 \mathrm{E}-02$ & $4.7722 \mathrm{E}-02$ \\
\hline${ }^{234} U$ & $4.7635 E-04$ & $4.7738 E-04$ \\
\hline${ }^{235} U$ & $4.4911 E-02$ & $4.4485 E-02$ \\
\hline${ }^{236} U$ & $1.7239 E-05$ & $2.1446 E-04$ \\
\hline${ }^{238} U$ & $2.7449 E-03$ & $2.5450 E-03$ \\
\hline $\mathrm{Be}$ & $6.2857 \mathrm{E}-09$ & - \\
\hline $\mathrm{Li}$ & $1.6323 \mathrm{E}-07$ & - \\
\hline $\mathrm{Al}$ & 2.5194E-06 & $2.0810 \mathrm{E}-06$ \\
\hline $\mathrm{Si}$ & $3.2272 \mathrm{E}-05$ & $4.7981 \mathrm{E}-05$ \\
\hline $\mathrm{Mn}$ & $5.2214 \mathrm{E}-06$ & $3.7751 \mathrm{E}-06$ \\
\hline $\mathrm{Ni}$ & 8.7279E-06 & $6.3102 \mathrm{E}-06$ \\
\hline $\mathrm{Cr}$ & $6.8961 \mathrm{E}-07$ & 4.9858E-07 \\
\hline $\mathrm{Cu}$ & $2.0152 \mathrm{E}-06$ & $1.4570 \mathrm{E}-06$ \\
\hline $\mathrm{B}$ & $5.2398 \mathrm{E}-07$ & $3.1162 \mathrm{E}-07$ \\
\hline Co & $9.6122 \mathrm{E}-08$ & - \\
\hline $\mathrm{Ca}$ & $1.4134 \mathrm{E}-06$ & - \\
\hline $\mathrm{C}$ & $1.9054 \mathrm{E}-04$ & $1.5707 \mathrm{E}-04$ \\
\hline $\mathrm{O}$ & $1.4162 \mathrm{E}-05$ & $1.4038 \mathrm{E}-05$ \\
\hline $\mathrm{N}$ & $2.4266 \mathrm{E}-05$ & $2.4052 \mathrm{E}-05$ \\
\hline Total & $4.8433 \mathrm{E}-02$ & $4.7980 \mathrm{E}-02$ \\
\hline
\end{tabular}


NEA/NSC/DOC(95)03/II
Volume II

HEU-MET-FAST-100

Table 3-15. Uranium Atom Densities in Top Section and Diametral Filler Rod of Detailed Benchmark Model, Case 2.

\begin{tabular}{|rcc|}
\hline & \multicolumn{2}{c|}{ Atom Density $($ atom $/ \mathrm{b}-\mathrm{cm})$} \\
\cline { 2 - 3 } $\begin{array}{c}\text { Element/ } \\
\text { Isotope }\end{array}$ & Upper Polar Cap & Diametral Filler Rod \\
\hline U Total & $4.8083 \mathrm{E}-02$ & $4.7722 \mathrm{E}-02$ \\
\hline${ }^{234} U$ & $4.7569 E-04$ & $4.7738 E-04$ \\
${ }^{235} U$ & $4.4849 E-02$ & $4.4485 E-02$ \\
${ }^{236} U$ & $1.7215 E-05$ & $2.1446 E-04$ \\
${ }^{238} U$ & $2.7411 E-03$ & - \\
\hline $\mathrm{Be}$ & $6.2770 \mathrm{E}-09$ & - \\
\hline $\mathrm{Li}$ & $1.6300 \mathrm{E}-07$ & $2.0810 \mathrm{E}-06$ \\
\hline $\mathrm{Al}$ & $2.5159 \mathrm{E}-06$ & $4.7981 \mathrm{E}-05$ \\
\hline $\mathrm{Si}$ & $3.2227 \mathrm{E}-05$ & $3.7751 \mathrm{E}-06$ \\
\hline $\mathrm{Mn}$ & $5.2142 \mathrm{E}-06$ & $6.3102 \mathrm{E}-06$ \\
\hline $\mathrm{Ni}$ & $8.7159 \mathrm{E}-06$ & $4.9858 \mathrm{E}-07$ \\
\hline $\mathrm{Cr}$ & $6.8866 \mathrm{E}-07$ & $1.4570 \mathrm{E}-06$ \\
\hline $\mathrm{Cu}$ & $2.0125 \mathrm{E}-06$ & $3.1162 \mathrm{E}-07$ \\
\hline $\mathrm{B}$ & $5.2326 \mathrm{E}-07$ & - \\
\hline $\mathrm{Co}$ & $9.5989 \mathrm{E}-08$ & - \\
\hline $\mathrm{Ca}$ & $1.4115 \mathrm{E}-06$ & $1.5707 \mathrm{E}-04$ \\
\hline $\mathrm{C}$ & $1.9028 \mathrm{E}-04$ & $2.4052 \mathrm{E}-05$ \\
\hline $\mathrm{O}$ & $1.4143 \mathrm{E}-05$ & $4.7980 \mathrm{E}-02$ \\
\hline $\mathrm{N}$ & $2.4233 \mathrm{E}-05$ & \\
\hline $\mathrm{Total}$ & $4.8366 \mathrm{E}-02$ & \\
\hline
\end{tabular}


The material data for the brass of the brass bolt is given in Table 3-16.

Table 3-16. Brass Atom Densities for Brass

Bolt in the Detailed Benchmark Model,

Case 1 and 2.

\begin{tabular}{|cc|}
\hline $\begin{array}{c}\text { Element/ } \\
\text { Isotope }\end{array}$ & Atom Density (atom/b-cm) \\
\hline $\mathrm{Cu}$ & $7.5056 \mathrm{E}-02$ \\
$\mathrm{Zn}$ & $8.1044 \mathrm{E}-03$ \\
\hline Total & $8.3160 \mathrm{E}-02$ \\
\hline
\end{tabular}

\subsubsection{Material Data of Simple Benchmark Model}

The material data for the uranium of the simple benchmark model is given in Table 3-17.

Table 3-17. Uranium Atom Densities,

Simple Benchmark Model Case 1 and 2. ${ }^{(a)}$

\begin{tabular}{||ccc||}
\hline & \multicolumn{2}{c||}{ Atom Density (atom/b-cm) } \\
\cline { 2 - 3 } $\begin{array}{c}\text { Element } \\
\text { Isotope }\end{array}$ & Case 1 & Case 2 \\
\hline U Total & $4.8097 \mathrm{E}-02$ & $4.8075 \mathrm{E}-02$ \\
\hline${ }^{234} U$ & $4.7590 E-04$ & $4.7568 E-04$ \\
${ }^{235} U$ & $4.4859 E-02$ & $4.4838 E-02$ \\
${ }^{236} U$ & $2.1871 E-05$ & $2.1938 E-05$ \\
\hline${ }^{238} U$ & $2.7404 E-03$ & $2.7390 E-03$ \\
\hline $\mathrm{Si}$ & $4.9713 \mathrm{E}-05$ & $4.9746 \mathrm{E}-05$ \\
\hline $\mathrm{B}$ & $3.4257 \mathrm{E}-07$ & $3.4357 \mathrm{E}-07$ \\
\hline $\mathrm{C}$ & $1.5929 \mathrm{E}-04$ & $1.5920 \mathrm{E}-04$ \\
\hline Total & $4.8307 \mathrm{E}-02$ & $4.8284 \mathrm{E}-02$ \\
\hline \hline
\end{tabular}

(a) When impurities were removed they were replaced with void. 
HEU-MET-FAST-100

\subsection{Temperature Data}

The benchmark model is evaluated at room temperature $(294 \mathrm{~K})$ for both the simple and detailed models.

\subsection{Experimental and Benchmark-Model $\mathbf{k}_{\text {eff }}$ and/or Subcritical Parameters}

The experimental configurations had an excess reactivity of $68.1 \pm 2.0 \notin$ for Case 1 and $-23.4 \pm 2.0 \notin$ for Case 2. The measured and calculated simplification biases and the temperature bias were applied to the experimental $\mathrm{k}_{\mathrm{eff}}$ to obtain the detailed and simple benchmark model $\mathrm{k}_{\mathrm{eff}}$ values found in Table 3-18. The uncertainty in the benchmark models was found by adding in quadrature the uncertainty derived in Section 2 and the uncertainty in the bias derived in Section 3.1. The two cases are highly correlated.

Table 3-18. Benchmark Experiment Eigenvalues.

\begin{tabular}{||lcccccc||}
\hline & \multicolumn{3}{c}{ Case 1 } & \multicolumn{2}{c|}{ Case 2 } \\
\hline \hline Experimental k $\mathrm{eff}$ & 1.00447 & \pm & $0.00013^{(\mathrm{a})}$ & 0.99846 & \pm & $0.00013^{(\mathrm{a})}$ \\
\hline Detailed Model Benchmark k $\mathrm{eff}_{\mathrm{eff}}$ & 1.0026 & \pm & $0.0007^{(\mathrm{b})}$ & 0.9966 & \pm & $0.0007^{(\mathrm{b})}$ \\
\hline Simple Model Benchmark k & 1.0031 & \pm & $0.0007^{(\mathrm{b})}$ & 0.9966 & \pm & $0.0007^{(\mathrm{b})}$ \\
\hline \hline
\end{tabular}

(a) This uncertainty is accounted for in Section 2.1.

(b) This uncertainty includes the experimental and bias uncertainty. 


\subsection{RESULTS OF SAMPLE CALCULATIONS}

Reference 1 provides a sample MCNP input deck for Case 2. When reviewing these results it should be noted that the measured $\mathrm{k}_{\text {eff }}$ derived in Appendix A and Table 5 of Reference 1 does not include the diametral filler rod in the configuration worth of $-35 \phi$. However, the sample input deck does include the diametral filler rod. This is a reactivity change of about $10 \notin$. Various other simplifications were used in the model given in Reference 1 that were not used in the models developed for this evaluation. Some errors have also been found in the model presented in Appendix A of Reference 1.

The benchmark specifications given in Section 3 were used to create inputs for MCNP5, KENO-VI ${ }^{\text {a }}$ MONK, COG, and XSDRNPM using ENDF/B-VII.0 continuous energy neutron cross section libraries and select other cross section libraries. Example input files for the benchmark model calculations can be found in Appendix A. Results of the MCNP5 sample calculations [(C-E)/E] range from $0.13 \%$ for Case 1 to $0.18 \%$ for Case 2, or about 1.6 $\sigma$ greater than the benchmark value for the Case 1 and $2.3 \sigma$ for Case 2. Results are summarized in Tables 4-1 and Table 4-2.

${ }^{a}$ D.F. Hollenbach, L.M. Petrie, S. Goluoglu, N.F. Landers, and M.E. Dunn, "KENO-VI: A General Quadratic Version of the KENO Program," ORNL/TM-2005/39 Version 6 Vol. II, Sect. F17, Oak Ridge National Laboratory (January 2009). 
NEA/NSC/DOC(95)03/II

Volume II

HEU-MET-FAST-100

Table 4-1. Sample Calculation Results for the Detailed Benchmark Model.

\begin{tabular}{|c|c|c|c|c|c|c|}
\hline & & & $\mathrm{k}_{\mathrm{eff}}$ & \pm & $\sigma$ & $\frac{C-E^{(\mathrm{e})}}{E}$ \\
\hline \multirow{2}{*}{\multicolumn{2}{|c|}{ Benchmark Model }} & Case 1 & 1.0026 & \pm & 0.0007 & - \\
\hline & & Case 2 & 0.9965 & \pm & 0.0007 & - \\
\hline \multirow{2}{*}{$\mathrm{MCNP}^{(\mathrm{a})}$} & \multirow{2}{*}{$\begin{array}{c}\text { ENDF/B- } \\
\text { VII.0 }\end{array}$} & Case 1 & 1.00385 & \pm & 0.00002 & $0.13 \%$ \\
\hline & & Case 2 & 0.99821 & \pm & 0.00002 & $0.17 \%$ \\
\hline \multirow{2}{*}{$\operatorname{MCNP5}^{(\mathrm{a})}$} & \multirow{2}{*}{ JEFF-3.1 } & Case 1 & 1.00039 & \pm & 0.00002 & $-0.22 \%$ \\
\hline & & Case 2 & 0.99472 & \pm & 0.00002 & $-0.18 \%$ \\
\hline \multirow{2}{*}{$\mathrm{MCNP}^{(\mathrm{a})}$} & \multirow{2}{*}{ JENDL-3.3 } & Case 1 & 1.00692 & \pm & 0.00002 & $0.43 \%$ \\
\hline & & Case 2 & 1.00133 & \pm & 0.00002 & $0.48 \%$ \\
\hline \multirow{2}{*}{$\mathrm{KENO} \mathrm{VI}^{(\mathrm{b})}$} & \multirow{2}{*}{$\begin{array}{l}\text { ENDF/B- } \\
\text { VII.0-CE }\end{array}$} & Case 1 & 1.00495 & \pm & 0.00002 & $0.24 \%$ \\
\hline & & Case 2 & 0.99947 & \pm & 0.00002 & $0.29 \%$ \\
\hline \multirow{2}{*}{ KENO-VI ${ }^{(\mathrm{b})}$} & \multirow{2}{*}{$\begin{array}{l}\text { ENDF/B- } \\
\text { VII.0-238g }\end{array}$} & Case 1 & 1.00495 & \pm & 0.00002 & $0.24 \%$ \\
\hline & & Case 2 & 0.99947 & \pm & 0.00002 & $0.29 \%$ \\
\hline \multirow{2}{*}{$\mathrm{MONK}^{(\mathrm{c})}$} & \multirow{2}{*}{$\begin{array}{c}\text { ENDF/B- } \\
\text { VII.0 }\end{array}$} & Case 1 & 1.0034 & \pm & 0.0001 & $0.08 \%$ \\
\hline & & Case 2 & 0.9985 & \pm & 0.0001 & $0.20 \%$ \\
\hline \multirow{2}{*}{$\mathrm{MONK}^{(\mathrm{c})}$} & \multirow{2}{*}{ JEFF-3.1 } & Case 1 & 0.9997 & \pm & 0.0001 & $-0.29 \%$ \\
\hline & & Case 2 & 0.9951 & \pm & 0.0001 & $-0.14 \%$ \\
\hline \multirow{2}{*}{ COG11.1 ${ }^{(\mathrm{d})}$} & \multirow{2}{*}{$\begin{array}{c}\text { ENDF/B- } \\
\text { VII. } 1\end{array}$} & Case 1 & 1.00421 & \pm & 0.00008 & $0.17 \%$ \\
\hline & & Case 2 & 0.99795 & \pm & 0.00003 & $0.14 \%$ \\
\hline \multirow{2}{*}{ COG11.1 ${ }^{(\mathrm{d})}$} & \multirow{2}{*}{ JEFF-3.1.2 } & Case 1 & 1.00054 & \pm & 0.00009 & $-0.20 \%$ \\
\hline & & Case 2 & 0.99439 & \pm & 0.00003 & $-0.22 \%$ \\
\hline \multirow{2}{*}{ COG11.1 ${ }^{(\mathrm{d})}$} & \multirow{2}{*}{ JENDL-4 } & Case 1 & 1.00193 & \pm & 0.00009 & $-0.06 \%$ \\
\hline & & Case 2 & 0.99598 & \pm & 0.00005 & $-0.06 \%$ \\
\hline
\end{tabular}

(a) Results obtained using 500,000 histories for 2650 cycles, skipping the first 150 cycles.

(b) Results provided by John D. Bess from Idaho National Laboratory (INL). Results obtained using 500000 histories for 2650 cycles, skipping the first 150 cycles.

(c) Results provided by James Dyrda from Atomic Weapons Establishment (AWE). Results obtained using 30 settling stages plus 6000 normal stages, 1000 super histories per stage and 10 generations per super-history.

(d) Results provided by David P. Heinrichs from Lawrence Livermore National Laboratory (LLNL).

Results obtained using 500,000 histories for 2650 cycles, skipping the first 150 cycles.

(e) ' $\mathrm{E}$ ' is the expected or benchmark value. ' $\mathrm{C}$ ' is the calculated value. 
NEA/NSC/DOC(95)03/II

Volume II

HEU-MET-FAST-100

Table 4-2. Sample Calculation Results for the Simple Benchmark Model.

\begin{tabular}{|c|c|c|c|c|c|c|}
\hline & & & $\mathrm{k}_{\mathrm{eff}}$ & \pm & $\sigma$ & $\frac{C-E^{(\mathrm{f})}}{E}$ \\
\hline \multirow{2}{*}{\multicolumn{2}{|c|}{ Benchmark Model }} & Case 1 & 1.0031 & \pm & 0.0007 & - \\
\hline & & Case 2 & 0.9966 & \pm & 0.0007 & - \\
\hline \multirow{2}{*}{$\mathrm{MCNP5}^{(\mathrm{a})}$} & \multirow{2}{*}{ ENDF/B-VII.0 } & Case 1 & 1.00441 & \pm & 0.00002 & $0.18 \%$ \\
\hline & & Case 2 & 0.99826 & \pm & 0.00002 & $0.17 \%$ \\
\hline \multirow{2}{*}{$\mathrm{MCNP5}^{(\mathrm{a})}$} & \multirow{2}{*}{ JEFF-3.1 } & Case 1 & 1.00088 & \pm & 0.00002 & $-0.17 \%$ \\
\hline & & Case 2 & 0.99477 & \pm & 0.00002 & $-0.18 \%$ \\
\hline \multirow{2}{*}{$\mathrm{MCNP5}^{(\mathrm{a})}$} & \multirow{2}{*}{ JENDL-3.3 } & Case 1 & 1.00744 & \pm & 0.00002 & $0.49 \%$ \\
\hline & & Case 2 & 1.00139 & \pm & 0.00002 & $0.49 \%$ \\
\hline \multirow{2}{*}{ KENO-V.a ${ }^{(b)}$} & \multirow{2}{*}{$\begin{array}{l}\text { ENDF/B- } \\
\text { VII.0-CE }\end{array}$} & Case 1 & 1.00416 & \pm & 0.00002 & $0.16 \%$ \\
\hline & & Case 2 & 0.99803 & \pm & 0.00002 & $0.15 \%$ \\
\hline \multirow{2}{*}{ KENO-V.a ${ }^{(b)}$} & \multirow{2}{*}{$\begin{array}{l}\text { ENDF/B- } \\
\text { VII.0-238g }\end{array}$} & Case 1 & 1.00548 & \pm & 0.00002 & $0.29 \%$ \\
\hline & & Case 2 & 0.99932 & \pm & 0.00002 & $0.28 \%$ \\
\hline \multirow{2}{*}{$\operatorname{MONK}^{(\mathrm{c})}$} & \multirow{2}{*}{ ENDF/B-VII.0 } & Case 1 & 1.0046 & \pm & 0.0001 & $0.20 \%$ \\
\hline & & Case 2 & 0.9986 & \pm & 0.0001 & $0.21 \%$ \\
\hline \multirow{2}{*}{$\operatorname{MONK}^{(\mathrm{c})}$} & \multirow{2}{*}{ JEFF-3.1 } & Case 1 & 1.0013 & \pm & 0.0001 & $-0.13 \%$ \\
\hline & & Case 2 & 0.9952 & \pm & 0.0001 & $-0.13 \%$ \\
\hline \multirow{2}{*}{ XSDRNPM $^{(\mathrm{d})}$} & \multirow{2}{*}{$\begin{array}{l}\text { ENDF/B- } \\
\text { VII.0-238g }\end{array}$} & Case 1 & 1.00575 & \pm & - & $0.32 \%$ \\
\hline & & Case 2 & 0.99960 & \pm & - & $0.31 \%$ \\
\hline \multirow{2}{*}{$\mathrm{XSDRNPM}^{(\mathrm{d})}$} & \multirow{2}{*}{$\begin{array}{c}\text { ENDF/B- } \\
\text { VII.0-27n19g }\end{array}$} & Case 1 & 1.00760 & \pm & - & $0.50 \%$ \\
\hline & & Case 2 & 1.00145 & \pm & - & $0.49 \%$ \\
\hline \multirow{2}{*}{ XSDRNPM $^{(\mathrm{d})}$} & \multirow{2}{*}{$\begin{array}{c}\text { ENDF/B-VI.8- } \\
238 \mathrm{~g}\end{array}$} & Case 1 & 1.00167 & \pm & - & $-0.09 \%$ \\
\hline & & Case 2 & 0.99553 & \pm & - & $-0.10 \%$ \\
\hline \multirow{2}{*}{$\mathrm{XSDRNPM}^{(\mathrm{d})}$} & \multirow{2}{*}{$\begin{array}{c}\text { ENDF/B-V.2- } \\
238 \mathrm{~g}\end{array}$} & Case 1 & 1.00184 & \pm & - & $-0.07 \%$ \\
\hline & & Case 2 & 0.99573 & \pm & - & $-0.08 \%$ \\
\hline \multirow{2}{*}{ COG11.1 $1^{(\mathrm{e})}$} & \multirow{2}{*}{ ENDF/B-VII.1 } & Case 1 & 1.00494 & \pm & 0.00003 & $0.19 \%$ \\
\hline & & Case 2 & 0.99875 & \pm & 0.00003 & $0.21 \%$ \\
\hline \multirow{2}{*}{ COG11.1 $1^{(\mathrm{e})}$} & \multirow{2}{*}{ JEFF-3.1.2 } & Case 1 & 1.00136 & \pm & 0.00004 & $-0.17 \%$ \\
\hline & & Case 2 & 0.99521 & \pm & 0.00003 & $-0.14 \%$ \\
\hline \multirow{2}{*}{ COG11.1 $1^{(\mathrm{e})}$} & \multirow{2}{*}{ JENDL-4 } & Case 1 & 1.00281 & \pm & 0.00004 & $-0.03 \%$ \\
\hline & & Case 2 & 0.99677 & \pm & 0.00005 & $0.02 \%$ \\
\hline
\end{tabular}

(a) Results obtained using 500,000 histories for 2650 cycles, skipping the first 150 cycles.

(b) Results provided by John D. Bess from INL. Results obtained using 500000 histories for 2650 cycles, skipping the first 150 cycles.

(c) Results provided by James Dyrda from AWE. Results obtained using 30 settling stages plus 6000 normal stages, 1000 super histories per stage and 10 generations per super-history.

(d) Results provided by John D. Bess from Idaho National Laboratory.

(e) Results provided by David P. Heinrichs from LLNL. Results obtained using 500,000 histories for 2650 cycles, skipping the first 150 cycles.

(f) ' $\mathrm{E}$ ' is the expected or benchmark value. ' $\mathrm{C}$ ' is the calculated value. 
NEA/NSC/DOC(95)03/II
Volume II

HEU-MET-FAST-100

\subsection{REFERENCES}

1. J.T. Mihalczo, J. J. Lynn, J. R. Taylor, G. E. Hansen, and D. B. Pelowitz, "Delayed Critical ORNL Unreflected Uranium (93.20) Metal Sphere and the Pure Unreflected Uranium (93.80) Sphere Critical Mass," Ann. Nucl. Energy, 29, 525-560 (2002).

2. J.T. Mihaclzo, J. J. Lynn, J. R. Taylor, and G. E. Hansen, "Measurements with an Unreflected Uranium (93.2\%) Metal Sphere,” PHYSOR 1993, Nashville, TN, September 19-23 (1993). 
NEA/NSC/DOC(95)03/II

Volume II

HEU-MET-FAST-100

\section{APPENDIX A: TYPICAL INPUT LISTINGS}

\section{A.1 MCNP Input Listing}

Models were creating using Monte Carlo n-Particle, version 5-1.60, (MCNP) and ENDF/B-VII.0 neutron cross section libraries. Isotopic abundances for all elements except uranium were taken from "Nuclides and Isotopes: Chart of the Nuclides," Sixteenth Edition, KAPL, 2002. MCNP5.1.60 models were run for 2500 active cycles (150 inactive cycles) with 500,000 histories per cycle.

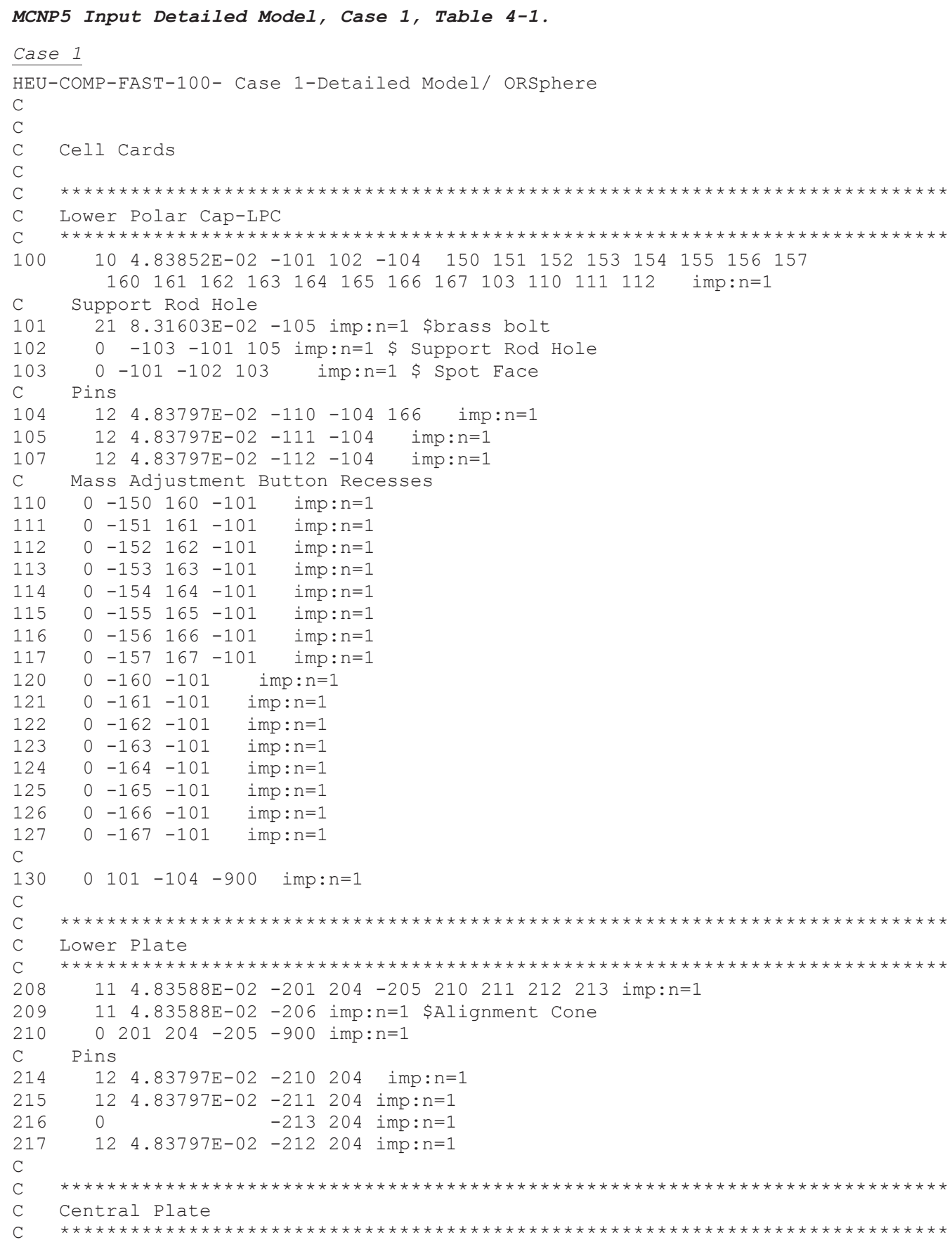




\section{NEA/NSC/DOC(95)03/II \\ Volume II}

\section{HEU-MET-FAST-100}

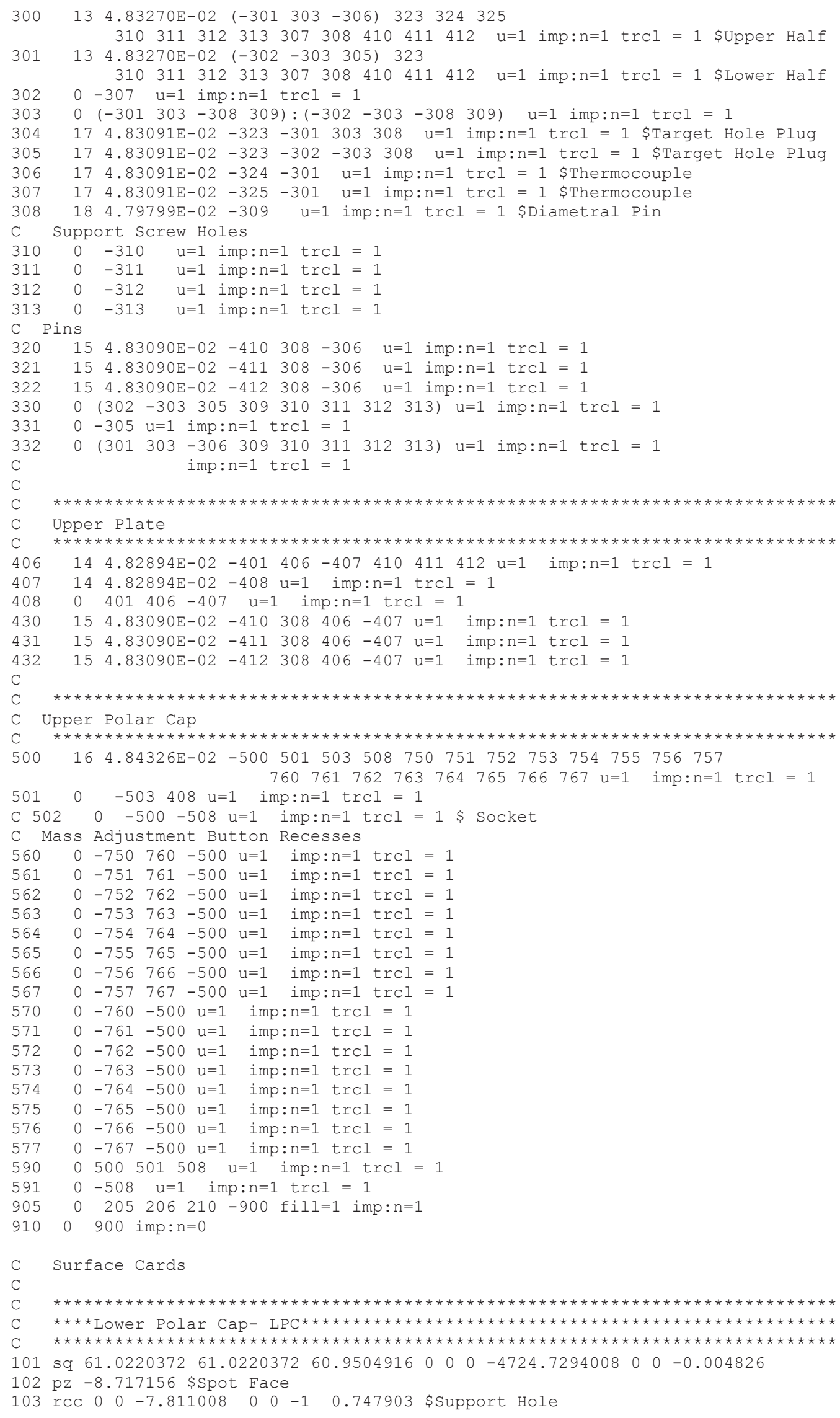

Revision: 0 


\section{NEA/NSC/DOC(95)03/II \\ Volume II}

\section{HEU-MET-FAST-100}

$104 \mathrm{pz} \quad-4.066286$ \$Top of LPC

$\begin{array}{llllllllll}105 & \text { rec } & 0 & 0 & -7.811008 & 0 & 0 & -0.8128 & 0.747903 & \text { \$Bolt }\end{array}$

C Pins

$\begin{array}{lllllllll}110 & \text { rCC } & -6.35 & 0 & -5.177536 & 0 & 0 & 3.754374 & 0.57531 \\ 111 & \text { rCC } & 3.175 & 5.49926 & -5.177536 & 0 & 0 & 3.747262 & 0.57531\end{array}$

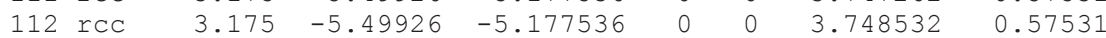

C LPC Mass Adjustment Button Recesses

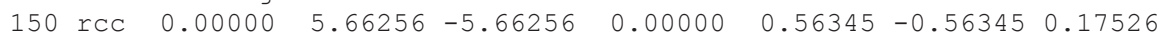

151 rCC $4.00403 \quad 4.00403 \quad-5.66256 \quad 0.39843 \quad 0.39843-0.56345 \quad 0.17526$

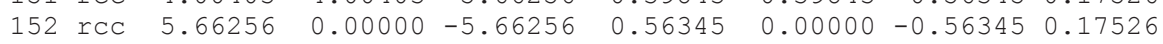

153 rcc $4.00403-4.00403-5.66256 \quad 0.39843-0.39843-0.563450 .17526$

$154 \mathrm{rCC} \quad 0.00000-5.66256-5.66256 \quad 0.00000-0.56345-0.56345 \quad 0.17526$

$155 \mathrm{rcc}-4.00403-4.00403-5.66256-0.39843-0.39843-0.563450 .17526$

$156 r C C-5.66256 \quad 0.00000-5.66256-0.56345 \quad 0.00000-0.56345 \quad 0.17526$

$157 \mathrm{rCC}-4.00403 \quad 4.00403-5.66256-0.39843 \quad 0.39843-0.56345 \quad 0.17526$

$160 \operatorname{rcc} \quad 0.00000 \quad 6.1439 \quad-6.1439 \quad 0.00000 \quad 0.08211-0.08211 \quad 1.11125$

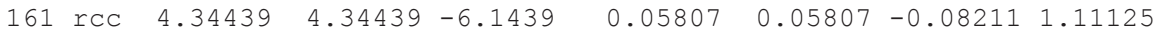

$\begin{array}{lllllllll}162 & \mathrm{rCC} & 6.1439 & 0.00000 & -6.1439 & 0.08211 & 0.00000 & -0.08211 & 1.11125\end{array}$

163 rCC $4.34439-4.34439-6.1439 \quad 0.05807-0.05807-0.082111 .11125$

$164 \mathrm{rCC} \quad 0.00000-6.1439-6.1439 \quad 0.00000-0.08211-0.082111 .11125$

165 rCC $-4.34439-4.34439-6.1439-0.05807-0.05807-0.082111 .11125$

$\begin{array}{llllllll}166 r c c & -6.1439 & 0.00000 & -6.1439 & -0.08211 & 0.00000 & -0.08211 & 1.11125\end{array}$

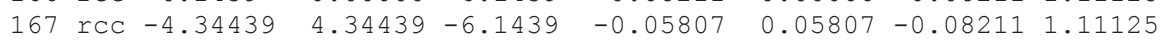

C

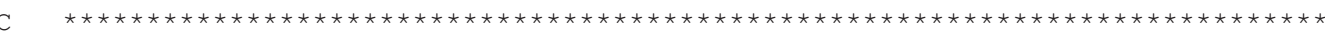

C $\quad * * * *$ Lower Plate- LP $* * * * * * * * * * * * * * * * * * * * * * * * * * * * * * * * * * * * * * * * * * * * * * * * * * * * * * * * *$

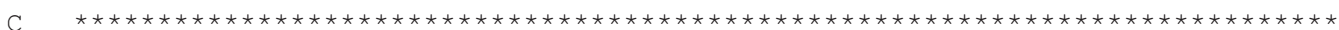

$201 \mathrm{sq} 14.492629414 .4926294 \quad 14.456850400000-1122.97037050000$

$204 \mathrm{pz} \quad-4.066286$ \$Bottom of LP

$205 \mathrm{pz}-1.429004$ \$ Top of lower plate

206 trc $0 \quad 0 \quad-1.429004000 .553720 .6350 .315309609$ \$ LP Alignment cone

C Lower Section Pins

$210 \begin{array}{llllllllll}\text { rCC } & -6.35 & 0 & -4.066286 & 0 & 0 & 2.643124 & 0.57531\end{array}$

$211 \operatorname{rcc} \quad 3.175 \quad 5.49926-4.066286 \quad 0 \quad 0 \quad 2.636012 \quad 0.57531$

$212 \operatorname{rcc} \quad 3.175 \quad-5.49926-4.066286 \quad 0 \quad 0 \quad 2.637282 \quad 0.57531$

$213 \operatorname{rcc} \quad 3.175 \quad 5.49926 \quad-1.430274 \quad 0 \quad 0 \quad 0.001270 \quad 0.57531$

C

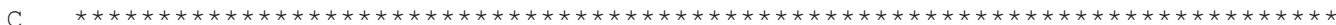

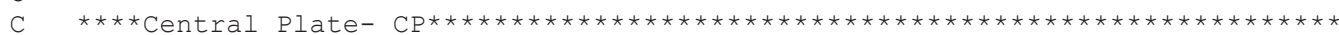

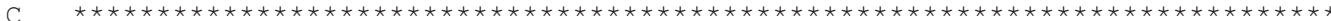

301 sq $2.04205242 .04205242 .02416290000-158.25825700000$ \$CP Upper Section

$302 \mathrm{sq} 2.04205242 .04205242 .05993990000-158.2582570000$ \$CP Lower Section

$303 \mathrm{pz} 0$

$305 \mathrm{pz}-1.429004$ \$bottom of Central Plate

$306 \mathrm{pz} 1.429004$ \$Top of Central Plate

$307 \operatorname{trc} 0 \quad 0 \quad-1.429004000 .57150 .63627 \quad 0.306314321$ \$ CP Alignment Hole

$308 \mathrm{cx} 0.17272$ \$Diametral Hole

309 rCC -8.91476500017 .82953000 .164211 \$ Diametral Pin

323 rcc $0.888238000 \quad 8.804910001 .27$ \$ Target Hole Plug

$324 \mathrm{rpp}-0.0889 \quad 0.0889-0.9525 \quad 4.1275 \quad 1.281684 \quad 1.429004$ \$Thermocouple

$325 \mathrm{rpp}-0.0889 \quad 0.0889 \quad 4.12758 .80491 \quad 1.134364 \quad 1.429004$ \$Thermocouple

C Support Rod Holes in $\mathrm{CP}$

$\begin{array}{llllllllll}310 & \text { rec } & 5.74467 & 5.74467 & 0 & 0.48134 & 0.48134 & 0 & 0.351028\end{array}$

$\begin{array}{lllllllllll}311 & \text { ICC } & 5.74467 & -5.74467 & 0 & 0.48134 & -0.48134 & 0 & 0.351028\end{array}$

$312 \operatorname{rCC}-5.74467-5.74467 \quad 0 \quad-0.48134-0.48134000 .351028$

$\begin{array}{llllllllll}313 \operatorname{rCC} & -5.74467 & 5.74467 & 0 & -0.48134 & 0.48134 & 0 & 0.351028\end{array}$

C

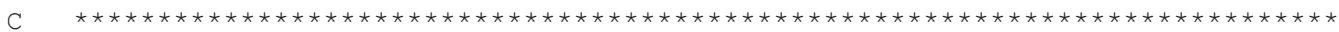

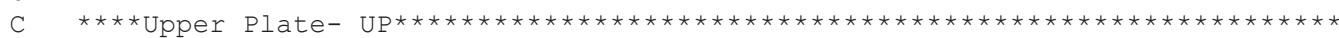

C $\quad * * * * * * * * * * * * * * * * * * * * * * * * * * * * * * * * * * * * * * * * * * * * * * * * * * * * * * * * * * * * * * * * * * * * * * * * * * * *$

401 sq $9.34959869 .3495986 \quad 9.313821600000-724.34989940000$

$406 \mathrm{pz} 1.429004$ \$Bottom of Upper Plate

$407 \mathrm{pz} 3.375152$ \$Top of upper Plate

408 trc 0003.375152000 .553720 .6350 .315309609 \$ UP Alignment Cone

C Central Section Pins

410 rcc $-6.35 \quad 0 \quad-1.429004 \quad 0 \quad 0 \quad 4.804156 \quad 0.57531$

$411 \operatorname{rcc} 3.175 \quad 5.49926-1.429004 \quad 0 \quad 0 \quad 4.804156 \quad 0.57531$

$412 \operatorname{rcc} 3.175-5.49926-1.429004 \quad 0 \quad 0 \quad 4.804156 \quad 0.57531$

C

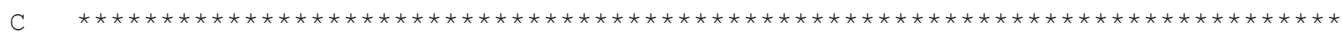

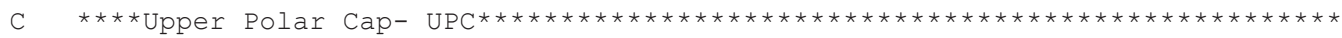

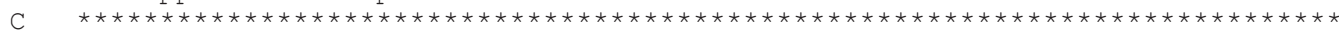

Revision: 0 


\section{NEA/NSC/DOC(95)03/II \\ Volume II}

\section{HEU-MET-FAST-100}

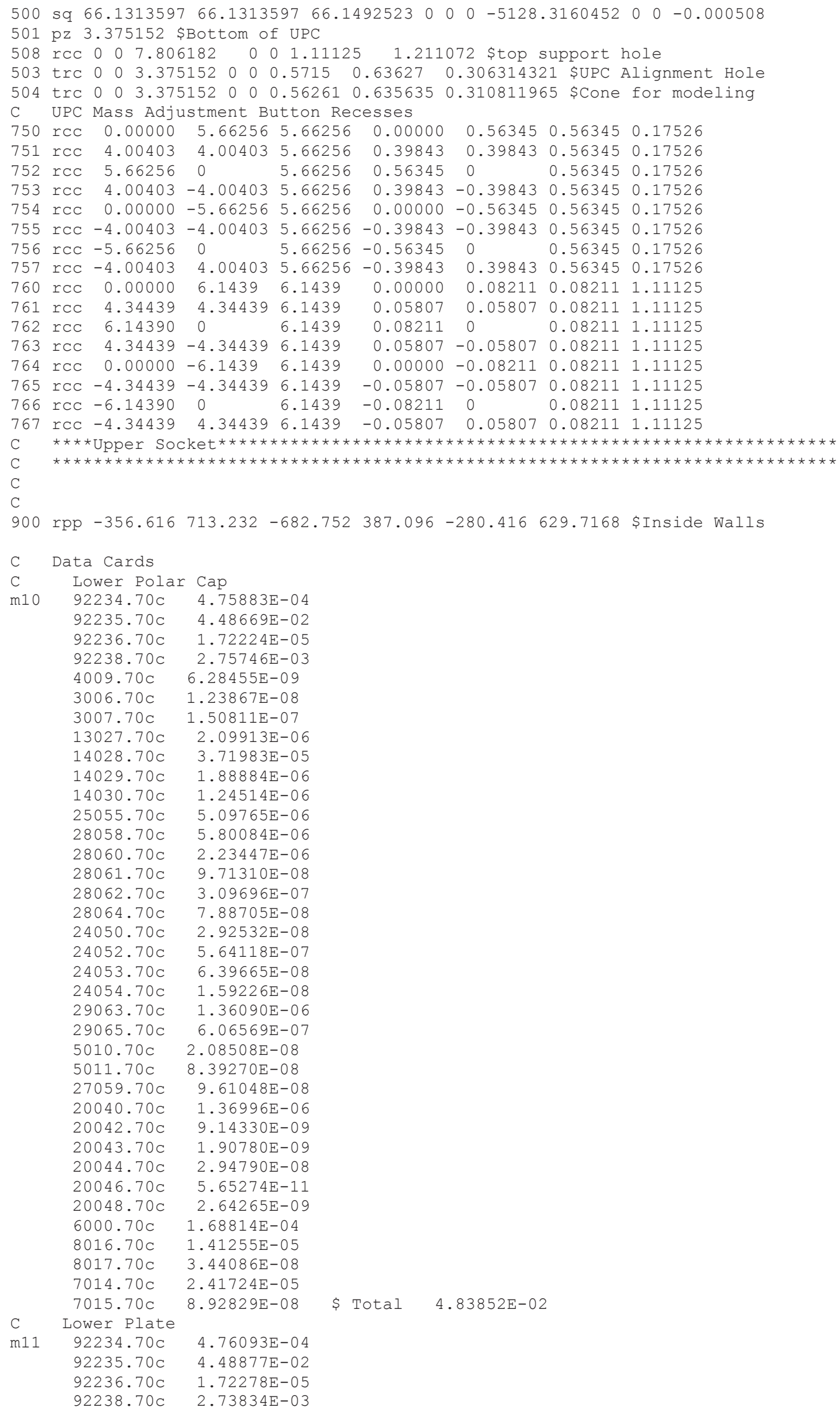

Revision: 0 
NEA/NSC/DOC(95)03/II

Volume II

HEU-MET-FAST-100

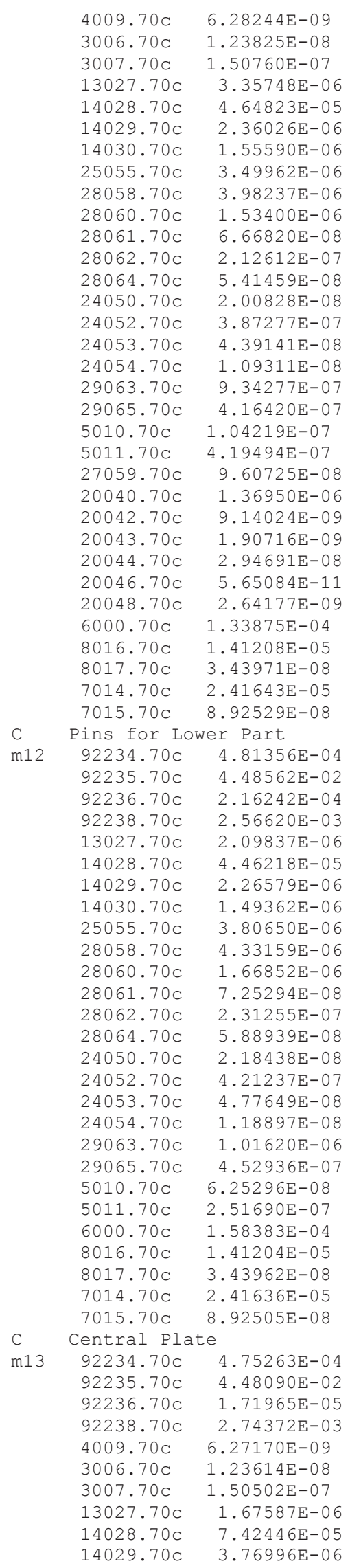

\$ Total 4.83588E-02

\$ Total 4.83797E-02

Revision: 0

Date: September 30, 2013

Page 83 of 160 
NEA/NSC/DOC(95)03/II

Volume II

HEU-MET-FAST-100

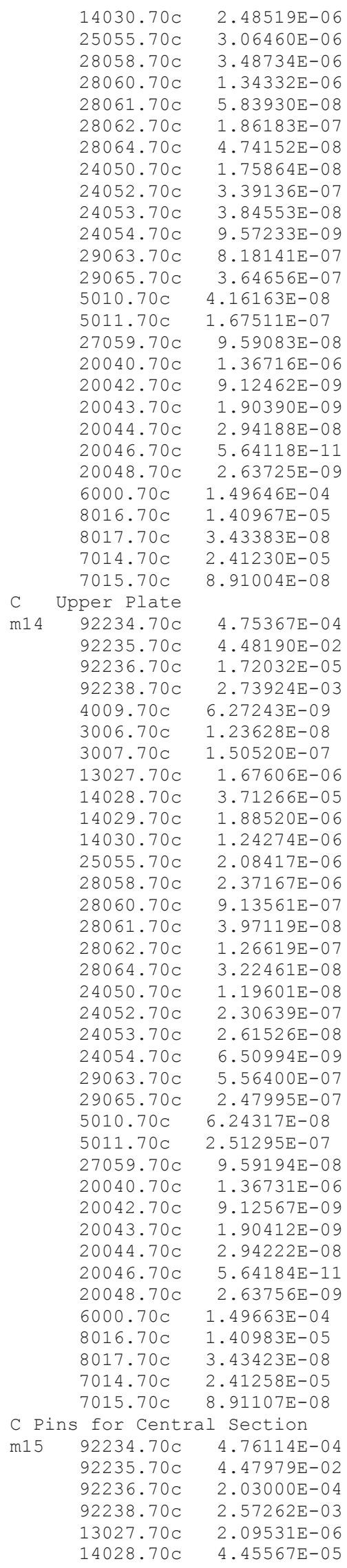

Revision: 0

Date: September 30, 2013

Page 84 of 160 
NEA/NSC/DOC(95)03/II

Volume II

HEU-MET-FAST-100

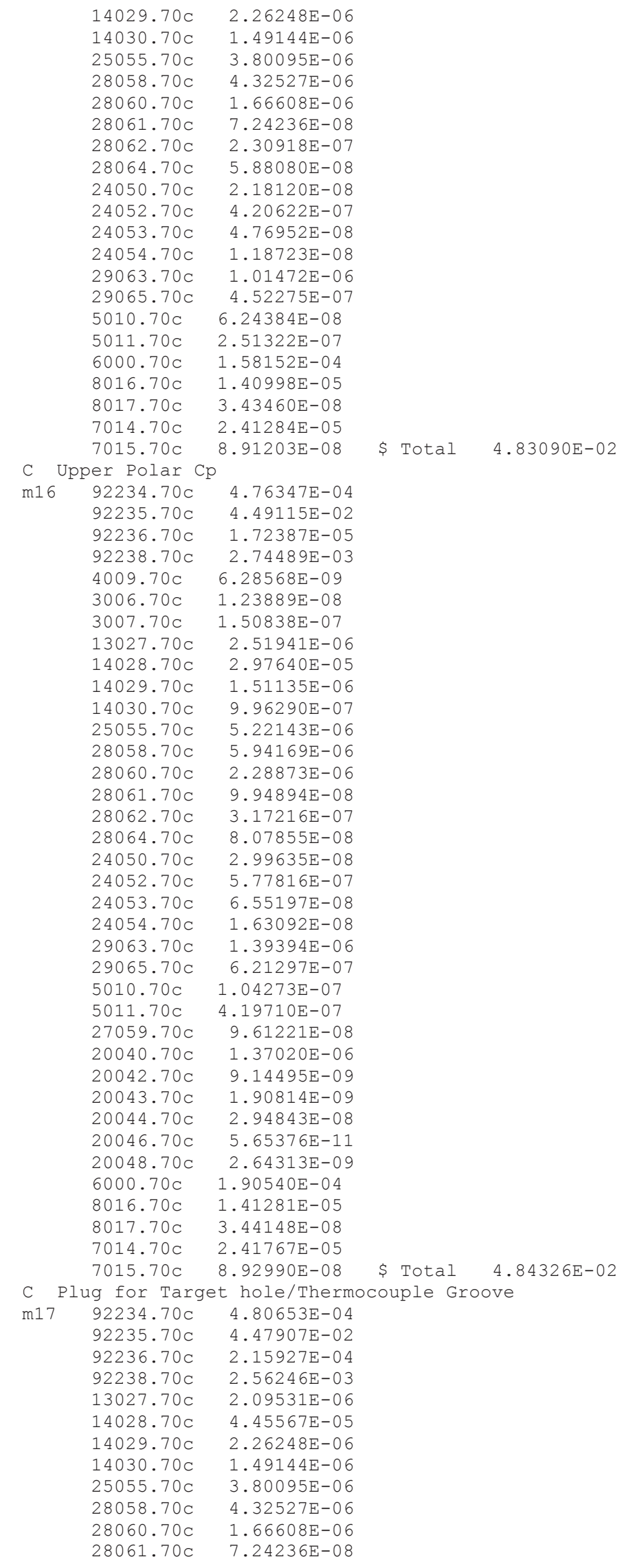

Revision: 0

Date: September 30, 2013

Page 85 of 160 
NEA/NSC/DOC(95)03/II

Volume II

HEU-MET-FAST-100

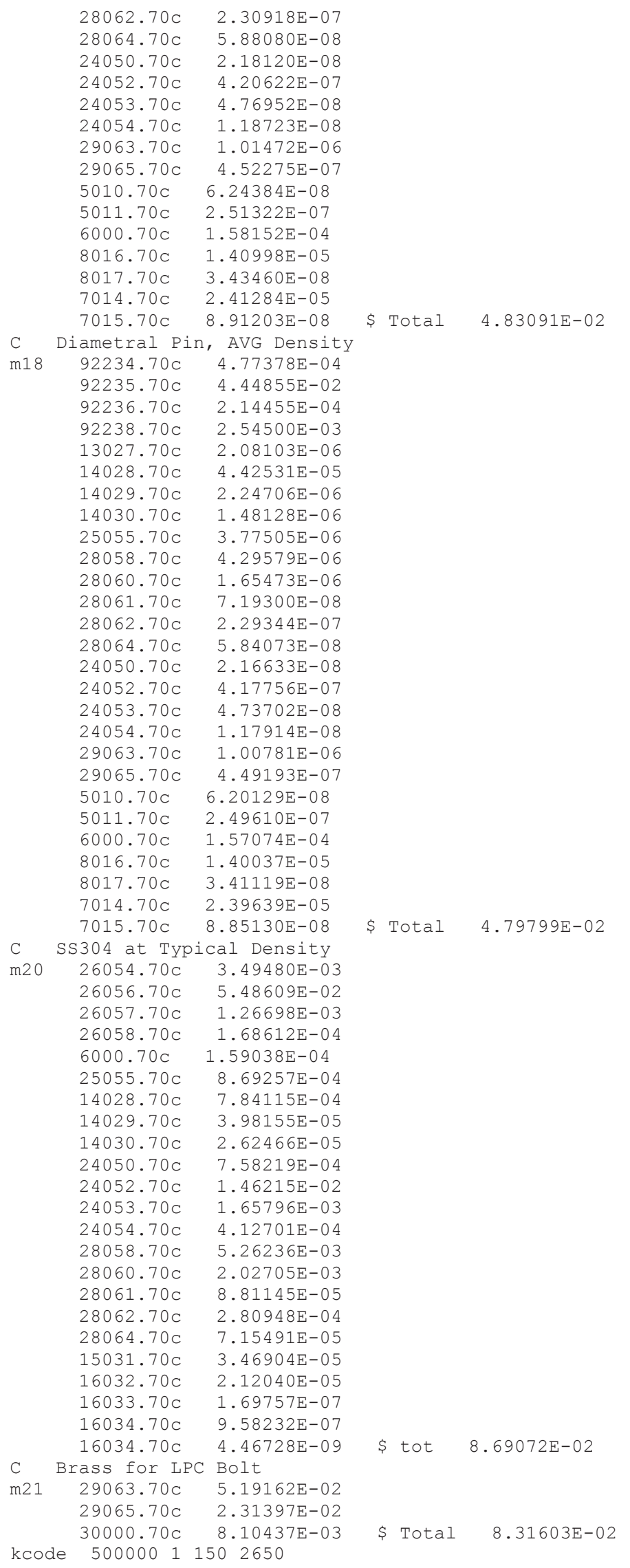

Revision: 0

Date: September 30, 2013

Page 86 of 160 
NEA/NSC/DOC(95)03/II

Volume II

\section{HEU-MET-FAST-100}

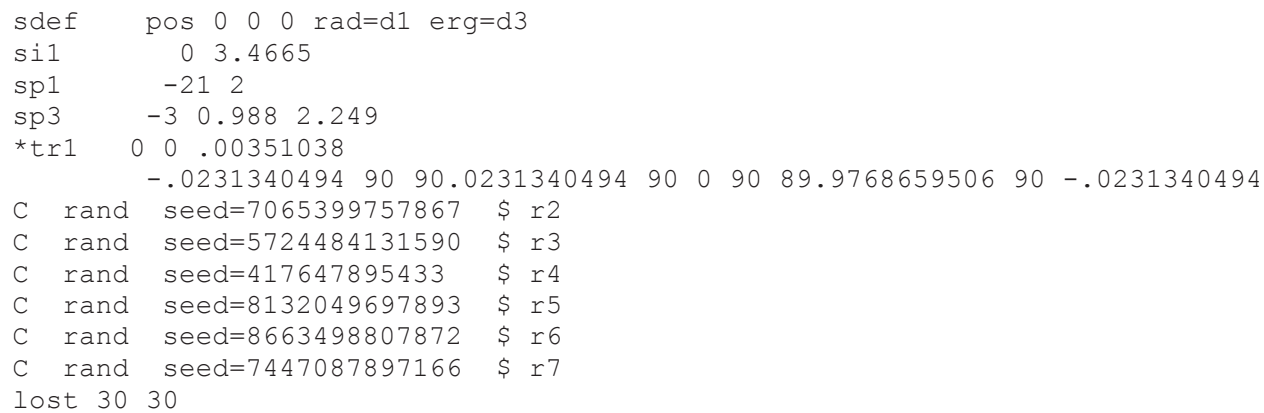




\section{NEA/NSC/DOC(95)03/II \\ Volume II}

\section{HEU-MET-FAST-100}

\section{MCNP5 Input Detailed Model, Case 2, Table 4-1.}

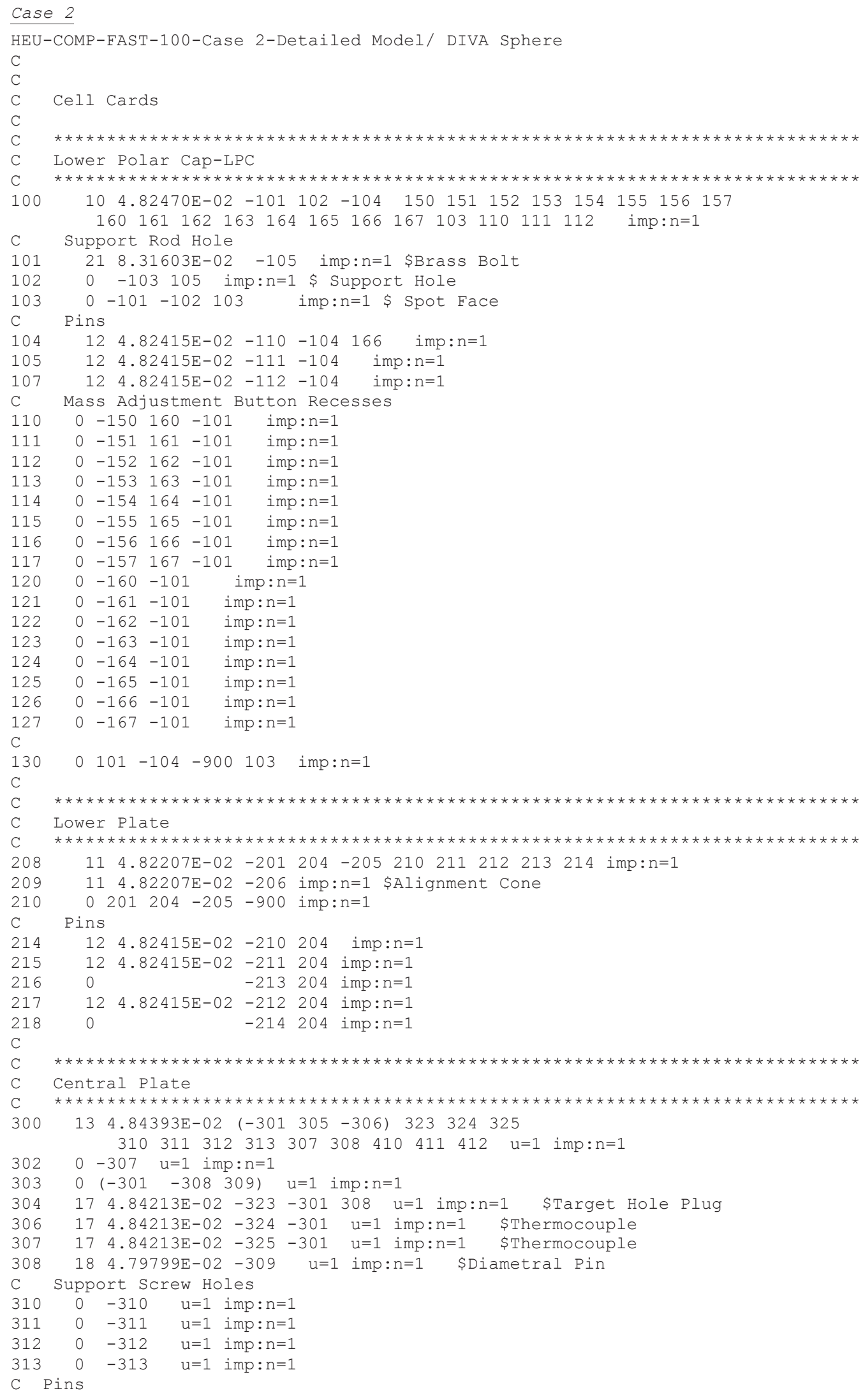




\section{NEA/NSC/DOC(95)03/II \\ Volume II}

\section{HEU-MET-FAST-100}

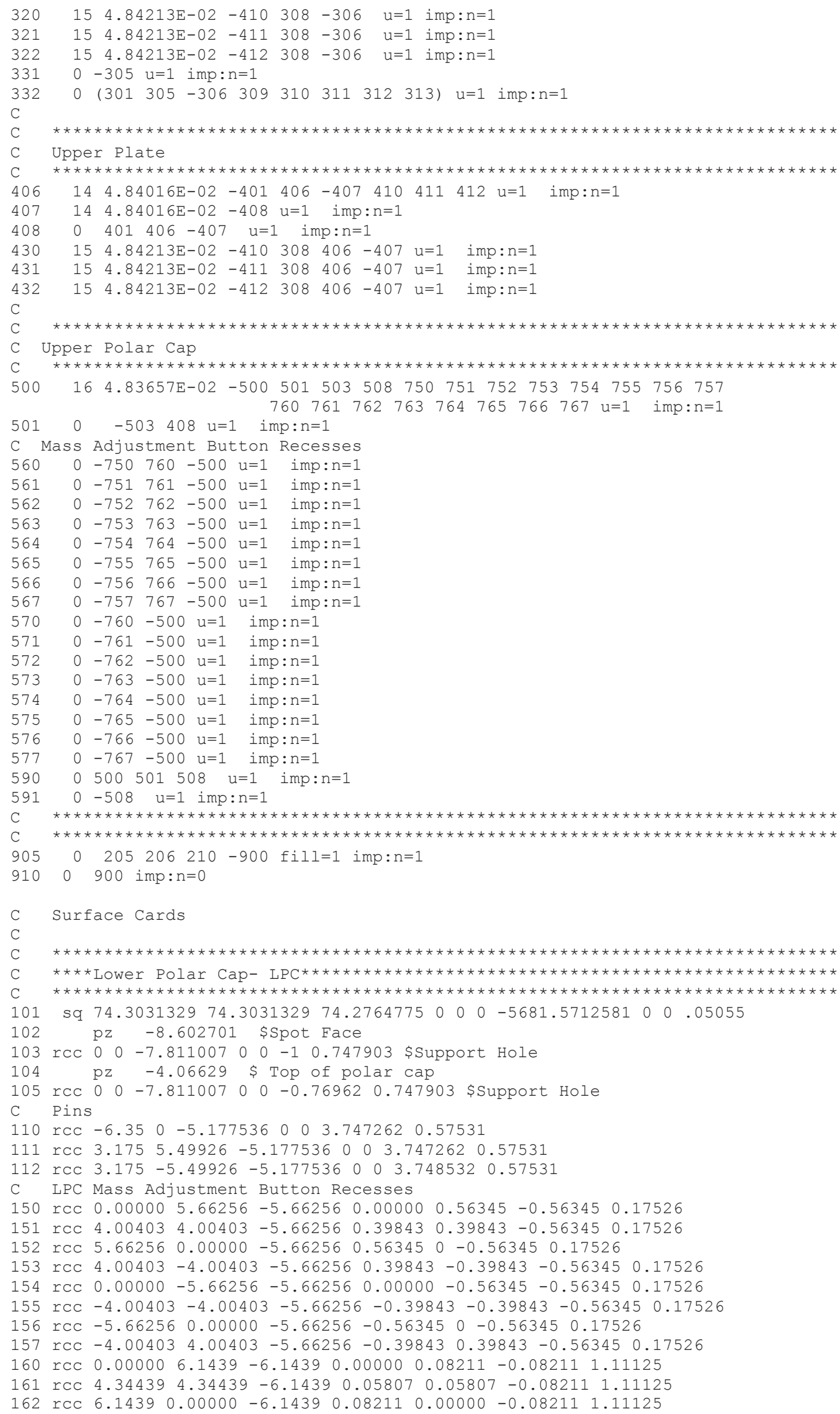

Revision: 0 


\section{NEA/NSC/DOC(95)03/II \\ Volume II}

\section{HEU-MET-FAST-100}

$163 \operatorname{rcc} 4.34439-4.34439-6.14390 .05807-0.05807-0.08211 \quad 1.11125$

164 rCc $0.00000-6.1439-6.14390 .00000-0.08211-0.082111 .11125$

165 rcc $-4.34439-4.34439-6.1439-0.05807-0.05807-0.082111 .11125$

$166 r C C-6.14390 .00000-6.1439-0.082110 .00000-0.08211 \quad 1.11125$

$167 \operatorname{rCc}-4.344394 .34439-6.1439-0.05807 \quad 0.05807-0.082111 .11125$

C

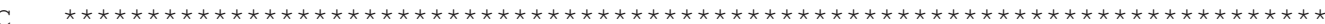

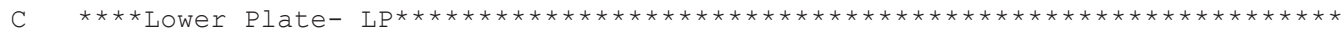

C $\quad * * * * * * * * * * * * * * * * * * * * * * * * * * * * * * * * * * * * * * * * * * * * * * * * * * * * * * * * * * * * * * * * * * * * * * * * * * * *$

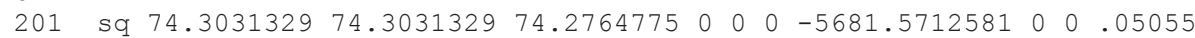

$204 \quad \mathrm{pz} \quad-4.06629$ \$Bottom of LP

$205 \mathrm{pz}-1.429004$ \$ Top of lower plate

206 trc $0 \quad 0 \quad-1.429004000 .553720 .6350 .315309609$ \$ LP Alignment cone

C Lower Section Pins

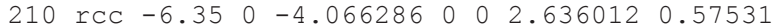

$211 \operatorname{rcc} 3.175 \quad 5.49926 \quad-4.066286 \quad 0 \quad 0 \quad 2.636012 \quad 0.57531$

$212 \operatorname{rcc} 3.175 \quad-5.49926-4.066286 \quad 0 \quad 0 \quad 2.637282 \quad 0.57531$

$213 \operatorname{rcc} 3.175 \quad 5.49926-1.430274 \quad 0 \quad 0 \quad 0.001270 \quad 0.57531$

214 rcc $-6.35 \quad 0 \quad-1.430274 \quad 0 \quad 0 \quad 0.001270 \quad 0.57531$

C

C

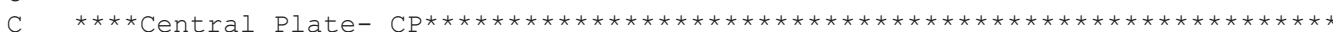

C $\quad * * * * * * * * * * * * * * * * * * * * * * * * * * * * * * * * * * * * * * * * * * * * * * * * * * * * * * * * * * * * * * * * * * * * * * * * * * * *$

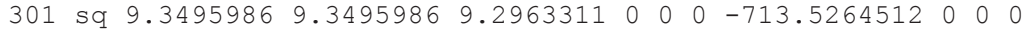

$305 \mathrm{pz}-1.429004$ \$bottom of Central Plate

306 pz 1.429004 \$Top of Central Plate

307 trc $0 \quad 0 \quad-1.429004000 .57150 .636270 .306314321$ \$ CP Alignment Hole

$308 \mathrm{cx} 0.17272$ \$Diametral Hole

309 rCC -8.91476500017 .82953000 .164211 \$ Diametral Pin

323 rec 0.888238008 .804910001 .27 \$ Target Hole Plug

$324 \mathrm{rpp}-0.08890 .0889-0.9525 \quad 4.1275 \quad 1.281684 \quad 1.429004$ \$Thermocouple

$325 \mathrm{rpp}-0.08890 .0889 \quad 4.1275 \quad 8.80491 \quad 1.134364 \quad 1.429004$ \$Thermocouple

C Support Rod Holes in $\mathrm{CP}$

$\begin{array}{lllllllll}310 & \operatorname{rCC} & 5.74467 & 5.74467 & 0 & 0.43734 & 0.43734 & 0 & 0.351028\end{array}$

311 rec $5.74467-5.74467 \quad 0 \quad 0.43734-0.43734 \quad 0 \quad 0.351028$

$\begin{array}{llllllllll}312 \text { rCC } & -5.74467 & -5.74467 & 0 & -0.43734 & -0.43734 & 0 & 0.351028\end{array}$

$\begin{array}{llllllllll}313 & \text { rCC } & -5.74467 & 5.74467 & 0 & -0.43734 & 0.43734 & 0 & 0.351028\end{array}$

C

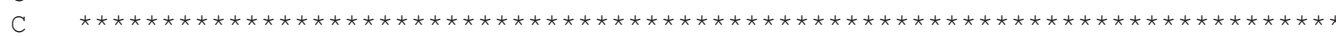

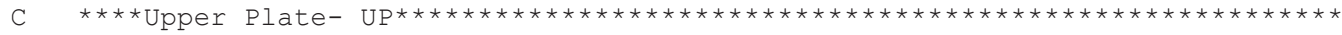

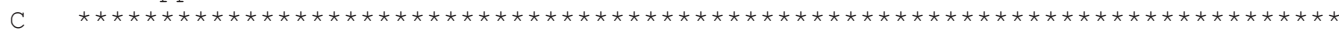

401 sq $9.34959869 .3495986 \quad 9.296331100000-713.52645120000$

$406 \mathrm{pz} 1.429004$ \$Bottom of Upper Plate

$407 \mathrm{pz} 3.375152$ \$Top of upper Plate

$408 \operatorname{trc} 0 \quad 0 \quad 3.375152000 .553720 .6350 .315309609$ \$ UP Alignment Cone

C Central Section Pins

410 rCC $-6.35-0.00063-1.42900400 \quad 4.804156 \quad 0.57531$

411 rcc $3.17445 \quad 5.49958-1.429004 \quad 0 \quad 0 \quad 4.804156 \quad 0.57531$

$412 \operatorname{rcc} 3.17555-5.49894-1.42900400 \quad 4.804156 \quad 0.57531$

C

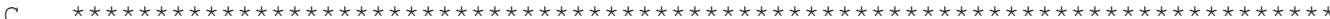

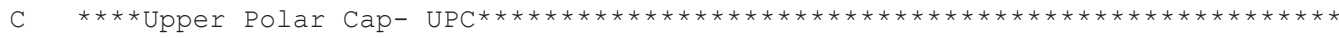

500 sq $65.429930065 .4299300 \quad 65.35440960000-5000.2641811000 .046482$

$501 \mathrm{pz} 3.375152$ \$Bottom of UPC

508 rec 007.8061820001 .111251 .211072 \$top support hole

503 trc $0 \quad 0 \quad 3.375152 \quad 0 \quad 0 \quad 0.57150 .63627 \quad 0.306314321$ \$ UPC Alignment Hole

$504 \operatorname{trc} 0 \quad 0 \quad 3.375152000 .562610 .6356350 .310811965$ \$Cone for modeling

C UPC Mass Adjustment Button Recesses

$\begin{array}{lllllllll}750 & \text { rcc } & 0.00000 & 5.66256 & 5.66256 & 0.00000 & 0.56345 & 0.56345 & 0.17526\end{array}$

$\begin{array}{lllllllll}751 & \operatorname{rCc} & 4.00403 & 4.00403 & 5.66256 & 0.39843 & 0.39843 & 0.56345 & 0.17526\end{array}$

$\begin{array}{lllllllll}752 & \operatorname{rcc} & 5.66256 & 0 & 5.66256 & 0.56345 & 0 & 0.56345 & 0.17526\end{array}$

753 rCC $4.00403-4.00403 \quad 5.66256 \quad 0.39843-0.39843 \quad 0.563450 .17526$

$\begin{array}{lllllllll}754 \mathrm{rcc} & 0.00000 & -5.66256 & 5.66256 & 0.00000 & -0.56345 & 0.56345 & 0.17526\end{array}$

755 rcc $-4.00403-4.00403 \quad 5.66256-0.39843-0.398430 .563450 .17526$

$756 r C C-5.66256 \quad 0 \quad 5.66256-0.5634500 .563450 .17526$

757 rcc $-4.004034 .00403 \quad 5.66256-0.39843 \quad 0.39843 \quad 0.56345 \quad 0.17526$

$\begin{array}{lllllllllll}760 & \text { rcc } & 0.00000 & 6.1439 & 6.1439 & 0.00000 & 0.08211 & 0.08211 & 1.11125\end{array}$

$\begin{array}{llllllllllll}761 & \text { rCC } & 4.34439 & 4.34439 & 6.1439 & 0.05807 & 0.05807 & 0.08211 & 1.11125\end{array}$

$\begin{array}{llllllllll}762 \operatorname{rcc} & 6.14390 & 0 & 6.1439 & 0.08211 & 0 & 0.08211 & 1.11125\end{array}$

$\begin{array}{llllllllll}763 \operatorname{rcc} & 4.34439 & -4.34439 & 6.1439 & 0.05807 & -0.05807 & 0.08211 & 1.11125\end{array}$

$764 \operatorname{rcc} 0.00000-6.14396 .14390 .00000-0.082110 .082111 .11125$

Revision: 0 


\section{NEA/NSC/DOC(95)03/II \\ Volume II}

\section{HEU-MET-FAST-100}

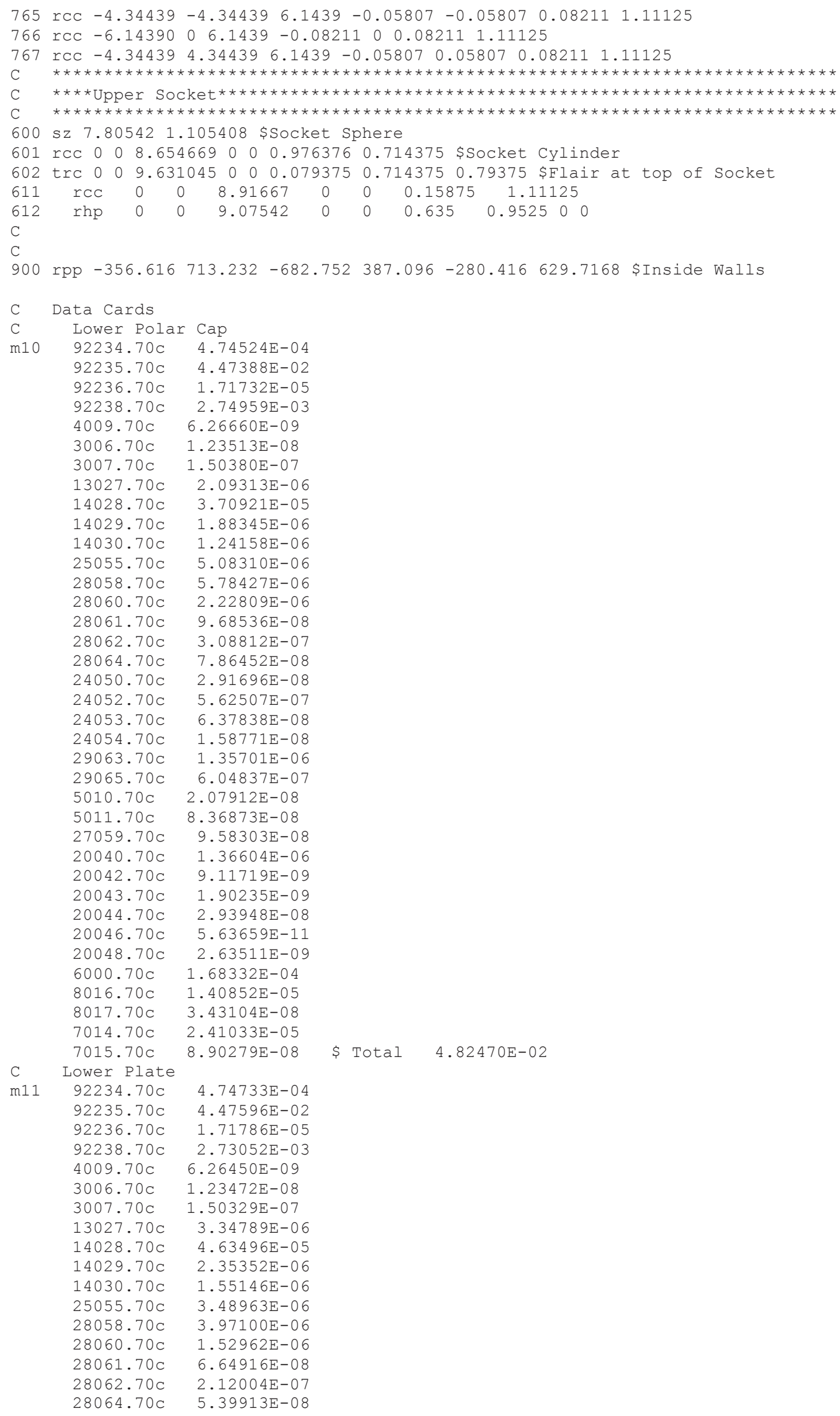

Revision: 0 
NEA/NSC/DOC(95)03/II

Volume II

HEU-MET-FAST-100

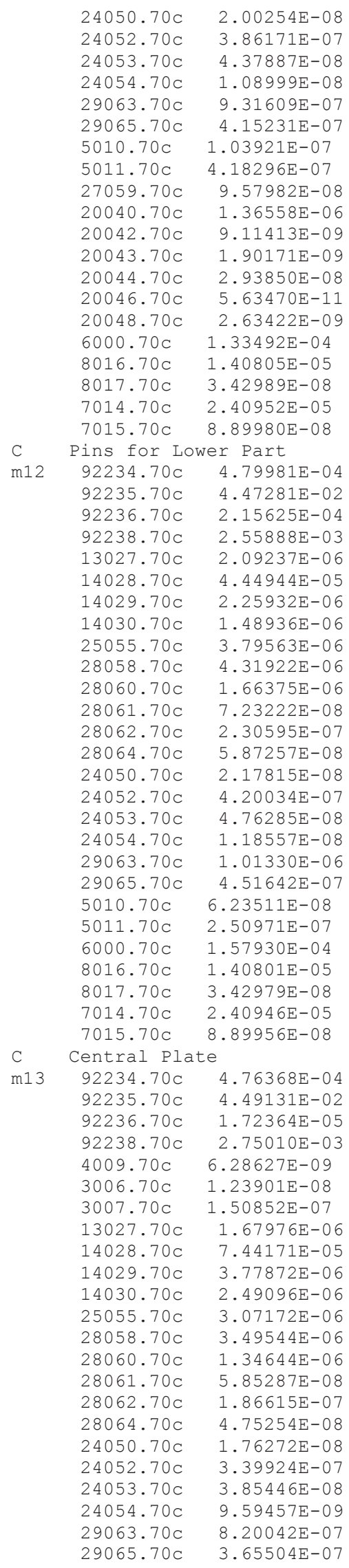

\$ Total 4.82207E-02

\$ Total 4.82415E-02

Revision: 0

Date: September 30, 2013

Page 92 of 160 
NEA/NSC/DOC(95)03/II

Volume II

HEU-MET-FAST-100

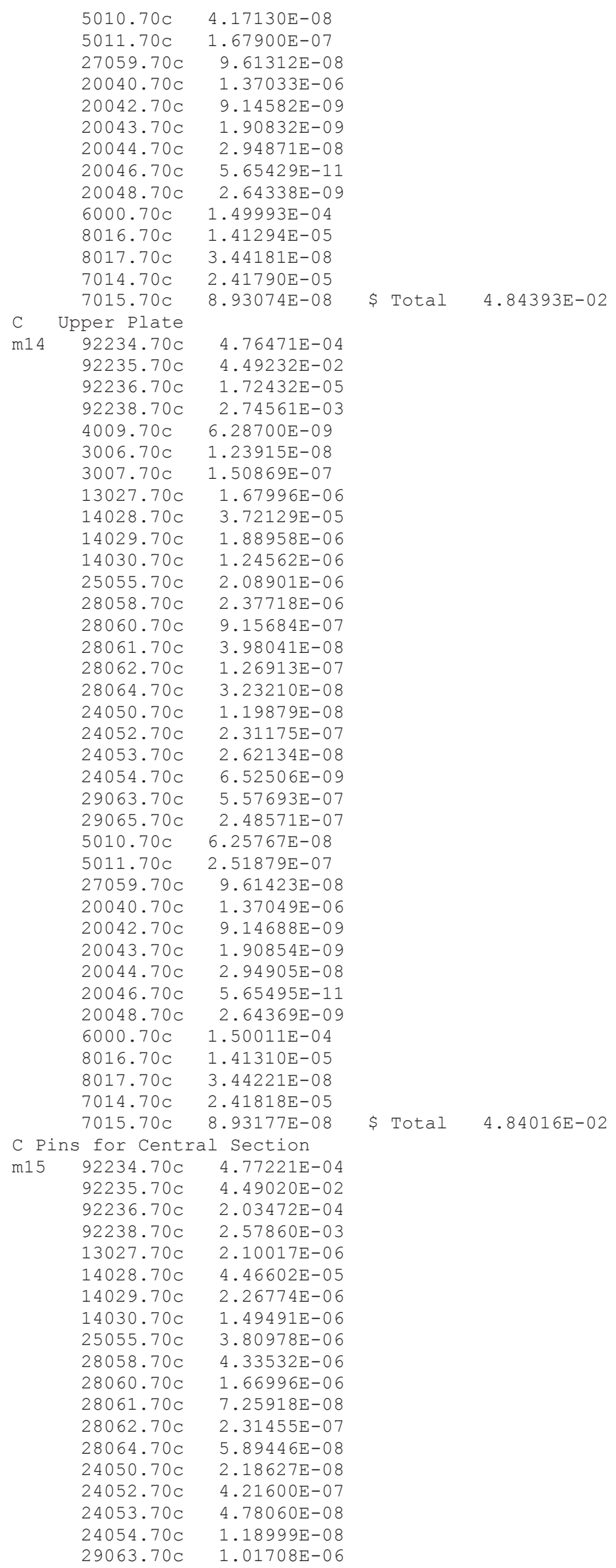

Revision: 0

Date: September 30, 2013

Page 93 of 160 
NEA/NSC/DOC(95)03/II

Volume II

HEU-MET-FAST-100

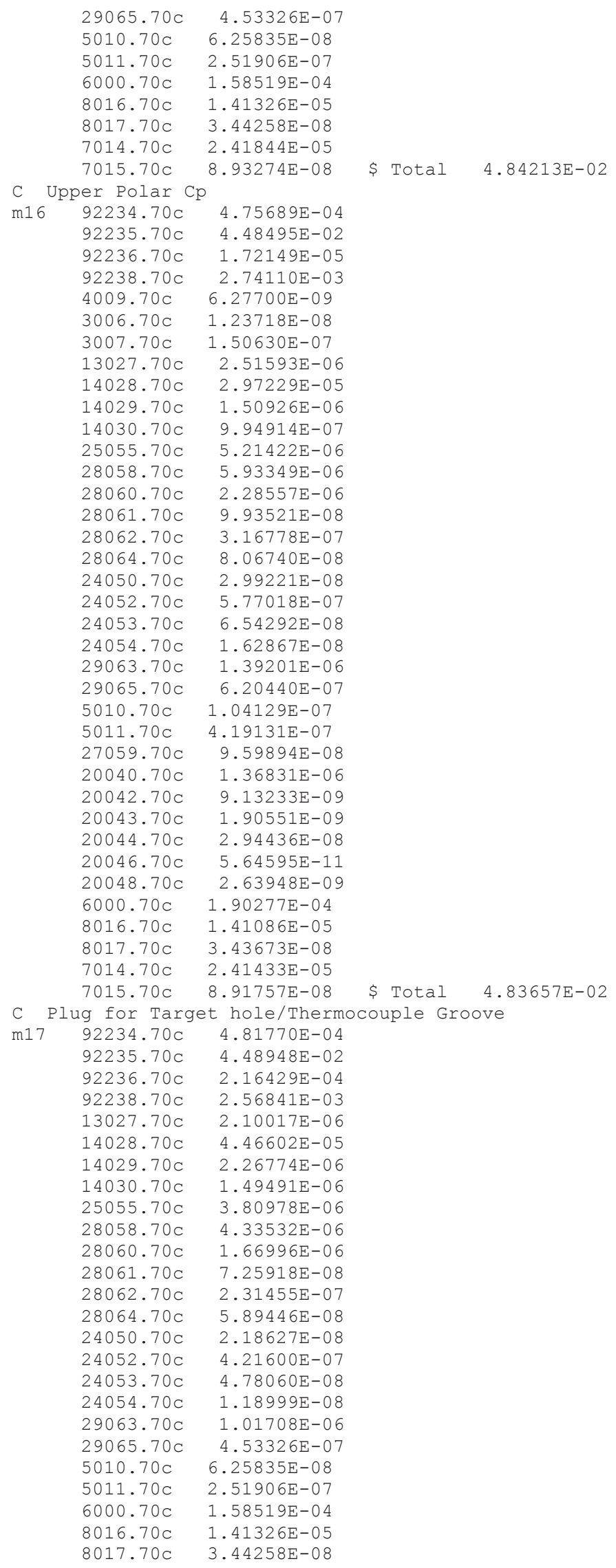

Revision: 0

Date: September 30, 2013

Page 94 of 160 
NEA/NSC/DOC(95)03/II

Volume II

HEU-MET-FAST-100

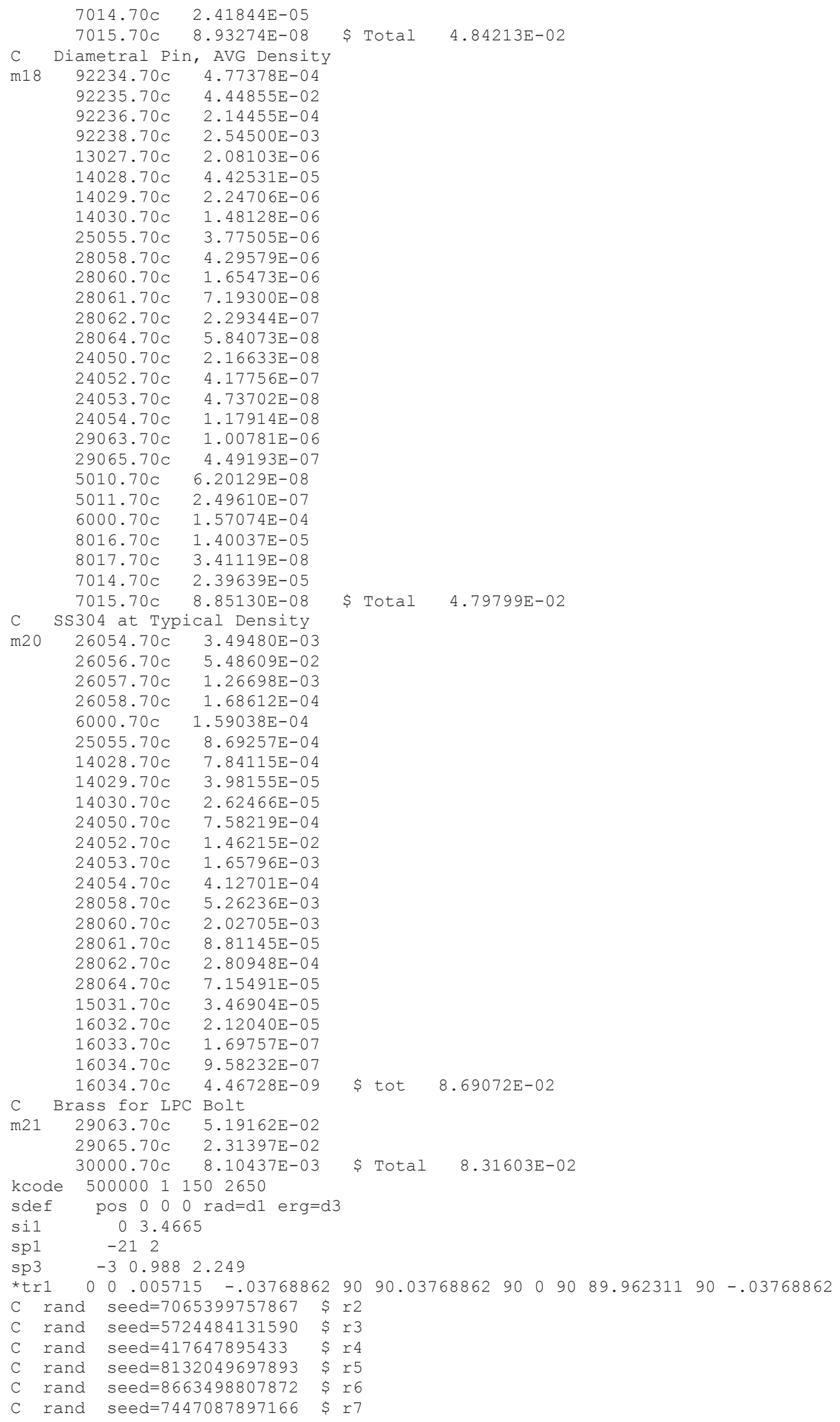

Revision: 0 
NEA/NSC/DOC(95)03/II

Volume II

HEU-MET-FAST-100

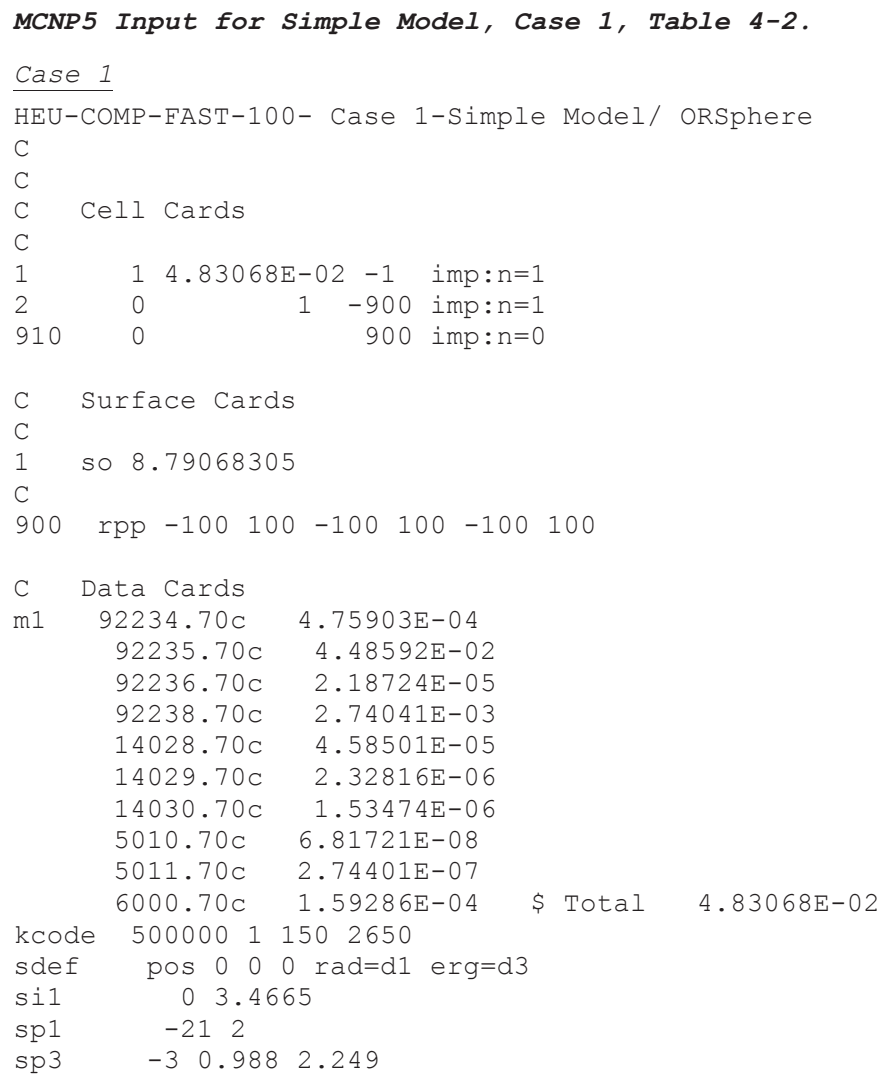


NEA/NSC/DOC(95)03/II

Volume II

HEU-MET-FAST-100

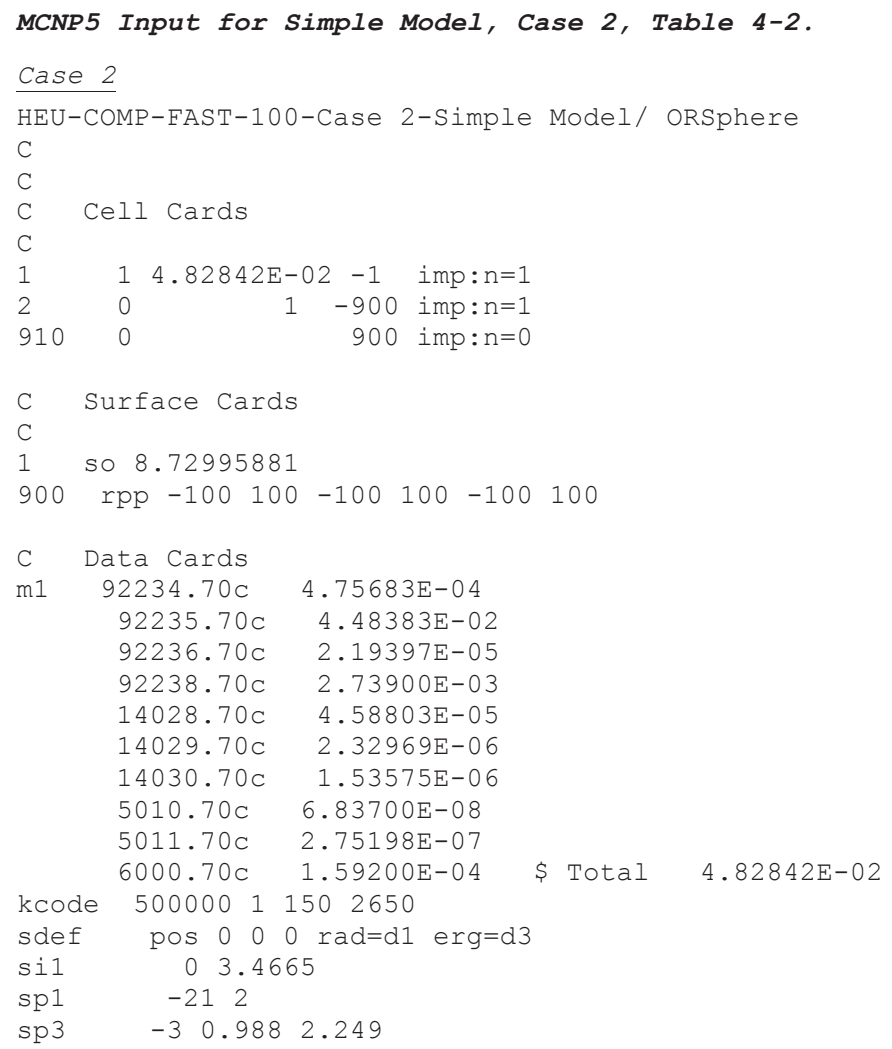


NEA/NSC/DOC(95)03/II

Volume II

HEU-MET-FAST-100

\section{A.2 KENO Input Listing}

KENO Input for Detailed Model, Case 1, Table 4-1.

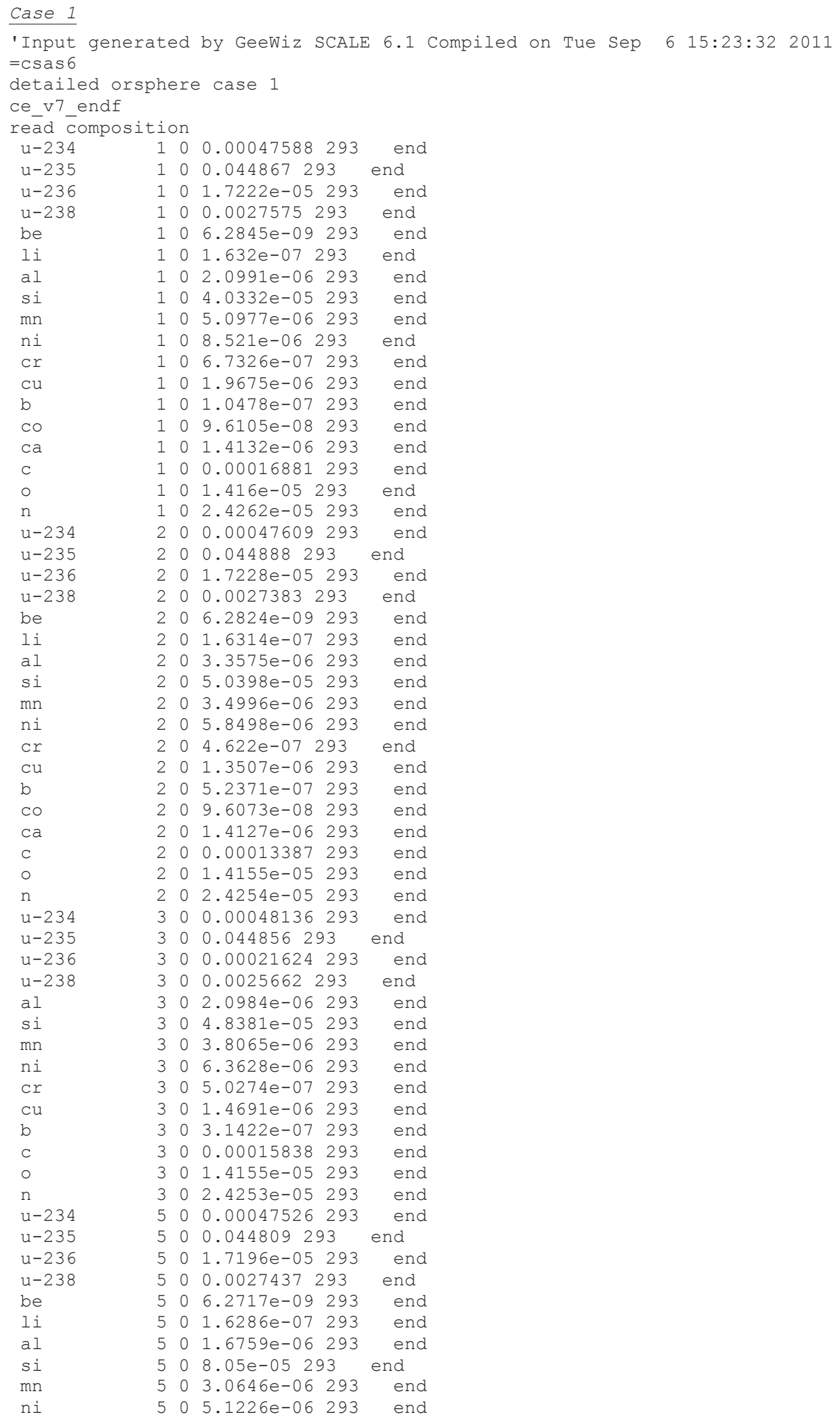

Revision: 0 
NEA/NSC/DOC(95)03/II

Volume II

HEU-MET-FAST-100

\begin{tabular}{|c|c|c|c|c|c|}
\hline $\mathrm{Cr}$ & 5 & 0 & $4.0475 e-07$ & 293 & end \\
\hline $\mathrm{Cu}$ & 5 & 0 & $1.1828 e-06$ & 293 & end \\
\hline $\mathrm{b}$ & 5 & 0 & $2.0913 e-07$ & 293 & end \\
\hline $\mathrm{CO}$ & 5 & 0 & $9.5908 e-08$ & 293 & end \\
\hline $\mathrm{Ca}$ & 5 & 0 & $1.4103 e-06$ & 293 & end \\
\hline $\mathrm{C}$ & 5 & 0 & 0.00014965 & 293 & end \\
\hline o & 5 & 0 & $1.4131 e-05$ & 293 & end \\
\hline$n$ & 5 & 0 & $2.4212 e-05$ & 293 & end \\
\hline$u-234$ & 6 & 0 & 0.00047537 & 293 & end \\
\hline$u-235$ & 6 & 0 & 0.04481929 & $93 \in$ & end \\
\hline$u-236$ & 6 & 0 & $1.7203 e-05$ & 293 & end \\
\hline$u-238$ & 6 & 0 & 0.00273922 & 293 & end \\
\hline be & 6 & 0 & $6.2724 e-09$ & 293 & end \\
\hline $1 i$ & 6 & 0 & $1.6288 e-07$ & 293 & end \\
\hline al & 6 & 0 & $1.6761 e-06$ & 293 & end \\
\hline si & 6 & 0 & $4.0255 e-05$ & 293 & end \\
\hline $\mathrm{mn}$ & 6 & 0 & $2.0842 e-06$ & 293 & end \\
\hline ni & 6 & 0 & $3.4838 e-06$ & 293 & end \\
\hline $\mathrm{Cr}$ & 6 & 0 & $2.7526 e-07$ & 293 & end \\
\hline $\mathrm{Cu}$ & 6 & 0 & $8.044 e-072$ & 293 & end \\
\hline $\mathrm{b}$ & 6 & 0 & $3.1373 e-07$ & 293 & end \\
\hline $\mathrm{CO}$ & 6 & 0 & $9.5919 e-08$ & 293 & end \\
\hline $\mathrm{Ca}$ & 6 & 0 & $1.4105 e-06$ & 293 & end \\
\hline $\mathrm{C}$ & 6 & 0 & 0.00014966 & 293 & end \\
\hline ० & 6 & 0 & $1.4133 e-05$ & 293 & end \\
\hline $\mathrm{n}$ & 6 & 0 & $2.4215 e-05$ & 293 & end \\
\hline$u-234$ & 7 & 0 & 0.00047611 & 293 & end \\
\hline$u-235$ & 7 & 0 & $0.044798 \quad 29$ & & end \\
\hline$u-236$ & 7 & 0 & 0.00020329 & & end \\
\hline$u-238$ & 7 & 0 & 0.00257262 & 293 & end \\
\hline al & 7 & 0 & $2.0953 e-06$ & 293 & end \\
\hline si & 7 & 0 & $4.8311 e-05$ & 293 & end \\
\hline $\mathrm{mn}$ & 7 & 0 & $3.801 e-062$ & 293 & end \\
\hline $\mathrm{ni}$ & 7 & 0 & $6.3535 e-06$ & 293 & end \\
\hline $\mathrm{Cr}$ & 7 & 0 & $5.02 e-0729$ & & end \\
\hline $\mathrm{cu}$ & 7 & 0 & $1.467 e-062$ & 293 & end \\
\hline $\mathrm{b}$ & 7 & 0 & $3.1376 e-07$ & 293 & end \\
\hline C & 7 & 0 & 0.00015815 & 293 & end \\
\hline o & 7 & 0 & $1.4134 e-05$ & 293 & end \\
\hline $\mathrm{n}$ & 7 & 0 & $2.4217 e-05$ & 293 & end \\
\hline$u-234$ & 8 & 0 & 0.00048065 & 293 & end \\
\hline$u-235$ & 8 & 0 & 0.04479129 & & end \\
\hline$u-236$ & 8 & 0 & 0.00021593 & 293 & end \\
\hline$u-238$ & 8 & 0 & 0.00256252 & 293 & end \\
\hline al & 8 & 0 & $2.0953 e-06$ & 293 & end \\
\hline $\mathrm{si}$ & 8 & 0 & $4.8311 e-05$ & 293 & end \\
\hline $\mathrm{mn}$ & 8 & 0 & $3.801 e-062$ & 293 & end \\
\hline $\mathrm{ni}$ & 8 & 0 & $6.3535 e-06$ & 293 & end \\
\hline $\mathrm{Cr}$ & 8 & 0 & $5.02 e-0729$ & 93 & end \\
\hline $\mathrm{Cu}$ & 8 & 0 & $1.467 e-062$ & 293 & end \\
\hline $\mathrm{b}$ & 8 & 0 & $3.1376 e-07$ & 293 & end \\
\hline C & 8 & 0 & 0.00015815 & 293 & end \\
\hline o & 8 & 0 & $1.4134 e-05$ & 293 & end \\
\hline $\mathrm{n}$ & 8 & 02 & $2.4217 e-05$ & 293 & end \\
\hline$u-234$ & 10 & 0 & 0.00047635 & 5293 & end \\
\hline$u-235$ & 10 & 0 & 0.0449112 & 293 & end \\
\hline$u-236$ & 10 & 0 & $1.7239 e-05$ & 5293 & end \\
\hline$u-238$ & 10 & 0 & 0.0027449 & 293 & end \\
\hline be & 10 & 0 & $6.2857 e-09$ & 293 & end \\
\hline $1 i$ & 10 & 0 & $1.6323 e-07$ & 7293 & end \\
\hline al & 10 & 0 & $2.5194 e-06$ & 5293 & end \\
\hline $\mathrm{si}$ & 10 & 0 & $3.2272 e-05$ & 293 & end \\
\hline $\mathrm{mn}$ & 10 & 0 & $5.2214 e-06$ & 5293 & end \\
\hline ni & 10 & 0 & $8.7279 e-06$ & 5293 & end \\
\hline $\mathrm{Cr}$ & 10 & 0 & $6.8961 e-07$ & 293 & end \\
\hline $\mathrm{Cu}$ & 10 & 0 & $2.0152 e-06$ & 5293 & end \\
\hline $\mathrm{b}$ & 10 & 0 & $5.2398 e-07$ & 7293 & end \\
\hline $\mathrm{CO}$ & 10 & 0 & $9.6122 e-08$ & 293 & end \\
\hline $\mathrm{Ca}$ & 10 & 0 & $1.4134 e-06$ & 5293 & end \\
\hline C & 10 & 0 & 0.00019054 & 293 & end \\
\hline o & 10 & 0 & $1.4162 e-05$ & 5293 & end \\
\hline $\mathrm{n}$ & 10 & 0 & $2.4266 e-05$ & 5293 & end \\
\hline
\end{tabular}

Revision: 0 


\section{NEA/NSC/DOC(95)03/II \\ Volume II}

\section{HEU-MET-FAST-100}

\begin{tabular}{|c|c|c|c|c|}
\hline$u-234$ & 12 & 0 & 0.00047738293 & end \\
\hline$u-235$ & 12 & 0 & 0.044485293 & end \\
\hline$u-236$ & 12 & 0 & 0.00021446293 & end \\
\hline$u-238$ & 12 & 0 & 0.002545293 & end \\
\hline al & 12 & 0 & $2.081 e-06293$ & end \\
\hline $\mathrm{si}$ & 12 & 0 & $4.7981 e-05293$ & end \\
\hline $\mathrm{mn}$ & 12 & 0 & $3.7751 e-06293$ & end \\
\hline $\mathrm{ni}$ & 12 & 0 & $6.3102 e-06293$ & end \\
\hline $\mathrm{Cr}$ & 12 & 0 & $4.9858 e-07293$ & end \\
\hline $\mathrm{cu}$ & 12 & 0 & $1.457 e-06293$ & end \\
\hline $\mathrm{b}$ & 12 & 0 & $3.1162 e-07293$ & end \\
\hline C & 12 & 0 & 0.00015707293 & end \\
\hline o & 12 & 0 & $1.4038 e-05293$ & end \\
\hline $\mathrm{n}$ & 12 & 0 & $2.4052 e-05293$ & end \\
\hline $\mathrm{cu}$ & 15 & 0 & 0.075056293 & end \\
\hline $\mathrm{zn}$ & 15 & 0 & 0.0081044293 & end \\
\hline
\end{tabular}

end composition

read parameter

gen $=2650$

$\mathrm{npg}=500000$

$\mathrm{nsk}=150$

$\mathrm{htm}=\mathrm{no}$

end parameter

read geometry

global unit 1

com="orcef sphere bottom section"

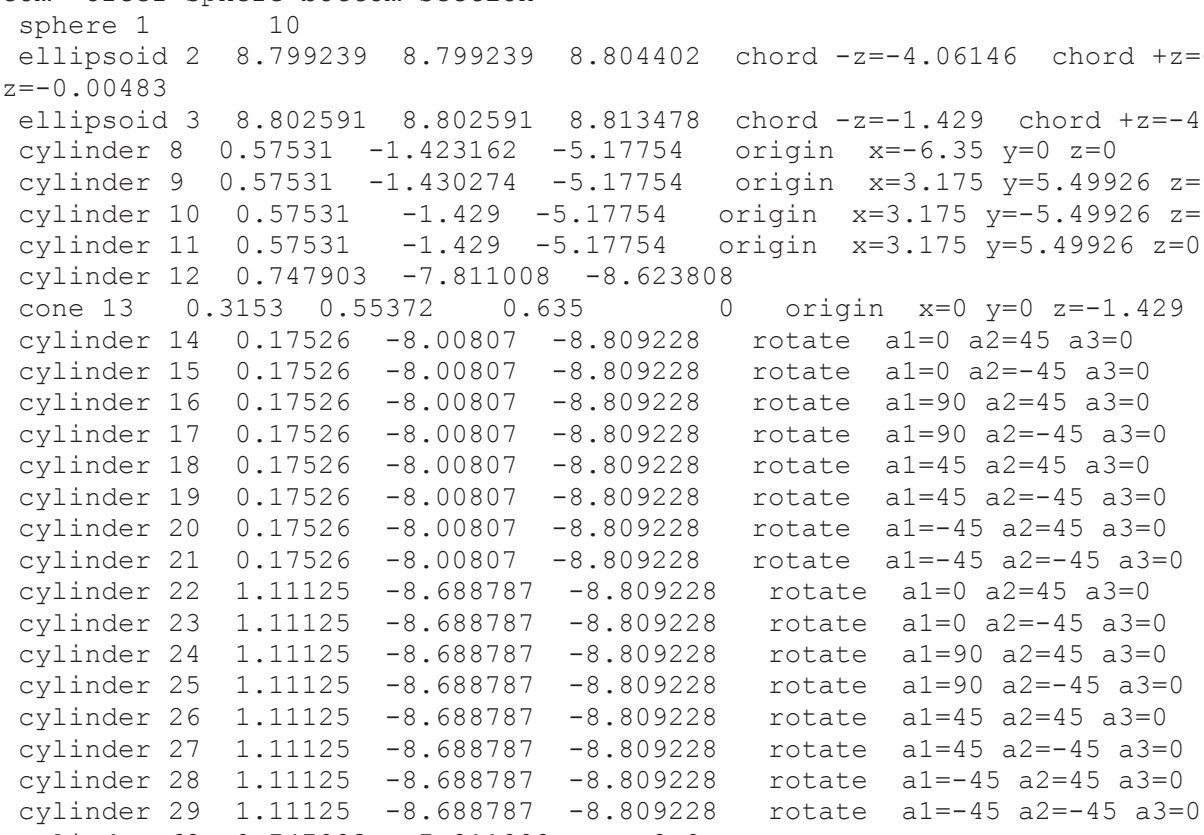

cylinder $2901.11125-8.688787-8.809228$

hole 2 origin $x=0 \quad y=0 \quad z=0.00351038$ rotate a1 $=-90$ a2=-0.02313405 a3=90

$\begin{array}{llllllllllllllllllllllllll}\text { media } & 1 & 1 & 2 & -8 & -10 & -11 & -14 & -15 & -16 & -17 & -18 & -19 & -20 & -21 & -22 & -23 & -24 & -25 & -26 & -27 & -28 & -29 & -68\end{array}$

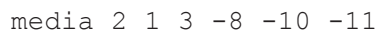

media 2113

media 318

media 3119

media 3110

$\begin{array}{lllll}\text { media } & 0 & 1 & -9 & 11\end{array}$

media 15112

$\begin{array}{llllll}\text { media } & 0 & 1 & 2 & 68 & -12\end{array}$

media $0 \begin{array}{lllll} & 1 & 14 & -22 & 2\end{array}$

$\begin{array}{llllll}\text { media } & 0 & 1 & 15 & -23 & 2\end{array}$

$\begin{array}{llllll}\text { media } & 0 & 1 & 16 & -24 & 2\end{array}$

$\begin{array}{llllll}\text { media } & 0 & 1 & 17 & -25 & 2\end{array}$

$\begin{array}{llllll}\text { media } & 0 & 1 & 18 & -26 & 2\end{array}$

$\begin{array}{llllll}\text { media } & 0 & 1 & 19 & -27 & 2\end{array}$

$\begin{array}{llllll}\text { media } & 0 & 1 & 20 & -28 & 2\end{array}$

media $0 \begin{array}{lllll} & 1 & 21 & -29 & 2\end{array}$

media 01222

Revision: 0 


\section{NEA/NSC/DOC(95)03/II \\ Volume II}

\section{HEU-MET-FAST-100}

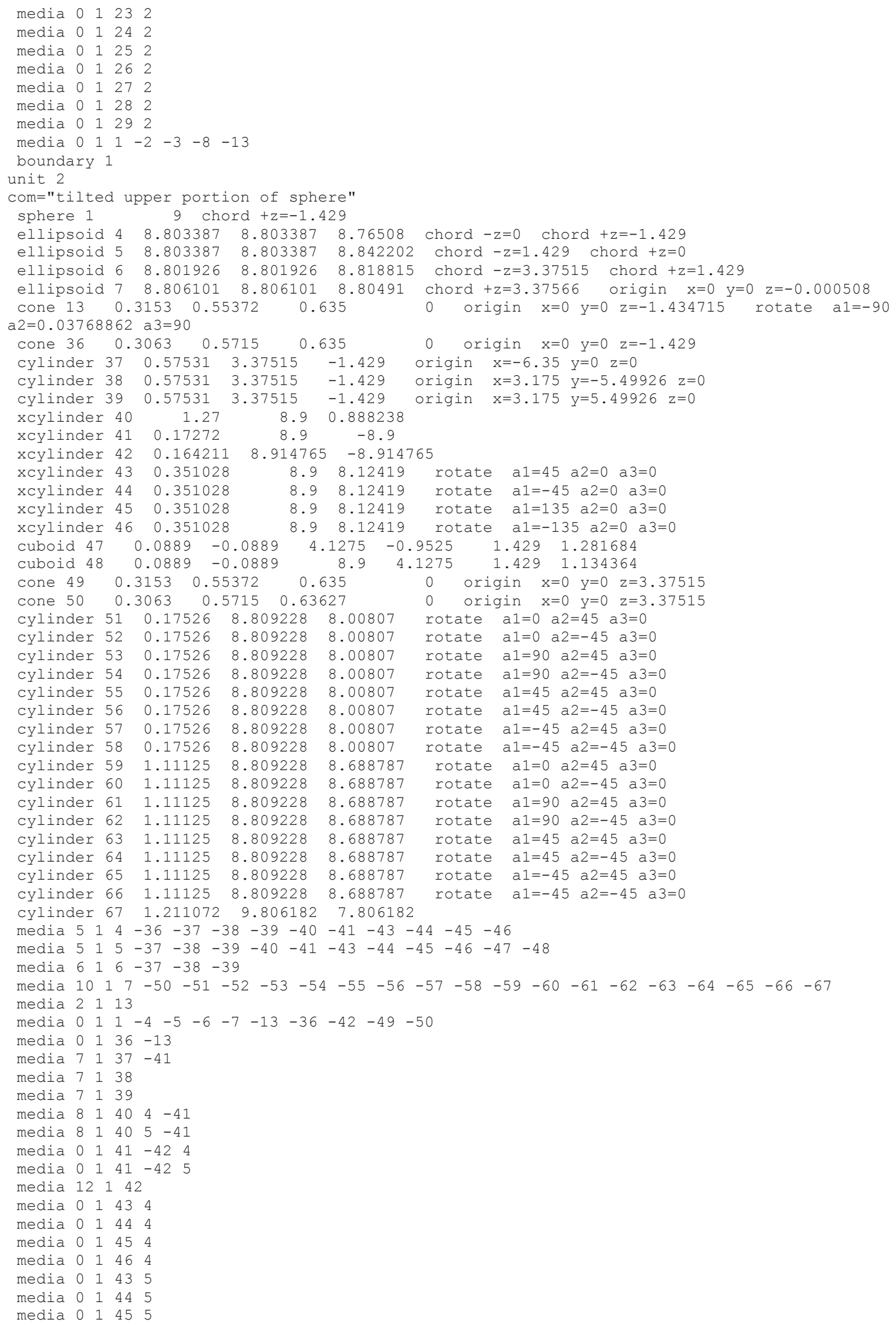

Revision: 0 
NEA/NSC/DOC(95)03/II

Volume II

HEU-MET-FAST-100

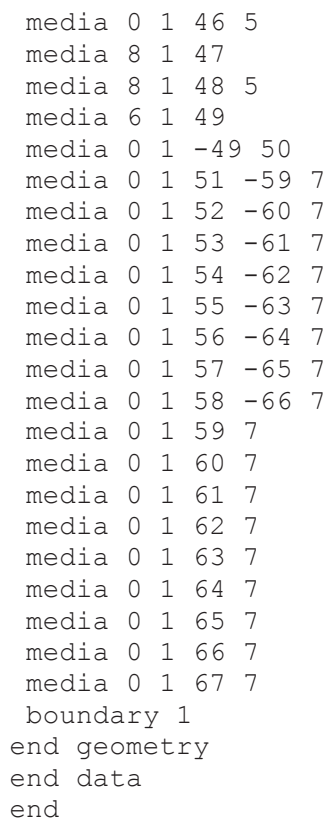


NEA/NSC/DOC(95)03/II

Volume II

HEU-MET-FAST-100

KENO Input for Detailed Model, Case 2, Table 4-1.

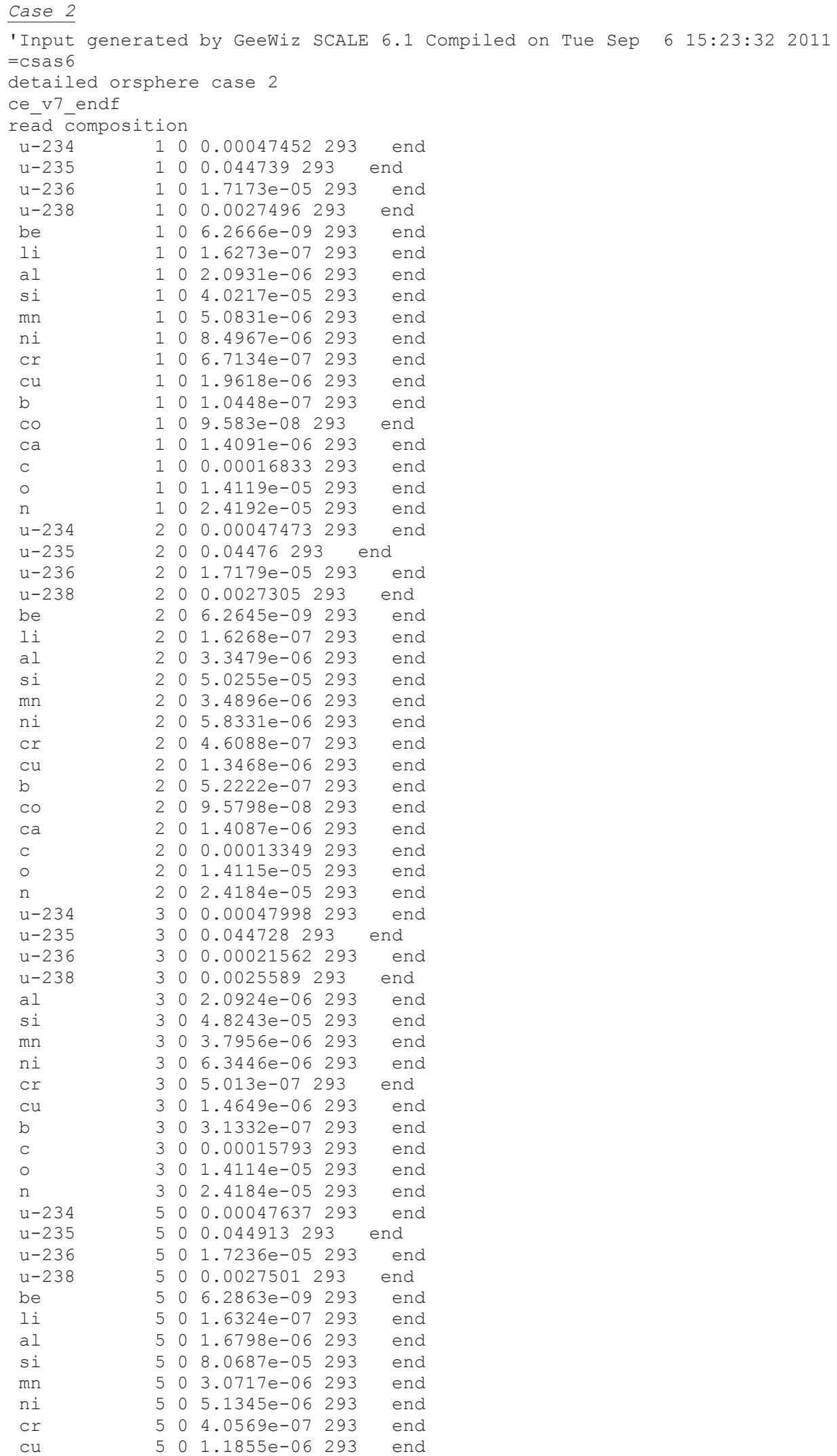

Revision: 0 
NEA/NSC/DOC(95)03/II

Volume II

HEU-MET-FAST-100

\begin{tabular}{|c|c|c|c|c|c|}
\hline $\mathrm{b}$ & 5 & 0 & $2.0961 e-072$ & 293 & end \\
\hline $\mathrm{CO}$ & 5 & 0 & $9.6131 e-08$ & 293 & end \\
\hline $\mathrm{ca}$ & 5 & 0 & $1.4136 e-06$ & 293 & end \\
\hline $\mathrm{C}$ & 5 & 0 & 0.000149992 & 293 & end \\
\hline ○ & 5 & 0 & $1.4164 e-052$ & 293 & end \\
\hline $\mathrm{n}$ & 5 & 0 & $2.4268 e-052$ & 293 & end \\
\hline$u-234$ & 6 & 0 & 0.000476472 & 293 & end \\
\hline$u-235$ & 6 & 0 & 0.044923293 & & end \\
\hline$u-236$ & 6 & 0 & $1.7243 e-052$ & 293 & end \\
\hline$u-238$ & 6 & 0 & 0.002745629 & 93 & end \\
\hline be & 6 & 0 & $6.287 e-0929$ & 93 & end \\
\hline $1 i$ & 6 & 0 & $1.6326 e-072$ & 293 & end \\
\hline al & 6 & 0 & $1.68 e-06293$ & & end \\
\hline si & 6 & 0 & $4.0348 e-052$ & 293 & end \\
\hline$m n$ & 6 & 0 & $2.089 e-0629$ & 93 & end \\
\hline ni & 6 & 0 & $3.4919 e-062$ & 293 & end \\
\hline $\mathrm{Cr}$ & 6 & 0 & $2.759 e-0729$ & 93 & end \\
\hline $\mathrm{Cu}$ & 6 & 0 & $8.0626 e-072$ & 293 & end \\
\hline $\mathrm{b}$ & 6 & 0 & $3.1446 e-072$ & 293 & end \\
\hline $\mathrm{CO}$ & 6 & 0 & $9.6142 e-082$ & 293 & end \\
\hline $\mathrm{ca}$ & 6 & 0 & $1.4137 e-062$ & 293 & end \\
\hline C & 6 & 0 & 0.000150012 & 293 & end \\
\hline ० & 6 & 0 & $1.4165 e-052$ & 293 & end \\
\hline $\mathrm{n}$ & 6 & 0 & $2.4271 e-052$ & 293 & end \\
\hline$u-234$ & 7 & 0 & 0.000477222 & 293 & end \\
\hline$u-235$ & 7 & 0 & $0.044902 \quad 293$ & & end \\
\hline$u-236$ & 7 & 0 & 0.000203472 & 293 & end \\
\hline$u-238$ & 7 & 0 & 0.002578629 & 93 & end \\
\hline al & 7 & 0 & $2.1002 e-062$ & 293 & end \\
\hline si & 7 & 0 & $4.8423 e-052$ & 293 & end \\
\hline $\mathrm{mn}$ & 7 & 0 & $3.8098 e-062$ & 293 & end \\
\hline ni & 7 & 0 & $6.3683 e-062$ & 293 & end \\
\hline $\mathrm{Cr}$ & 7 & 0 & $5.0317 e-072$ & 293 & end \\
\hline $\mathrm{Cu}$ & 7 & 0 & $1.4704 e-062$ & 293 & end \\
\hline $\mathrm{b}$ & 7 & 0 & $3.1449 e-072$ & 293 & end \\
\hline C & 7 & 0 & 0.000158522 & 293 & end \\
\hline ० & 7 & 0 & $1.4167 e-052$ & 293 & end \\
\hline $\mathrm{n}$ & 7 & 0 & $2.4274 e-052$ & 293 & end \\
\hline$u-234$ & 8 & 0 & 0.000481772 & 293 & end \\
\hline$u-235$ & 8 & 0 & 0.044895293 & & end \\
\hline$u-236$ & 8 & 0 & 0.000216432 & 293 & end \\
\hline$u-238$ & 8 & 0 & 0.002568429 & 93 & end \\
\hline al & 8 & 0 & $2.1002 e-062$ & 293 & end \\
\hline si & 8 & 0 & $4.8423 e-052$ & 293 & end \\
\hline$m n$ & 8 & 0 & $3.8098 e-062$ & 293 & end \\
\hline$n i$ & 8 & 0 & $6.3683 e-062$ & 293 & end \\
\hline $\mathrm{Cr}$ & 8 & 0 & $5.0317 e-072$ & 293 & end \\
\hline $\mathrm{Cu}$ & 8 & 0 & $1.4704 e-062$ & 293 & end \\
\hline $\mathrm{b}$ & 8 & 0 & $3.1449 e-072$ & 293 & end \\
\hline C & 8 & 0 & 0.000158522 & 293 & end \\
\hline ० & 8 & 0 & $1.4167 e-052$ & 293 & end \\
\hline n & 8 & 02 & $2.4274 e-052$ & 293 & end \\
\hline$u-234$ & 10 & 0 & 0.00047569 & 293 & end \\
\hline$u-235$ & 10 & 0 & 0.04484929 & 93 & end \\
\hline$u-236$ & 10 & 0 & $1.7215 e-05$ & 293 & end \\
\hline$u-238$ & 10 & 0 & 0.00274112 & 293 & end \\
\hline be & 10 & 0 & $6.277 e-092$ & 293 & end \\
\hline $1 i$ & 10 & 0 & $1.63 e-0729$ & 93 & end \\
\hline al & 10 & 0 & $2.5159 e-06$ & 293 & end \\
\hline si & 10 & 0 & $3.2227 e-05$ & 293 & end \\
\hline $\mathrm{mn}$ & 10 & 0 & $5.2142 e-06$ & 293 & end \\
\hline ni & 10 & 0 & $8.7159 e-06$ & 293 & end \\
\hline $\mathrm{Cr}$ & 10 & 0 & $6.8866 e-07$ & 293 & end \\
\hline $\mathrm{Cu}$ & 10 & 0 & $2.0125 e-06$ & 293 & end \\
\hline $\mathrm{b}$ & 10 & 0 & $5.2326 e-07$ & 293 & end \\
\hline $\mathrm{CO}$ & 10 & 0 & $9.5989 e-08$ & 293 & end \\
\hline $\mathrm{ca}$ & 10 & 0 & $1.4115 e-06$ & 293 & end \\
\hline C & 10 & 0 & 0.00019028 & 293 & end \\
\hline ○ & 10 & 0 & $1.4143 e-05$ & 293 & end \\
\hline $\mathrm{n}$ & 10 & 0 & $2.4233 e-05$ & 293 & end \\
\hline$u-234$ & 12 & 0 & 0.00047738 & 293 & end \\
\hline$u-235$ & 12 & 0 & 0.04448529 & & end \\
\hline
\end{tabular}

Revision: 0 


\section{NEA/NSC/DOC(95)03/II \\ Volume II}

\section{HEU-MET-FAST-100}

\begin{tabular}{|c|c|c|c|c|}
\hline$u-236$ & 12 & 0 & 0.00021446293 & end \\
\hline$u-238$ & 12 & 0 & 0.002545293 & end \\
\hline al & 12 & 0 & $2.081 e-06293$ & end \\
\hline si & 12 & 0 & $4.7981 e-05293$ & end \\
\hline $\mathrm{mn}$ & 12 & 0 & $3.7751 e-06293$ & end \\
\hline ni & 12 & 0 & $6.3102 e-06293$ & end \\
\hline $\mathrm{Cr}$ & 12 & 0 & $4.9858 e-07293$ & end \\
\hline $\mathrm{Cu}$ & 12 & 0 & $1.457 e-06293$ & end \\
\hline $\mathrm{b}$ & 12 & 0 & $3.1162 e-07293$ & end \\
\hline C & 12 & 0 & 0.00015707293 & end \\
\hline o & 12 & 0 & $1.4038 e-05293$ & end \\
\hline$n$ & 12 & 0 & $2.4052 e-05293$ & end \\
\hline $\mathrm{Cu}$ & 15 & 0 & 0.075056293 & end \\
\hline $\mathrm{Cu}$ & 15 & 0 & 0.0081044293 & end \\
\hline
\end{tabular}

end composition

read parameter

gen $=2650$

$\mathrm{npg}=500000$

$\mathrm{nsk}=150$

htm $=$ no

end parameter

read geometry

global unit 1

com="orcef sphere"

sphere 1

ellipsoid 28.744413 8.744413 8.745982 chord $-\mathrm{z}=-4.11683$ chord $+\mathrm{z}=-8.653251$ origin $\mathrm{x}=0$ y=0

$z=0.050546$

$\begin{array}{lllllll}\text { ellipsoid } & 3 & 8.744413 & 8.744413 & 8.745982 & \text { chord }-z=-1.429 & \text { chord }+z=-4.06629 \\ \text { ellipsoid } 4 & 8.735917 & 8.735917 & 8.760911 & \text { chord }-z=0 & \text { chord }+z=-1.429\end{array}$

ellipsoid $5 \quad 8.7359178 .735917 \quad 8.760911$ chord $-z=1.429$ chord $+z=0$

ellipsoid $6 \quad 8.735917-8.735917-8.760911$ chord $-z=3.37515$ chord $+z=1.429$

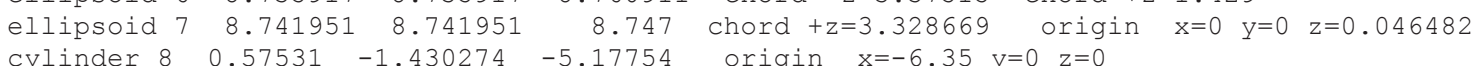

cylinder $90.57531 \quad-1.430274 \quad-5.17754$ origin $x=3.175 \quad y=5.49926 \quad z=0$

cylinder $10 \quad 0.57531 \quad-1.429 \quad-5.17754 \quad$ origin $x=3.175 \quad y=-5.49926 \quad z=0$

cylinder $11 \quad 0.57531 \quad-1.429 \quad-5.17754 \quad$ origin $x=3.175 \quad y=5.49926 \quad z=0$

cylinder $12 \quad 0.747903 \quad-7.811008 \quad-8.580628$

cone $13-0.3153 \quad 0.55372 \quad 0.635 \quad 0.580628$ origin $x=0 \quad y=0=-1.429$

cylinder $140.17526-8.00807 \quad-8.809228$ rotate a1=0 a $2=45$ a $3=0$

cylinder $150.17526-8.00807 \quad-8.809228$ rotate a $1=0$ a $2=-45$ a3 $=0$

cylinder $16 \quad 0.17526-8.00807 \quad-8.809228 \quad$ rotate $a 1=90$ a2 $=45$ a3 $=0$

cylinder $18 \quad 0.17526 \quad-8.00807 \quad-8.809228$ rotate $a 1=45$ a2 $=45$ a3 $=0$

cylinder $190.17526-8.00807 \quad-8.809228 \quad$ rotate $a 1=45$ a2 $=-45$ a $3=0$

cylinder $20 \quad 0.17526-8.00807 \quad-8.809228$ rotate a $1=-45$ a $2=45$ a $3=0$

cylinder $210.17526-8.00807 \quad-8.809228$ rotate a $1=-45$ a $2=-45$ a $3=0$

cylinder $22 \quad 1.11125 \quad-8.688787 \quad-8.809228 \quad$ rotate $a 1=0$ a2 $=45$ a3 $=0$

cylinder $23 \quad 1.11125-8.688787 \quad-8.809228$ rotate a $1=0$ a $2=-45$ a $3=0$

cylinder $24 \quad 1.11125 \quad-8.688787 \quad-8.809228$ rotate a1=90 a2=45 a3=0

cylinder $25 \quad 1.11125-8.688787-8.809228$ rotate $a 1=90$ a $2=-45$ a $3=0$

cylinder $26 \quad 1.11125-8.688787 \quad-8.809228$ rotate a1=45 a2=45 a3=0

cylinder $27 \quad 1.11125-8.688787-8.809228$ rotate $a 1=45$ a $2=-45$ a $3=0$

cylinder $28 \quad 1.11125 \quad-8.688787 \quad-8.809228$ rotate $a 1=-45$ a2 $=45$ a3=0

cylinder $29 \quad 1.11125 \quad-8.688787 \quad-8.809228$ rotate $a 1=-45$ a $2=-45$ a $3=0$

cone $36 \quad 0.3063 \quad 0.5715 \quad 0.635 \quad 0 \quad$ origin $x=0 \quad y=0 \quad z=-1.429$

cylinder $37 \quad 0.57531 \quad 3.37515 \quad-1.429 \quad$ origin $x=-6.35 \quad y=0 \quad z=0$

cylinder $38 \quad 0.57531 \quad 3.37515 \quad-1.429$ origin $x=3.175 \quad y=-5.49926 \quad z=0$

cylinder $390.57531 \quad 3.37515 \quad-1.429 \quad$ origin $x=3.175 \quad y=5.49926 \quad z=0$

xcylinder $40 \quad 1.27 \quad 8.9 \quad 0.888238$

xcylinder $41 \quad 0.17272 \quad 8.9 \quad-8.9$

xcylinder $42 \quad 0.164211 \quad 8.914765 \quad-8.914765$

xcylinder $43 \quad 0.351028 \quad 8.9 \quad 8.12419$ rotate $a 1=45$ a $2=0$ a $3=0$

xcylinder $44 \quad 0.351028 \quad 8.9 \quad 8.12419$ rotate $a 1=-45$ a $2=0$ a $3=0$

xcylinder $45 \quad 0.351028 \quad 8.9 \quad 8.12419$ rotate a1=135 a2=0 a3=0

xcylinder $46 \quad 0.351028 \quad 8.12419$ rotate $a 1=-135$ a2 $=0$ a3=0

$\begin{array}{lllllll}\text { cuboid } 47 & 0.0889 & -0.0889 & 4.1275 & -0.9525 & 1.429 & 1.281684\end{array}$

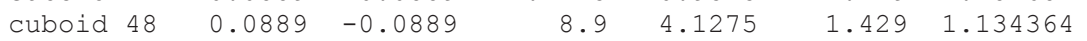

cone $49 \quad 0.3153 \quad 0.55372 \quad 0.635 \quad 0 \quad$ origin $x=0 \quad y=0 \quad z=3.37515$

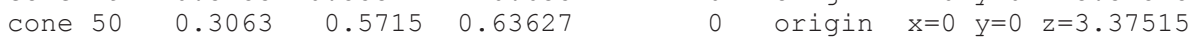

cylinder $51 \quad 0.17526 \quad 8.809228 \quad 8.00807$ rotate a1=0 a $2=45$ a $3=0$

cylinder $520.175268 .809228 \quad 8.00807$ rotate $a 1=0$ a $2=-45$ a $3=0$

cylinder $530.175268 .809228 \quad 8.00807$ rotate $a 1=90$ a $2=45$ a $3=0$ 


\section{NEA/NSC/DOC(95)03/II \\ Volume II}

\section{HEU-MET-FAST-100}

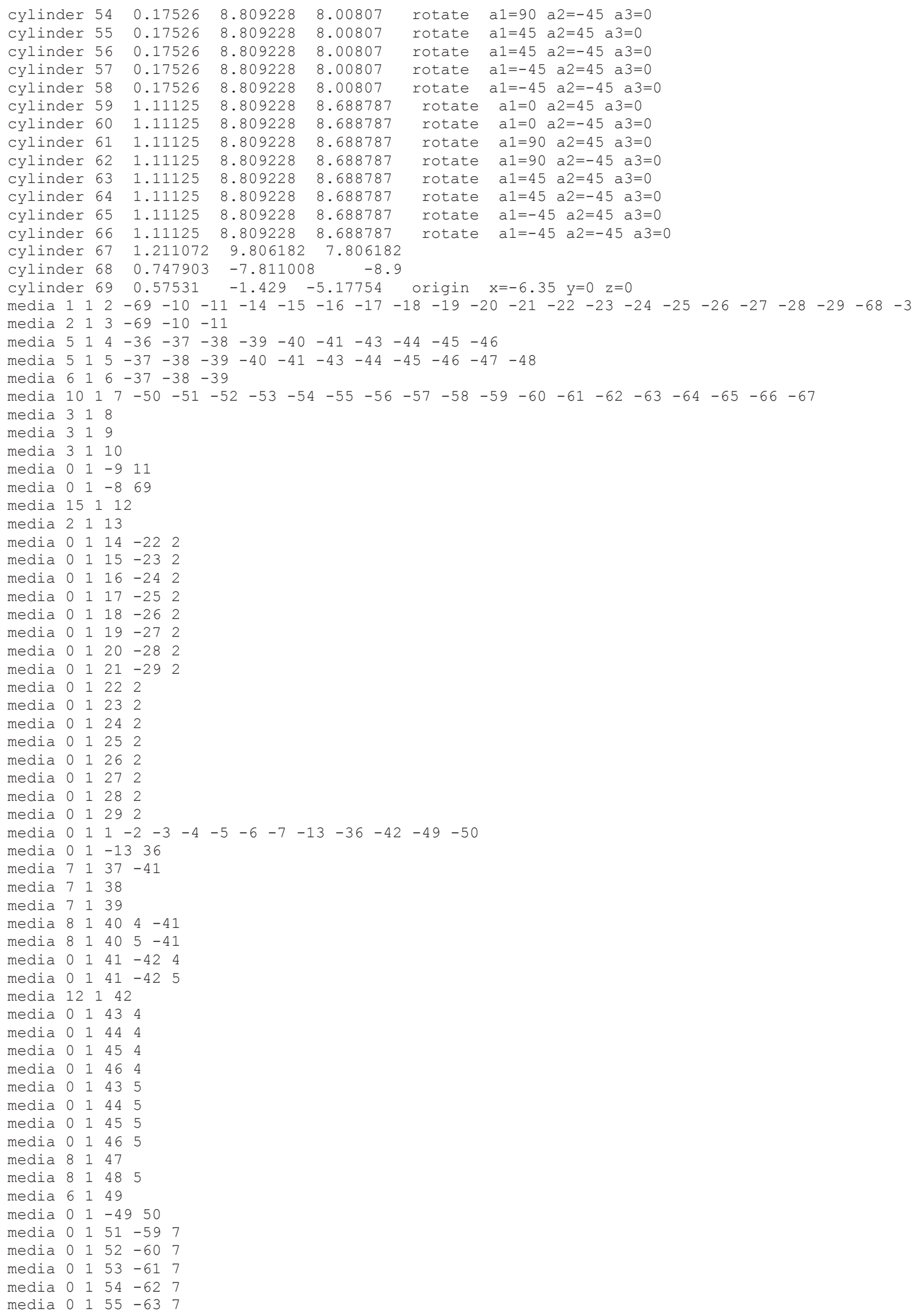

Revision: 0 
NEA/NSC/DOC(95)03/II

Volume II

HEU-MET-FAST-100

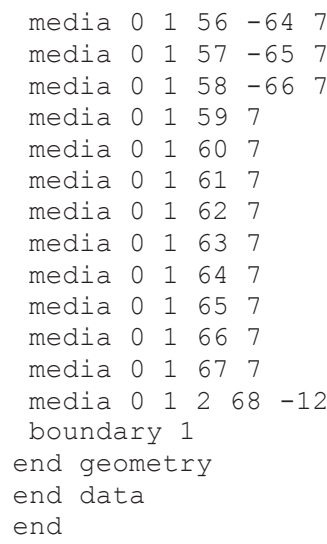


NEA/NSC/DOC(95)03/II

Volume II

HEU-MET-FAST-100

KENO Input for Simple Model, Case 1, Table 4-2.

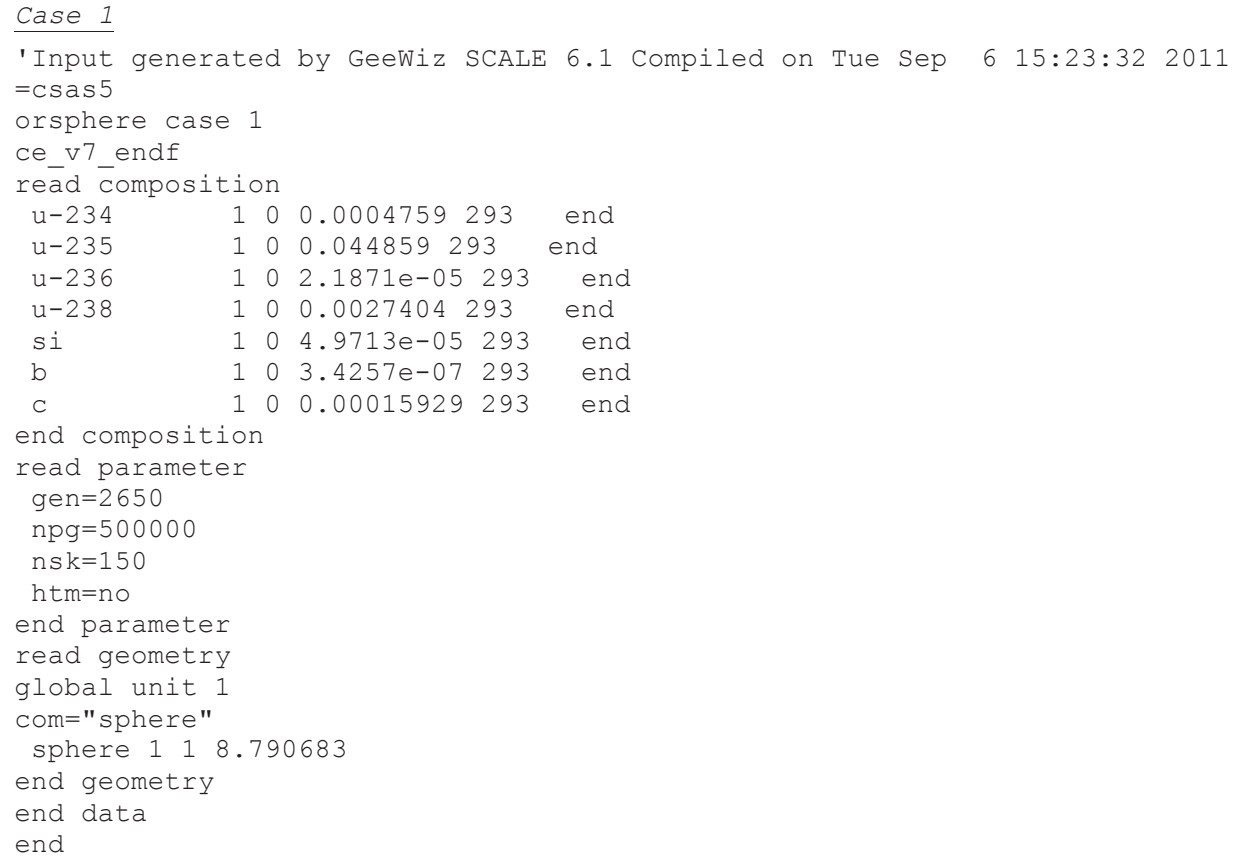


NEA/NSC/DOC(95)03/II

Volume II

\section{HEU-MET-FAST-100}

KENO Input for Simple Model, Case 2, Table 4-2.

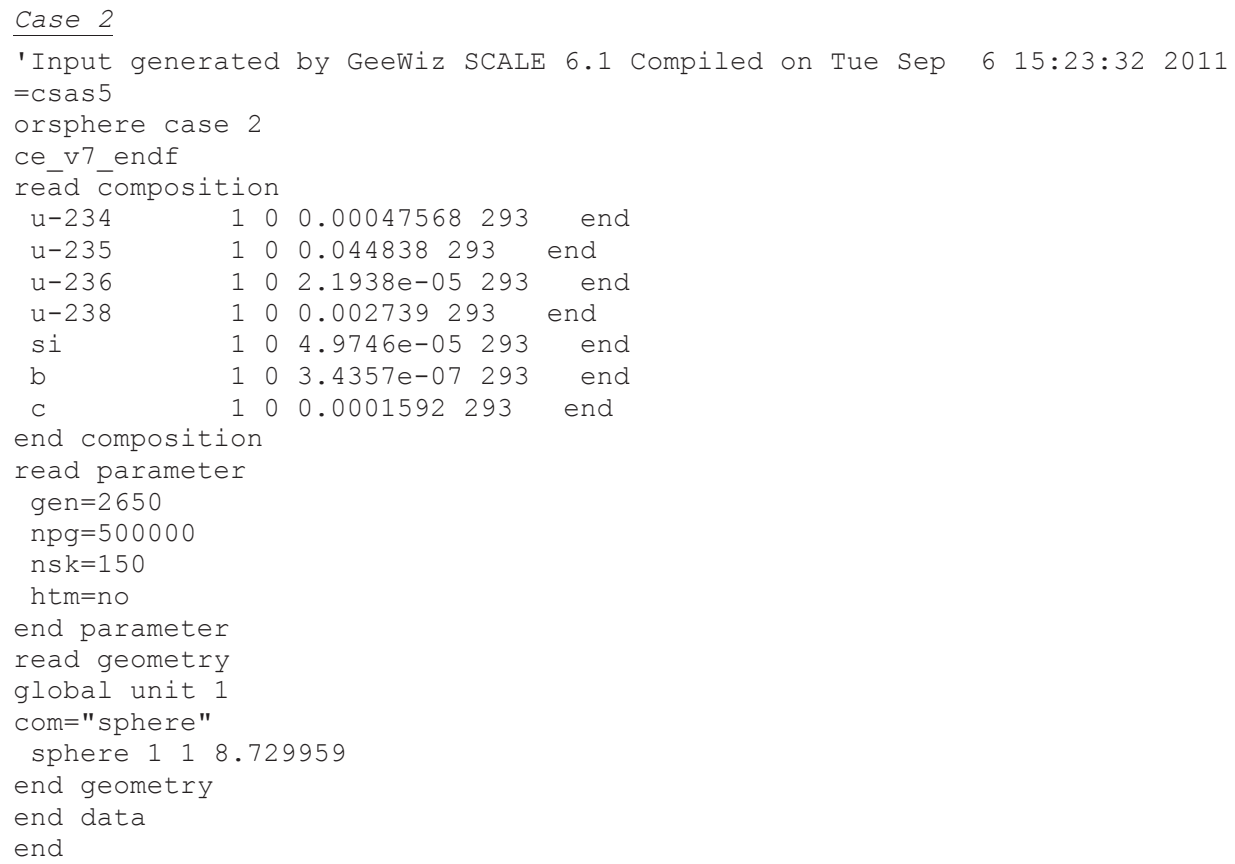


NEA/NSC/DOC(95)03/II

Volume II

HEU-MET-FAST-100

\section{A.3 MONK Input Listing}

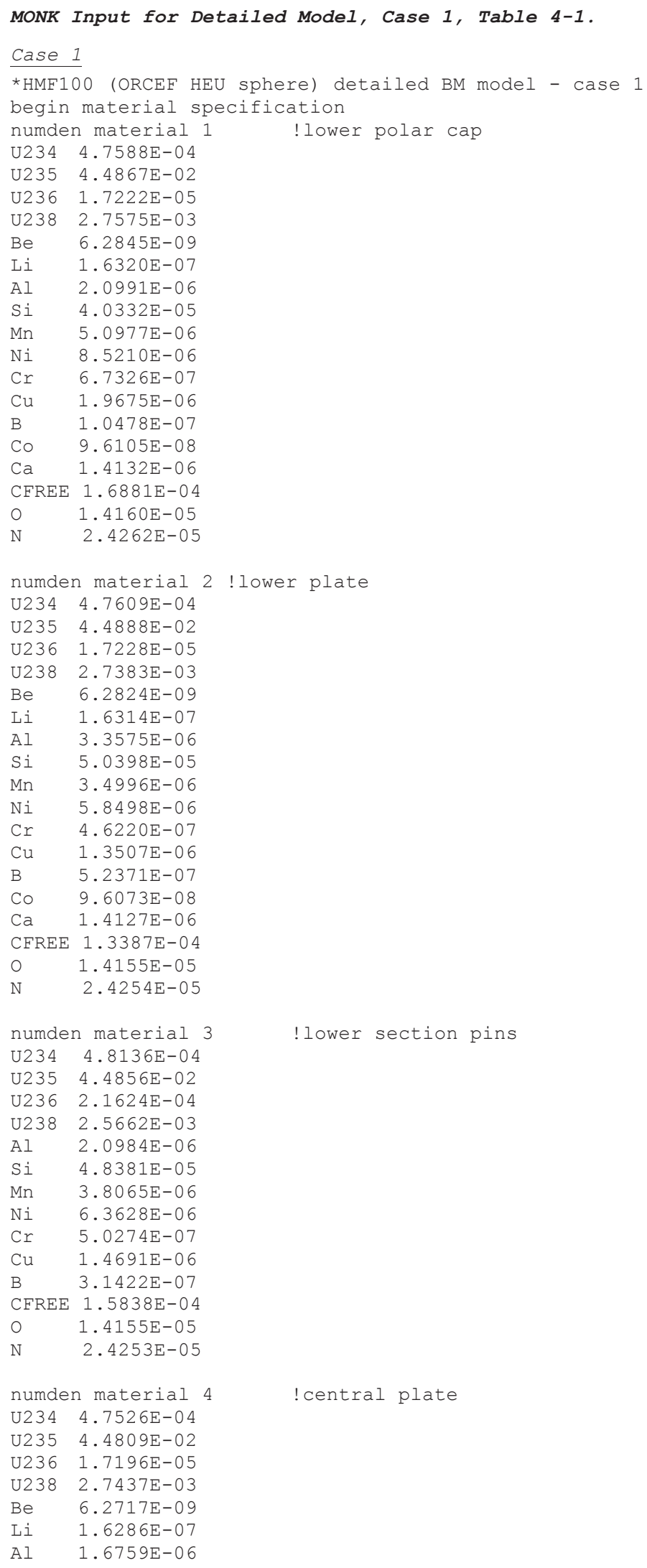


NEA/NSC/DOC(95)03/II

Volume II

HEU-MET-FAST-100

$\begin{array}{ll}\mathrm{Si} & 8.0500 \mathrm{E}-05 \\ \mathrm{Mn} & 3.0646 \mathrm{E}-06 \\ \mathrm{Ni} & 5.1226 \mathrm{E}-06 \\ \mathrm{Cr} & 4.0475 \mathrm{E}-07 \\ \mathrm{Cu} & 1.1828 \mathrm{E}-06 \\ \mathrm{~B} & 2.0913 \mathrm{E}-07 \\ \mathrm{Co} & 9.5908 \mathrm{E}-08 \\ \mathrm{Ca} & 1.4103 \mathrm{E}-06 \\ \mathrm{CFREE} & 1.4965 \mathrm{E}-04 \\ \mathrm{O} & 1.4131 \mathrm{E}-05 \\ \mathrm{~N} & 2.4212 \mathrm{E}-05\end{array}$

numden material 5

U234 4.7537E-04

U235 4.4819E-02

U236 $1.7203 \mathrm{E}-05$

U238 2.7392E-03

$\mathrm{Be} \quad 6.2724 \mathrm{E}-09$

Li $\quad 1.6288 \mathrm{E}-07$

Al $\quad 1.6761 \mathrm{E}-06$

Si $\quad 4.0255 \mathrm{E}-05$

Mn 2.0842E-06

$\mathrm{Ni} \quad 3.4838 \mathrm{E}-06$

Cr $2.7526 \mathrm{E}-07$

$\mathrm{Cu} \quad 8.0440 \mathrm{E}-07$

B 3.1373E-07

Co $9.5919 \mathrm{E}-08$

$\mathrm{Ca} \quad 1.4105 \mathrm{E}-06$

CFREE 1.4966E-04

O $\quad 1.4133 \mathrm{E}-05$

N 2.4215E-05

numden material 6

U234 4.7611E-04

U235 4.4798E-02

U236 $2.0300 \mathrm{E}-04$

U238 2.5726E-03

Al $2.0953 \mathrm{E}-06$

Si $\quad 4.8311 \mathrm{E}-05$

Mn 3.8010E-06

$\mathrm{Ni} \quad 6.3535 \mathrm{E}-06$

Cr $\quad 5.0200 \mathrm{E}-07$

$\mathrm{Cu} \quad 1.4670 \mathrm{E}-06$

B $\quad 3.1376 \mathrm{E}-07$

CFREE $1.5815 \mathrm{E}-04$

O $\quad 1.4134 \mathrm{E}-05$

N $\quad 2.4217 \mathrm{E}-05$

numden material 7

U234 $4.8065 \mathrm{E}-04$

U235 4.4791E-02

U236 2.1593E-04

U238 $2.5625 \mathrm{E}-03$

Al $2.0953 \mathrm{E}-06$

$\mathrm{Si} \quad 4.8311 \mathrm{E}-05$

Mn $\quad 3.8010 \mathrm{E}-06$

$\mathrm{Ni} \quad 6.3535 \mathrm{E}-06$

Cr $\quad 5.0200 \mathrm{E}-07$

$\mathrm{Cu} \quad 1.4670 \mathrm{E}-06$

B $3.1376 \mathrm{E}-07$

CFREE 1.5815E-04

O $\quad 1.4134 \mathrm{E}-05$

$\mathrm{N} \quad 2.4217 \mathrm{E}-05$

numden material 8

U234 4.7635E-04

U235 4.4911E-02

U236 $1.7239 \mathrm{E}-05$

U238 2.7449E-03

$\mathrm{Be} \quad 6.2857 \mathrm{E}-09$

Li $\quad 1.6323 \mathrm{E}-07$

Al $\quad 2.5194 \mathrm{E}-06$

Revision: 0

Date: September 30, 2013 !upper plate

!pins for centre section

!plug for target \& thermocouple

! upper polar cap 
NEA/NSC/DOC(95)03/II

Volume II

HEU-MET-FAST-100

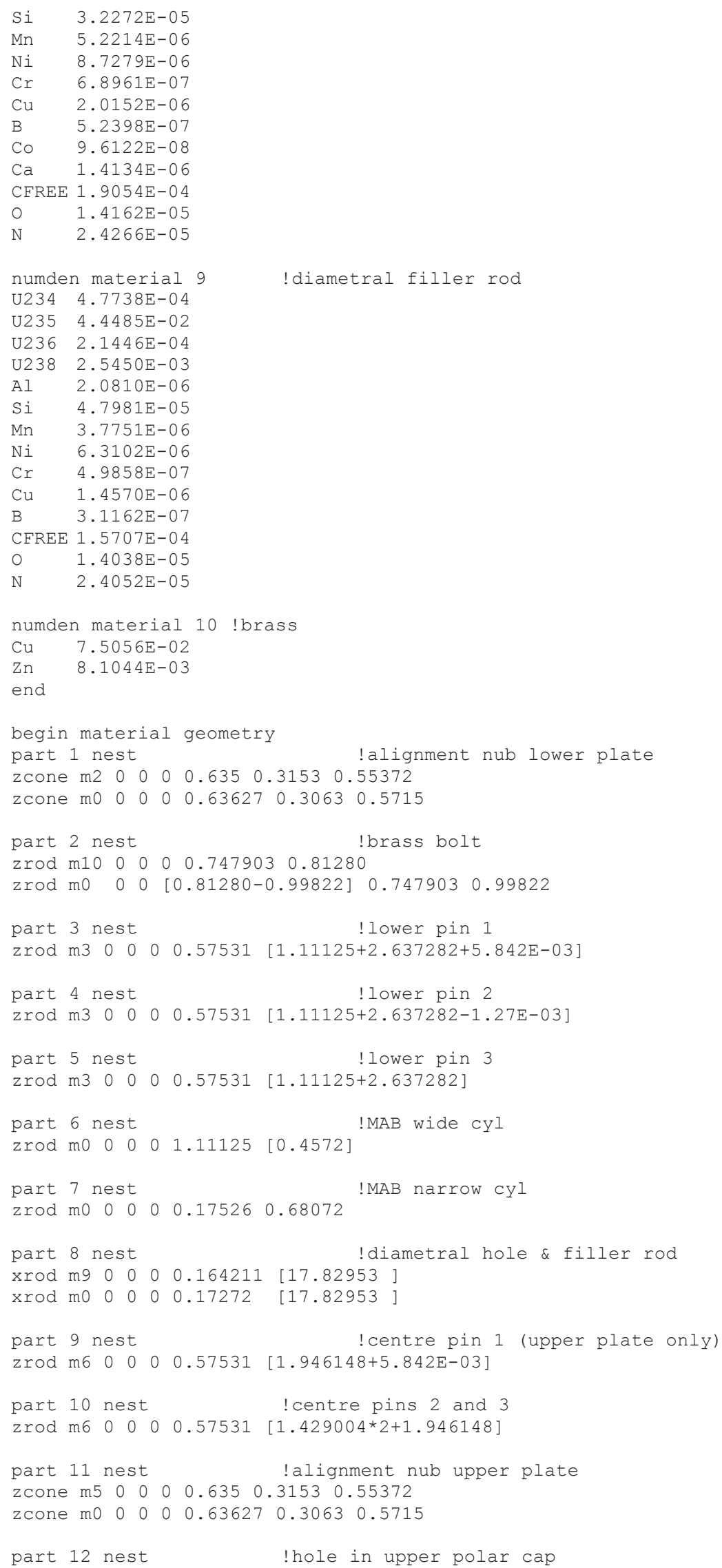




\section{NEA/NSC/DOC(95)03/II \\ Volume II}

\section{HEU-MET-FAST-100}

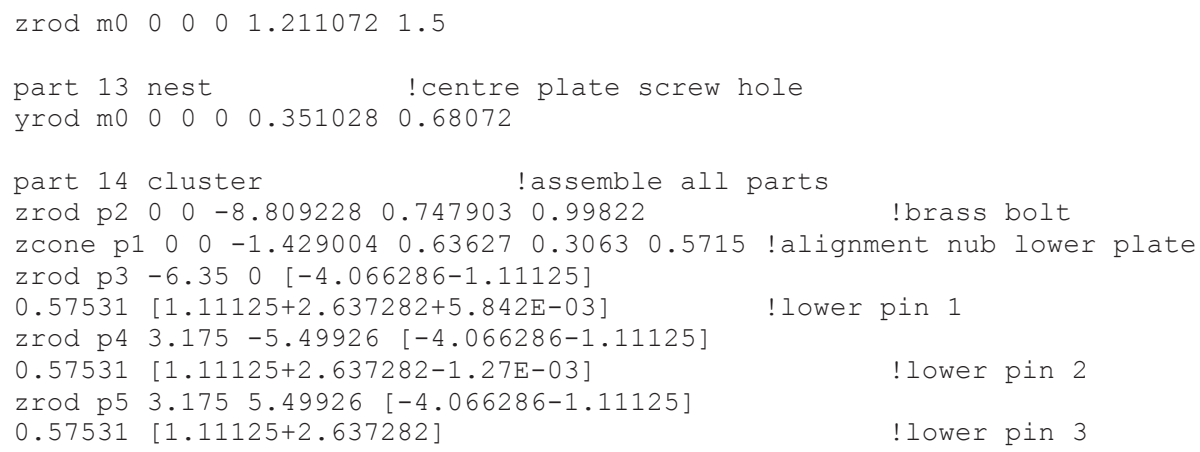

Revision: 0 


\section{NEA/NSC/DOC(95)03/II \\ Volume II}

\section{HEU-MET-FAST-100}

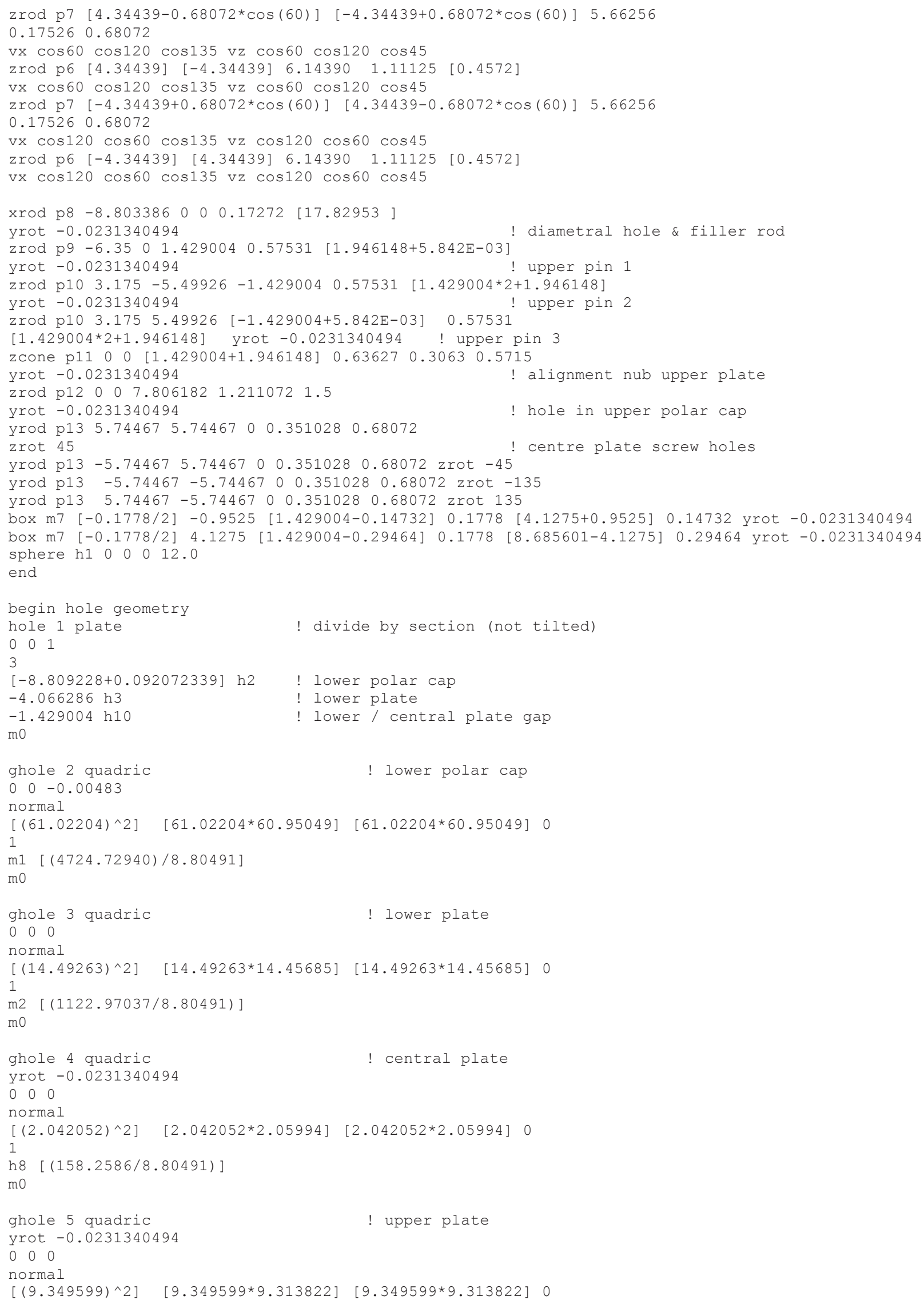

Revision: 0 
NEA/NSC/DOC(95)03/II

Volume II

HEU-MET-FAST-100

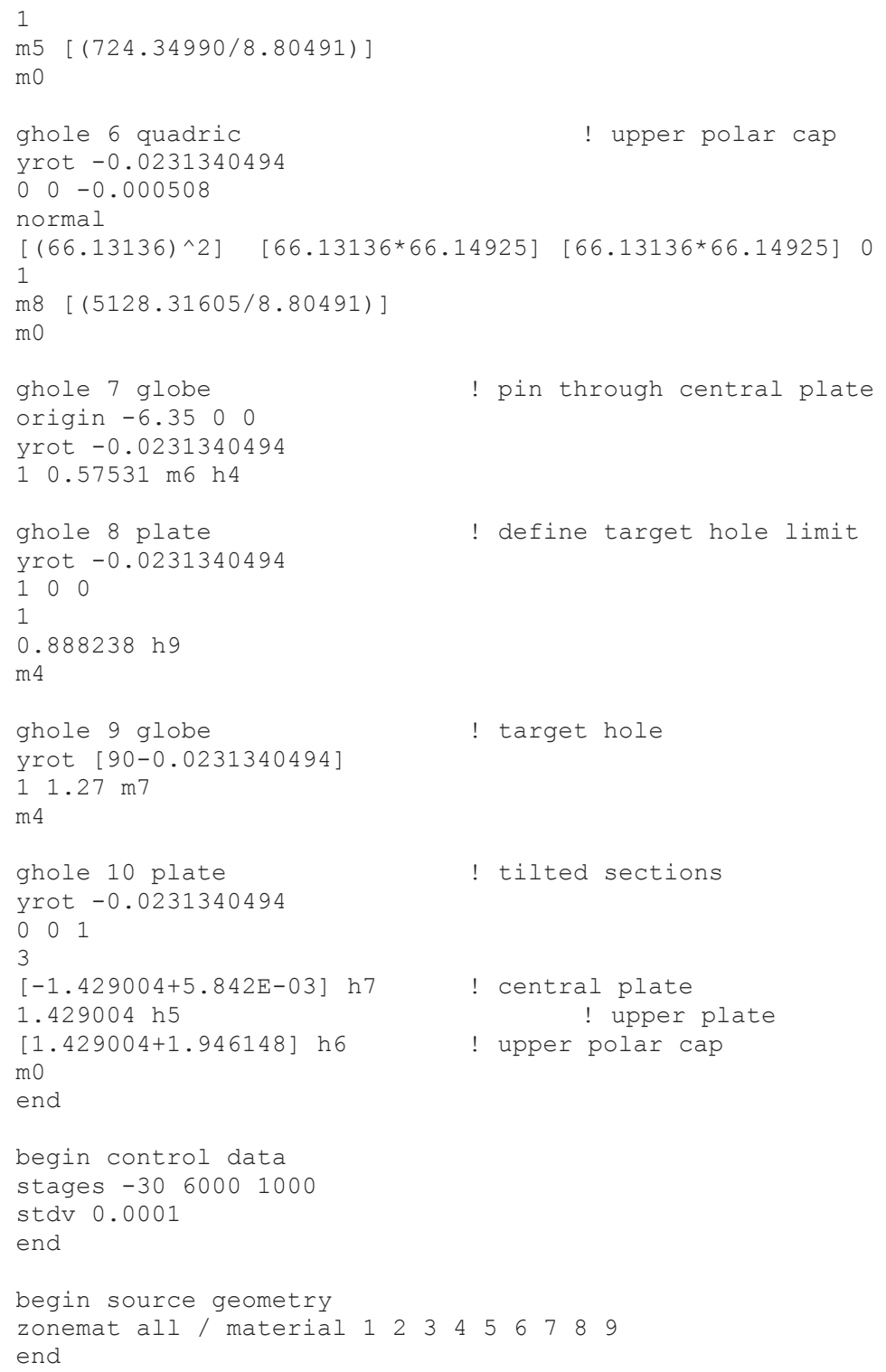


NEA/NSC/DOC(95)03/II

Volume II

HEU-MET-FAST-100

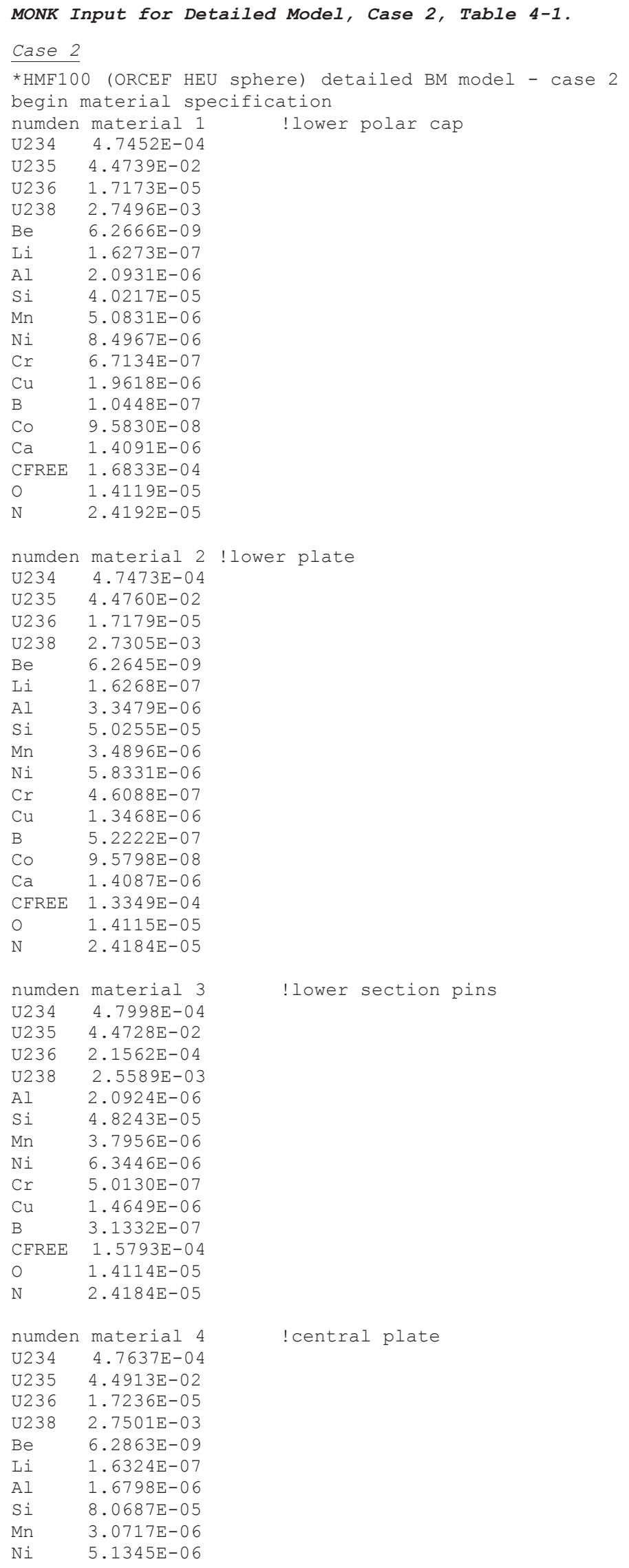

Revision: 0

Date: September 30, 2013 
NEA/NSC/DOC(95)03/II

Volume II

HEU-MET-FAST-100

$\begin{array}{ll}\mathrm{Cr} & 4.0569 \mathrm{E}-07 \\ \mathrm{Cu} & 1.1855 \mathrm{E}-06 \\ \mathrm{~B} & 2.0961 \mathrm{E}-07 \\ \mathrm{Co} & 9.6131 \mathrm{E}-08 \\ \mathrm{Ca} & 1.4136 \mathrm{E}-06 \\ \mathrm{CFREE} & 1.4999 \mathrm{E}-04 \\ \mathrm{O} & 1.4164 \mathrm{E}-05 \\ \mathrm{~N} & 2.4268 \mathrm{E}-05\end{array}$

numden material 5

U234 4.7647E-04

U235 4.4923E-02

U236 $1.7243 \mathrm{E}-05$

U238 $2.7456 \mathrm{E}-03$

$\mathrm{Be} \quad 6.2870 \mathrm{E}-09$

Li $\quad 1.6326 \mathrm{E}-07$

Al $\quad 1.6800 \mathrm{E}-06$

Si $\quad 4.0348 \mathrm{E}-05$

Mn 2.0890E-06

$\mathrm{Ni} \quad 3.4919 \mathrm{E}-06$

Cr $2.7590 \mathrm{E}-07$

$\mathrm{Cu} \quad 8.0626 \mathrm{E}-07$

B $\quad 3.1446 \mathrm{E}-07$

Co $\quad 9.6142 \mathrm{E}-08$

$\mathrm{Ca} \quad 1.4137 \mathrm{E}-06$

CFREE $\quad 1.5001 \mathrm{E}-04$

O $1.4165 \mathrm{E}-05$

N $2.4271 \mathrm{E}-05$

numden material 6

U234 4.7722E-04

U235 4.4902E-02

U236 2.0347E-04

U238 $2.5786 \mathrm{E}-03$

Al 2.1002E-06

$\mathrm{Si} \quad 4.8423 \mathrm{E}-05$

Mn $\quad 3.8098 \mathrm{E}-06$

$\mathrm{Ni} \quad 6.3683 \mathrm{E}-06$

Cr $\quad 5.0317 \mathrm{E}-07$

$\mathrm{Cu} \quad 1.4704 \mathrm{E}-06$

B $\quad 3.1449 \mathrm{E}-07$

CFREE $\quad 1.5852 \mathrm{E}-04$

O $1.4167 \mathrm{E}-05$

N $2.4274 \mathrm{E}-05$

numden material 7

U234 4.8177E-04

U235 4.4895E-02

U236 2.1643E-04

U238 $2.5684 \mathrm{E}-03$

Al $2.1002 \mathrm{E}-06$

$\mathrm{Si} \quad 4.8423 \mathrm{E}-05$

Mn $\quad 3.8098 \mathrm{E}-06$

$\mathrm{Ni} \quad 6.3683 \mathrm{E}-06$

Cr $\quad 5.0317 \mathrm{E}-07$

$\mathrm{Cu} \quad 1.4704 \mathrm{E}-06$

B 3.1449E-07

CFREE $\quad 1.5852 \mathrm{E}-04$

O $\quad 1.4167 \mathrm{E}-05$

N $\quad 2.4274 \mathrm{E}-05$

numden material 8

U234 4.7569E-04

U235 4.4849E-02

U236 $1.7215 \mathrm{E}-05$

U238 2.7411E-03

$\mathrm{Be} \quad 6.2770 \mathrm{E}-09$

Li $\quad 1.6300 \mathrm{E}-07$

Al $2.5159 \mathrm{E}-06$

Si $\quad 3.2227 \mathrm{E}-05$

Mn $\quad 5.2142 \mathrm{E}-06$

$\mathrm{Ni} \quad 8.7159 \mathrm{E}-06$

Revision: 0

Date: September 30, 2013
! upper plate

!pins for centre section

!plug for target \& thermocouple

!upper polar cap 


\section{NEA/NSC/DOC(95)03/II \\ Volume II}

\section{HEU-MET-FAST-100}

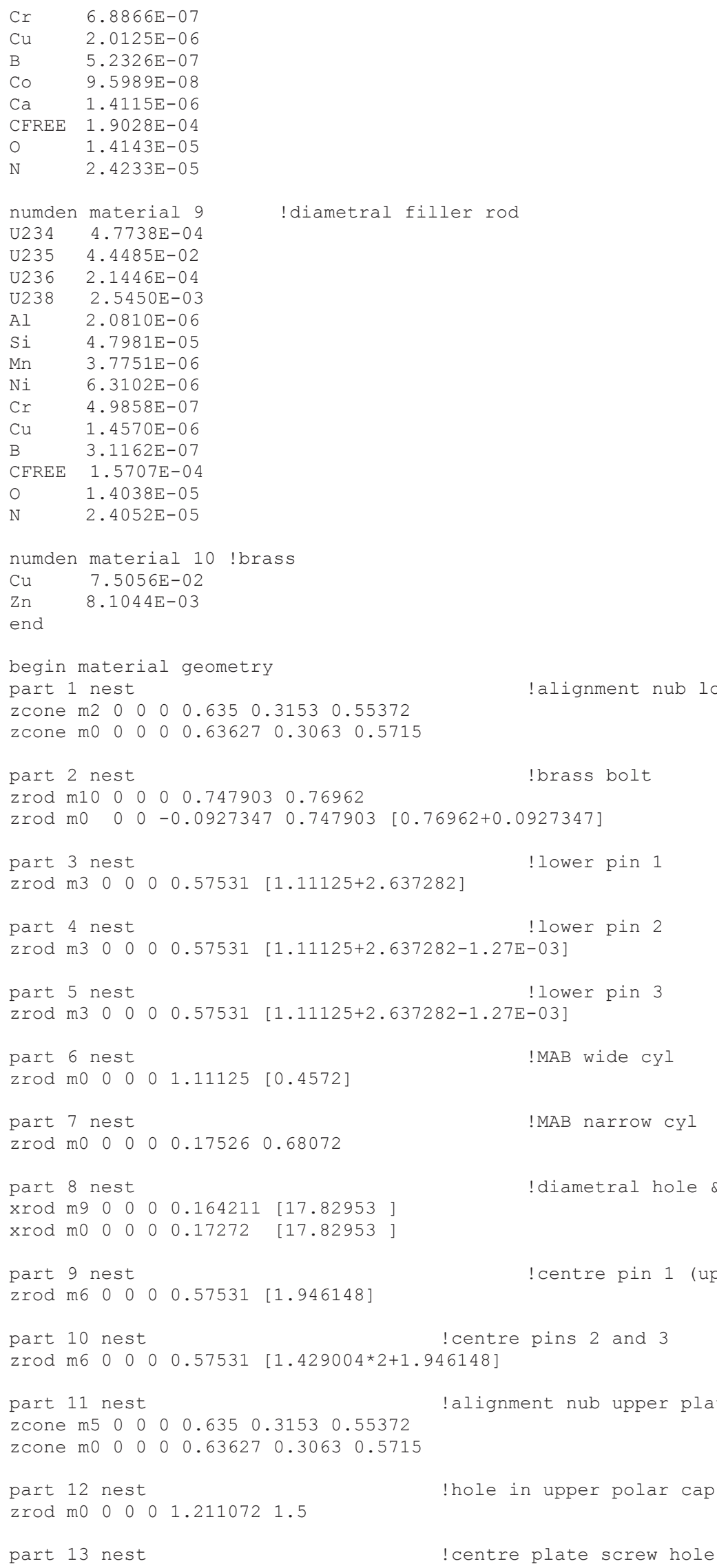




\section{NEA/NSC/DOC(95)03/II \\ Volume II}

\section{HEU-MET-FAST-100}

yrod mo $00000.351028 \quad 0.68072$

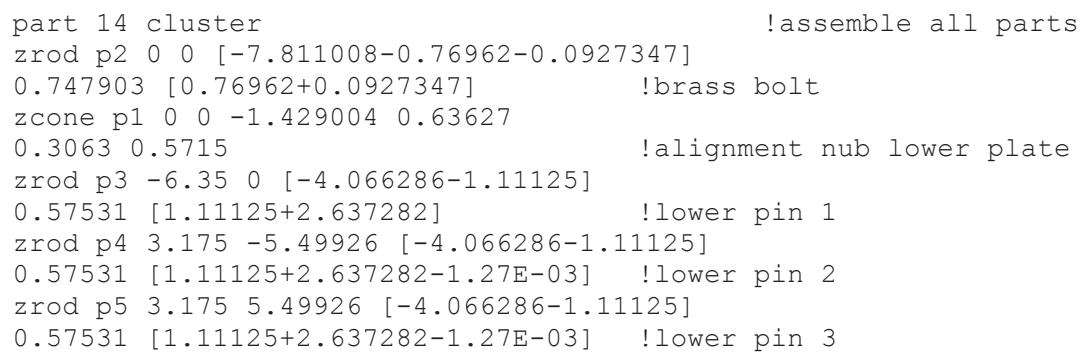




\section{NEA/NSC/DOC(95)03/II \\ Volume II}

\section{HEU-MET-FAST-100}

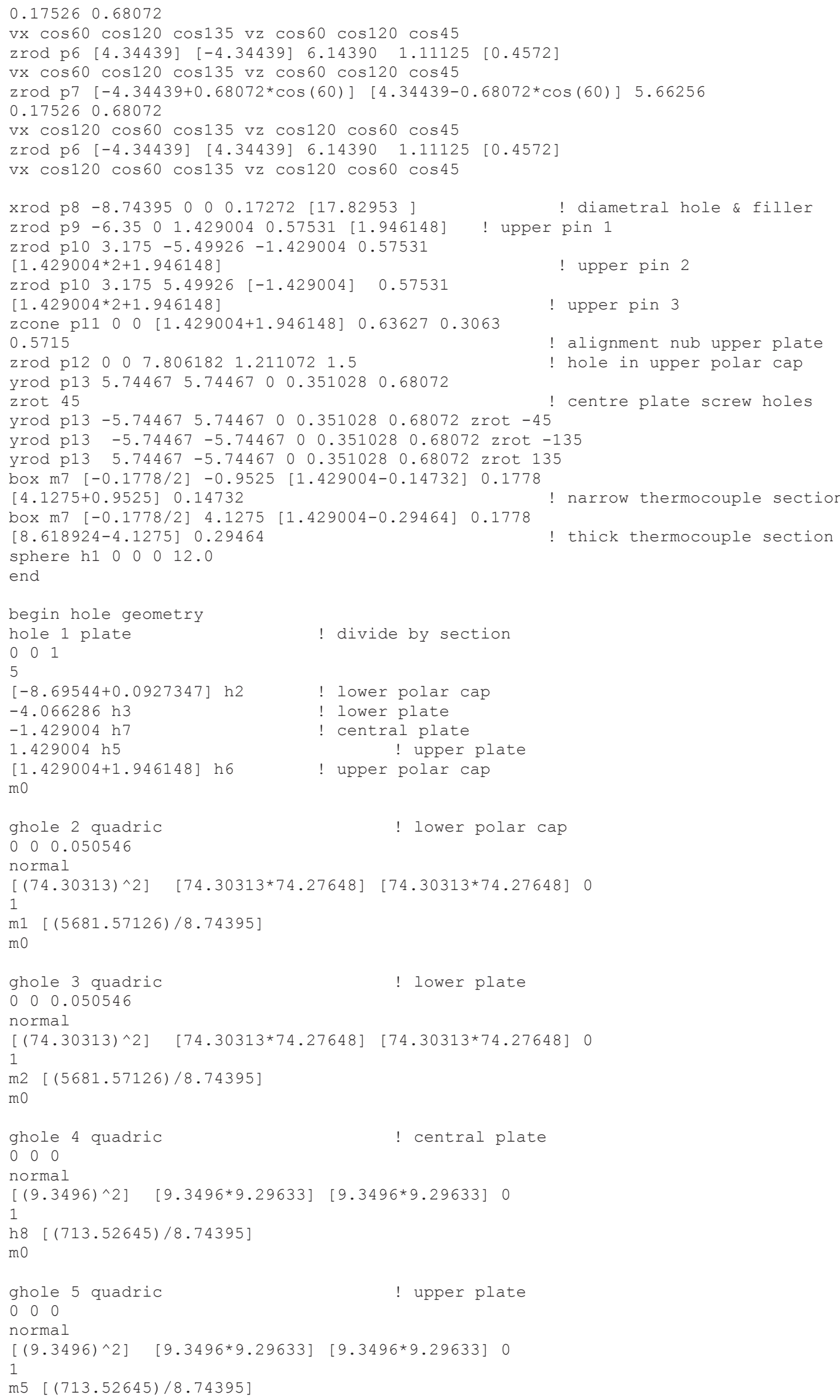

Revision: 0 
NEA/NSC/DOC(95)03/II

Volume II

HEU-MET-FAST-100

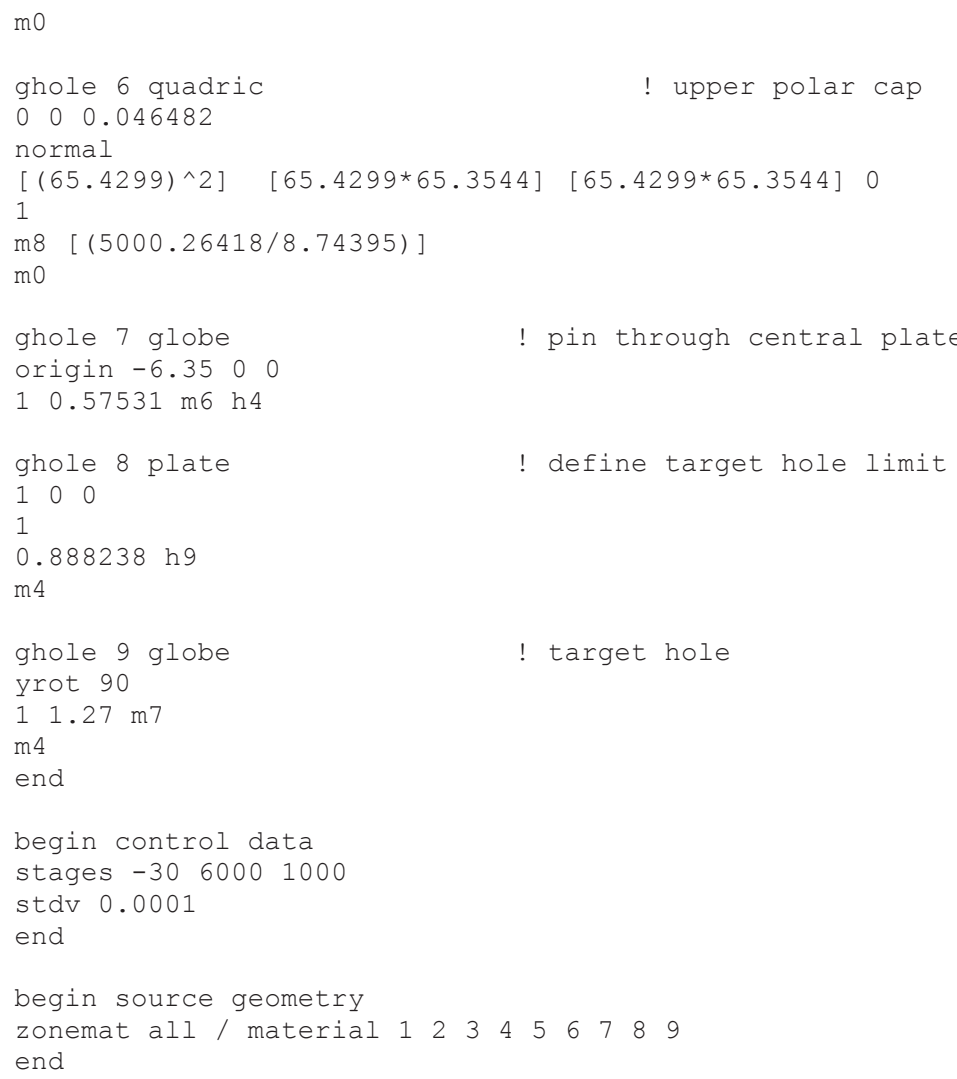


NEA/NSC/DOC(95)03/II

Volume II

HEU-MET-FAST-100

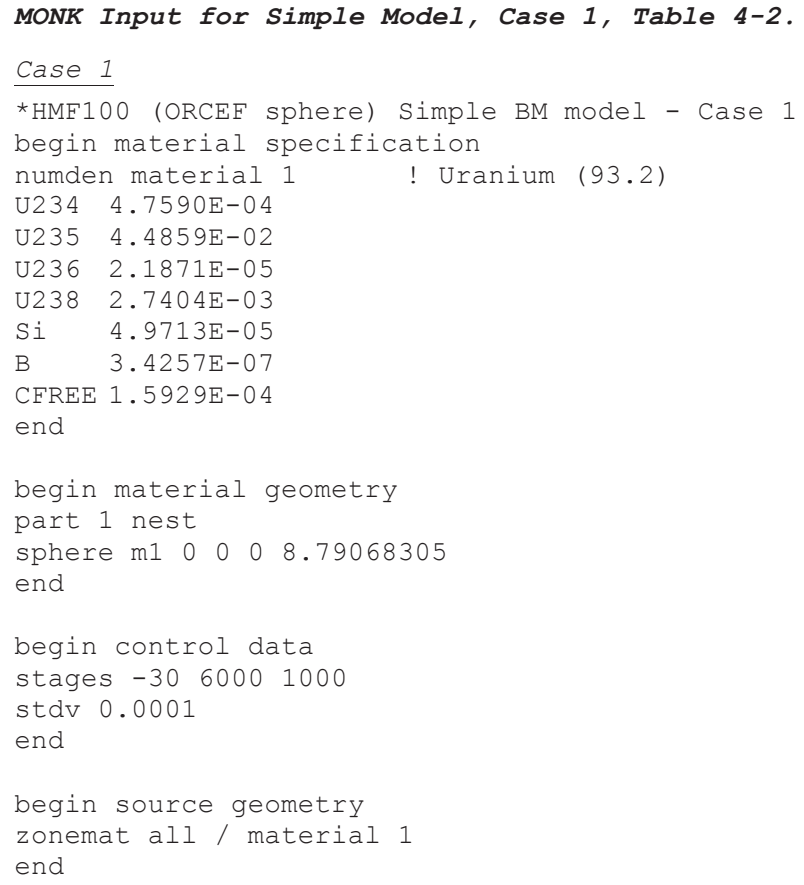


NEA/NSC/DOC(95)03/II

Volume II

HEU-MET-FAST-100

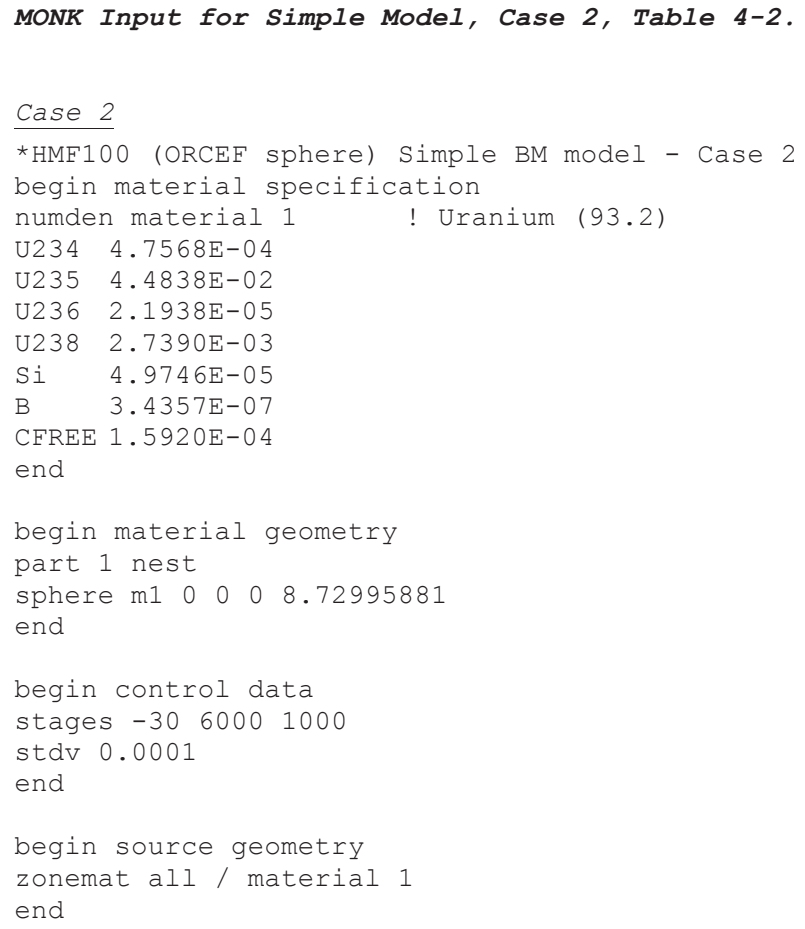


NEA/NSC/DOC(95)03/II

Volume II

HEU-MET-FAST-100

\section{A.4 XSDRN Input Listing}

XSDRN Input for Simple Model, Case 1, Table 4-2.

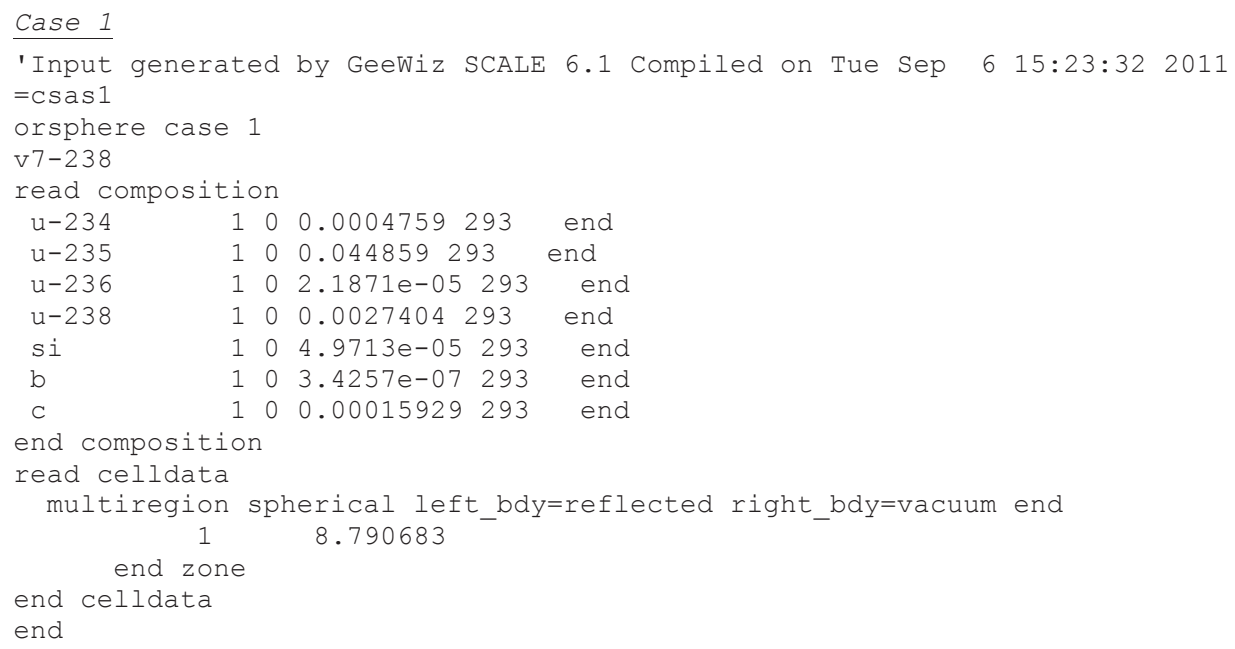


NEA/NSC/DOC(95)03/II

Volume II

\section{HEU-MET-FAST-100}

XSDRN Input for Simple Model, Case 2, Table 4-2.

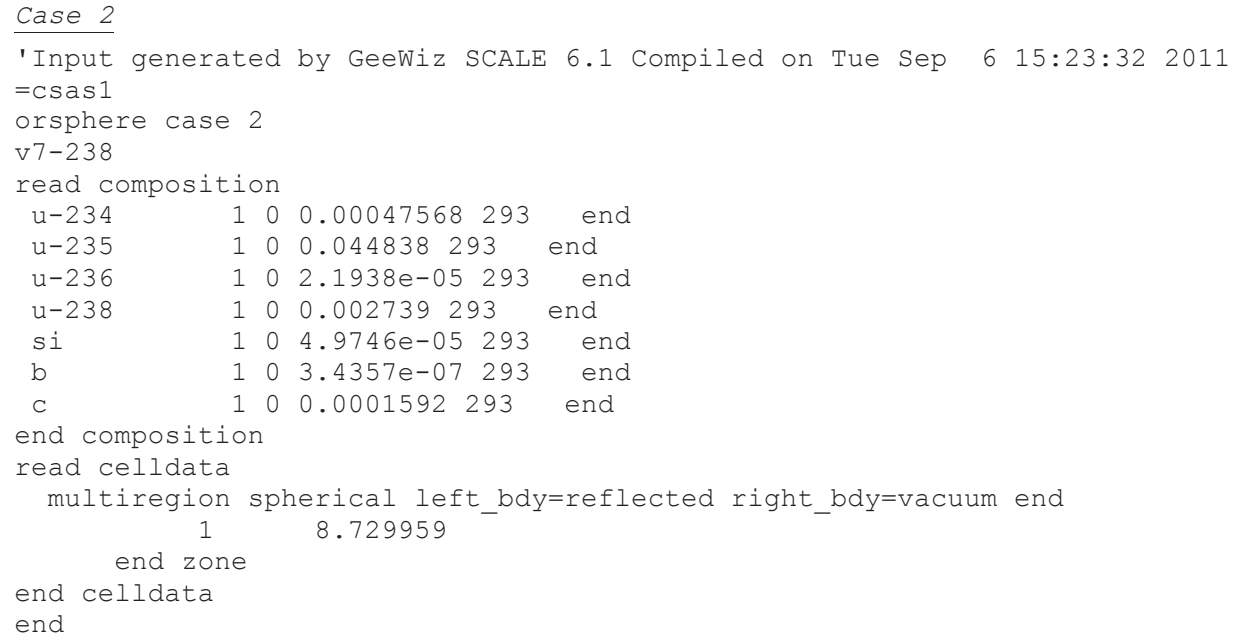


HEU-MET-FAST-100

\section{A.4 COG11.1 Input Listing}

Models were creating using COG11.1 and ENDF/B-VII.1 neutron cross section libraries. Models were run for 2500 active cycles (150 inactive cycles) with 500,000 histories per cycle. Input decks were created and run by David P. Heinrichs from LLNL.

COG11.1 Input for Detailed Model, Case 1, Table 4-1.

Case 1

HMF100-1: ORSPHERE with 3.4665 inch average radius

basic

neutron delayedn CM URRPT

criticality

npart=50000 nbatch=5050 sdt=0.00001 nfirst=51 norm=1. nsource=1 000 assign-mc

1 orange 2 pink 3 red 4 lime 5 sky 6 green 7 blue 8 black 9 yellow

mix nlib=ENDFB7R1 ptlib=PT.ENDFB7R1. BNL sablib=T.ENDFB7R1

mat $=1$ bunches u234 4.7588-4 u235 4.4867-2 u236 $1.7222-5$ u238 2.7575-3 be $6.2845-9$ li $1.6320-7$ al

2.0991-6 si $4.0332-5 \mathrm{mn} 5.0977-6$ \$ HEU,

ni 8.5210-6 cr 6.7326-7 cu 1.9675-6 b 1.0478-7 co 9.6105-8 ca $1.4132-6$ c

$1.6881-40161.4160-5$ n 2.4262-5 \$ Lower Cap

mat $=2$ bunches u234 4.7609-4 u235 4.4888-2 u236 $1.7228-5$ u238 2.7383-3 be $6.2824-9$ li $1.6314-7$ al

$3.3575-6$ si $5.0398-5 \mathrm{mn} 3.4996-6$ \$EU,

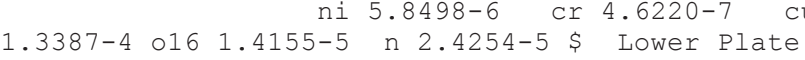

mat $=3$ bunches u234 4.8136-4 u235 4.4856-2 u236 2.1624-4 u238 2.5662-3

2.0984-6 si $4.8381-5 \mathrm{mn} 3.8065-6$ HEU,

ni $6.3628-6$ cr $5.0274-7$ cu $1.4691-6 \quad$ b $3.1422-7$

1.5838-4 o16 1.4155-5 n 2.4253-5 \$ Lower Pins

mat $=4$ bunches u234 4.7526-4 u235 4.4809-2 u236 $1.7196-5$ u238 2.7437-3 be $6.2717-9$ li $1.6286-7$ al

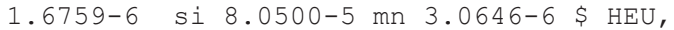
ni 5.1226-6 cr 4.0475-7 cu $1.1828-6 \quad$ b $2.0913-7$ co $9.5908-8$ ca $1.4103-6 \quad c$

$1.4965-40161.4131-5$ n 2.4212-5 \$ Center Plate

mat $=5$ bunches u234 4.7611-4 u235 4.4798-2 u236 2.0300-4 u238 2.5726-3 al

2.0953-6 si $4.8311-5 \mathrm{mn} \mathrm{3.8010-6} \mathrm{\$} \mathrm{HEU,}$

$\begin{array}{rrrr}n i & 6.3535-6 \text { cr } 5.0200-7 \text { ch } \\ 1.5815-4 & 016 & 1.4134-5 \text { n } 2.4217-5 \text { \$ Center Pins }\end{array}$

mat $=6$ bunches u234 4.8065-4 u235 4.4791-2 u236 2.1593-4 u238 2.5625-3

2.0953-6 si 4.8311-5 mn 3.8010-6 \$ HEU,

ni 6.3535-6 cr 5.0200-7 cu 1.4670-6 b 3.1376-7

$1.5815-40161.4134-5$ n $2.4217-5$ \$ Plugs

mat $=7$ bunches u234 4.7738-4 u235 4.4485-2 u236 2.1446-4 u238 2.5450-3

2.0810-6 si $4.7981-5 \mathrm{mn} 3.7751-6$ \$ HEU, Diametral

ni $6.3102-6$ cr $4.9858-7$ cu $1.4570-6$ b $3.1162-7$

$1.5707-4$ o16 1.4038-5 n 2.4052-5 \$ Filler Rod

mat $=8$ bunches u234 4.7537-4 u235 4.4819-2 u236 $1.7203-5$ u238 $2.7392-3$ be $6.2724-9$ li $1.6288-7$ al

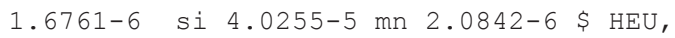

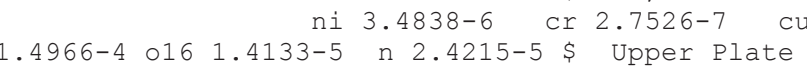

mat $=9$ bunches u234 4.7635-4 u235 4.4911-2 u236 $1.7239-5$ u238 $2.7449-3$ be $6.2857-9$ li $1.6323-7$ al

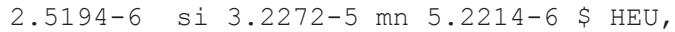

$$
\text { ni } 8.7279-6 \text { cr } 6.8961-7 \text { cu 2.0152-6 b } 5.2398-7 \text { co } 9.6122-8 \text { ca } 1.4134-6 \quad \text { c }
$$

1.9054-4 o16 1.4162-5 n 2.4266-5 \$ Upper Cap

mat $=10$ bunches cu 7.5056-2 zn 8.1044-3

\$ Brass Bolt

geometry

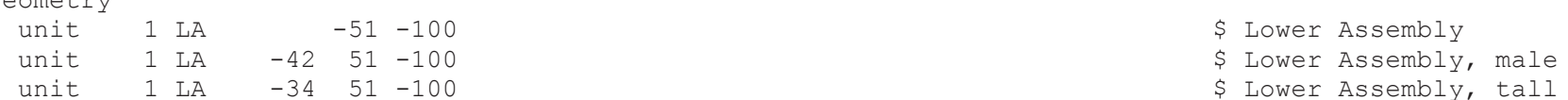

pin

unit 2 UA $344251-100$ tr $000.003510388 .803385280-0.000046213$ \$ Uper Assembly,

$0.00351038 \mathrm{~cm}$ verticle shift, tilted 0.0231340494 degrees

define unit 1 sower assembly

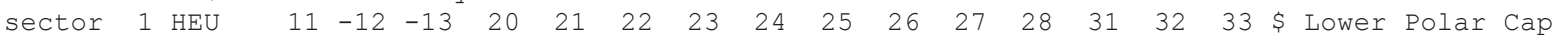

sector 10 Brass $-20 \quad 29$

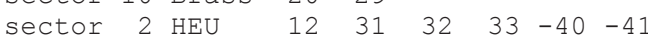

sector 2 HEU $40-42$

\$ Brass Bolt

\$ Lower Plate

\$ Lower Plate, male

Revision: 0 


\section{NEA/NSC/DOC(95)03/II}

Volume II

\section{HEU-MET-FAST-100}

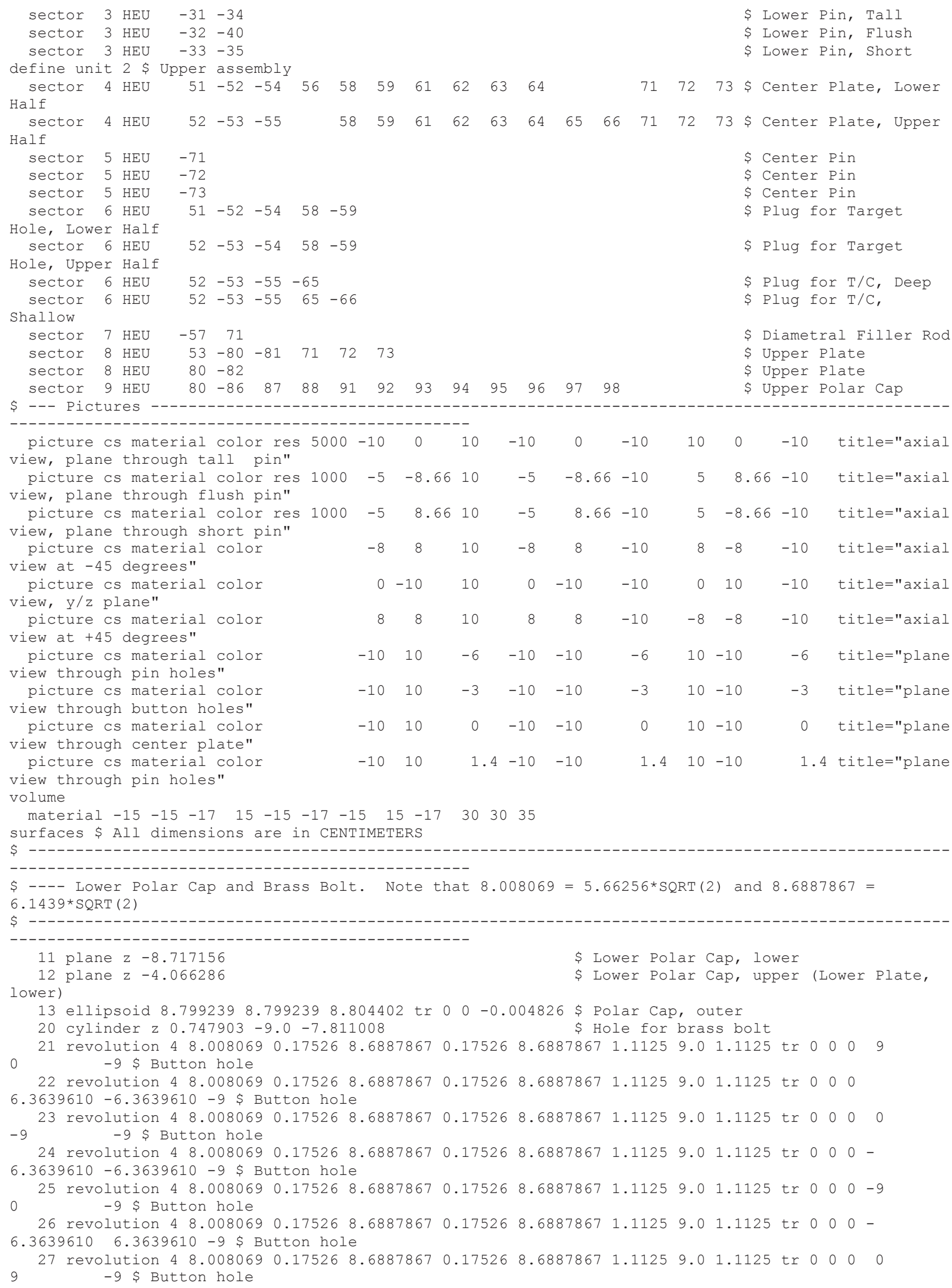

Revision: 0

Date: September 30, 2013

Page 127 of 160 


\section{NEA/NSC/DOC(95)03/II \\ Volume II}

\section{HEU-MET-FAST-100}

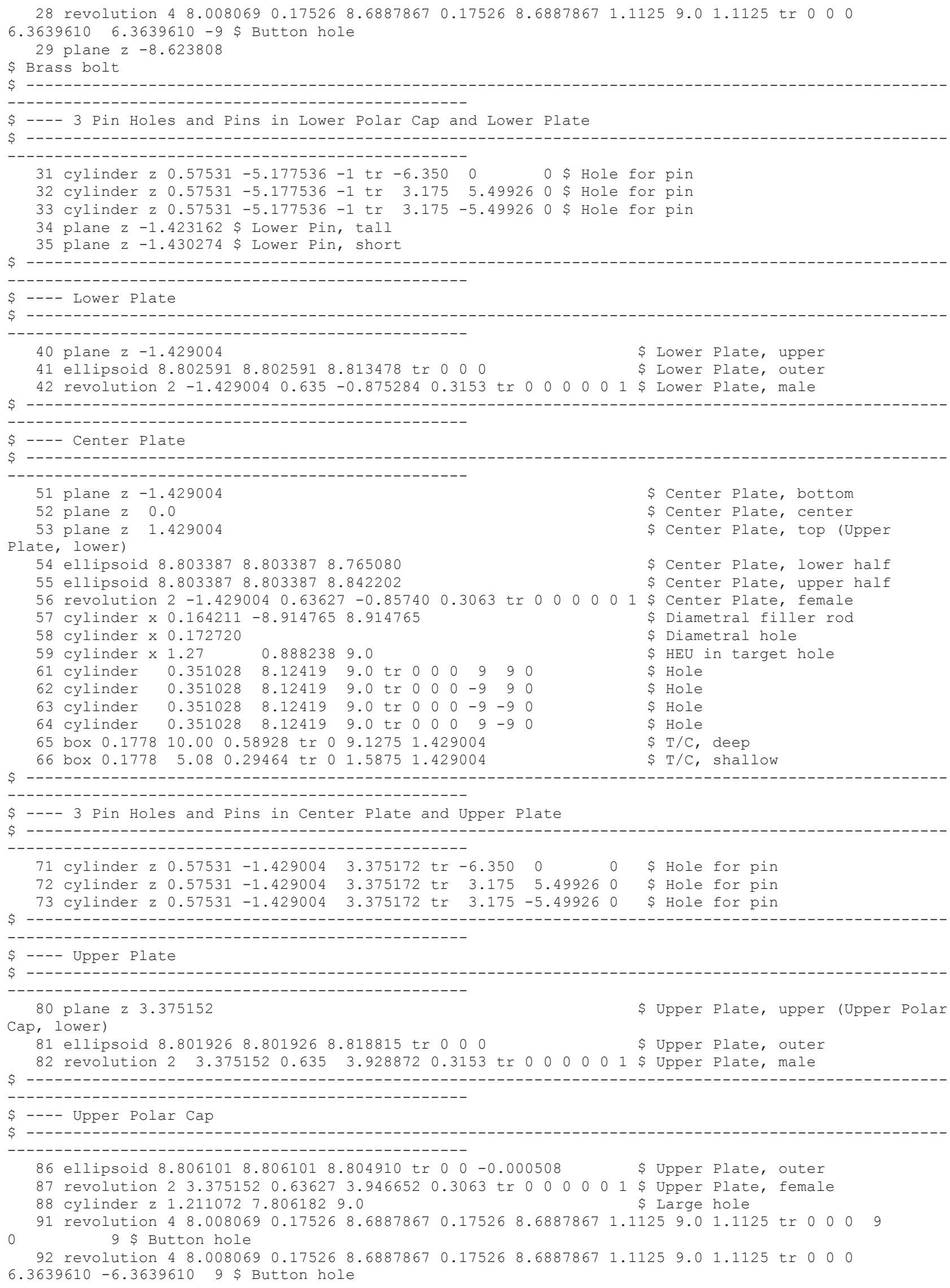

Revision: 0 


\section{NEA/NSC/DOC(95)03/II \\ Volume II}

\section{HEU-MET-FAST-100}

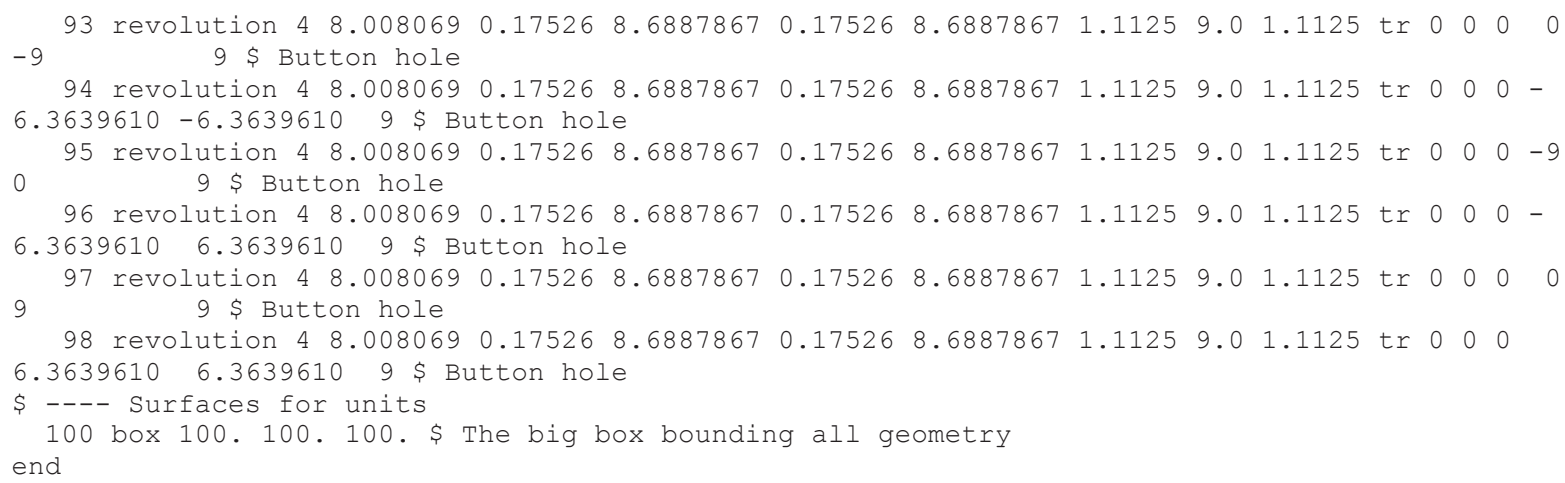




\section{NEA/NSC/DOC(95)03/II \\ Volume II}

\section{HEU-MET-FAST-100}

\section{COG11.1 Input for Detailed Model, Case 2, Table 4-1.}

Case 2

HMF100-2: ORSPHERE with 3.4420 inch average radius

basic

neutron delayedn CM URRPT

criticality

npart $=500000$ nbatch=2650 $\mathrm{sdt}=0.00001$ nfirst=151 norm=1. nsource=1 000 assign-mc

1 orange 2 pink 3 red 4 lime 5 sky 6 green 7 blue 8 black 9 yellow

mix nlib=ENDFB7R1 ptlib=PT.ENDFB7R1. BNL

mat $=1$ bunches u234 4.7452-4 u235 4.4739-2 u236 $1.7173-5$ u238 $2.7496-3$ be $6.2666-9$ li $1.6273-7$ al

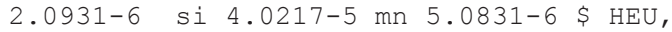

1.6833-4 ni $8.4967-6$ cr $6.7134-7$ cu $1.9618-6 \quad$ b $1.0448-7$ co $9.5830-8$ ca $1.4091-6 \quad$ c mat $=2$ bunches u234 4.7473-4 u235 4.4760-2 u236 $1.7179-5$ u238 2.7305-3 be $6.2645-9$ li $1.6268-7$ al

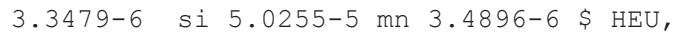

ni $5.8331-6$ cr $4.6088-7$ cu $1.3468-6 \quad$ b $5.2222-7$ co $9.5798-8$ ca $1.4087-6 \quad \mathrm{c}$

$1.3349-40161.4115-5$ n 2.4184-5 \$ Lower Plate

mat $=3$ bunches u234 $4.7998-4$ u235 $4.4728-2$ u236 $2.1562-4$ u238 $2.5589-3$
$2.0924-6$ si $4.8243-5 \mathrm{mn} \mathrm{3.7956-6}$ \$ HEU,

1.5793-4 o16 $1.4114-5$ 6.3446-6 cr $5.0130-7$ cu $1.4649-6$ b $3.1332-7$

mat $=4$ bunches u234 4.7637-4 u235 4.4913-2 u236 $1.7236-5$ u238 $2.7501-3$ be $6.2863-9 \quad 1 i \quad 1.6324-7$ al

$1.6798-6$ si $8.0687-5 \mathrm{mn} 3.0717-6$ \$EU,

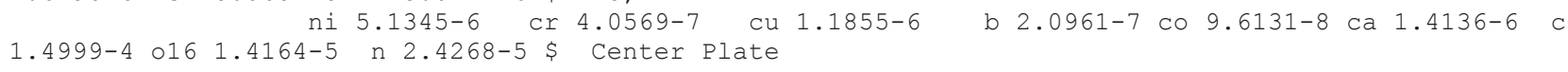

mat $=5$ bunches u234 4.7722-4 u235 4.4902-2 u236 2.0347-4 u238 2.5786-3 al

2.1002-6 si $4.8423-5 \mathrm{mn} \mathrm{3.8098-6} \mathrm{\$} \mathrm{HEU,}$

ni 6.3683-6 cr 5.0317-7 cu $1.4704-6$ b 3.1449-7

1.4167-5 n 2.4274-5\$ Center Pins

mat $=6$ bunches u234 4.8177-4 u235 4.4895-2 u236 2.1643-4 u238 2.5684-3

2.1002-6 si 4.8423-5 mn 3.8098-6 \$ HEU,

$$
\text { ni } 6.3683-6 \text { cr } 5.0317-7 \text { cu } 1.4704-6 \text { b } 3.1449-7
$$

$1.5852-4$ o16 1.4167-5 n 2.4274-5 \$ Plugs

mat $=7$ bunches u234 4.7738-4 u235 4.4485-2 u236 2.1446-4 u238 2.5450-3

2.0810-6 si 4.7981-5 mn 3.7751-6 \$ HEU, Diametral

ni $6.3102-6$ cr $4.9858-7$ cu $1.4570-6$ b $3.1162-7$

$1.5707-40161.4038-5$ n 2.4052-5 \$ Filler Rod

mat $=8$ bunches u234 4.7647-4 u235 4.4923-2 u236 $1.7243-5$ u238 2.7456-3 be $6.2870-9$ li $1.6326-7$ al

$1.6800-6$ si $4.0348-5 \mathrm{mn} 2.0890-6$ \$ HEU,

1.5001-4 ni 3.4919-6 cr 2.7590-7 cu 8.0626-7 b 3.1446-7 co 9.6142-8 ca $1.4137-6$ c

mat $=9$ bunches u234 4.7569-4 u235 4.4849-2 u236 $1.7215-5$ u238 2.7411-3 be $6.2770-9$ li $1.6300-7$ al

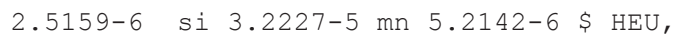

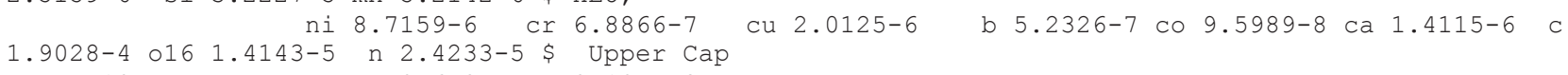
mat $=10$ bunches cu $7.5056-2$ zn $8.1044-3$

\$ Brass Bolt

geometry

$\$---$ Lower sphere

$\begin{array}{lllllllllllllllllllll}\text { sector } 1 & \text { HEU } & -10 & 11 & -12 & 20 & 21 & 22 & 23 & 24 & 25 & 26 & 27 & 28 & 31 & 32 & 33 & \text { Lower Polar Cap }\end{array}$

sector 10 Brass $-20 \quad 13$

$\begin{array}{llllllll}\text { sector } 2 & \mathrm{HEU} & -10 & 12 & -14 & 31 & 32 & 33\end{array}$

sector 2 HEU $14-30$

sector 3 HEU $-31-34$

sector 3 HEU $-32-14$

sector 3 HEU $-33-34$

$\$--$ Center section

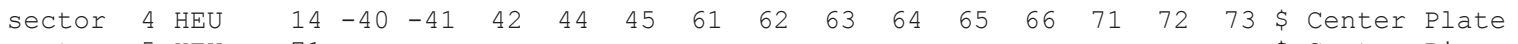

sector 5 HEU -71

sector 5 HEU -72

sector 5 HEU -73

sector $6 \mathrm{HEU} \quad-40 \quad 44-45$

sector 6 HEU $\quad-40-41-65 \quad 66$

sector $6 \mathrm{HEU} \quad-40-41 \quad 65-66$

Shallow

sector 7 HEU -43

\$ --- Top section

$\begin{array}{lllllllll}\text { sector } 8 \mathrm{HEU} & 41 & -80 & -81 & 71 & 72 & 73\end{array}$

sector 8 HEU $41 \quad 80-82$

$\$$ Brass Bolt

\$ Lower Plate

\$ Lower Plate, male

\$ Lower Pin, Short

\$ Lower Pin, Flush

\$ Lower Pin, Short

Revision: 0

\$ Center Pin

\$ Center Pin

\$ Center Pin

\$ Plug for Target Hole

\$ Plug for $T / C$, Deep

$\$$ Plug for $T / C$,

\$ Diametral Filler Rod

\$ Upper Plate

\$ Upper Plate, male 


\section{NEA/NSC/DOC(95)03/II}

Volume II

\section{HEU-MET-FAST-100}

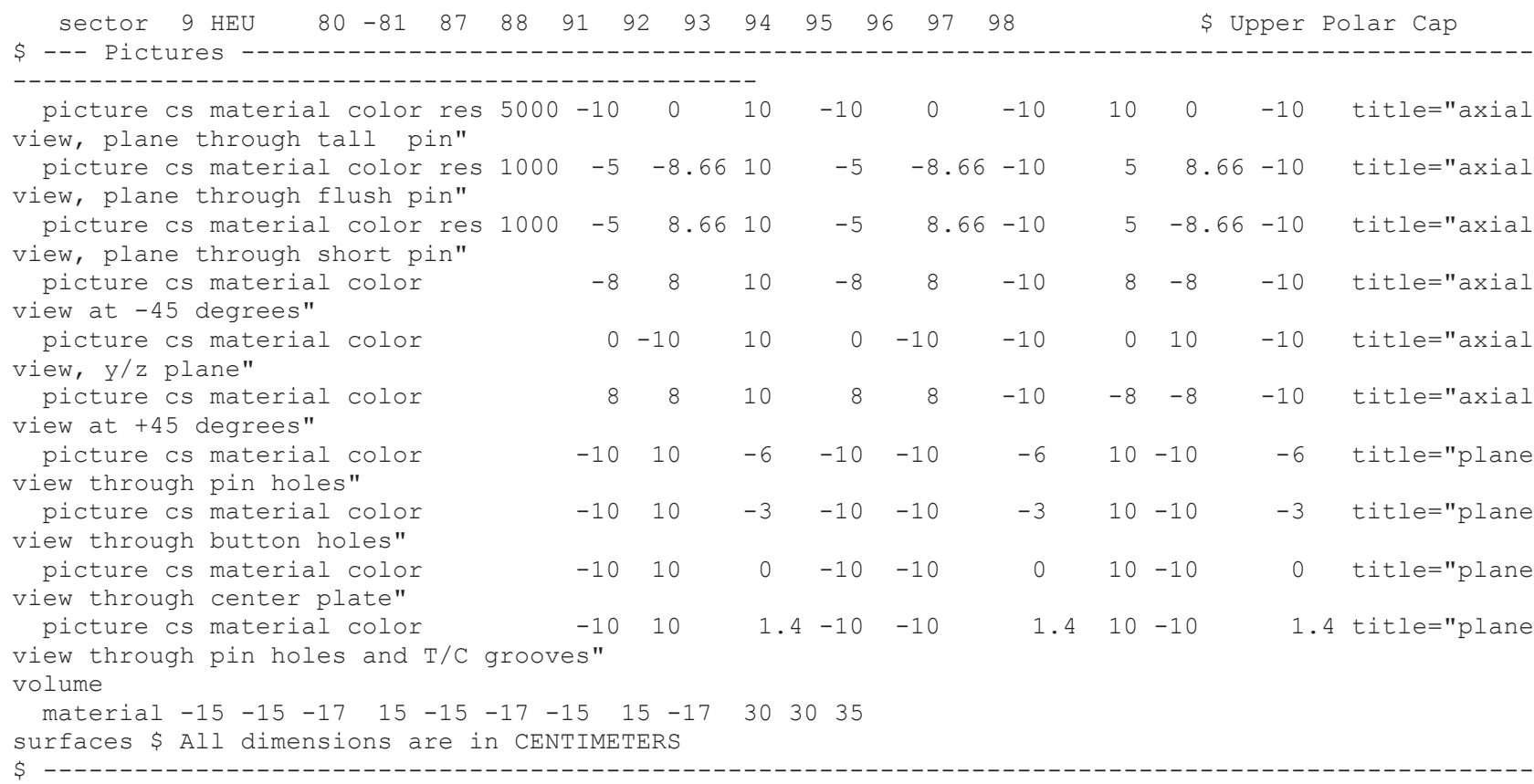

-

\$---- Lower Polar Cap, Brass Bolt and Lower Plate. Note that 8.008069 = 5.66256*SQRT (2) and $8.6887867=6.1439 *$ SQRT $(2)$

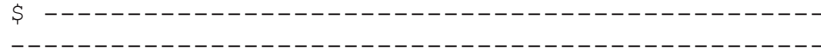

10 ellipsoid 8.744413 8.7444138.745982 tr 000.050546 \$ Lower Sphere (Polar Cap and Lower

Plate), outer

11 plane z -8.602705 \$ Lower Polar Cap, lower

12 plane z -4.066286 \$ Lower Polar Cap, upper; and Lower

Plate, lower

13 plane z -8.580628

14 plane z -1.429004

\$ Brass bolt

bottom

20 cylinder z $0.747903-9.0-7.811008 \quad$ \$ Hole for brass bolt

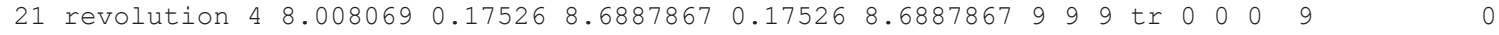

-9 \$ Button hole

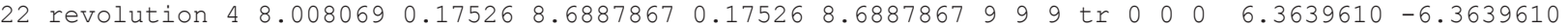

-9 \$ Button hole

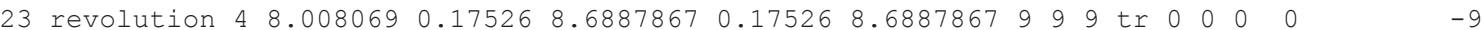

-9 \$ Button hole

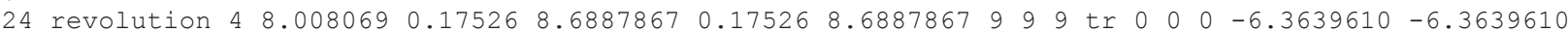

-9 \$ Button hole

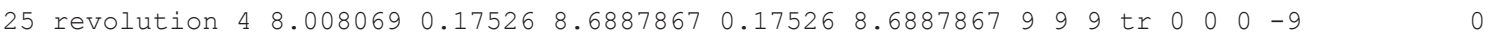

-9 \$ Button hole

26 revolution $4 \quad 8.008069 \quad 0.17526 \quad 8.6887867 \quad 0.17526 \quad 8.68878679999$ tr $00000.6 .3639610 \quad 6.3639610$

-9 \$ Button hole

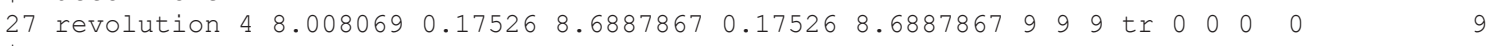

-9 \$ Button hole

28 revolution $4 \quad 8.0080690 .17526 \quad 8.6887867 \quad 0.17526 \quad 8.68878679999$ tr $000006.3639610 \quad 6.3639610$

-9 \$ Button hole

30 revolution $2-1.4290040 .635-0.8752840 .3153 \operatorname{tr} 000001$ Lower Plate, male

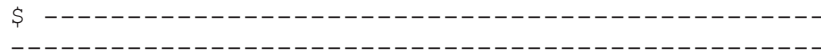

$\$---3$ Pin Holes and Pins in Lower Polar Cap and Lower Plate

$\$$

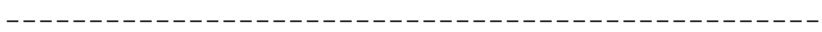

31 cylinder z $0.57531-5.177536$ - 1 tr $-6.350 \quad 0 \quad 0$ \$ Hole for pin

32 cylinder z $0.57531-5.177536$ - 1 tr $3.175 \quad 5.499260$ \$ Hole for pin

33 cylinder z $0.57531-5.177536$-1 tr $3.175-5.499260$ \$ Hole for pin

34 plane z -1.430274 \$ Lower Pin, short

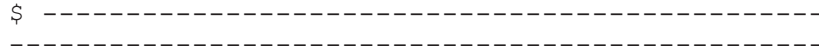

$\$$---- Center Plate

Revision: 0 


\section{NEA/NSC/DOC(95)03/II \\ Volume II}

\section{HEU-MET-FAST-100}

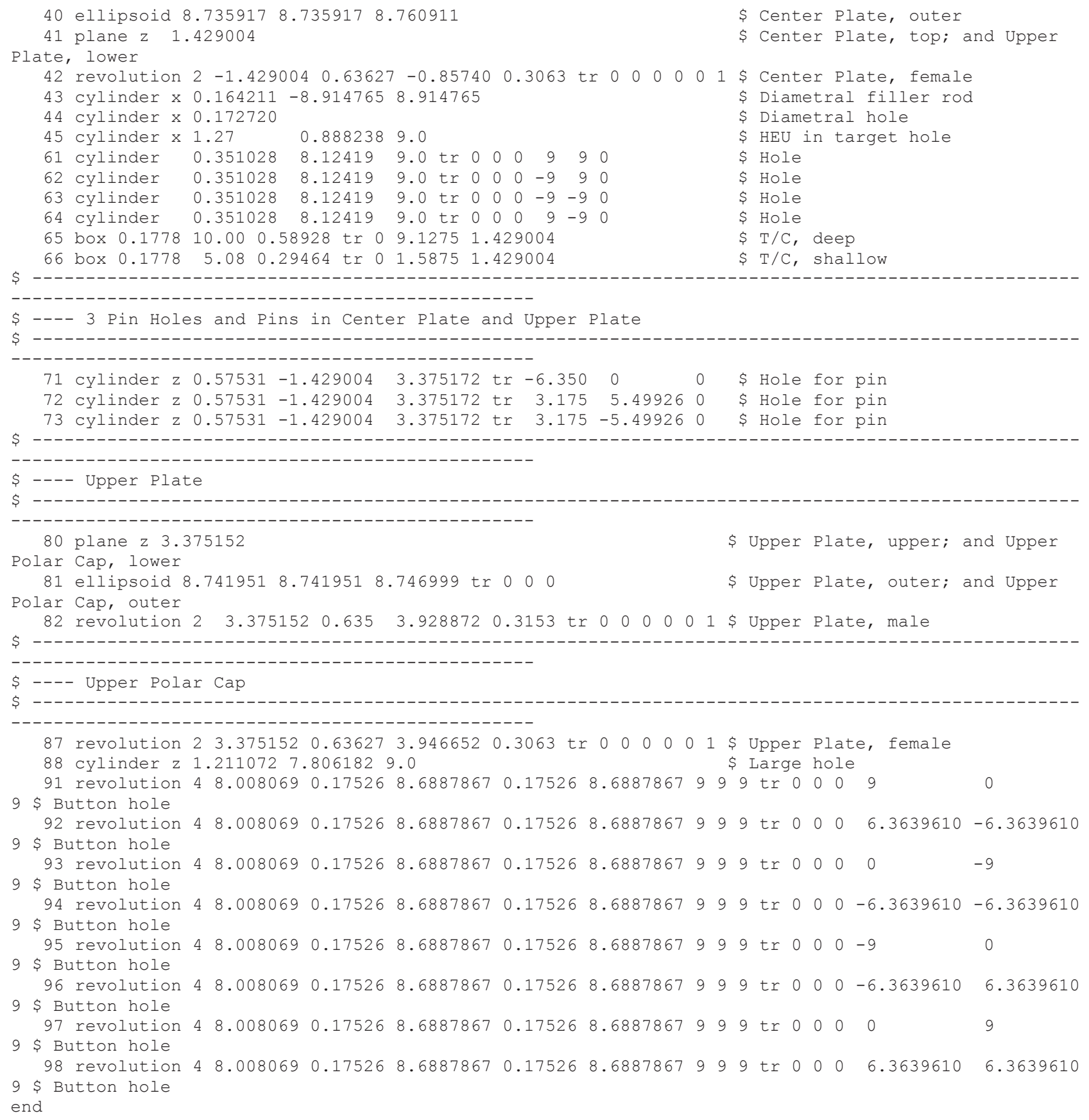


NEA/NSC/DOC(95)03/II

Volume II

\section{HEU-MET-FAST-100}

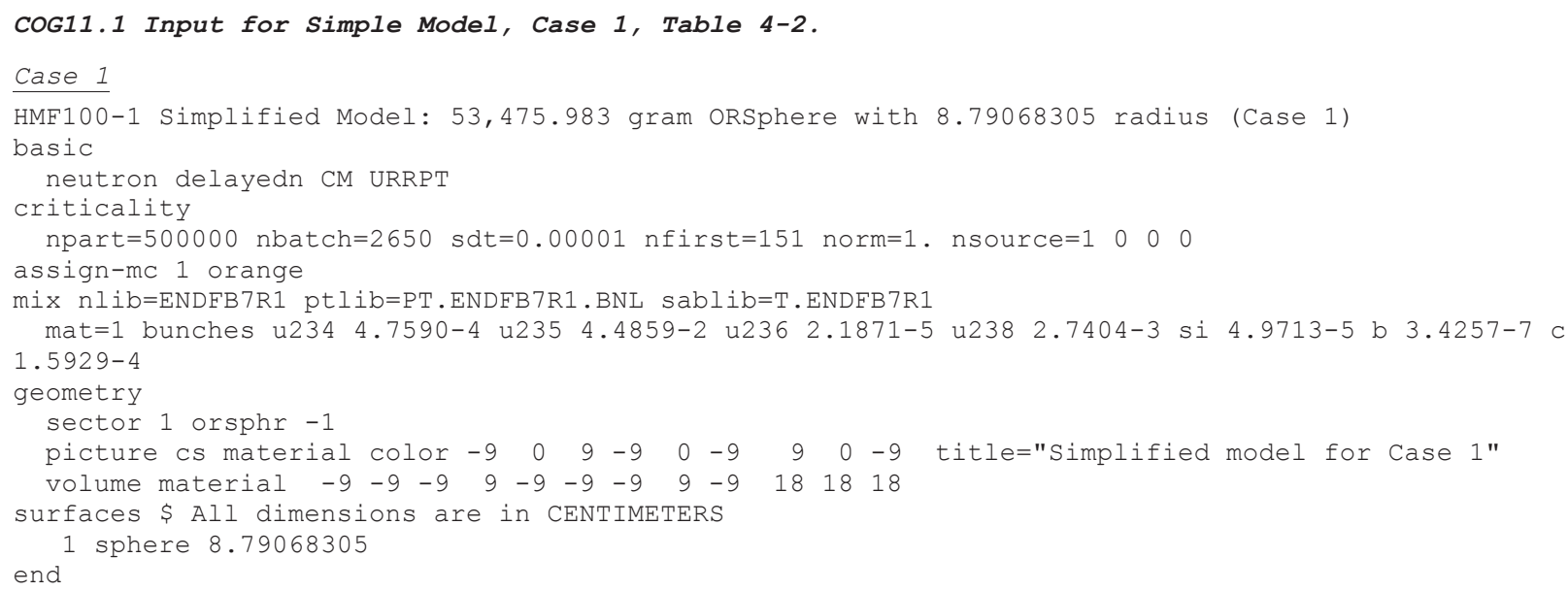


NEA/NSC/DOC(95)03/II

Volume II

\section{HEU-MET-FAST-100}

CoG11.1 Input for Simple Model, Case 2, Table 4-2.

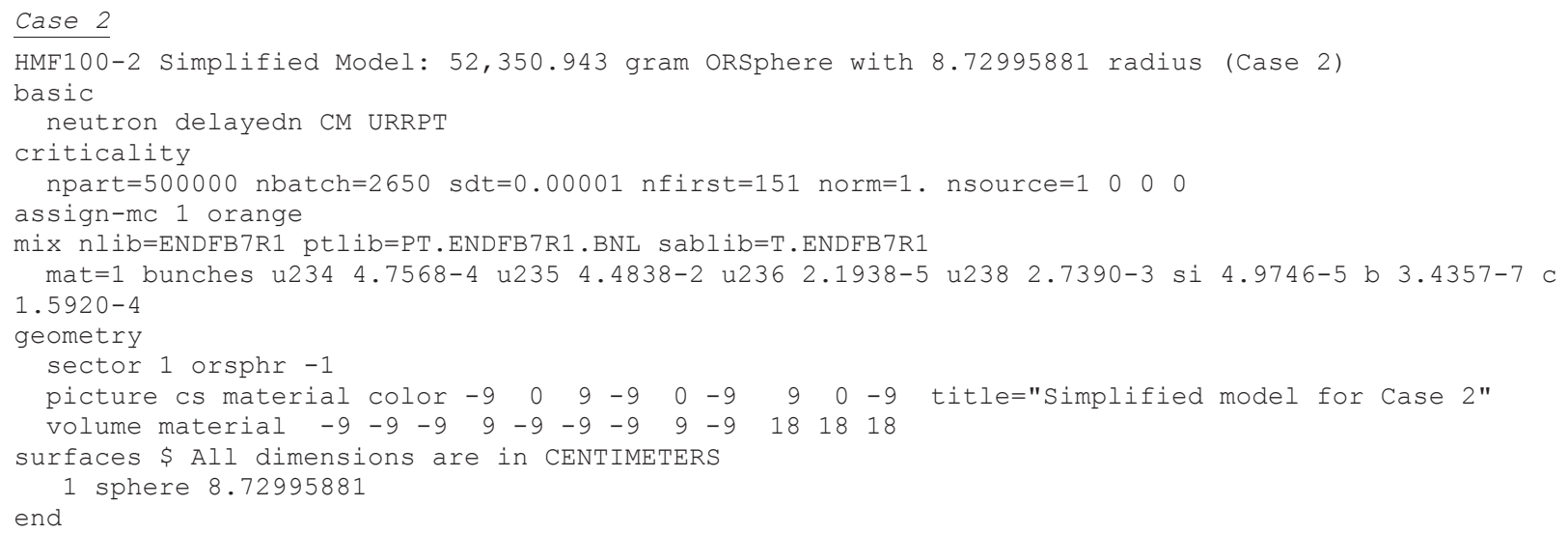




\section{APPENDIX B: DERIVATION OF ELLIPSOID EQUATION AND VOLUMES}

Each section of sphere had a measured deviation from spherical for each plate (Case 1) or section (Case 2). Using a general ellipsoid equation, Equation B.1, an equation to describe each plate or section was developed and an equation to calculate the volume of each plate was derived. The deviation from spherical at the top and bottom of each plate or section is used. Using the deviation from spherical and the height of each plate $\mathrm{x}, \mathrm{y}, \mathrm{z}$ coordinates could be derived. It was assumed that $\mathrm{x}=\mathrm{y}$ and the $\mathrm{y}=0$ plane was used to derive the equations. Because the sum of the heights of the plates/sections does not equal the diameter of the sphere the center of the ellipsoid curve for the lower and upper polar cap for Case 1 and the bottom section and upper polar cap for Case 2 must be shifted. For the initial derivation the center of the ellipsoid is assumed to be at the origin $(\bar{x}, \bar{y}, \bar{z}=0,0,0)$. The actual center of the ellipsoids is derived later. The method is outlined and described below 


\begin{tabular}{|c|c|c|}
\hline $\begin{array}{l}\text { Equation } \\
\text { B.1 }\end{array}$ & $A(x-\bar{x})^{2}+B(y-\bar{y})^{2}+C(z-\bar{z})^{2}+G=0$ & -General ellipsoid equation \\
\hline $\begin{array}{l}\text { Equation } \\
\text { B. } 2\end{array}$ & $A(x-0)^{2}+B(y-0)^{2}+C(z-0)^{2}+G=0$ & -Assume $0,0,0$ origin \\
\hline $\begin{array}{l}\text { Equation } \\
\text { B. } 3\end{array}$ & $A x^{2}+B(0)^{2}+C z^{2}+G=0$ & -Use $y=0$ plane \\
\hline $\begin{array}{l}\text { Equation } \\
\text { B. } 4\end{array}$ & $A x_{1}^{2}+C z_{1}^{2}+G=0$ & \multirow{2}{*}{$\begin{array}{l}\text {-Substitute in points at top and } \\
\text { bottom of plate/section, } x_{1}, 0, z_{1} \\
\text { and } x_{2}, 0, z_{2}\end{array}$} \\
\hline $\begin{array}{l}\text { Equation } \\
\text { B.5 }\end{array}$ & $A x_{2}^{2}+C z_{2}^{2}+G=0$ & \\
\hline $\begin{array}{l}\text { Equation } \\
\text { B. } 6\end{array}$ & $A\left(x_{1}^{2}-x_{2}^{2}\right)+C\left(z_{1}^{2}-z_{2}^{2}\right)=0$ & -Subtract equations \\
\hline $\begin{array}{l}\text { Equation } \\
\text { B.7 }\end{array}$ & $A\left(x_{1}^{2}-x_{2}^{2}\right)=C\left(z_{2}^{2}-z_{1}^{2}\right)$ & \multirow[t]{2}{*}{-Solve for $A / C$} \\
\hline $\begin{array}{l}\text { Equation } \\
\text { B.8 }\end{array}$ & $A / C=\left(z_{2}^{2}-z_{1}^{2}\right) /\left(x_{1}^{2}-x_{2}^{2}\right)$ & \\
\hline
\end{tabular}

Equation

B.9

$$
\frac{A}{C}\left(x^{2}+y^{2}\right)+z^{2}+\frac{G}{C}=0
$$

\section{Equation}

B. 10

$$
\frac{A}{C} x_{1}^{2}+z_{1}^{2}+\frac{G}{C}=0
$$

Equation

B.11

$$
\frac{G}{C}=-\frac{A}{C} x_{1}{ }^{2}-z_{1}{ }^{2}
$$

Equation

B.12

$$
\frac{G}{C}=\frac{\left(z_{1}^{2}-z_{2}^{2}\right)}{\left(x_{1}{ }^{2}-x_{2}^{2}\right)} x_{1}{ }^{2}-z_{1}{ }^{2}
$$

Equation

$$
\begin{gathered}
\left(z_{2}{ }^{2}-z_{1}{ }^{2}\right) /\left(x_{1}{ }^{2}-x_{2}{ }^{2}\right) \\
-z_{1}{ }^{2}=0
\end{gathered}
$$

\section{Equation}

B. 14

$$
\begin{gathered}
\left(z_{2}{ }^{2}-z_{1}{ }^{2}\right)\left(x^{2}+y^{2}\right)+\left(x_{1}{ }^{2}-x_{2}{ }^{2}\right) z^{2}+\left(z_{1}{ }^{2}-z_{2}{ }^{2}\right) x_{1}{ }^{2} \\
-\left(x_{1}{ }^{2}-x_{2}{ }^{2}\right) z_{1}{ }^{2}=0
\end{gathered}
$$

Equations

B. 15

B. 16

B.17

$$
\begin{aligned}
& A=B=\left(z_{2}{ }^{2}-z_{1}{ }^{2}\right) \\
& \mathrm{C}=\left(x_{1}{ }^{2}-x_{2}{ }^{2}\right)
\end{aligned}
$$$$
\mathrm{G}=\left(z_{1}{ }^{2}-z_{2}{ }^{2}\right) x_{1}{ }^{2}-\left(x_{1}{ }^{2}-x_{2}{ }^{2}\right) z_{1}{ }^{2}
$$

-Divide Equation B.2 and B.4 by C. Equation B.9 uses symmetry and the fact that $\mathrm{A}=\mathrm{B}$.

-Solve for $G / C$

-Plug Equation B.8 into B.11 (distribution of negative sign switches order of numerator)

-Plug Equation B.8 and B.12 into Equation B.9

-Multiply by $\left(x_{1}{ }^{2}-x_{2}{ }^{2}\right)$

-Extract A,B,C, and G Coefficients from Equation B.14 
Next, an equation for the volume of each plate/section is derived. This required simplifying the three dimension ellipsoid equation to a one dimensional ellipse equation in the $\mathrm{y}=0$ plane and then rotating the curve around the $\mathrm{z}$ axis. The resulting solid of revolution is identical to the ellipsoid and has equal volume. To begin Equation B.3 is solved for x (Equation B.17); this is the equation of the ellipse that is plugged into the solid of revolution equation given as Equation B.18.

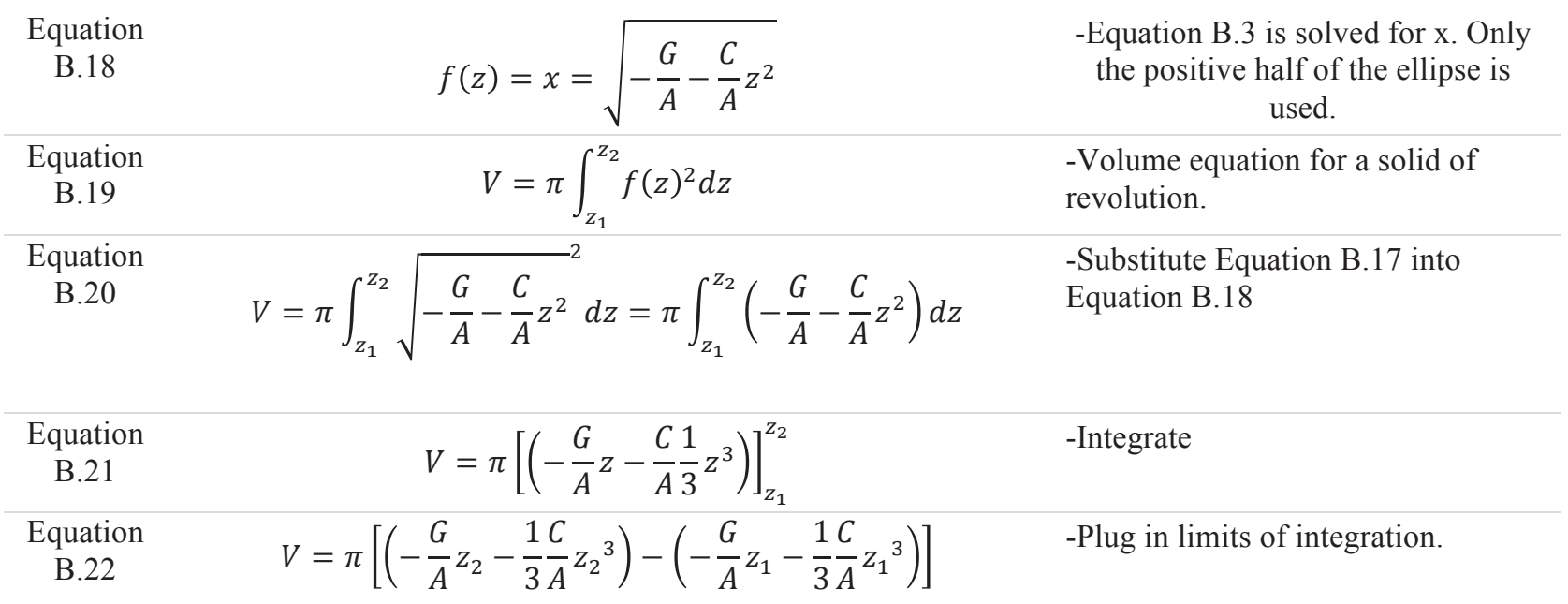

Finally, the shift of the sphere was calculated by taking the difference between the $z_{1}$ and $z_{2}$ used for the equation derivation and volume calculation and the actual height of the bottom and top of the plates/sections with relation to the center of the model. The center of the model was the center of the diametral hole which was the center of the sphere for Case 1 and $0.0508 \mathrm{~cm}$ below the center of the sphere for Case 2. Table B-1 and B-2 gives the $x_{1}, z_{1}, x_{2}$, and $z_{2}$ values used in the equation derivations. These values were based on the heights of the plates and polar caps, the nominal radius, and the deviation from spherical. A radius of 3.4665 in. $(8.80491 \mathrm{~cm})$ was used for Case 1 and 3.4425 in. $(8.74395 \mathrm{~cm})$ for Case 2. Table B-1 and B-2 also give the ellipsoid coefficients for each section of sphere. This format was used because it is often used in neutron codes. The general mathematical format for an ellipsoid equation is given as Equation B.24 and the relation between the coefficients for the two equations is given as Equation B.25.

$\begin{array}{cc}\text { Equation } & A x^{2}+B y^{2}+C(z-\bar{z})^{2}+G=0 \\ \text { B.23 } & \frac{x^{2}}{a^{2}}+\frac{y^{2}}{b^{2}}+\frac{z^{2}}{c^{2}}=1 \\ \text { Equation } & a^{2}=-G / A \\ \text { B.24 } & b^{2}=-G / B \\ \text { Equation } & c^{2}=-G / C \\ \text { B.25 } & \end{array}$


Table B-1. Derivation of Ellipsoid Equations and Volumes, Case 1. ${ }^{\text {(a) }}$

\begin{tabular}{|c|c|c|c|c|c|c|}
\hline Variable & $\begin{array}{c}\text { Lower Polar } \\
\text { Cap }\end{array}$ & Lower Plate & $\begin{array}{l}\text { Center Plate } \\
\text { Lower Half }^{(\mathrm{b})}\end{array}$ & $\begin{array}{l}\text { Center Plate } \\
\text { Upper Half }^{(b)}\end{array}$ & Upper Plate & $\begin{array}{c}\text { Upper Polar } \\
\text { Cap }\end{array}$ \\
\hline $\begin{array}{l}\text { Deviation at } \\
\text { Top (in./cm) }\end{array}$ & $\begin{array}{l}-1.8 \mathrm{E}-03 / \\
-4.57 \mathrm{E}-03\end{array}$ & $\begin{array}{l}-8.0 \mathrm{E}-04 / \\
-2.03 \mathrm{E}-03\end{array}$ & $\begin{array}{l}-6.0 \mathrm{E}-04 / \\
-1.52 \mathrm{E}-03\end{array}$ & $\begin{array}{l}-2.0 \mathrm{E}-04 / \\
-5.08 \mathrm{E}-04\end{array}$ & $\begin{array}{c}-2.0 \mathrm{E}-04 / \\
-5.08 \mathrm{E}-04\end{array}$ & $\begin{array}{c}0.0 / \\
0.0\end{array}$ \\
\hline $\begin{array}{l}\text { Deviation at } \\
\text { Bottom } \\
\text { (in./cm) }\end{array}$ & $\begin{array}{l}-2.0 \mathrm{E}-04 / \\
-5.08 \mathrm{E}-04\end{array}$ & $\begin{array}{l}0.0 / \\
0.0\end{array}$ & $\begin{array}{l}-1.0 \mathrm{E}-03 / \\
-2.54 \mathrm{E}-03\end{array}$ & $\begin{array}{l}-6.0 \mathrm{E}-04 / \\
-1.52 \mathrm{E}-03\end{array}$ & $\begin{array}{l}-1.0 \mathrm{E}-03 / \\
-2.54 \mathrm{E}-03\end{array}$ & $\begin{array}{l}4.0 \mathrm{E}-04 / \\
1.02 \mathrm{E}-03\end{array}$ \\
\hline $\begin{array}{l}\mathrm{R} \text { at Top } \\
(\mathrm{cm})^{(\mathrm{c})}\end{array}$ & 8.800338 & 8.802878 & 8.803386 & 8.804402 & 8.804402 & 8.80491 \\
\hline $\begin{array}{l}\mathrm{R} \text { at Bottom } \\
(\mathrm{cm})^{(\mathrm{c})}\end{array}$ & 8.804402 & 8.80491 & 8.80237 & 8.803386 & 8.80237 & 8.805926 \\
\hline $\begin{array}{l}\text { Height of Top, } \\
z_{1}(\mathrm{~cm})^{(\mathrm{d})}\end{array}$ & -4.06146 & -1.429004 & 0 & 1.429004 & 3.375152 & 8.8049100 \\
\hline$x_{1}(\mathrm{~cm})^{(\mathrm{e})}$ & 7.807080 & 8.686116 & 8.803386 & 8.687660 & 8.131780 & 0 \\
\hline $\begin{array}{l}\text { Height of } \\
\text { bottom, } \\
z_{2}(\mathrm{~cm})^{(\mathrm{d})}\end{array}$ & -8.804402 & -4.066286 & -1.429004 & 0 & 1.429004 & 3.375660 \\
\hline$x_{2}(\mathrm{~cm})^{(\mathrm{e})}$ & 0 & 7.809722 & 8.685601 & 8.803386 & 8.685601 & 8.133219 \\
\hline $\begin{array}{l}\text { Actual Height } \\
\text { of Top }^{(f)}\end{array}$ & -4.066286 & -1.429004 & 0 & 1.429004 & 3.375152 & 8.8044020 \\
\hline $\bar{Z}^{(\mathrm{g})}$ & -0.004826 & 0 & 0 & 0 & 0 & -0.000508 \\
\hline $\mathrm{A}=\mathrm{B}^{(\mathrm{h})}$ & 61.02204 & 14.49263 & 2.04205 & 2.04205 & 9.34960 & 66.13136 \\
\hline $\mathrm{C}^{(\mathrm{h})}$ & 60.95049 & 14.45685 & 2.05994 & 2.02416 & 9.31382 & 66.14925 \\
\hline $\mathrm{G}^{(\mathrm{h})}$ & -4724.72940 & -1122.97037 & -158.25826 & -158.25826 & -724.34990 & -5128.31605 \\
\hline $\mathrm{V}\left(\mathrm{cm}^{3}\right)$ & 509.89289 & 574.80300 & 344.84014 & 344.89368 & 436.61075 & 647.95477 \\
\hline
\end{tabular}

(a) Values were not rounded until the end of the calculations. A truncated number of digits are shown in this table.

(b) The Center Plate had to be modeled as two parts.

(c) This value is $8.80491 \mathrm{~cm}$ plus the deviation from spherical.

(d) These heights are in relation to the center of the ellipsoid if it were at 0, 0, 0. For the lower polar cap and upper polar cap these do not equal the heights in relation to the center of the model. This is due to the fact that the sum of the heights of the plates is larger than the radius of the curve.

(e) $x=\sqrt{R^{2}-z^{2}}$

(f) This is the height of the top of the plate or polar cap in relation to the center of the model which is the center of the sphere for Case 1. It is the sum of the heights of the plates. These heights are shown in Figure 3-2, 3-4, 35, 3-6, and 3-9.

(g) This is the shift of the ellipsoid for the lower and upper polar caps so that the tops and bottoms of all the plates and polar caps align. It is the difference between the Actual Height of Top and $z_{1}$.

(h) Due to the method of derivation, for surfaces above the $\mathrm{z}=0$ plane these coefficients must be multiplied by -1 to get them into standard MCNP format. 
NEA/NSC/DOC(95)03/II

Volume II

HEU-MET-FAST-100

Table B-2. Derivation of Ellipsoid Equations and Volumes, Case 2. ${ }^{\text {(a) }}$

\begin{tabular}{|c|c|c|c|}
\hline Variable & Bottom Section $^{(\text {b) }}$ & Center Section $^{(\mathrm{b})}$ & Upper Polar Cap \\
\hline Deviation at Top (in./cm) & $2.0 \mathrm{E}-04 / 5.08 \mathrm{E}-04$ & $-1.70 \mathrm{E}-03 /-4.32 \mathrm{E}-03$ & $1.2 \mathrm{E}-03 / 3.05 \mathrm{E}-03$ \\
\hline $\begin{array}{l}\text { Deviation at Bottom } \\
\text { (in./cm) }\end{array}$ & 8.0E-04/2.03E-03 & $-2.9 \mathrm{E}-03 /-7.37 \mathrm{E}-03$ & $-5.0 \mathrm{E}-04 /-1.27 \mathrm{E}-03$ \\
\hline $\mathrm{R}$ at Top $(\mathrm{cm})^{(\mathrm{c})}$ & 8.744458 & 8.739632 & 8.746998 \\
\hline $\mathrm{R}$ at Bottom $(\mathrm{cm})^{(\mathrm{c})}$ & 8.745982 & 8.736584 & 8.74268 \\
\hline Height of Top, $z_{1}(\mathrm{~cm})^{(\mathrm{d})}$ & -1.4795500 & 3.3751520 & 8.7469980 \\
\hline$x_{1}(\mathrm{~cm})^{(\mathrm{e})}$ & 8.618380 & 8.061608 & 0 \\
\hline $\begin{array}{l}\text { Height of bottom, } \\
z_{2}(\mathrm{~cm})^{(\mathrm{d})}\end{array}$ & -8.745982 & -1.429004 & 3.328670 \\
\hline$x_{2}(\mathrm{~cm})^{(\mathrm{e}}$ & 0 & 8.618924 & 8.084207 \\
\hline Actual Height of Top ${ }^{(\mathrm{f})}$ & -1.4290040 & 3.3751520 & 8.7934800 \\
\hline $\bar{z}^{(\mathrm{g})}$ & 0.050546 & 0 & 0.046482 \\
\hline $\mathrm{A}=\mathrm{B}^{(\mathrm{h})}$ & 74.30313 & 9.34960 & 65.42993 \\
\hline $\mathrm{C}^{(\mathrm{h})}$ & 74.27648 & 9.29633 & 65.35441 \\
\hline $\mathrm{G}^{(\mathrm{h})}$ & -5681.57126 & -713.52645 & -5000.26418 \\
\hline $\mathrm{V}\left(\mathrm{cm}^{3}\right)$ & 1048.61776 & 1108.74634 & 639.43142 \\
\hline
\end{tabular}

(a) Values were not rounded until the end of the calculations. A truncated number of digits were preserved in this table.

(b) For Case 2 the lower polar cap and lower plate are treated as one section and the center plate and upper plate are treated as one section.

(c) This value is $8.74395 \mathrm{~cm}$ plus the deviation from spherical

(d) These heights are in relation to the center of the ellipsoid if it were at 0, 0, 0. For the lower polar cap and upper polar cap these do not equal the heights in relation to the center of the model.

(e) $x=\sqrt{R^{2}-z^{2}}$

(f) This is the height of the top of the plate or polar cap in relation to the center of the model which is the center of the diametral hole and $0.0508 \mathrm{~cm}$ below the center of the sphere for Case 2. It is the sum of the heights of the plates. These heights are shown in Figure 3-3, 3-7, and 3-10.

(g) This is the shift of the ellipsoid for the lower and upper polar caps so that the tops and bottoms of all the plates and polar caps align. It is the difference between the Actual Height of Top and $z_{1}$.

(h) Due to the method of derivation, for surfaces above the $\mathrm{z}=0$ plane these coefficients must be multiplied by -1 to get them into standard format. 
NEA/NSC/DOC(95)03/II

Volume II

HEU-MET-FAST-100

\section{APPENDIX C: METHOD TO CALCULATE VOLUMES AND DENSITIES}

In order to calculate the total volume of each plate or section for the detailed benchmark model and the average enrichment for the simple benchmark model the volume of each void or penetration must be calculated.

First, the volume of the button recesses was calculated. For Case 1 the calculation was straight forward. The volume was split into the dome section, the cylindrical bore hole and the screw hole. The following method was used to calculate the total volume

Table C-1. Calculation of Button Recesses Volume, Case 1.

\begin{tabular}{|c|c|c|c|}
\hline Screw Hole Dia. & $D_{\text {screw }}$ & $=0.138$ in.$/ 0.35052 \mathrm{~cm}$ & -Given \\
\hline Screw Hole Depth & $h_{\text {screw }}$ & $=0.268$ in.$/ 0.68072 \mathrm{~cm}$ & -Given \\
\hline Cylinder Height & $h_{\text {bore }}$ & $=0.018$ in.$/ 0.04572 \mathrm{~cm}$ & -Given \\
\hline Recess Dia. & $D_{\text {bore }}$ & $=0.875 \mathrm{in} . / 2.2225 \mathrm{~cm}$ & -Given \\
\hline Dome Height & $\begin{array}{l}h_{\text {dome }} \\
=R-\sqrt{R^{2}-\left(D_{\text {bore }} / 2\right)^{2}}\end{array}$ & $=0.0704 \mathrm{~cm}$ & $\begin{array}{l}-\mathrm{R} \text { is radius surface. } \\
\text { Assumed to be average } \\
\text { radius of } 8.80491 \mathrm{~cm} .\end{array}$ \\
\hline Dome Volume & $\begin{array}{r}V_{\text {dome }}=1 / 3 \pi h_{\text {dome }}{ }^{2}(3 R \\
\left.-h_{\text {dome }}\right)\end{array}$ & $=0.13675 \mathrm{~cm}^{3}$ & $\begin{array}{l}\text {-Equation for dome } \\
\text { volume }\end{array}$ \\
\hline Recess Volume & $V_{\text {bore }}=\frac{\pi}{4} D_{\text {bore }}{ }^{2} h_{\text {bore }}$ & $=0.17737 \mathrm{~cm}^{3}$ & $\begin{array}{l}\text {-Equation for cylinder } \\
\text { volume }\end{array}$ \\
\hline Screw Hole Vol. & $V_{\text {screw }} \frac{\pi}{4} D_{\text {screw }}{ }^{2} h_{\text {screw }}$ & $=0.06569 \mathrm{~cm}^{3}$ & $\begin{array}{l}\text {-Equation for cylinder } \\
\text { volume }\end{array}$ \\
\hline Total Volume & $V=8\left(V_{\text {dome }}+V_{\text {bore }}+V_{\text {screw }}\right)$ & $=3.038473 \mathrm{~cm}^{3}$ & $\begin{array}{l}\text {-Assume all eight } \\
\text { cylinders have equal } \\
\text { volume. }\end{array}$ \\
\hline
\end{tabular}

For Case 2 only a flat spot was left of the bottom section when the sphere was re-machined. The new radius of the flat spot on the lower polar cap was not given and thus the dome height of the flat spot had to be calculated. The mass adjustment button recess on the $y=0$ plane was used to perform these calculations. The center line of the mass adjustment button recesses sat on the $\mathrm{x}=\mathrm{z}$ line when the origin is at the center of the diametral hole. The point at which this line intersected the curve of the ellipsoid of the polar cap was calculated. The coordinates of the bottom of the screw hole and the bottom of the recess was also calculated and, using the distance formula, the depth of the mass adjustment button recesses after re-machining was calculated. Table C-2 outlines this calculation for the lower polar cap mass adjustment button as well as the total volume calculation. 
Table C-2. Calculation of Lower Polar Cap Button Recesses Depth, Case 2.

\begin{tabular}{|c|c|c|c|}
\hline $\begin{array}{l}\text { Ellipsoid } \\
\text { Equation }\end{array}$ & \multicolumn{2}{|c|}{$\begin{array}{l}74.30313(x)^{2}+74.30313(y)^{2} \\
\quad+74.27648(z-0.050546)^{2}-5681.57126=0\end{array}$} & $\begin{array}{l}\text {-Derived in } \\
\text { Appendix B }\end{array}$ \\
\hline $\begin{array}{l}\text { Intersection of } \\
\text { curve and } x=z \\
\text { in } y=0 \text { plane }\end{array}$ & $\begin{array}{c}74.30313(z)^{2}+74.30313(0)^{2} \\
+74.27648(z-0.050546)^{2} \\
-5681.57126=0 \\
z=6.20901,-6.158470\end{array}$ & $\begin{array}{l}z_{1}=x_{1}= \\
-6.15847 \mathrm{~cm}\end{array}$ & $\begin{array}{l}\text {-The negative value } \\
\text { is used for the lower } \\
\text { polar cap. }\end{array}$ \\
\hline $\begin{array}{l}\text { Coordinates of } \\
\text { bottom of } \\
\text { screw hole. } \\
\text { Calculated } \\
\text { using Case } 1 \\
\text { values and } \\
\text { remain constant } \\
\text { for Case } 2 . \\
\text { Results for only } \\
\text { the } y=0 \text { or } \\
\theta=\pi \text { plane are } \\
\text { given here. }\end{array}$ & $\begin{array}{c}x=\rho \sin \varphi \cos \theta, y=\rho \sin \varphi \sin \theta, z=\rho \cos \varphi \\
\rho=R^{\operatorname{case} 1}-\left(h_{\text {screw }}+h_{\text {bore }}+h_{\text {dome }}\right)^{\operatorname{case} 1} \\
\varphi=\frac{3 \pi}{4} \\
\theta=0, \frac{\pi}{4}, \frac{\pi}{2}, \frac{3 \pi}{4}, \pi, \frac{5 \pi}{4}, \frac{3 \pi}{2}, \frac{7 \pi}{4}\end{array}$ & $\begin{array}{c}\rho=8.00806 \mathrm{~cm} \\
\varphi=\frac{3 \pi}{4} \\
\theta=\pi \\
x_{2}=-5.6626 \mathrm{~cm} \\
z_{2}=-5.6626 \mathrm{~cm} \\
y=0\end{array}$ & $\begin{array}{l}\text {-Screw hole location } \\
\text { is easily defined } \\
\text { with spherical } \\
\text { coordinates and can } \\
\text { then be transformed } \\
\text { into Cartesian } \\
\text { coordinates. }\end{array}$ \\
\hline Total Depth & $h_{t o t}=\sqrt{\left(x_{2}-x_{1}\right)^{2}+\left(z_{2}-z_{1}\right)^{2}}$ & $=0.70132 \mathrm{~cm}$ & -Distance formula \\
\hline Depth of Dome & $h_{\text {dome }}=h_{\text {tot }}-h_{\text {screw }}$ & $=0.0206 \mathrm{~cm}$ & $\begin{array}{l}\text {-Calculate dome } \\
\text { height }\end{array}$ \\
\hline Total Volume & $V=8\left(V_{\text {dome }}+V_{\text {screw }}\right)$ & $=0.61867 \mathrm{~cm}$ & $\begin{array}{l}\text {-The bore section of } \\
\text { the button recess } \\
\text { has been removed } \\
\text { and only the dome } \\
\text { section and screw } \\
\text { hole remain. }\end{array}$ \\
\hline
\end{tabular}

(a) The same method is used to calculate the coordinates of the bottom of the bore hole except $\rho=R^{\text {case1 }}-$ $\left(h_{\text {bore }}+h_{\text {dome }}\right)^{\text {case } 1}=8.6888$.

For Case 2 the height of the mass adjustment button bore hole was reduced in the upper polar cap. The new depth was not given and was calculated in a manner similar to that used to calculate the button recess depth for the lower polar cap. The new dome height for the $2.2225-\mathrm{cm}$ diameter button recess also had to be calculated in order to calculate the new bore hole depth. Table C-3 outlines this calculation for the upper polar cap mass adjustment buttons. 
HEU-MET-FAST-100

Table C-3. Calculation of Upper Polar Cap Button Recess Depth, Case 2.

\begin{tabular}{|c|c|c|c|}
\hline Ellipsoid Equation & \multicolumn{2}{|c|}{$\begin{array}{l}65.4299(x)^{2}+65.4299(y)^{2} \\
\quad+65.3544(z-0.046482)^{2}-5000.26418=0\end{array}$} & $\begin{array}{l}\text {-Derived in } \\
\text { Appendix B }\end{array}$ \\
\hline $\begin{array}{l}\text { Intersection of curve } \\
\text { and } \mathrm{x}=\mathrm{z} \text { in } \mathrm{y}=0 \text { plane }\end{array}$ & $\begin{array}{c}65.4299(z)^{2}+65.4299(0)^{2} \\
+65.3544(z-0.046482)^{2} \\
-5000.26418=0 \\
z=6.20646,-6.16001\end{array}$ & $\begin{array}{l}z_{1}=x_{1} \\
=6.20646 \mathrm{~cm}\end{array}$ & $\begin{array}{l}\text {-The positive value } \\
\text { is used for the upper } \\
\text { polar cap. }\end{array}$ \\
\hline $\begin{array}{l}\text { Coordinates of } \\
\text { bottom of screw } \\
\text { hole. }{ }^{\text {(a) }} \text { Calculated } \\
\text { using Case } 1 \text { values } \\
\text { and remain constant } \\
\text { for Case } 2 . \text { Results } \\
\text { for only the y=0 or } \\
\theta=0 \text { plane are } \\
\text { given here. }\end{array}$ & $\begin{array}{c}x=\rho \sin \varphi \cos \theta, y=\rho \sin \varphi \sin \theta, z=\rho \cos \varphi \\
\rho=R^{\operatorname{case} 1}-\left(h_{\text {screw }}+h_{\text {bore }}+h_{\text {dome }}\right)^{\operatorname{case} 1} \\
\varphi=\frac{\pi}{4} \\
\theta=0, \frac{\pi}{4}, \frac{\pi}{2}, \frac{3 \pi}{4}, \pi, \frac{5 \pi}{4}, \frac{3 \pi}{2}, \frac{7 \pi}{4}\end{array}$ & $\begin{aligned} \rho= & 8.00806 \mathrm{~cm} \\
& \varphi=\frac{\pi}{4} \\
& \theta=0 \\
x_{2}= & 5.6626 \mathrm{~cm} \\
z_{2}= & 5.6626 \mathrm{~cm} \\
& y=0\end{aligned}$ & $\begin{array}{l}\text {-Screw hole } \\
\text { location is easily } \\
\text { defined with } \\
\text { spherical } \\
\text { coordinates and can } \\
\text { then be transformed } \\
\text { into Cartesian } \\
\text { coordinates. }\end{array}$ \\
\hline Total Depth & $h_{t o t}=\sqrt{\left(x_{2}-x_{1}\right)^{2}+\left(z_{2}-z_{1}\right)^{2}}$ & $=0.76919 \mathrm{~cm}$ & -Distance formula \\
\hline Dome Height & $h_{\text {dome }}=R-\sqrt{R^{2}-\left(D_{\text {bore }} / 2\right)^{2}}$ & $=0.0709 \mathrm{~cm}$ & $\begin{array}{l}\text { - } \mathrm{R} \text { is radius surface. } \\
\text { Assumed to be } \\
\text { average radius of } \\
8.74268 \mathrm{~cm} \text {. The } \\
\text { diameter of the } \\
\text { recess was } 2.2225 \text {. }\end{array}$ \\
\hline Depth of Dome & $h_{\text {bore }}=h_{\text {tot }}-h_{\text {screw }}-h_{\text {dome }}$ & $=0.1756 \mathrm{~cm}$ & $\begin{array}{l}\text {-Calculate dome } \\
\text { height }\end{array}$ \\
\hline Total Volume & $V=8\left(V_{\text {dome }}+V_{\text {bore }}+V_{\text {screw }}\right)$ & $=2.172346 \mathrm{~cm}^{3}$ & $\begin{array}{l}\text {-The bore section of } \\
\text { the button recess } \\
\text { has been removed } \\
\text { and only the dome } \\
\text { section and screw } \\
\text { hole remain. }\end{array}$ \\
\hline
\end{tabular}

(a) The same method is used to calculate the coordinates of the bottom of the bore recess except $\rho=R^{\text {case } 1}-$ $\left(h_{\text {bore }}+h_{\text {dome }}\right)^{\text {case } 1}=8.6888$.

All other volume calculations were more straightforward. Tables C-4 through C-9 summarize the volumes for each individual part, the total volume, and compares volume calculated by Christine E. White of INL using AutoCAD ${ }^{\circledR}$ 2012, (C2011 Autodesk,Inc.). Calculated volumes were used in the calculation of atom densities for this evaluation. Tables C-4 through C-9 also provide the total volume for each section, the section mass, and the resulting density. ${ }^{\mathrm{a}}$

\footnotetext{
${ }^{a}$ Inconsistencies between Case 1 and Case 2 densities are addressed in Section 3.1.1. 
NEA/NSC/DOC(95)03/II

Volume II

HEU-MET-FAST-100

Table C-4. ORSphere Volumes, Case 1.

\begin{tabular}{|c|c|c|}
\hline & Calculated & AutoCAD ${ }^{\mathbb{R}}$ \\
\hline \multicolumn{3}{|c|}{ Bottom Section Volume } \\
\hline \multicolumn{3}{|l|}{ Lower Polar Cap Volume } \\
\hline Total Ellipsoid Section Volume ${ }^{(a)}$ & 509.6592146 & 509.6557064 \\
\hline Support Hole & -1.592353171 & -1.5923538 \\
\hline Pin Hole Volume (3) & -3.466464423 & -3.4664644 \\
\hline Mass Adjustment Button Recesses (8) & -3.038473102 & -3.047776 \\
\hline \multicolumn{3}{|l|}{ Total Lower Polar Cap Volume } \\
\hline \multicolumn{3}{|l|}{ Lower Plate Volume } \\
\hline Total Ellipsoid Section Volume & 574.8029968 & 574.800623 \\
\hline Pin Hole (3) & -8.226811453 & -8.231566 \\
\hline Cutoff Alignment Cone & 0.407303759 & 0.4075603 \\
\hline Total Lower Plate Volume & 566.98349 & 566.9888449 \\
\hline \multicolumn{3}{|l|}{ Additional Lower Section Volume } \\
\hline Pins (3) & 11.69803 & -- \\
\hline Bottom Section Volume/Mass/Density $^{(\mathbf{b})}$ & 1080.243 & $8.80132 \mathrm{~g} / \mathrm{cm}^{3}$ \\
\hline
\end{tabular}

(a) Volume of Spot Face, $0.23368 \mathrm{~cm}^{3}$, has already been removed.

(b) Calculated volumes were used in density calculations.

Table C-5. ORSphere Volumes, Case 2.

\begin{tabular}{|c|c|c|}
\hline & Calculated & AutoCAD ${ }^{\circledR}$ \\
\hline \multicolumn{3}{|c|}{ Bottom Section Volume } \\
\hline \multicolumn{3}{|l|}{ Lower Polar Cap Volume } \\
\hline Total Ellipsoid Section Volume ${ }^{(a)}$ & 484.50130 & 484.48419 \\
\hline Support Hole & -1.39123 & -1.39122 \\
\hline Pin Hole Volume (3) & -3.46646 & -3.46646 \\
\hline Mass Adjustment Button Recesses (8) & -0.61867 & -0.61930 \\
\hline Total Lower Polar Cap Volume & 479.02493 & 479.00720 \\
\hline \multicolumn{3}{|l|}{ Lower Plate Volume } \\
\hline Total Ellipsoid Section Volume & 563.88110 & 563.88023 \\
\hline Pin Hole (3) & -8.22681 & -8.22682 \\
\hline Cutoff Alignment Cone & 0.40756 & 0.40756 \\
\hline Total Lower Plate Volume & 556.06185 & 556.06097 \\
\hline \multicolumn{3}{|l|}{ Additional Lower Section Volume } \\
\hline Pins $(3)$ & 11.69063 & -- \\
\hline Bottom Section Volume/Mass/Density ${ }^{(\mathrm{b})}$ & 1046.77742 & $8.74762 \mathrm{~g} / \mathrm{cm}$ \\
\hline
\end{tabular}

(a) Volume of Spot Face, $0.23536 \mathrm{~cm}^{3}$, has already been removed.

(b) Calculated volumes were used in density calculations. 
NEA/NSC/DOC(95)03/II

Volume II

HEU-MET-FAST-100

Table C-6. ORSphere Volumes, Case 1.

\begin{tabular}{|c|c|c|}
\hline \multicolumn{3}{|c|}{ Center Section Volumes } \\
\hline & Calculated & AutoCAD $^{(R)}$ \\
\hline \multicolumn{3}{|l|}{ Center Plate Volume } \\
\hline Total Ellipsoid Section Volume & 689.73381 & 689.73484 \\
\hline Pin Holes (3) & -8.91535 & -8.91535 \\
\hline Support Screw Holes (4) & -1.04863 & -1.04863 \\
\hline Target Hole & -39.88151 & -39.87369 \\
\hline Thermocouple Groove & -0.378098 & -0.37312 \\
\hline Diametral Hole $^{(a)}$ & -0.80300 & -0.80162 \\
\hline Cutoff Alignment Cone Hole & -0.415081 & -0.41508 \\
\hline Total Center Plate Volume & 638.292142 & -638.30975 \\
\hline \multicolumn{3}{|l|}{ Upper Plate Volume } \\
\hline Total Ellipsoid Section Volume & 436.610750 & 436.60721 \\
\hline Pin Holes (3) & -6.070869 & -6.07087 \\
\hline Cutoff Alignment Cone & 0.407560 & 0.40756 \\
\hline Total Upper Plate Volume & 430.947442 & 430.94633 \\
\hline \multicolumn{3}{|l|}{ Additional Center Section Volumes } \\
\hline Pin Volume ${ }^{(b)}(3)$ & 14.88085 & -- \\
\hline Target Plug ${ }^{(\mathrm{c})}$ & 39.13962 & 39.13200 \\
\hline Thermocouple & 0.37810 & 0.37312 \\
\hline Center Section Volume/Mass/Density $^{(\mathrm{d})}$ & \multicolumn{2}{|c|}{$1123.63813 \mathrm{~cm}^{3} / 21095.06 \mathrm{~g} / 18.77389 \mathrm{~g} / \mathrm{cm}^{3}$} \\
\hline Filler Rod Volume/Mass/Density ${ }^{(\mathrm{d})}$ & \multicolumn{2}{|c|}{$1.510408 \mathrm{~cm}^{3} / 28.163 \mathrm{~g} / 18.64596 \mathrm{~g} / \mathrm{cm}^{3}$} \\
\hline
\end{tabular}

(a) Volume excludes volume already accounted for by pin hole and target plug hole volumes.

(b) Pin volume excludes $0.105369-\mathrm{cm}^{3}$ hole where diametral hole passes through one HEU pin.

(c) Target Plug volume excludes volume of diametral hole.

(d) Calculated volumes were used in density calculations. 
NEA/NSC/DOC(95)03/II

Volume II

HEU-MET-FAST-100

Table C-7. ORSphere Volumes, Case 2.

\begin{tabular}{|c|c|c|}
\hline \multicolumn{3}{|c|}{ Center Section Volumes } \\
\hline & Calculated & AutoCAD ${ }^{(B)}$ \\
\hline \multicolumn{3}{|l|}{ Center Plate Volume } \\
\hline Total Ellipsoid Section Volume & 679.14379 & 679.14033 \\
\hline Pin Holes (3) & -8.91535 & -8.91535 \\
\hline Support Screw Holes (4) & -0.95224 & -0.94167 \\
\hline Target Hole & -39.56452 & -39.53095 \\
\hline Thermocouple Groove & -0.37484 & -0.36953 \\
\hline Diametral Hole ${ }^{(a)}$ & -0.71394 & -0.79529 \\
\hline Cutoff Alignment Cone Hole & -0.41508 & -0.41508 \\
\hline Total Center Plate Volume & 628.20783 & 628.17246 \\
\hline \multicolumn{3}{|l|}{ Upper Plate Volume } \\
\hline Total Ellipsoid Section Volume & 429.60255 & 429.59795 \\
\hline Pine Holes (3) & -6.07087 & -6.07087 \\
\hline Cutoff Alignment Cone & 0.40756 & 0.40756 \\
\hline Total Upper Plate Volume & 423.93924 & 423.93464 \\
\hline \multicolumn{3}{|l|}{ Additional Center Section Volumes } \\
\hline Pin Volume ${ }^{(b)}(3)$ & 14.88085 & -- \\
\hline Target Plug $^{(\mathrm{c})}$ & 38.74521 & 38.79495 \\
\hline Thermocouple & 0.374838 & 0.36953 \\
\hline Center Section Volume/Mass/Density $^{(\mathrm{d})}$ & \multicolumn{2}{|c|}{$1106.14797 \mathrm{~cm}^{3} / 20814.95 \mathrm{~g} / 18.8175 \mathrm{~g} / \mathrm{cm}^{3}$} \\
\hline Filler Rod Volume/Mass/Density ${ }^{(\mathrm{d})}$ & \multicolumn{2}{|c|}{$1.510408 \mathrm{~cm}^{3} / 28.163 \mathrm{~g} / 18.64596 \mathrm{~g} / \mathrm{cm}^{3}$} \\
\hline
\end{tabular}

(a) Volume excludes volume already accounted for by pin hole and target plug hole volumes.

(b) Pin volume excludes $0.105369-\mathrm{cm}^{3}$ hole where diametral hole passes through one HEU pin.

(c) Target Plug volume excludes volume of diametral hole.

(d) Calculated volumes were used in density calculations.

Table C-8. ORSphere Volumes, Case 1.

\begin{tabular}{||lcc||}
\hline \multicolumn{3}{|c||}{ Upper Section Volumes } \\
\hline \hline Upper Polar Cap Volume & Calculated & AutoCAD $^{\circledR}$ \\
Total Ellipsoid Section Volume & & \\
Cutoff Alignment Cone Hole & 647.9548 & 647.9334 \\
Mass Adjustment Button Recesses (8) & -0.415081 & -0.415081 \\
Upper Socket Hole & -3.038473 & -3.045819 \\
Total Upper Polar Cap Volume & -4.407062 & -4.407059 \\
\hline Upper Section Volume/Mass/Density & 640.0942 & 640.0654 \\
\hline \hline
\end{tabular}

(a) Calculated volumes were used in density calculations. 
NEA/NSC/DOC(95)03/II

Volume II

HEU-MET-FAST-100

Table C-9. ORSphere Volumes, Case 2.

\begin{tabular}{|c|c|c|}
\hline \multicolumn{3}{|c|}{ Upper Section Volumes } \\
\hline & Calculated & AutoCAD $^{(B)}$ \\
\hline \multicolumn{3}{|l|}{ Upper Polar Cap Volume } \\
\hline Total Ellipsoid Section Volume & 639.4314 & 639.4104 \\
\hline Cutoff Alignment Cone Hole & -0.41508 & -0.41508 \\
\hline Mass Adjustment Button Recesses (8) & 2.172345 & 2.172334 \\
\hline Upper Socket Hole & 4.355357 & 4.355292 \\
\hline Total Upper Polar Cap Volume & 632.4886 & 632.4676 \\
\hline Upper Section Volume/Mass/Density ${ }^{(\text {a) }}$ & \multicolumn{2}{|c|}{$632.48864 \mathrm{~cm}^{3} / 11883.24 \mathrm{~g} / 18.788807 \mathrm{~g} / \mathrm{cm}^{3}$} \\
\hline
\end{tabular}

(a) Calculated volumes were used in density calculations. 
NEA/NSC/DOC(95)03/II

Volume II

HEU-MET-FAST-100

\section{APPENDIX D: DERIVATION OF SIMPLE BENCHMARK MODEL AVERAGE ISOTOPIC AND IMPURITY CONTENT}

The average sphere enrichment and impurity content was calculated by taking a volume-weighted average for each sphere part in the bottom, middle, and top section, and then taking a mass weighted average of the three parts plus the diametral filler rod. The isotopic content for each part was given in Table 1-3 and are summarized in Tables D-1 through D-3. The uranium fraction and impurities given in Table 1-4 were normalized to a total mass fraction of one. Impurities besides silicon, boron and carbon were replaced with void which decreased the total mass fraction. The uranium fraction and impurity content are also summarized in Tables D-1 through D-3. Impurities besides silicon, boron and carbon are retained in the tables for reference since they are in the detailed benchmark model but were replaced with void in the simple benchmark model.

Table D-1. Material Data, Bottom Section, Case 1 and 2.

\begin{tabular}{|rccc||}
\hline & \multicolumn{3}{c|}{$\begin{array}{c}\text { Normalized Uranium Weight Fraction, Uranium Isotopic } \\
\text { Distributions, and Impurity Content }\end{array}$} \\
\hline & Lower Polar Cap & Lower Plate & Pins \\
\hline $\mathrm{g} \mathrm{U} / \mathrm{g}$ Total & $9.99577 \mathrm{E}-01$ & $9.99612 \mathrm{E}-01$ & $9.99595 \mathrm{E}-01$ \\
\hline${ }^{234} U$ & $0.98410 \%$ & $0.98450 \%$ & $0.99540 \%$ \\
${ }^{235} U$ & $93.18000 \%$ & $93.22000 \%$ & $93.15600 \%$ \\
${ }^{236} U$ & $0.03592 \%$ & $0.03593 \%$ & $0.45100 \%$ \\
${ }^{238} U$ & $5.79998 \%$ & $5.75957 \%$ & $5.39760 \%$ \\
\hline $\mathrm{Be}, \mathrm{ppm}$ & $5.0023 \mathrm{E}-03$ & $5.0006 \mathrm{E}-03$ & - \\
\hline $\mathrm{Li}, \mathrm{ppm}$ & $1.0005 \mathrm{E}-01$ & $1.0001 \mathrm{E}-01$ & - \\
\hline $\mathrm{Al}, \mathrm{ppm}$ & $5.0023 \mathrm{E}+00$ & $8.0010 \mathrm{E}+00$ & $5.0005 \mathrm{E}+00$ \\
\hline $\mathrm{Si}, \mathbf{p p m}$ & $1.0005 \mathrm{E}+02$ & $1.2502 \mathrm{E}+02$ & $1.2001 \mathrm{E}+02$ \\
\hline $\mathrm{Mn}, \mathrm{ppm}$ & $2.4735 \mathrm{E}+01$ & $1.6981 \mathrm{E}+01$ & $1.8470 \mathrm{E}+01$ \\
\hline $\mathrm{Ni}, \mathrm{ppm}$ & $4.4169 \mathrm{E}+01$ & $3.0323 \mathrm{E}+01$ & $3.2982 \mathrm{E}+01$ \\
\hline $\mathrm{Cr}, \mathrm{ppm}$ & $3.0918 \mathrm{E}+00$ & $2.1226 \mathrm{E}+00$ & $2.3087 \mathrm{E}+00$ \\
\hline $\mathrm{Cu}, \mathrm{ppm}$ & $1.1042 \mathrm{E}+01$ & $7.5807 \mathrm{E}+00$ & $8.2455 \mathrm{E}+00$ \\
\hline $\mathrm{B}, \mathbf{p p m}$ & $1.0005 \mathrm{E}-01$ & $5.0006 \mathrm{E}-01$ & $3.0003 \mathrm{E}-01$ \\
\hline $\mathrm{Co}, \mathrm{ppm}$ & $5.0023 \mathrm{E}-01$ & $5.0006 \mathrm{E}-01$ & - \\
\hline $\mathrm{Ca}, \mathrm{ppm}$ & $5.0023 \mathrm{E}+00$ & $5.0006 \mathrm{E}+00$ & - \\
\hline $\mathrm{C}, \mathbf{p p m}$ & $1.7908 \mathrm{E}+02$ & $1.4202 \mathrm{E}+02$ & $1.6802 \mathrm{E}+02$ \\
\hline $\mathrm{O}, \mathrm{ppm}$ & $2.0009 \mathrm{E}+01$ & $2.0002 \mathrm{E}+01$ & $2.0002 \mathrm{E}+01$ \\
\hline $\mathrm{N}, \mathrm{ppm}$ & $3.0014 \mathrm{E}+01$ & $3.0004 \mathrm{E}+01$ & $3.0003 \mathrm{E}+01$ \\
\hline
\end{tabular}


NEA/NSC/DOC(95)03/II
Volume II

HEU-MET-FAST-100

Table D-2. Material Data, Center Section, Case 1 and 2.

\begin{tabular}{|c|c|c|c|c|}
\hline & \multicolumn{4}{|c|}{$\begin{array}{c}\text { Normalized Uranium Weight Fraction, Uranium Isotopic Distributions, and Impurity } \\
\text { Content }\end{array}$} \\
\hline & Central Plate & Upper Plate & Pin & $\begin{array}{c}\text { Target Hole Plug } \\
\text { and Thermocouple } \\
\text { Filler } \\
\end{array}$ \\
\hline g U/g Total & $9.99531 \mathrm{E}-01$ & $9.99647 \mathrm{E}-01$ & 9.99595E-01 & $9.99595 \mathrm{E}-01$ \\
\hline${ }^{234} U$ & $0.98430 \%$ & $0.98440 \%$ & $0.98600 \%$ & $0.99540 \%$ \\
\hline${ }^{235} U$ & $93.20000 \%$ & $93.21000 \%$ & $93.17100 \%$ & $93.15600 \%$ \\
\hline${ }^{236} U$ & $0.03592 \%$ & $0.03593 \%$ & $0.42400 \%$ & $0.45100 \%$ \\
\hline${ }^{238} U$ & $5.77978 \%$ & $5.76967 \%$ & $5.41900 \%$ & $5.39760 \%$ \\
\hline $\mathrm{Be}, \mathrm{ppm}$ & 4.9994E-03 & 4.9999E-03 & - & - \\
\hline Li, ppm & $9.9987 \mathrm{E}-02$ & 9.9999E-02 & - & - \\
\hline $\mathrm{Al}, \mathrm{ppm}$ & $3.9995 \mathrm{E}+00$ & $3.9999 \mathrm{E}+00$ & $5.0005 \mathrm{E}+00$ & $5.0005 \mathrm{E}+00$ \\
\hline Si, ppm & $1.9997 \mathrm{E}+02$ & $9.9999 \mathrm{E}+01$ & $1.2001 \mathrm{E}+02$ & $1.2001 \mathrm{E}+02$ \\
\hline $\mathrm{Mn}, \mathrm{ppm}$ & $1.4892 \mathrm{E}+01$ & $1.0128 \mathrm{E}+01$ & $1.8470 \mathrm{E}+01$ & $1.8470 \mathrm{E}+01$ \\
\hline $\mathrm{Ni}, \mathrm{ppm}$ & $2.6592 \mathrm{E}+01$ & $1.8085 \mathrm{E}+01$ & $3.2982 \mathrm{E}+01$ & $3.2982 \mathrm{E}+01$ \\
\hline $\mathrm{Cr}, \mathrm{ppm}$ & $1.8615 \mathrm{E}+00$ & $1.2659 \mathrm{E}+00$ & $2.3087 \mathrm{E}+00$ & $2.3087 \mathrm{E}+00$ \\
\hline $\mathrm{Cu}, \mathrm{ppm}$ & $6.6481 \mathrm{E}+00$ & $4.5212 \mathrm{E}+00$ & $8.2455 \mathrm{E}+00$ & $8.2455 \mathrm{E}+00$ \\
\hline B, ppm & $1.9997 \mathrm{E}-01$ & $3.0000 \mathrm{E}-01$ & $3.0003 \mathrm{E}-01$ & $3.0003 \mathrm{E}-01$ \\
\hline Co, ppm & 4.9994E-01 & 4.9999E-01 & - & - \\
\hline $\mathrm{Ca}, \mathrm{ppm}$ & $4.9994 \mathrm{E}+00$ & $4.9999 \mathrm{E}+00$ & - & - \\
\hline $\mathrm{C}, \mathbf{p p m}$ & $1.5898 \mathrm{E}+02$ & $1.5900 \mathrm{E}+02$ & $1.6802 \mathrm{E}+02$ & $1.6802 \mathrm{E}+02$ \\
\hline $\mathrm{O}, \mathrm{ppm}$ & $1.9997 \mathrm{E}+01$ & $2.0000 \mathrm{E}+01$ & $2.0002 \mathrm{E}+01$ & $2.0002 \mathrm{E}+01$ \\
\hline $\mathrm{N}, \mathrm{ppm}$ & $2.9996 \mathrm{E}+01$ & $3.0000 \mathrm{E}+01$ & $3.0003 \mathrm{E}+01$ & $3.0003 \mathrm{E}+01$ \\
\hline
\end{tabular}


NEA/NSC/DOC(95)03/II

Volume II

HEU-MET-FAST-100

Table D-3. Material Data, Top Section and Diametral Filler Rod, Case 1 and 2.

\begin{tabular}{||ccc||}
\hline \multicolumn{3}{||c|}{$\begin{array}{c}\text { Normalized Uranium Weight Fraction, } \\
\text { Uranium Isotopic Distributions, and Impurity } \\
\text { Content }\end{array}$} \\
\hline & Upper Polar Cap & Diametral Filler Rod \\
\hline g U/g Total & $9.99577 \mathrm{E}-01$ & $9.99595 \mathrm{E}-01$ \\
${ }^{234} U$ & $0.98410 \%$ & $0.99540 \%$ \\
${ }^{235} U$ & $93.18000 \%$ & $93.15600 \%$ \\
${ }^{236} U$ & $0.03592 \%$ & $0.45100 \%$ \\
${ }^{238} U$ & $5.79998 \%$ & $5.39760 \%$ \\
\hline $\mathrm{Be}, \mathrm{ppm}$ & $5.0023 \mathrm{E}-03$ & - \\
\hline $\mathrm{Li}, \mathrm{ppm}$ & $1.0005 \mathrm{E}-01$ & - \\
\hline $\mathrm{Al}, \mathrm{ppm}$ & $5.0023 \mathrm{E}+00$ & $5.0005 \mathrm{E}+00$ \\
\hline $\mathrm{Si}, \mathbf{p p m}$ & $1.0005 \mathrm{E}+02$ & $1.2001 \mathrm{E}+02$ \\
\hline $\mathrm{Mn}, \mathrm{ppm}$ & $2.4735 \mathrm{E}+01$ & $1.8470 \mathrm{E}+01$ \\
\hline $\mathrm{Ni}, \mathrm{ppm}$ & $4.4169 \mathrm{E}+01$ & $3.2982 \mathrm{E}+01$ \\
\hline $\mathrm{Cr}, \mathrm{ppm}$ & $3.0918 \mathrm{E}+00$ & $2.3087 \mathrm{E}+00$ \\
\hline $\mathrm{Cu}, \mathrm{ppm}$ & $1.1042 \mathrm{E}+01$ & $8.2455 \mathrm{E}+00$ \\
\hline $\mathrm{B}, \mathbf{p p m}$ & $1.0005 \mathrm{E}-01$ & $3.0003 \mathrm{E}-01$ \\
\hline $\mathrm{Co}, \mathrm{ppm}$ & $5.0023 \mathrm{E}-01$ & - \\
\hline $\mathrm{Ca}, \mathrm{ppm}$ & $5.0023 \mathrm{E}+00$ & - \\
\hline $\mathrm{C}, \mathbf{p p m}$ & $1.7908 \mathrm{E}+02$ & $1.6802 \mathrm{E}+02$ \\
\hline $\mathrm{O}, \mathrm{ppm}$ & $2.0009 \mathrm{E}+01$ & $2.0002 \mathrm{E}+01$ \\
\hline $\mathrm{N}, \mathrm{ppm}$ & $3.0014 \mathrm{E}+01$ & $3.0003 \mathrm{E}+01$ \\
\hline \hline
\end{tabular}

Next, the impurity content/isotopic distribution of each part was multiplied by the volume of that part within each section. These products for each individual part were summed together and then divided by the total volume of each part. An example of this process for the middle section of sphere for Case 1 is shown with the following equations. The impurity contents and isotopic distributions are taken from Table D-2 and the volumes are taken from Table C-6. This resulted in volume weighted averaged for the impurity content and isotopic distribution of each part. A volume weighted average had to be used because the mass of each individual part was not known. 


$$
\begin{aligned}
& x_{\text {section }}^{j}=\frac{\sum_{i=1}^{n} x_{i}^{j} V_{i}}{\sum_{i=1}^{n} V_{i}} \\
& y_{\text {section }}^{k}=\frac{\sum_{i=1}^{n} y_{i}^{k} V_{i}}{\sum_{i=1}^{n} V_{i}}
\end{aligned}
$$

$$
x_{\text {center }}^{\text {boron }}=\frac{x_{C P}^{\text {boron }} \cdot V_{C P}+x_{U P}^{\text {boron }} \cdot V_{U P}+x_{T P}^{\text {boron }} \cdot V_{T P}+x_{P i n s}^{\text {boron }} \cdot V_{P i n}+x_{T G}^{\text {boron }} \cdot V_{T G}}{V_{C P}+V_{U P}+V_{T P}+V_{P i n s}+V_{T G}}
$$

$$
\begin{gathered}
-x_{i}^{j}=\text { impurity content } \\
\text { of } j^{\text {th }} \text { of part } i \\
-V_{i}=\text { volume of part } i \\
-y_{i}^{k}=\text { isotopic content } \\
\text { of } k^{\text {th }} \text { isotopic of } \\
\text { part } i
\end{gathered}
$$

-CP-Center Plate

-UP-Upper Plate

-TP- Target Plug

-TG-Thermocouple

Groove

$$
\begin{gathered}
x_{\text {center }}^{\text {boron }}=\frac{0.19997 \cdot 638.292142+0.3 \cdot 430.947442+0.30003 \cdot 39.13962+0.30003 \cdot 14.88085+0.30003 \cdot 0.37810}{638.292142+430.947442+39.13962+14.88085+0.37810} \\
x_{\text {center }}^{\text {boron }}=0.243179 \text { ppm Boron }^{\mathrm{a}}
\end{gathered}
$$

Once the volume-weighted average has been calculated, see Table D-4 and D-5 for results for each section, the mass weighted average of the entire sphere was calculated. This was done by a similar method but with mass rather than volume, using the following general equations. The mass weighted average was taken over the bottom, middle, top sections of sphere and the diametral filler rod. Table D-4 and D-5 also has the results of this calculation.

$$
\begin{gathered}
x_{\text {sphere }}^{j}=\frac{\sum_{l=1}^{n} x_{l}^{j} m_{l}}{\sum_{l=1}^{n} m_{l}} \\
y_{\text {sphere }}^{k}=\frac{\sum_{l=1}^{n} y_{l}^{k} m_{l}}{\sum_{l=1}^{n} m_{l}}
\end{gathered}
$$

$-x_{l}^{j}=$ impurity content

of $j^{\text {th }}$ of section $l$

$-m_{l}=$ mass of section $l$

$-y_{l}^{k}=$ isotopic content

of $k^{\text {th }}$ isotopic of

part $l$

\footnotetext{
${ }^{a}$ It should be noted that this calculation was completed without rounding the normalized impurity content or part volumes. When the rounded values presented here are used a different average impurity content is obtained $(0.241527$ $\mathrm{ppm})$. The value calculated without rounding of normalized impurity content and volumes is used in the simple benchmark model. 
NEA/NSC/DOC(95)03/II

Volume II

HEU-MET-FAST-100

Table D-4. Material Data, Simple Benchmark Model, Case 1.

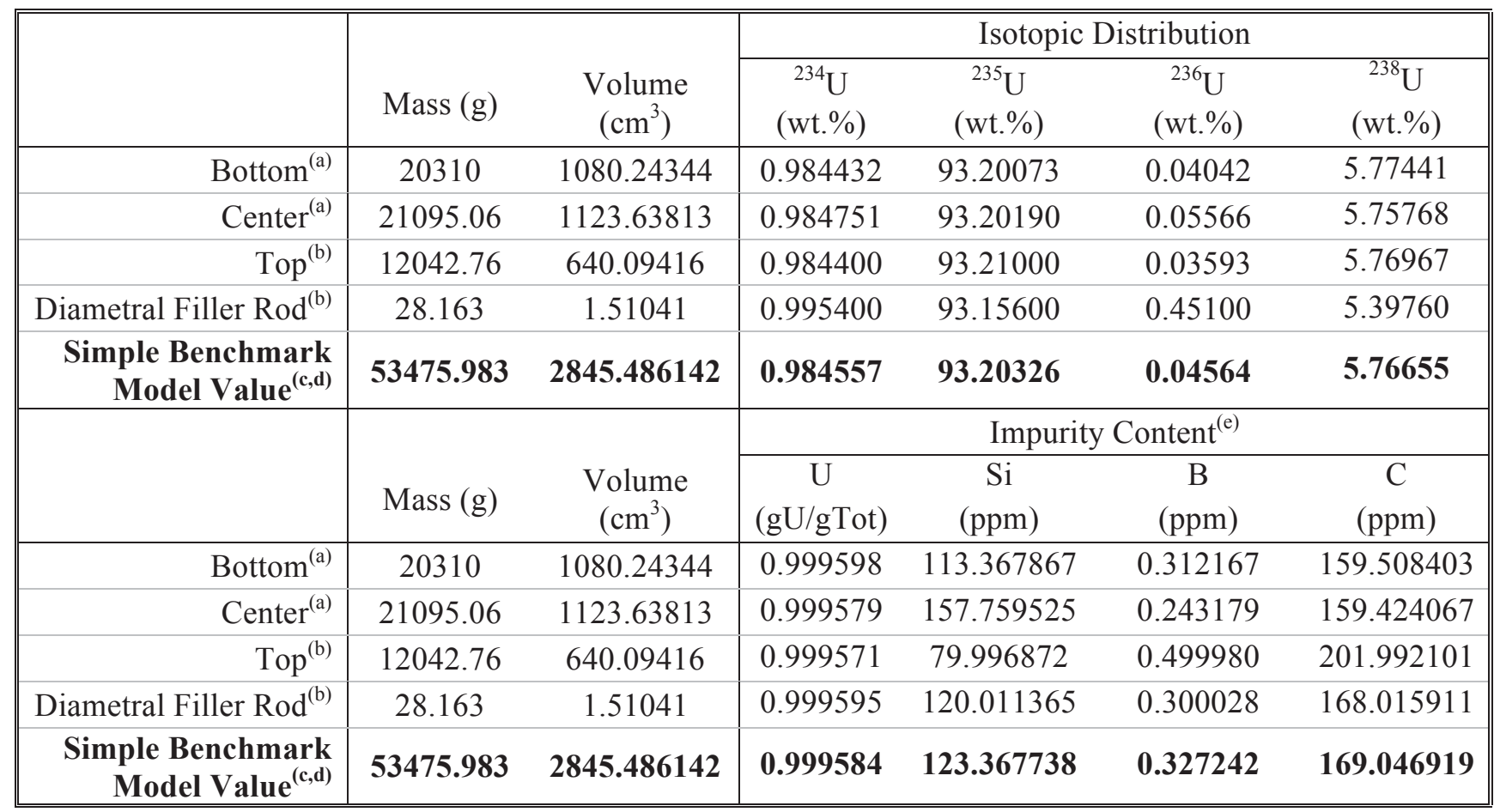

(a) These isotopic and impurity contents are the volume weighted average using the contents and volumes of each part within the section

(b) The volume weighted average did not need to be taken because only one part made up the entire section, i.e. there were not pins or plugs in this section.

(c) These isotopic and impurity contents are the mass weighted average using the volume weighted contents and masses of each section.

(d) Volume weighted average and normalized impurity contents were not rounded before calculating the mass weighted average of the simple benchmark model.

(e) The uranium fraction and impurity content do not sum to a value of one because impurities besides $\mathrm{Si}$, $\mathrm{B}$, and $\mathrm{C}$ were replaced with void, thus reducing the total weight fraction of the material, before an average was taken. 
NEA/NSC/DOC(95)03/II

Volume II

HEU-MET-FAST-100

Table D-5. Material Data, Simple Benchmark Model, Case 2.

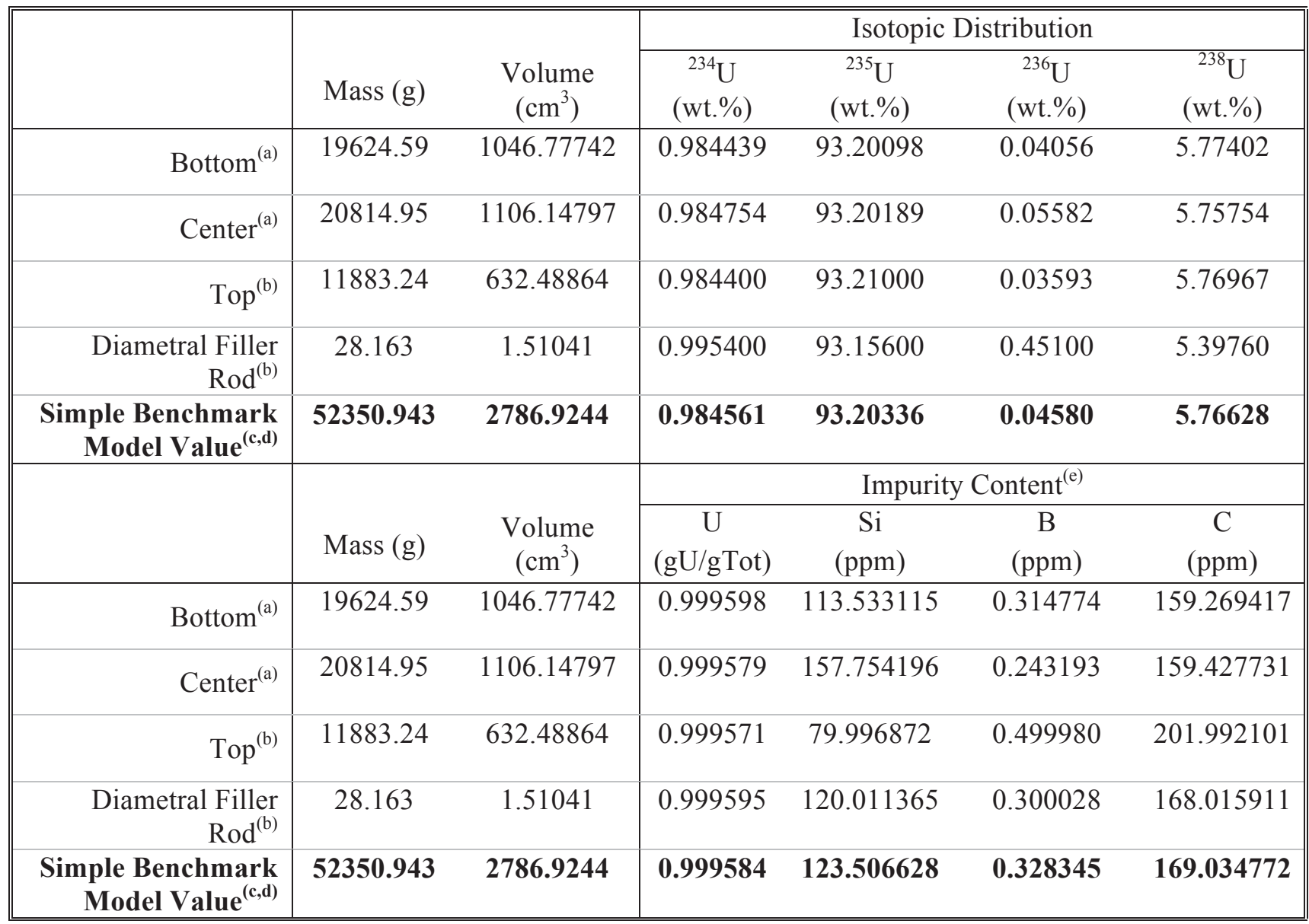

(a) These isotopic and impurity contents are the volume weighted average using the contents and volumes of each part within the section

(b) The volume weighted average did not need to be taken because only one part made up the entire section, i.e. there were not pins or plugs in this section.

(c) These isotopic and impurity contents are the mass weighted average using the volume weighted contents and masses of each section.

(d) Volume weighted average and normalized impurity contents were not rounded before calculating the mass weighted average of the simple benchmark model.

(e) The uranium fraction and impurity content do not sum to a value of one because impurities besides Si, B, and C were replaced with void, thus reducing the total weight fraction of the material, before any average was done. 


\section{APPENDIX E: DERIVATION OF TILT ANGLE}

When the bottom section was lifted to meet the center section of the sphere for Case 1 the pin which extended beyond the top surface of the lower plate caused the center plate to tilt. A gap of $0.01143 \mathrm{~cm}$ was present on the side of the sphere by the protruding pin and zero on the opposite side. The gap and dimensions are given in Figure 3-4. In order to determine the tilt angle of the center plate the gap and height of the protruding pin were used as well as the diameter of the plates at the upper and lower surfaces of the lower and center plates. These surfaces formed two triangles, a larger triangle with the gap and a smaller right triangle with the edge of the pin. Figure E.1 is a simplified, not-to-scale drawing of the plates to show the dimensions used to derive the tilt angle.

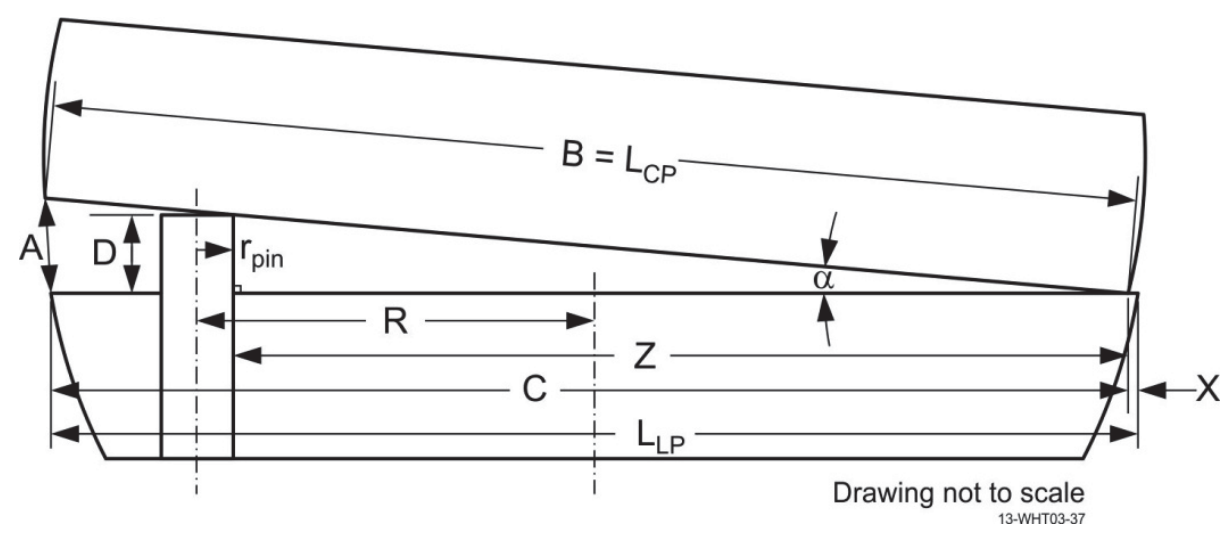

Figure E-1. Simplified, Not-to-Scale Sketch of Tilt Angle Between Lower and Center Plate, Case 1.

\section{Given Dimensions}

A Gap between edges of lower and center plate

Does not form a right angle with either plate

$=0.01143 \mathrm{~cm}$

$\mathrm{B}=\mathrm{L}_{\mathrm{CP}} \quad$ Diameter of bottom surface of center plate

$$
=2 \cdot 8.685601=17.371202 \mathrm{~cm}
$$

D Height of pin protrusion

$$
=0.005842 \mathrm{~cm}
$$

$\mathrm{L}_{\mathrm{LP}} \quad$ Diameter of top surface of lower plate

$$
=2 \cdot 8.6861159=17.3722318 \mathrm{~cm}
$$

$\mathrm{R}$ Distance to center of pin from center of lower plate

$=6.35 \mathrm{~cm}$

$\mathrm{r}_{\text {pin }} \quad$ Radius of pin

$=0.57531 \mathrm{~cm}$
Derived Variables

$\mathrm{X}$ Distance the edge of the center plate is shifted in from the edge of the lower plate due to the rotation of the plate.

C Distance between edge of lower plate and point at which upper plate touches the lower plate.

Z Distance between edge of pin and point at which upper plate touches the lower plate.

$\alpha \quad$ Angle between lower plate and center plate. 
The large triangle formed by the plate surfaces and the measured gap between the edges of the plates is a non-right triangle that can be solved using the law of cosines, Equation E.1. Two variables, $\mathrm{C}$ and $\alpha$, are unknown in Equation E.1. C can be related to X using Equation E.2. Using the smaller, right triangle, $\mathrm{X}$ can be solved for using the intermediate variable Z. This relationship is shown in Equations E.3 and E.4.

$$
\begin{array}{cc}
\mathrm{A}^{2}=\mathrm{B}^{2}+\mathrm{C}^{2}-2 \mathrm{BC} \cos (\alpha) & \text { Equation E.1 } \\
\mathrm{C}=\mathrm{L}_{\mathrm{LP}}-X & \text { Equation E.2 } \\
\tan (\alpha)=\frac{\mathrm{D}}{Z} & \text { Equation E.3 } \\
Z=\frac{L_{L P}}{2}-X+R-r_{\text {pin }} & \text { Equation E.4 }
\end{array}
$$

If known variable are plugged into Equation E.4 and then $\mathrm{Z}$ is then plugged into Equation E.3, an equation for $\mathrm{X}$ in terms of $\alpha$ can then be obtained, Equation E.5. Next, X can be plugged into Equation E.2 and the resulting $\mathrm{C}$ can be plugged into Equation E.1 to obtain Equation E.6.

$$
\begin{gathered}
Z=14.4608059-X \\
\tan (\alpha)=\frac{\mathrm{D}}{14.6808059-X} \\
X=14.4608059-\frac{0.005842}{\tan (\alpha)} \\
\mathrm{C}=17.3722318-\left(14.4608059-\frac{0.005842}{\tan (\alpha)}\right) \\
\mathrm{C}=2.9114259+\frac{0.005842}{\tan (\alpha)} \\
0.01143^{2}=17.371202^{2}+\left(2.9114259+\frac{0.005842}{\tan (\alpha)}\right)^{2}- \\
2 \cdot 17.371202 \cdot\left(2.9114259+\frac{0.005842}{\tan (\alpha)}\right) \cos (\alpha)
\end{gathered}
$$

Equation E.5

Equation E.6

Equation E.6 can then be solved to obtain a tilt angle of $0.0231340494^{\circ}$. If this angle is then used in Equation E.5 a value of $-0.008 \mathrm{~cm}$ is obtained, implying the center plate overhangs the lower plate. The experimenter stated that this would not have happened. The discrepancy is attributed to not knowing the exact point of rotation for the center plate. If a vertical shift of 0.00351038 is used and the center plate is rotated about the center point, thus the centers of the lower and center plate remain perpendicular, the $\mathrm{X}$ value in Figure E-1 becomes $+0.0005 \mathrm{~cm}$. At the lower end the center plate would then $\mathrm{sit} \sim 3.4 \times 10^{-6} \mathrm{~cm}$ above the lower plate. This distance is within the uncertainty in the gap between plates. The center plate would sit just on the corner of the HEU pin. The distance A, however, would only be $\sim 0.007 \mathrm{~cm}$ rather than $0.01143 \mathrm{~cm}$. The effect of the different gap is within the uncertainty in the tilt angle.

A vertical shift of $0.00351038 \mathrm{~cm}$ and an angle of rotation of 0.0231340494 degrees along the $\mathrm{X}$-axis is used in the detailed benchmark model for Case 1. 


\section{APPENDIX F: APPROXIMATION OF SUPPORT STRUCTURE WORTH}

A model to approximate the worth of the support structure was created. Because of a lack of dimension and material data some details of the structure had to be assumed. Photographs and drawings were consulted in the process of modeling and approximating the support structure. Some additional information was provided by the experimenter regarding the support structure. The support structure for the top section was a mechanical drive for the measurements of ORSphere. It was mounted off of a cross shape object spanning the 4 carbon steel posts of the assembly machine. The arms of the cross were $4 \times 4$ inch square aluminum pipes with a $1 / 4$-inch-thick wall. The arms extended diagonally between posts with a mechanical drive mounted in the center that had the upper support rod attached to it. The rods supporting the central section were stainless steel tubing. ${ }^{a}$

The experiment was supported by the vertical lift table's four posts on a $4 \mathrm{ft}$. $(121.92 \mathrm{~cm})$ square. Only the four posts of the vertical lift table were modeled. The posts were carbon steel but were modeled as stainless steel with an OD of 3 in. ( $3.81 \mathrm{~cm} \mathrm{OR})$ and $1 / 4$ in. thick walls $(3.175 \mathrm{~cm} \mathrm{IR})$. The four posts were modeled with an arbitrary height of $200 \mathrm{~cm}$, extending from the bottom of the lower support structure to just above the upper cross beam support structure. The four posts can be seen in Figures F-1 and F-2.

According to the experimenter, the upper support cross beams were $4 \times 4$-in.-square-aluminum pipes with $1 / 4$ in.-thick walls and attached to the vertical posts using a fitting that surrounded the outer diameter of the post. The cross beams held the support rod and socket for the upper polar cap. The cross beams were modeled as being $4 \times 4$-in.(10.16x10.16-cm)-square-aluminum pipes with a $1 / 4$ in. $(0.635 \mathrm{~cm})$ thick wall and extending between the four vertical posts; the fittings that mounted the cross beams to the posts were not modeled. Figures F-1 and F-2 show the cross beams.

The center support structure is also shown in Figures F-1 and F-2 and consisted of four fuel hangers which were pinned to the center plate using Type 304 stainless steel pins. Minimal definitive information is given for the center fuel plate hangers. Notes from the experimenter give the hanger OD as $0.5 \mathrm{in}$., ID as 0.375 in., and the length as approximately 31-1/2 in.; the hanger length was adjustable to ensure proper placement of the center fuel plate. The fuel hangers were stainless steel tubes with an IR of $0.47625 \mathrm{~cm}$ and an OR of $0.635 \mathrm{~cm}$. The stainless steel pins had a radius of $0.351028 \mathrm{~cm}$. The length of the pins was not given. The length of the pins was approximated and modeled as $0.975 \mathrm{~cm}$.

\footnotetext{
${ }^{a}$ Personal email communication with J.T. Mihalczo, July 29, 2013.
} 
NEA/NSC/DOC(95)03/II

Volume II

HEU-MET-FAST-100

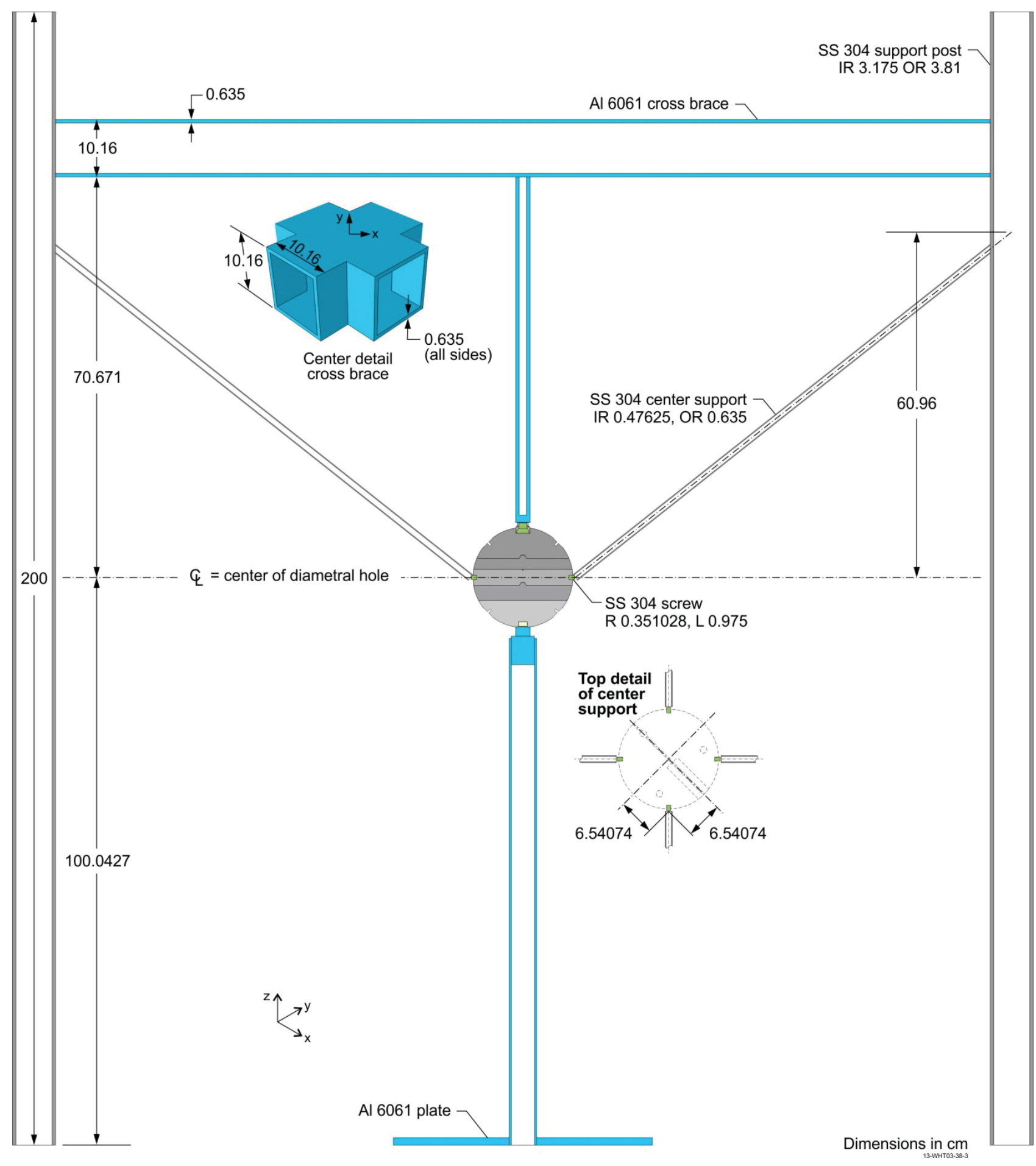

Figure F-1. Cross-Section View of Support Structure. 


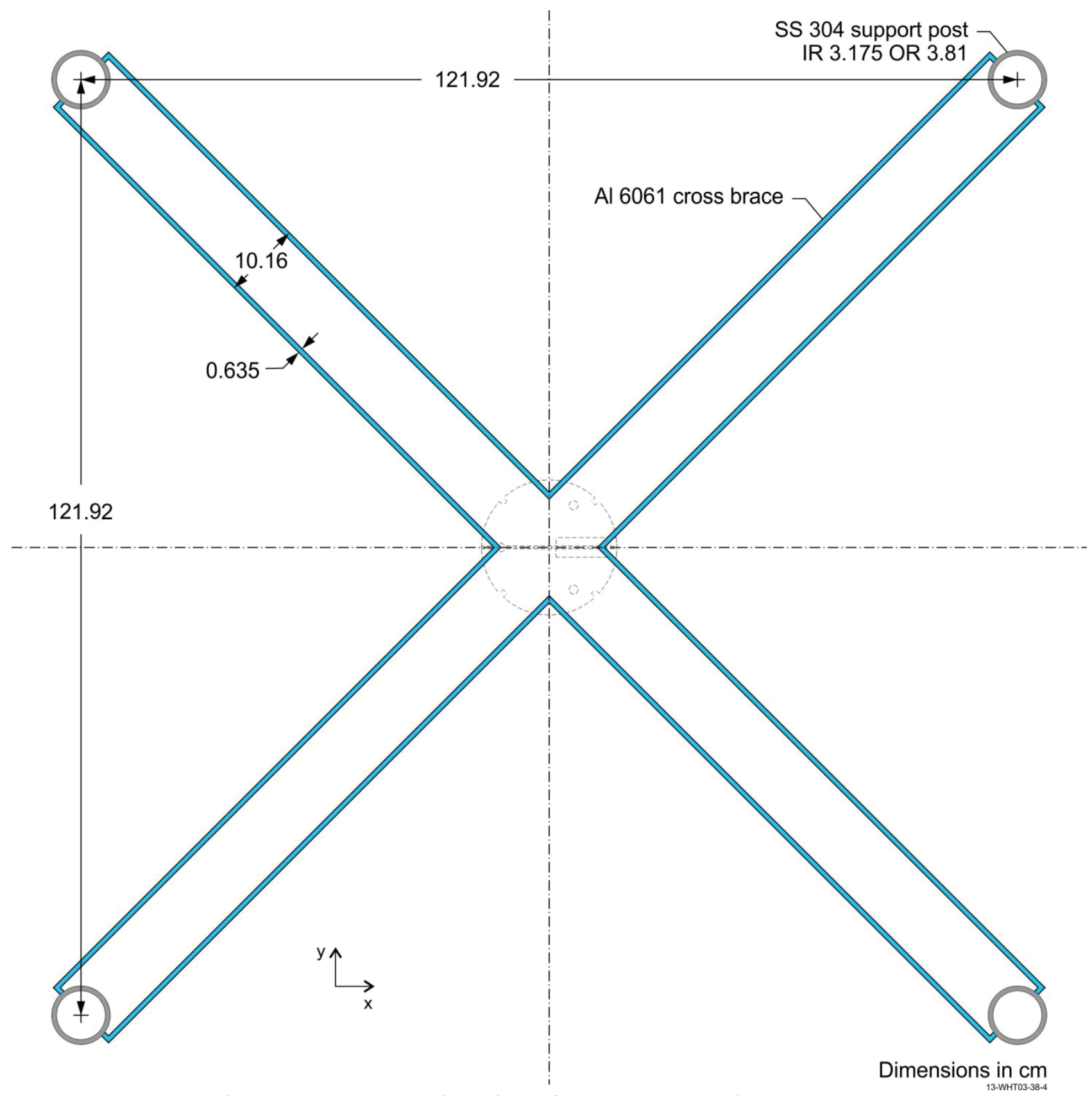

Figure F-2. Cross-Section View of Support Posts and Cross Beams.

The bottom support structure was aluminum 6061 and the dimensions are given in Figure 1-20. The bottom support structure was simplified in the structural support worth approximation models. The brass bolt was included in the benchmark model. The 2-5/8 in. tall, aluminum plug sat flush with the spot face on the lower polar cap. The smaller, $1 \mathrm{in}$. diameter section of plug had a height of $0.5 \mathrm{in}$. The larger diameter section of plug had a diameter of 1.610 in., the inner diameter of 1-1/2 IPS-SCH40. The transition between the two diameters had a $45^{\circ}$ angle. This corresponds to a transition height of 0.305 in. Rather than modeling the transition one half the height was added to the smaller diameter section of plug and one half was added to the larger diameter section of plug. This resulted in the smaller diameter section of plug having a height of $0.6525 \mathrm{in} .(1.65735 \mathrm{~cm})$ and the larger diameter section of plug having a height of $1.9725 \mathrm{in} .(5.01015 \mathrm{~cm})$. The main body of the support stand was modeled as a pipe with an OD of $1.9100 \mathrm{in}$. (2.413 cm OR), an ID of 
1.610 in. $(2.0447 \mathrm{~cm} \mathrm{IR})$, and a length of $34.695 \mathrm{in} .(88.1253 \mathrm{~cm})$. The plate at the bottom of the stand was 0.5 in. thick $(1.27 \mathrm{~cm})$ with a diameter of $18 \mathrm{in} .(22.86 \mathrm{~cm} \mathrm{R})$. The total height from the top of the aluminum plug to the bottom of the aluminum plate was $36 \mathrm{in} .(91.44 \mathrm{~cm})$. Four fins steadied the aluminum stand. The fins were $30^{\circ}$ right triangles with a base length of $20.447 \mathrm{~cm}$, a height of $35.415 \mathrm{~cm}$, and a thickness of 0.635 $\mathrm{cm}$. The dimensions of the lower support structure are given in Figure F-3.

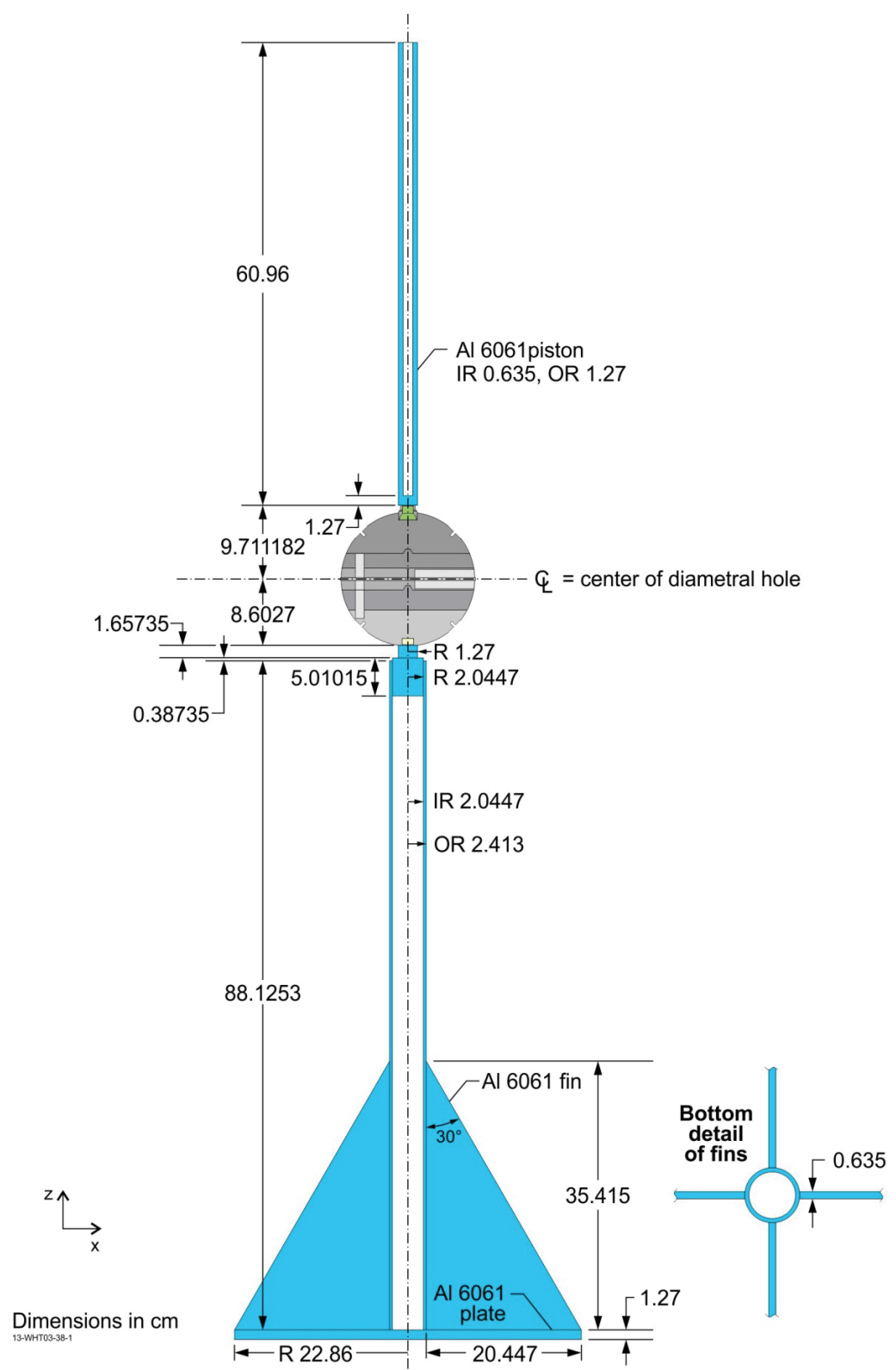

Figure F-3. Cross-Section View of Lower Support Stand and Support Rod.

The socket and support rod were not present in the benchmark model. The dimensions of the socket are given in Figure 1-16. No dimensions for the support rod were given. The mass of the stainless steel on the interior of the socket is not given but the mass of the uranium on the outside of the socket was $64 \mathrm{~g}$. The 
height of the ball portion and cylindrical portion of the stainless steel was not given so dimensions were estimated based on the given dimensions, see Figure F-4 (dimensions are given in inches). When the density of the uranium in the upper socket was calculated the density was $18.9 \mathrm{~g} / \mathrm{cm}^{3}$, much higher than the 18.75 $\mathrm{g} / \mathrm{cm}^{3}$ density the experimenter gave (see Section 1.2.6). The density of the ball was varied until the density was $18.751 \mathrm{~g} / \mathrm{cm}^{3}$. The dimensions of the upper socket in the support structure approximation model are given in Figure F-5.

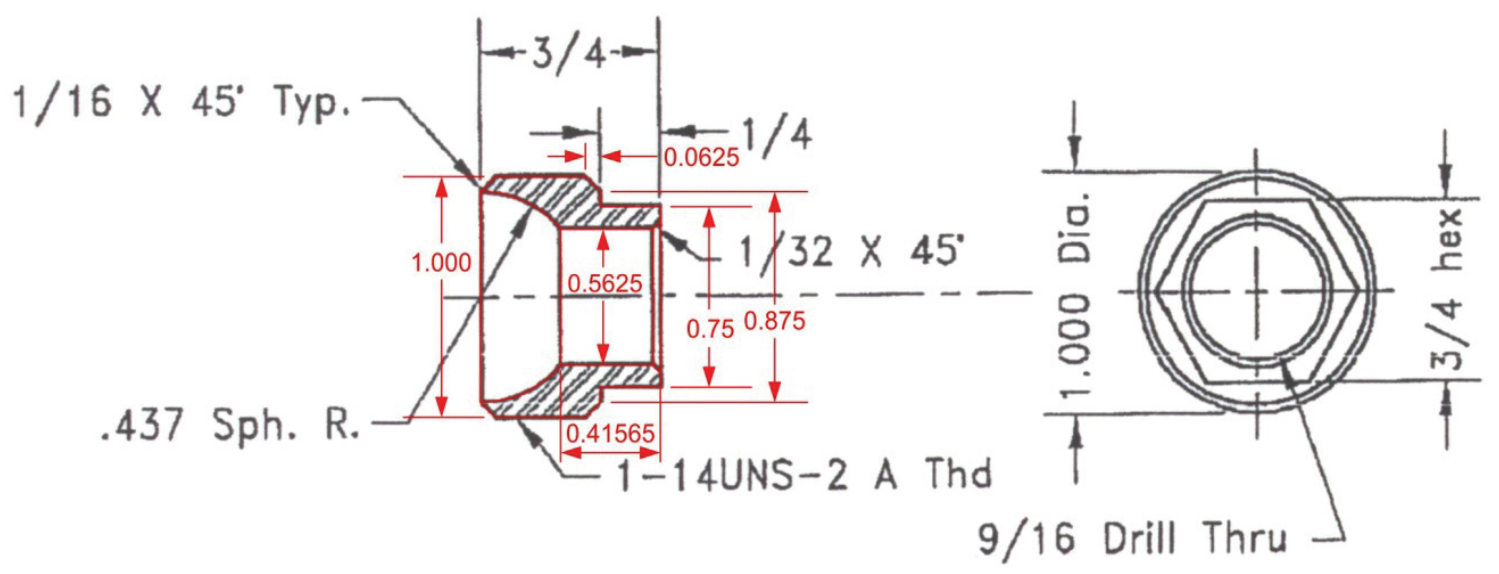

Figure F-4. Upper Socket Estimated Dimensions. ${ }^{a}$

As is seen in Figure F-5, the chamfer at the bottom of the socket was not modeled and the chamfer at the middle of the socket was modeled as a clean $90^{\circ}$ cutaway. These two simplifications have opposing effects and thus have no effect of the model. The diameter of the hole for the upper socket in the upper polar cap was $2.422144 \mathrm{~cm}$ (.9536 in.). This diameter disagrees with the 1.000-in. diameter given in Figure F-4. The 2.422144-cm diameter (1.211072-cm radius) was used because it accounts for the threads of the socket and socket hole and the undercut to thread root in the upper polar cap (see Figure 1-15). The support rod was model as a simple tube, flush with the top of the socket, with an OD of 1 in. (1.27 cm OR), an ID of 1/2 in. $(0.635 \mathrm{~cm} \mathrm{IR})$, and a length of $2 \mathrm{ft} .(60.96 \mathrm{~cm})$. A solid $1.27 \mathrm{~cm}$ thick plug was modeled in the lower end of the aluminum tube.

This support structure model was an approximation. The calculation worth is $-21.52 \pm 1.2 \not$. Although slightly lower, this approximation verifies that the measured correction of $25.19 \pm 1.76 \varnothing$ is reasonable.

\footnotetext{
${ }^{\text {a }}$ Estimated dimensions are in red. 
NEA/NSC/DOC(95)03/II

Volume II

HEU-MET-FAST-100
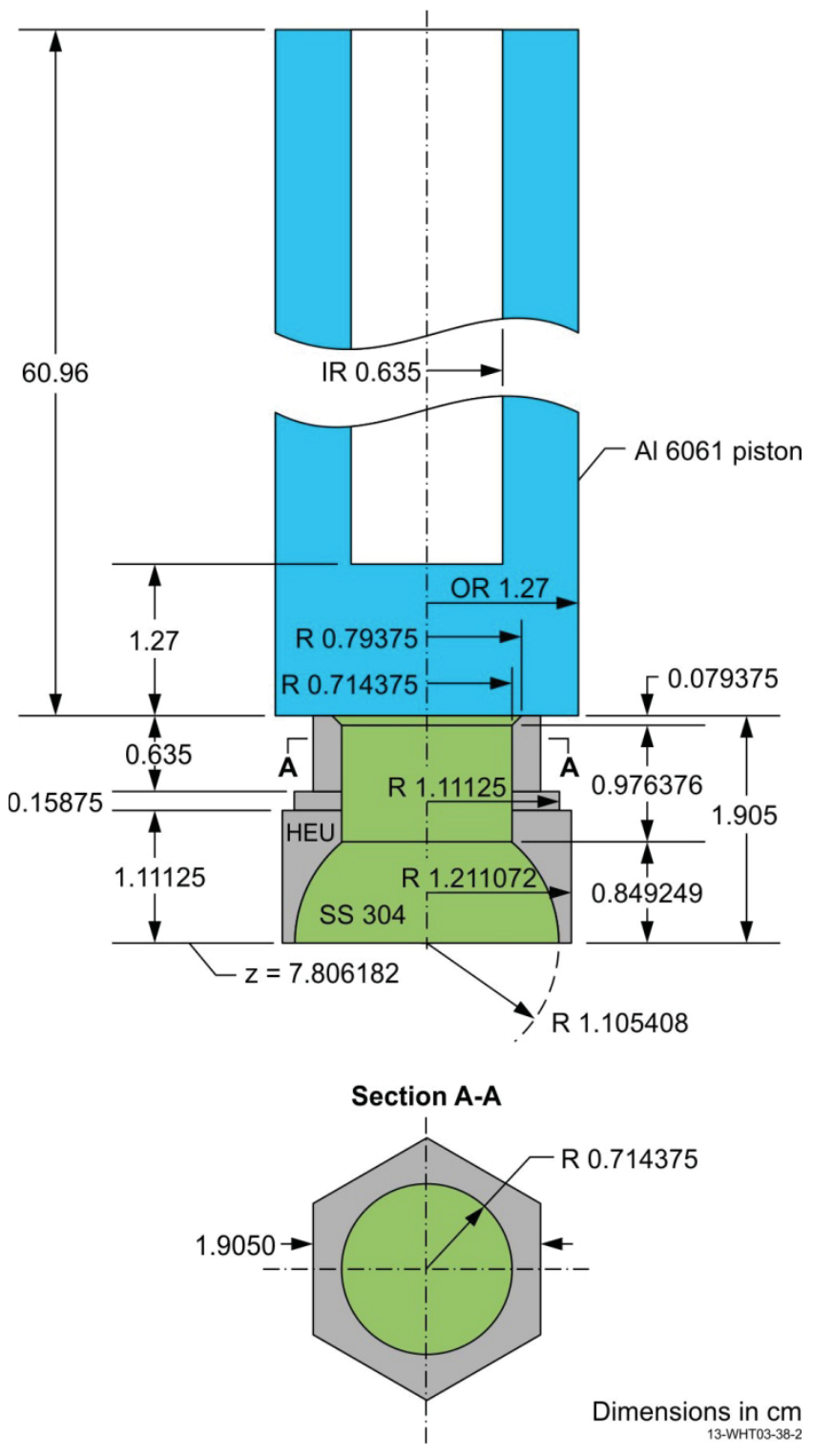

Figure F-5. Upper Socket Model Dimensions. 